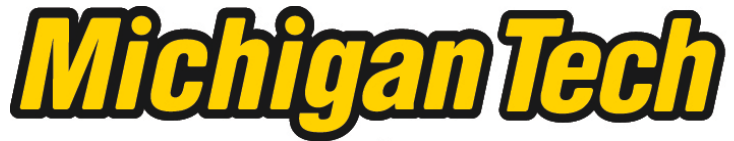 \\ Michigan Technological University Create the Future Digital Commons @ Michigan Tech
}

Dissertations, Master's Theses and Master's Reports - Open

Dissertations, Master's Theses and Master's

Reports

2006

\section{Carbon dioxide sequestration in cement kiln dust through miner carbonation}

Deborah N. Huntzinger

Michigan Technological University

Follow this and additional works at: https://digitalcommons.mtu.edu/etds

Part of the Geology Commons

Copyright 2006 Deborah N. Huntzinger

\section{Recommended Citation}

Huntzinger, Deborah N., "Carbon dioxide sequestration in cement kiln dust through miner carbonation", Dissertation, Michigan Technological University, 2006.

https://doi.org/10.37099/mtu.dc.etds/325

Follow this and additional works at: https://digitalcommons.mtu.edu/etds

Part of the Geology Commons 


\title{
CARBON DIOXIDE SEQUESTRATION IN CEMENT KILN DUST THROUGH MINERAL CARBONATION
}

\author{
By:
}

Deborah N. Huntzinger

\begin{abstract}
A DISSERTATION
Submitted in partial fulfillment of the requirements

for the degree of

DOCTOR OF PHILOSOPHY

(Geological Engineering)

MICHIGAN TECHNOLOGICAL UNIVERSITY

2006
\end{abstract}

Copyright @ Deborah N. Huntzinger 2006 
This dissertation, "Carbon Dioxide Sequestration in Cement Kiln Dust through Mineral Carbonation," is hereby approved in partial fulfillment of the requirements for the degree of DOCTOR OF PHILOSOPHY in the field of Geological Engineering.

DEPARTMENT or PROGRAM:

Geological and Mining Engineering and Sciences

Signatures:

Dissertation Advisor

John S. Gierke

Department Chair

Wayne D. Pennington

Date 


\begin{abstract}
The feasibility of carbon sequestration in cement kiln dust (CKD) was investigated in a series of batch and column experiments conducted under ambient temperature and pressure conditions. The significance of this work is the demonstration that alkaline wastes, such as $\mathrm{CKD}$, are highly reactive with carbon dioxide $\left(\mathrm{CO}_{2}\right)$. In the presence of water, CKD can sequester greater than $80 \%$ of its theoretical capacity for carbon without any amendments or modifications to the waste. Other mineral carbonation technologies for carbon sequestration rely on the use of mined mineral feedstocks as the source of oxides. The mining, pre-processing and reaction conditions needed to create favorable carbonation kinetics all require significant additions of energy to the system. Therefore, their actual net reduction in $\mathrm{CO}_{2}$ is uncertain. Many suitable alkaline wastes are produced at sites that also generate significant quantities of $\mathrm{CO}_{2}$. While independently, the reduction in $\mathrm{CO}_{2}$ emissions from mineral carbonation in $\mathrm{CKD}$ is small $(\sim 13 \%$ of process related emissions), when this technology is applied to similar wastes of other industries, the collective net reduction in emissions may be significant.

The technical investigations presented in this dissertation progress from proof of feasibility through examination of the extent of sequestration in core samples taken from an aged CKD waste pile, to more fundamental batch and microscopy studies which analyze the rates and mechanisms controlling mineral carbonation reactions in a variety of fresh CKD types. Finally, the scale of the system was increased to assess the sequestration efficiency under more pilot or field-scale conditions and to clarify the importance of particle-scale processes under more dynamic (flowing gas) conditions. A
\end{abstract}


comprehensive set of material characterization methods, including thermal analysis, $\mathrm{X}$ ray diffraction, and X-ray fluorescence, were used to confirm extents of carbonation and to better elucidate those compositional factors controlling the reactions. The results of these studies show that the rate of carbonation in CKD is controlled by the extent of carbonation. With increased degrees of conversion, particle-scale processes such as intraparticle diffusion and $\mathrm{CaCO}_{3}$ micropore precipitation patterns begin to limit the rate and possibly the extent of the reactions. Rates may also be influenced by the nature of the oxides participating in the reaction, slowing when the free or unbound oxides are consumed and reaction conditions shift towards the consumption of less reactive $\mathrm{Ca}$ species. While microscale processes and composition affects appear to be important at later times, the overall degrees of carbonation observed in the wastes were significant (> $80 \%$ ), a majority of which occurs within the first 2 days of reaction. Under the operational conditions applied in this study, the degree of carbonation in CKD achieved in column-scale systems was comparable to those observed under ideal batch conditions. In addition, the similarity in sequestration performance among several different CKD waste types indicates that, aside from available oxide content, no compositional factors significantly hinder the ability of the waste to sequester $\mathrm{CO}_{2}$. 


\section{PREFACE}

The following document has been formatted as an Electronic Thesis or Dissertation (ETD). Hyperlinks and bookmarks are intended to facilitate navigation from the table of contents and to section headings within the Unifying Chapter, as well as to the four manuscripts included in this document. After following a hyperlink, the reader may use the back button on the tool bar to return to the previous location in the document. 


\section{ACKNOWLEDGEMENTS}

This research was funded in part by the Department of Geological \& Mining Engineering \& Sciences at Michigan Technological University (MTU), the Institute of Hazardous Materials Management (IHMM), the Michigan Space Grant Consortium (MSGC), MTU's Sustainable Futures Institute (SFI) and the National Science Foundation (NSF) through an Integrated Graduate Education and Research Traineeship (IGERT) fellowship (NSF Grant Number 0333401).

I would like to thank my committee members: Dr. Gregg Bluth, Dr. Larry Sutter, and Dr. Alex Mayer for their time and input in my research. Working with them has been a privilege. I would like to extent my deepest gratitude to my advisor, Dr. John S. Gierke for his tireless support and guidance. John has been a valuable mentor throughout my time at Tech and his encouragement throughout the years will not be forgotten. My gratitude also extends to Cecilia Anderson for her excellent microscopy analysis of samples taken from the batch experiments and for her help in the laboratory.

I would also like to thank Karl Peterson and Scott Schlorholtz (University of Iowa) for their tremendous help in the material characterization of my samples; to Bob Barron, Jennifer Numrich, and Rebekkah Nelson for their assistance in the laboratory, and Greg Barger at Ash Grove Cement Company for the cement kiln dust (CKD) samples that he provided for this study, as well as the time and information he generously shared with me during the initial stages of this research.

I would like to express my greatest appreciation to my parents, Sharon and Bruce Huntzinger, who have supported me through every stage of life. I wouldn't have made it to this point in life without their support. 


\section{TABLE OF CONTENTS}

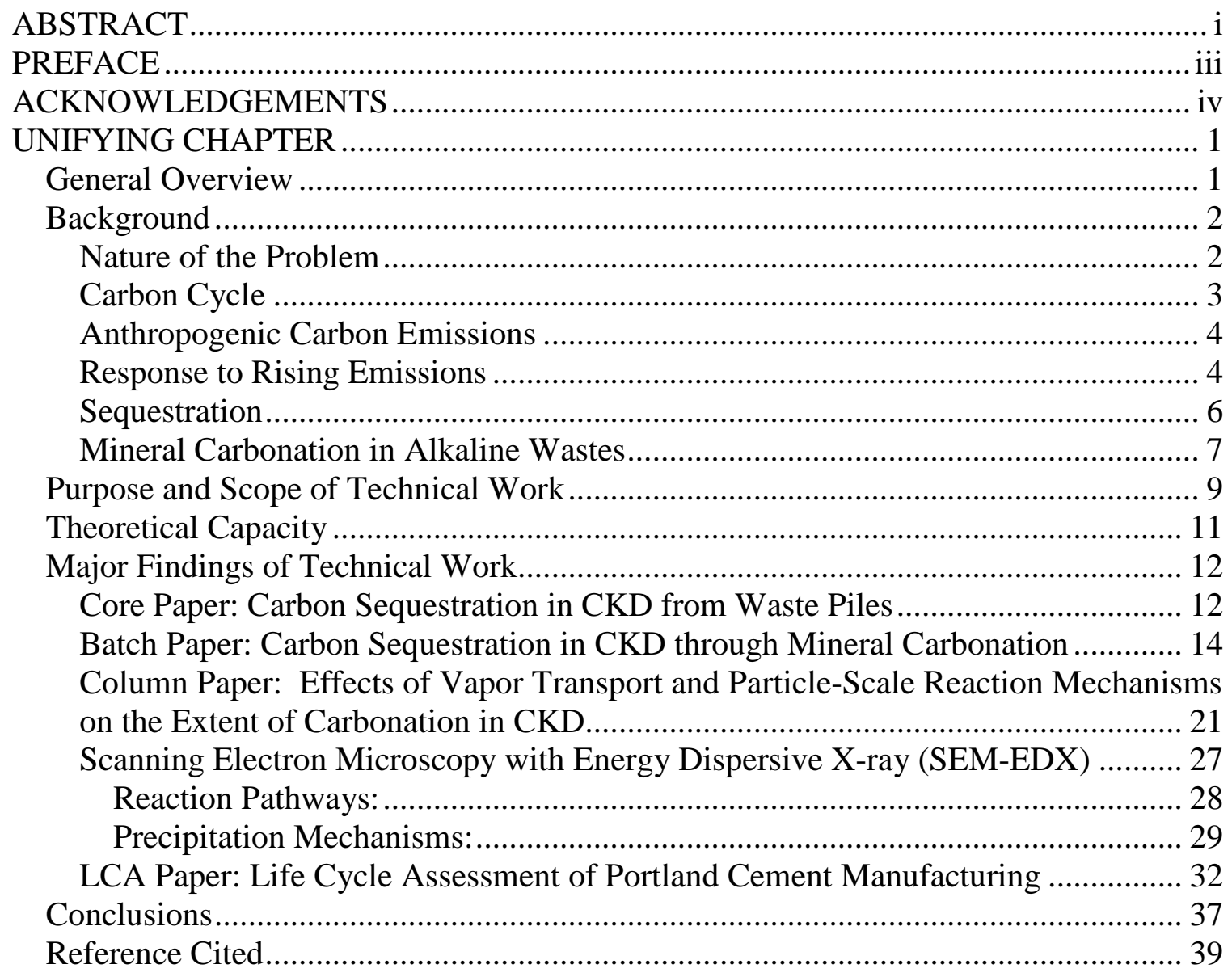

CORE PAPER: Mineral Carbonation for Carbon Sequestration in Cement Kiln Dust from Waste Piles

BATCH PAPER: Carbon Dioxide Sequestration in Cement Kiln Dust through Mineral Carbonation

COLUMN PAPER: Effects of Vapor Transport and Particle-Scale Reaction Mechanisms on the Extent of Carbonation in Cement Kiln Dust

LCA PAPER: A Life Cycle Assessment of Portland Cement Manufacturing: Traditional Process with Alternative Technologies

APPENDIX I: The Feasibility of Carbon Emission Control Policies within the United States

APPENDIX II: Laboratory Data and Supporting Tables for Mansucripts $\quad$ [CD ROM] 


\section{UNIFYING CHAPTER}

\section{General Overview}

The overall goal of this dissertation was to investigate the use of solid alkaline industrial wastes, specifically cement kiln dust (CKD), to sequester $\mathrm{CO}_{2}$. A combination of batch, column, and microscopy experiments were conducted with several CKD types in order to, first demonstrate the feasibility of mineral carbonation in waste products and show its viability as a potential sequestration technology; and second to improve the fundamental understanding of the mineral carbonation process within alkaline wastes, specifically to identify those mechanisms that may be rate- or extent-limiting. To strengthen the technical aspects of this study and to place the significance of this work in a more global framework, two additional studies were conducted: one which examined the feasibility of carbon emissions regulations within the United States and another that investigated the potential environmental impact reduction from the use of alternative cement manufacturing processes, including the sequestration of $\mathrm{CO}_{2}$ in $\mathrm{CKD}$.

This study focused on the sequestration of carbon in CKD through the process of mineral carbonation. A majority of the sequestration efforts to date have focused on the storage of $\mathrm{CO}_{2}$ in large reservoirs capable of capturing mass quantities of carbon. While the potential benefits of such sequestration projects are quite large, there still remains significant uncertainty regarding the long-term stability of the stored carbon. This uncertainty has slowed implementation. While not as grand in scale, industry specific sequestration options have the potential to reduce emissions at their source; the cumulative effects of which could be significant. One such option is the use of alkaline industrial solid wastes to capture carbon through the formation of mineral carbonates. 
Many suitable solid residues are produced at sites that also produce significant quantities of $\mathrm{CO}_{2}$, such as steel or cement manufacturing facilities. Sequestration in wastes such as CKD is well worth investigating because of: (1) the stability of the carbonate endproducts; (2) the general availability of the wastes; (3) their high surface area and increased oxide content, which makes them highly reactive at ambient temperatures and pressures; and (4) the potential stabilizing effect the carbonation reactions can have on the waste (i.e., reduced $\mathrm{pH}$ ).

\section{Background}

\section{Nature of the Problem}

The Earth's temperature is regulated by natural greenhouse gases, such as water vapor, carbon dioxide $\left(\mathrm{CO}_{2}\right)$, nitrogen oxide $\left(\mathrm{NO}_{2}\right)$, and methane $\left(\mathrm{NH}_{4}\right)$. Sunlight is reflected off the Earth's surface in the form of infrared radiation (heat). Greenhouse gases absorb terrestrial radiation, "trapping" heat in the atmosphere (NEIC 2004). Over time, the amount of energy sent from the sun to the Earth's surface should balance the amount of energy radiated back into space (EIA 2004, US EPA 2005). Natural processes, such as plant growth and decay, volcanic activity, and rock weathering contribute to and regulate the concentration of these gases in the atmosphere. Anthropogenic activities, however, are adding additional quantities of carbon to the system at a rate faster than can be effectively balanced by Earth's natural processes. The result has been an increase in atmospheric $\mathrm{CO}_{2}$ concentrations of approximately $100 \mathrm{ppm}_{\mathrm{v}}$ since the start of the industrial revolution (Feely et al. 2004; US EPA 2005). Based on ice core records, concentrations have not reached this magnitude in at least the last 420,000 years (Pedit et al.1999). Although other greenhouse gases, such as methane, trap more heat per molecule 
than $\mathrm{CO}_{2}$, aside from water vapor $\mathrm{CO}_{2}$ is the most abundant of the greenhouse gases and therefore is the largest contributor to the enhanced greenhouse effect $(\sim 70 \%)$ (IPCC 2001). The concern stems from both the rate at which atmospheric concentrations are changing and from our uncertainty in how elevated atmospheric $\mathrm{CO}_{2}$ concentrations will perturb Earth's existing natural cycling processes through either the intensification or creation of positive and negative feedback loops (Falkowski et al. 2000; Feely et al. 2004; Sabine et al. 2004; Field and Raupach 2004; US EPA 2005).

\section{Carbon Cycle}

Carbon dioxide $\left(\mathrm{CO}_{2}\right)$ is naturally cycled among the Earth's atmospheric, oceanic, and terrestrial systems in a process called the "carbon cycle". Therefore, the fate of $\mathrm{CO}_{2}$ in the atmosphere is a function of complex biogeochemical processes. We understand enough about the carbon cycle to recognize that natural processes like oceanic uptake of $\mathrm{CO}_{2}$ and soil and biotic storage can buffer, to some extent, the rate of increase of $\mathrm{CO}_{2}$ in the atmosphere. However, we are entering uncharted waters because we have exited the climate domain long controlled by the Earth's glacial-interglacial dynamics (Falkowski et al. 2000), and we cannot yet predict how anthropogenic activities will affect climate in the long term. The carbon cycle does not operate in a vacuum and fluctuations in its inventories can disturb other natural processes, both climatological and biogeochemical (Falkowski et al. 2000). This is not to say that the system will not adapt to these changes. We just do not know what this future system will look like. Because of this uncertainty, the perceived need to reduce $\mathrm{CO}_{2}$ emissions to the pre-industrial levels has intensified. 


\section{Anthropogenic Carbon Emissions}

Increased public awareness of the threats posed by global warming has led to greater concern over the impact of anthropogenic carbon emissions on the global climate. The current level of carbon dioxide $\left(\mathrm{CO}_{2}\right)$ in the atmosphere is approaching $380 \mathrm{ppm}_{\mathrm{v}}$ (Feely et al. 2004; Sabine et. al 2004). Without market, technological, and societal changes, concentrations are projected to increase to over $800 \mathrm{ppm}_{\mathrm{v}}$ by the end of the century (Feely et al. 2004). Since the pre-industrial revolution, both changes in land-use patterns and the intensity of our development activities have had a notable impact on atmospheric $\mathrm{CO}_{2}$ concentrations. The largest source of anthropogenic carbon emissions is from fossil fuel combustion, and energy consumption is rising due to our growing economy's demand for fuel (Appendix I). Non-energy related industrial activities also produce a significant quantity of process-related $\mathrm{CO}_{2}$ emissions through the transformation of raw materials (US EPA 2005). Of these, cement manufacturing and iron and steel production are the most carbon intensive.

\section{Response to Rising Emissions}

In a report to Congress in 1989 concerning global warming, the EPA (1989) stated that "the landscape of North America will change in ways it cannot be fully predicted. The ultimate effects will last for centuries and will be irreversible....Strategies to reverse such impacts on natural ecosystem are not currently available." Even with such a bold statement by the EPA and similar warnings by others in the research community, relatively little has been done to reduce greenhouse gas emissions, nationally or globally. "The Feasibility of Carbon Emission Control Policies within the United States" provided in Appendix I examines the positive and normative aspects of potential carbon emissions 
policies within the United States, as well as the social and economic implications of different policy strategies. The goal of this report was to gain a general understanding of the political climate surrounding the climate change debate and to better understand the likelihood of carbon emission policies being enacted in the U.S. This report (Appendix I) fulfilled part of the requirements for a course taken on the foundations of public policy while in residence at Southern University in Baton Rouge, LA. While not a rigorous analysis of the policy framework surrounding the global warming debate, the report does provide a good summary of the motivators and barriers seen as influencing the different climate change policies being proposed to Congress. The focus is primarily on the use of market-based approaches to reduce $\mathrm{CO}_{2}$ emissions and applies Social or Public Choice ${ }^{1}$ arguments, along with the problem of Collective Action to help explain the hesitancy of Congress and other political stake holders (e.g., government officials, voters, lobbyists) in supporting market-based controls for $\mathrm{CO}_{2}$ emissions.

The common pool ${ }^{2}$ characteristic of the greenhouse effect makes solutions for controlling pollution more difficult. The long-term nature of the problem and more urgent direct social and economic needs appear to cause some U.S. politicians to avoid enacting stringent climate change policies. Even though the past and current administrations have proposed legislation to cap and regulation GHG emissions, no policies have passed in Congress. Thus, one significant question seems to remain: whether global warming is

\footnotetext{
${ }^{1}$ Public and Social choice theories are closely related and are used to study the behavior of voters, politicians, and government officials (political actors) and how their individual interests and judgments of well-being translate into collective (group) preferences. It is often used to explain how special interests can bring about policy that conflicts with the overall desires of the general public (see Appendix I for a more detailed discussion).

${ }^{2}$ The term "common-pool" is often used to describe a natural or human-made resource that is open for use by the public. Without controls, the resource faces destruction in the long run due to congestion, overuse, and/or pollution. The concept of "common-pool" resources is discussed in greater detail in Appendix I.
} 
considered a serious enough problem by society to impose policies that may not be in our best short-term economic interest?

Regardless of the United State's reluctance to enact GHG regulations, international consensus is building in support of carbon emission abatement and the stabilization of atmospheric $\mathrm{CO}_{2}$ to pre-1990 levels. In general, the focus has been placed in marketbased approaches (Appendix I) because they allow for the separation of the ends from the means. Thus, attention can be directed towards finding acceptable and cost-effective approaches to emission reductions, many of which might be industry specific; because unlike $\mathrm{NO}_{\mathrm{x}}$ and $\mathrm{SO}_{2}$, there are currently no commercially available, industry-wide technologies for removing and storing (sequestering) $\mathrm{CO}_{2}$ (Appendix I). Thus the tendency has been to lean towards larger-scale solutions, ones which either reduce the dependence on fossil fuels or provide for the capture and long-term storage of excess carbon (e.g., geologic sequestration, oceanic storage, terrestrial sequestration).

No single approach, including sequestration or shifts in energy dependence, will provide the solution to the growing carbon problem. A balanced, carbon-management strategy is likely required; one which contains a portfolio of technologies, including the development of carbonless energy sources and the capture of $\mathrm{CO}_{2}$ emissions using a variety of carbon sequestration technologies (NETL 2004; SCOPE 62 2004).

\section{Sequestration}

Carbon Sequestration generally refers to the capture and permanent, safe storage of $\mathrm{CO}_{2}$. A majority of the sequestration efforts have been focused on the storage of $\mathrm{CO}_{2}$ in large reservoirs such as the oceans, deep geologic formations, and terrestrial biosphere (USDOE 2005; Huijgen and Comans 2003; and NRC 2003). Smaller scale or industry 
specific sequestration options are often overlooked because they lack the "global" extent of other options. Not all sequestration solutions, however, need to be global in scale. The main advantage of mineral carbonation is the formation of carbonate minerals such as calcite $\left(\mathrm{CaCO}_{3}\right)$ and magnesite $\left(\mathrm{MgCO}_{3}\right)$, end-products which are known to be stable over geologic time scales.

\section{Mineral Carbonation in Alkaline Wastes}

Of the existing research studies examining mineral carbonation, most have focused on the use of mined mineral rock as feedstock (refer to literature cited in the Core Paper). Industrial solid wastes and residues, however, may provide more reactive mineral sources that require little to no pre-processing. In addition, the utilization of alkaline waste materials has two potential advantages over other mineral $\mathrm{CO}_{2}$ sequestration technologies: waste materials provide an inexpensive source of calcium or magnesium mineral matter; and the environmental quality of the waste materials may be improved through pH-neutralization and mineral transformation (Huijgen and Comans 2003). The downside of utilizing waste products for carbonation again comes from the issue of scale. But alkaline solid wastes are worth considering for reduction of emissions at their source. In fact, this is one major advantage of the utilization of alkaline wastes for carbon sequestration: many suitable solid residues are produced at sites that also produce significant quantities of $\mathrm{CO}_{2}$, such as steel manufacturing, municipal solid waste incinerators, and cement manufacturing facilities.

Both steel and cement manufacturing are ranked the highest among non-energy related carbon emitters. Moreover, the cement industry is the third largest source of $\mathrm{CO}_{2}$ emissions in the U.S. (US EPA 2005). Approximately 5\% of global carbon emissions can 
be attributed to the manufacturing of cement, with roughly half of the $\mathrm{CO}_{2}$ coming from the calcining process, and the remaining originating from the burning of fuels used to fire the kiln (Hendriks et al. 2000). The calcining process releases $\mathrm{CO}_{2}$ from the conversion of calcium carbonates to lime (Figure 1) at temperatures greater than $1300{ }^{\circ} \mathrm{C}$. Cement production generates a world carbon emission of approximately $0.80 \mathrm{~kg} \mathrm{CO}_{2}$ per $\mathrm{kg}$ cement produced (Hendriks et al. 2000). While not the largest cement producer, North America is one of the most carbon intensive, generating $0.89 \mathrm{~kg} \mathrm{CO}_{2}$ per $\mathrm{kg}$ cement produced, second only to India.

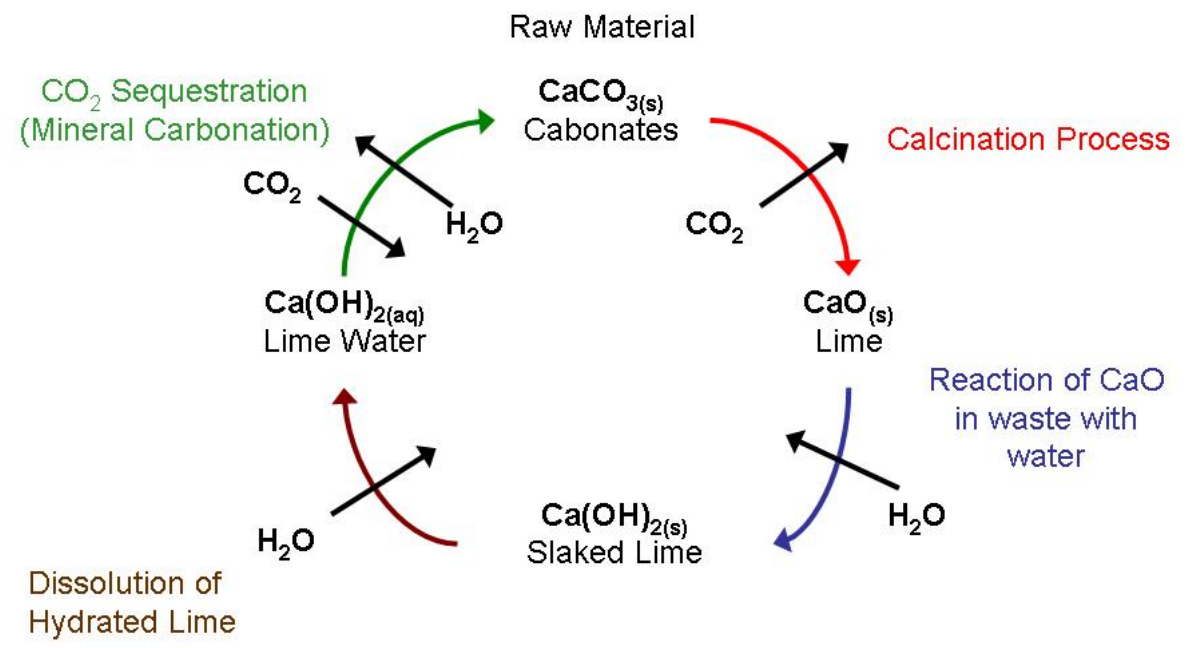

Figure 1. Schematic showing the calcining processes during the manufacturing of cement and the associated reactions related to the carbon sequestration using cement kiln dust.

Based on stoichiometry, variations in material composition, and theoretical determinations of sequestration capacity (refer to discussion on theoretical extent in the 


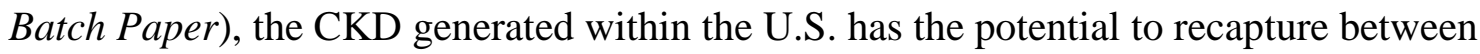
0.74 and $5.12 \mathrm{Tg} \mathrm{CO}_{2}$ per year by sequestration (value depends on waste composition and the percentage recycled). From estimates of combustion and process-related $\mathrm{CO}_{2}$ emissions (van Oss and Padovani 2003), this equates to up to $13 \%$ of the $\mathrm{CO}_{2}$ emitted from the calcination process $\left(\sim 6.5 \%\right.$ reduction in U.S. cement related $\mathrm{CO}_{2}$ emissions, or a $0.33 \%$ reduction in global $\mathrm{CO}_{2}$ emissions). Thus, the reuse of $\mathrm{CKD}$ for $\mathrm{CO}_{2}$ sequestration has the potential to be a valuable means for partially closing the $\mathrm{CO}_{2}$ loop created by the calcining processes (Figure 1) and for meeting voluntary or mandatory emission reduction goals. While the impacts of mineral carbonation in alkaline wastes may not compare in scale to those of other sequestration technologies, it is worthy of investigation because of the stability of the end-products, beneficial use of waste materials, and favorable thermodynamics of the carbonation reactions.

\section{Purpose and Scope of Technical Work}

The aim of this research is to improve the fundamental understanding of the mineral carbonation reactions occurring during the sequestration of $\mathrm{CO}_{2}$ by CKD. More specifically, to elucidate the important physical, chemical, and transport processes controlling the rate and degree of carbonation achievable in the waste. A series of experiment studies were conducted to: first, demonstrate the feasibility of mineral carbonation in CKD at ambient temperatures and pressures; second, to measure the rate and extent of sequestration under ideal (static, unlimited $\mathrm{CO}_{2}$ supply) conditions; and third, to assess the importance of particle-scale processes on sequestration performance under dynamic (gas flowing) conditions. The results of this work are presented in three 
technical papers, prepared for submission to the Journal of Hazardous Materials (Core $\underline{\text { Paper) and Environmental Science and Technology (Batch and Column Papers). }}$

The fourth paper included in this dissertation presents the culmination of collaborative work with Thomas Eatmon, a doctoral student in the Nelson Mandela School of Public Policy at Southern University in Baton Rouge, LA. We conducted a life cycle assessment (LCA) of the manufacturing of traditional and alternative Portland cement products (LCA Paper). The analysis included assessment of a pozzolanic (blended) cement, as well as various treatments of CKD during the production process, including full recycling and carbon sequestration. The paper has been submitted to a special issue of the Journal of Cleaner Production concerning the scientific and technological approaches to the sustainable management of natural resources.

Finally, incorporated into this work (primarily the Column Paper) are the results of a scanning electron microscopy with energy-dispersive X-ray (SEM-EDX) study conducted by Cecilia Anderson, a Master's student in the Department of Geologic and Mining Engineering and Sciences. The application of microscopic analysis for visualizing the carbonation reactions was included in my initial research proposal presented to my committee in December of 2003. As outlined in the proposal, the goal of the SEM work was to develop a conceptual picture describing the physical and chemical framework of the mineral carbonation process at the particle scale. The actual analysis was undertaken by Ms. Anderson as part of her Master's research. However, because of my development of the initial research idea, as well as my supervision of Ms. Anderson's work, a summary of the major results of her SEM-EDX analysis are included here. 


\section{Theoretical Capacity}

Integral to the experimental studies was the determination of CKD's theoretical capacity for sequestration. It was assumed that reactive calcium species in the waste (e.g., free $\left.\mathrm{CaO}, \mathrm{Ca}(\mathrm{OH})_{2}, \mathrm{Ca}_{2} \mathrm{SiO}_{3}\right)$ are the major phases participating in the carbonation reactions. The composition of CKD, however, can vary widely and other oxides (e.g., $\mathrm{MgO}, \mathrm{FeO}_{2}, \mathrm{~K}_{2} \mathrm{O}$, and $\mathrm{Na}_{2} \mathrm{O}$ ) may also contribute, to a lesser extent, to the sequestration of $\mathrm{CO}_{2}$ through a number of ancillary reaction pathways. Therefore, in order to estimate theoretical capacities for each of the CKD types used in this study, consideration was given both to the waste's oxide composition and the assumed extent to which those oxides are available for reaction. The equation for theoretical extent developed was based, in part, on work by Steinour (1959) and his estimates of $\mathrm{CO}_{2}$ sequestration in mortars and concrete. For each CKD type, the theoretical extent of carbonation in CKD (as a percentage of dry mass) was calculated as follows:

$$
\begin{gathered}
\% \mathrm{ThCO}_{2}=0.785\left(\% \mathrm{CaO}-0.56 \% \mathrm{CaCO}_{3}-0.7 \cdot \% \mathrm{SO}_{3}\right)+1.091 . \% \mathrm{MgO}+ \\
0.71 . \% \mathrm{Na}_{2} \mathrm{O}+0.468\left(\% \mathrm{~K}_{2} \mathrm{O}-0.632 . \% \mathrm{KCl}\right)
\end{gathered}
$$

Where the species in equation 1 are represented in terms of percent dry mass and the stoichiometric mass factors assume that all of the $\mathrm{CaO}$ (except that bound in $\mathrm{CaSO}_{4}$ and $\mathrm{CaCO}_{3}$ ) will form $\mathrm{CaCO}_{3}, \mathrm{MgO}$ will form $\mathrm{MgCO}_{3}$, and $\mathrm{Na}_{2} \mathrm{O}$ and $\mathrm{K}_{2} \mathrm{O}$ (less that bound in sylvite, $\mathrm{KCl}$ ) will form $\mathrm{Na}_{2} \mathrm{CO}_{3}$ and $\mathrm{K}_{2} \mathrm{CO}_{3}$.

Theoretical extent was used in the Core, Batch, and Column Papers to determine the degree of carbonation (sequestration) achieved by the wastes. Depending on the experimental study (column versus batch) the mechanics of calculating the degree of 
carbonation varied. However, in each case, degree refers to the amount of sequestration achieved versus that extent theoretically possible.

\section{Major Findings of Technical Work}

\section{Core Paper: Carbon Sequestration in CKD from Waste Piles}

In this paper, the feasibility of carbon sequestration in waste CKD was investigated in a series of column experiments. Initially the study was designed to provide preliminary estimates of carbonation performance for a National Science Foundation proposal. The proposal was not funded, but the results of the study were promising. The significance of this work is that it shows carbon sequestration can be achieved under ambient temperature and pressure conditions, without modification to the wastes; and even CKD that has been landfilled and has undergone some level of weathering and carbonation can still sequester significant amounts of $\mathrm{CO}_{2}$.

A section of core taken from an aged CKD waste pile (Alpena, MI) was obtained from the Civil Engineering Department at Michigan Tech. Prior to the column experiments, a series of preliminary batch tests were conducted in Tedlar bags with limited supplies of $\mathrm{CO}_{2}$. The measurable consumption of $\mathrm{CO}_{2}$ in these preliminary experiments prompted the column study. In order to adequately assess the carbonation performance of the columns, material analysis was conducted on reacted and unreacted samples using thermal gravimetrical analysis, X-ray diffraction, and X-ray fluorescence. This level of characterization helped to verify reaction products and provided an independent measure of the extent of carbonation achieved in the cores.

Four columns were fabricated from the core segment and ranged in length from 5.0 to $13.4 \mathrm{~cm}$ (7.3 cm diameter, Figure 2). Gas flow rates between 45 to $60 \mathrm{~mL} / \mathrm{min}$ were 
maintained through the columns and effluent samples were analyzed with a gas chromatograph. The columns were operated under varied moisture and gas concentration conditions, as well as with humidified and dry influent gases. Refer to the Core Paper for more detail concerning column operating conditions.

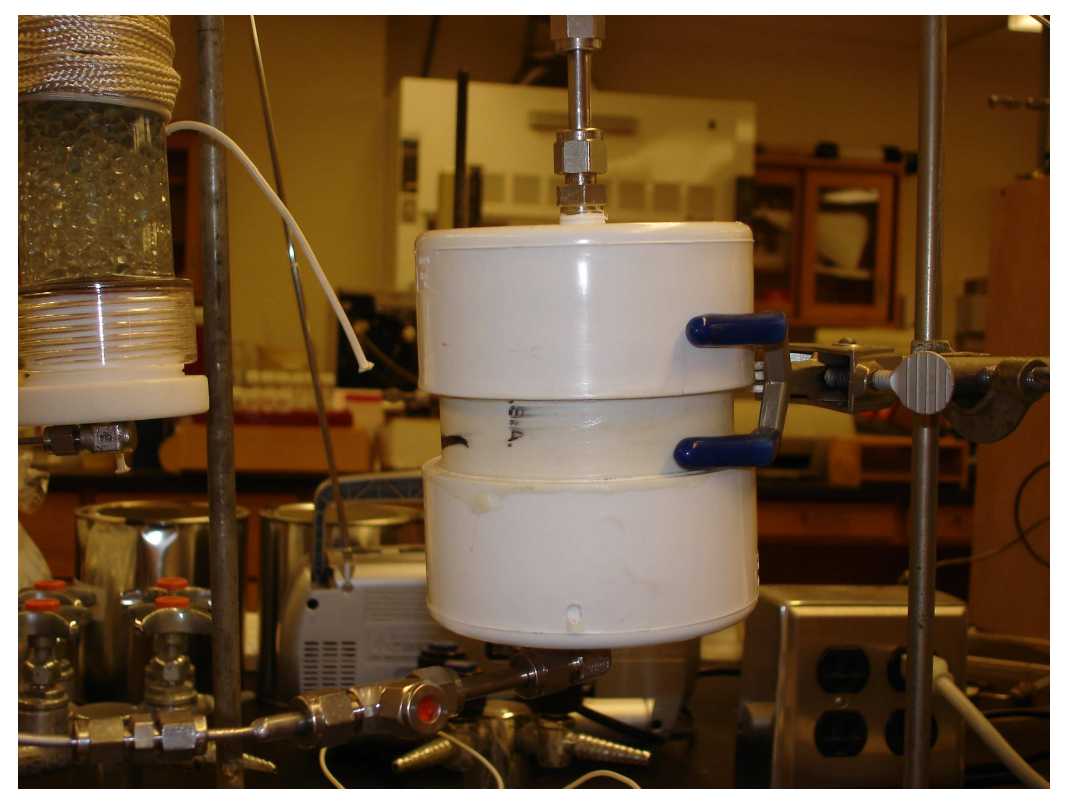

Figure 2. Core column created out of sections of core taken from an aged CKD waste pile and encased in PVC.

The high percentage of calcite and the presence of ettringite $\left(\mathrm{Ca}_{6} \mathrm{Al}_{2}\left(\mathrm{SO}_{4}\right)_{3}(\mathrm{OH})_{12^{-}}\right.$ $26 \mathrm{H}_{2} \mathrm{O}$ ) in pre-carbonated samples suggest that the waste pile from which the CKD core was taken had been exposed to moisture and likely undergone some carbonation. Nevertheless, degrees of carbonation greater than $70 \%$ were achieved under ambient temperature and pressure conditions ( $\underline{\text { Table 1)}}$. In general, the extent of carbonation/sequestration was greater in columns with lower water contents, probably due to increased access to reaction sites. The major sequestration product was calcite, however the degree of sequestration observed in the core columns suggests that calcite 
was not the only carbonate species formed during the experiments (refer to the Core Paper for a more detailed discussion on the measured sequestration extent and composition changes due to carbonation). Some of the variability observed likely resulted from variation in composition within the $\mathrm{CKD}$ core. Because the columns were constructed of intact core segments, extracting a pre-carbonated sample from each column for analysis was not feasible. The core segment may have intersected layers with differing composition within the waste pile, and this variability leads to some uncertainty in the degrees of carbonation calculated for each of the columns.

Table 1. The mass of $\mathrm{CO}_{2}$ sequestered compared to the theoretical amount of sequestration possible in columns constructed from intact core segments of waste cement kiln dust.

\begin{tabular}{|c|c|c|c|c|c|}
\hline Column & $\begin{array}{c}\text { Operation } \\
\text { Time } \\
(\mathbf{d a y s})\end{array}$ & $\begin{array}{c}\text { Observed } \\
\text { Mass } \\
\text { Change }^{\mathbf{a}} \\
(\mathbf{g})\end{array}$ & $\begin{array}{c}\mathbf{C O}_{\mathbf{2}} \\
\text { Sequestered }^{\mathbf{b}} \\
\mathbf{( g )}\end{array}$ & $\begin{array}{c}\text { Theoretical } \\
\text { Sequestration }_{\mathbf{c}} \mathbf{( g )}\end{array}$ & $\begin{array}{c}\text { Observed } \\
\text { Sequestration } \\
\text { Degree }^{\mathbf{d}}\end{array}$ \\
\hline $\mathrm{A}$ & 3.4 & 10.8 & 11.8 & 15.7 & $75.0 \%$ \\
\hline $\mathrm{B}$ & 4.9 & 14.9 & 15.3 & 16.2 & $94.3 \%$ \\
\hline $\mathrm{C}$ & 3.3 & 22.5 & 22.3 & 22.0 & $101.2 \%$ \\
\hline $\mathrm{D}$ & 12.0 & 29.2 & 34.6 & 49.0 & $70.6 \%$ \\
\hline
\end{tabular}

${ }^{a}$ Observed mass changes in Columns C and D were corrected for water vapor loss due to injection of dry gas.

${ }^{\mathrm{b}} \mathrm{CO}_{2}$ sequestered is based on frontal analysis of effluent $\mathrm{CO}_{2}$ concentrations from each column.

${ }^{\mathrm{c}}$ Theoretical mass of sequestration assuming that $\mathrm{Na}$ and $\mathrm{K}$ carbonates form.

${ }^{\mathrm{d}}$ Degree of carbonation achieved in each column based on theoretical mass of sequestration.

\section{$\underline{\text { Batch Paper: Carbon Sequestration in CKD through Mineral Carbonation }}$}

In this paper, the degree of mineral carbonation in cement kiln dust (CKD) was examined through a series of batch experiments. The study was designed in order to gain a better fundamental understanding of the reaction mechanisms controlling the carbonation process under ideal (static, unlimited $\mathrm{CO}_{2}$ ) conditions. CKD samples were 
obtained from three separate cement manufacturing facilities, operating with differing kiln types. Three out of the four samples came from the Ash Grove Cement Company, headquartered in Overland Park, KS. Ash Grove operates 9 cement manufacturing facilities in both the United States and Canada. The samples used in this study were from their Chanute (dry kiln with pre-heater and alkali-bypass system; AG Bypass High and AG Bypass Low) and Midlothian (wet kiln with electrostatic precipitator/baghouse; $A G$ Wet) plants, both of which operate (to varying degrees) using tire- and hazardous-wastederived fuels. The other sample (CT Wet) was obtained from Continental Cement, a small, wet-kiln plant in Hannibal, MS (see Batch Paper for more information about CKD types used in this study).

One of the difficulties in using alkaline wastes for $\mathrm{CO}_{2}$ sequestration is the large variability in composition within a given waste type. The composition of CKD is highly dependent on the kiln type, source materials, and fuel types being used, as well as the grade of cement being produced. This variability complicates the standardization and optimization of the sequestration process. CKD generated within a given cement plant, however, tends to be relatively consistent in composition, and plant operators often conduct detailed material analysis of their wastes as part of their operation. The oxide contents of the wastes examined in this study are representative of the range in composition reported for CKD (refer to Batch Paper). Two of the CKD types used in this study (AG Bypass High and AG Bypass Low) were taken from an alkali recirculation system. The demand for low-alkali cement varies regionally and depends on the potential of alkali-silica reactions (ASR) in the final concrete mix. CKD's high in alkalis (K and $\mathrm{Na}$ oxides) cannot be recycled back into the kiln and are typically either landfilled or sold 
for agricultural amendments. Additionally, recirculation dusts tend to have appreciable fractions of free calcium oxides $\left(\mathrm{CaO}\right.$ and $\left.\mathrm{Ca}(\mathrm{OH})_{2}\right)$ which make them more suitable for carbonation. It is not known, however, whether the high mass percentages of volatile substances (alkali salts, sulfates, and chlorides) affect the formation of carbonates in these wastes. Therefore the question becomes: other than the percentage of available $\mathrm{CaO}$ and other reactive oxides in the $\mathrm{CKD}$, does composition impact the degree of carbonation achievable in the waste? The batch study was designed to address this question, along with questions related to reaction mechanism and kinetics.

In order to gain a better fundamental understanding of the compositional factors (if any) and reaction mechanisms controlling carbonation, a comprehensive set of material characterization methods was conducted on pre- and post-carbonated samples. These methods included: thermal analysis (thermal gravimetric and differential thermal analysis (TGA/DTA) and total carbon analysis (TCA)), X-ray diffraction (both quantitative and qualitative), X-Ray fluorescence, and scanning-electron microscope (SEM) microanalysis. Compositional analysis provided information about the reaction products formed, the increase in abundance of carbonates (such as calcite), and an independent check on the extent of carbonation in the samples.

The batch experiments were performed in a stainless steel 288-L "glove" box, with $\sim 100 \%$ relative humidity and $\sim 80 \% \mathrm{CO}_{2}$ atmosphere (Figure 3). One to 5-gram samples of CKD were placed in aluminum weighting tins, oven-dried, and spiked with deionized water at desired water-to-solid ratios (0 (no water) - 1.25). Prepared samples were reacted in the chamber for a range of reaction times ( 8 hrs to 8 days) under ambient temperature and pressure conditions. The gain in dry mass between the initial pre- 
carbonated samples and dried carbonated product was assumed to equal the mass of $\mathrm{CO}_{2}$ sequestered by the sample. The validity of using mass change as a measure of sequestration extent was verified with independent material analysis results (see Batch Paper for a more detailed discussion on material analysis methods and results).

Based on detailed material analysis, the carbonation reactions appear to occur primarily through the reaction of $\mathrm{CO}_{2}$ with $\mathrm{Ca}(\mathrm{OH})_{2}$. In all cases, no free $\mathrm{CaO}$ was found remaining in the reacted samples. As in the core column study (refer to Core Paper), $\mathrm{CaCO}_{3}$ was the predominant carbonation product and well-defined calcite phases (via quantitative X-ray diffraction, QXRD) accounted for over $75 \%$ of the observed carbonation. Aside from available $\mathrm{CaO}$ and $\mathrm{KCl}$ content, the composition of the wastes did not appear to have a significant impact on the overall degree of carbonation achieved. The waste material having the greatest potential for sequestration is the AG Bypass High, mostly due to its high free $\mathrm{CaO}$ content. However, when measured against the theoretical estimates of sequestration, the AG Bypass Low CKD performed better than the rest. Its high degree of carbonation may be attributed to the increased halide content of waste, which may have improved the extent of carbonation by promoting the dissolution of calcium species (refer to Batch Paper). 


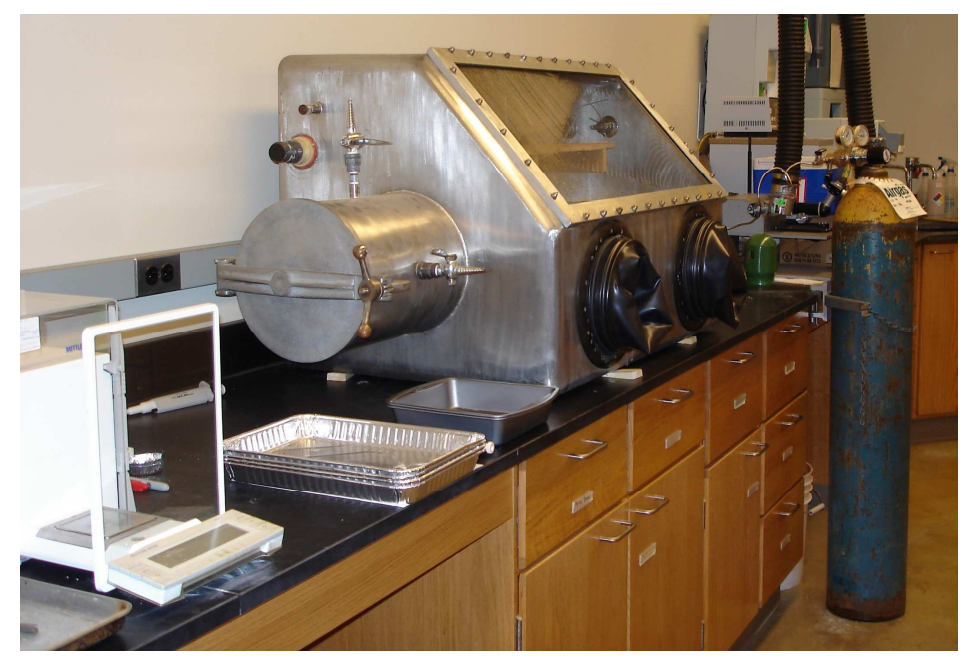

Figure 3. Reaction chamber used during the batch experiments.

In all CKD types the degree of carbonation increased with time, with greater than 75 to $80 \%$ of the carbonation occurring at early times (or less than 2 days) and more gradual conversion of oxides to carbonates as the reactions progressed (Figure 4). The exponential shape of the time-dependent curve suggests that the rate-limiting mechanism controlling carbonation changes as the extent of carbonation proceeds (refer to Batch $\underline{\text { Paper). Individually, these rate-controlling mechanisms can be difficult to measure. }}$ Therefore, analogous processes were sought out to help provide insight into the factors controlling mineral carbonation in CKD. Initially, an empirical rate formulation was applied, one similar in form to that describing biochemical oxygen demand (BOD) in wastewaters (Snoeyink and Jenkins 1980). However, the oxygen consumption expression for BOD is rooted in first-order reaction assumptions, and when translated to sequestration to describe the degree of carbonation with time, it failed to adequately represent observed trends at later times.

Because of the similarity in CKD composition to that of cement, focus was shifted to rate expressions commonly used to describe the complex chemistry of cement hydration. 
Hydration reaction kinetics are often analyzed using lumped rate expressions that represent both the reaction and mass transfer mechanisms controlling the overall or net rate of hydration. From the work developed by Avrami (1939) and applied by Biernacki et al. (2001), the extent of the carbonation in CKD was expressed as:

$$
\xi(t)=1-e^{-k t^{n}}
$$

Where $\xi(t)$ is the degree of carbonation at some time, $t ; k$ is the rate constant; and $n$ is an exponential factor, which is proposed to have fundamental process underpinnings but really is an empirical parameter. Equation 2 is based on the kinetics of phase change and relies on a "lumped" rate constant rather than stoichiometry.

The observed trend in degree of carbonation with time is the same for all CKD types. Therefore, the empirical rate expression (equation 2) was fit to the batch results from all CKDs as a whole, rather than independently (Figure 5). The values for the rate constant $(k)$ and reaction exponent $(n)$ were optimized by minimizing the root mean square of the sum of the normalized residuals between predicted and experimental degrees of carbonation. The actual fitted values for $k$ and $n$ are not important. Because the rate constant, $k$, and the fitting exponent, $n$, are lumped parameters which values are influenced by both reaction and transport mechanisms, extracting the relative importance of one mechanism (e.g., reaction) over the other (e.g., transport) from these fitted values is difficult and impractical (refer to Batch Paper). What is significant from this analysis is that the functional form of the empirical hydration equation describes the degree of carbonation with time better than conventional first- or second-order kinetic equations (refer to Figure 5). 

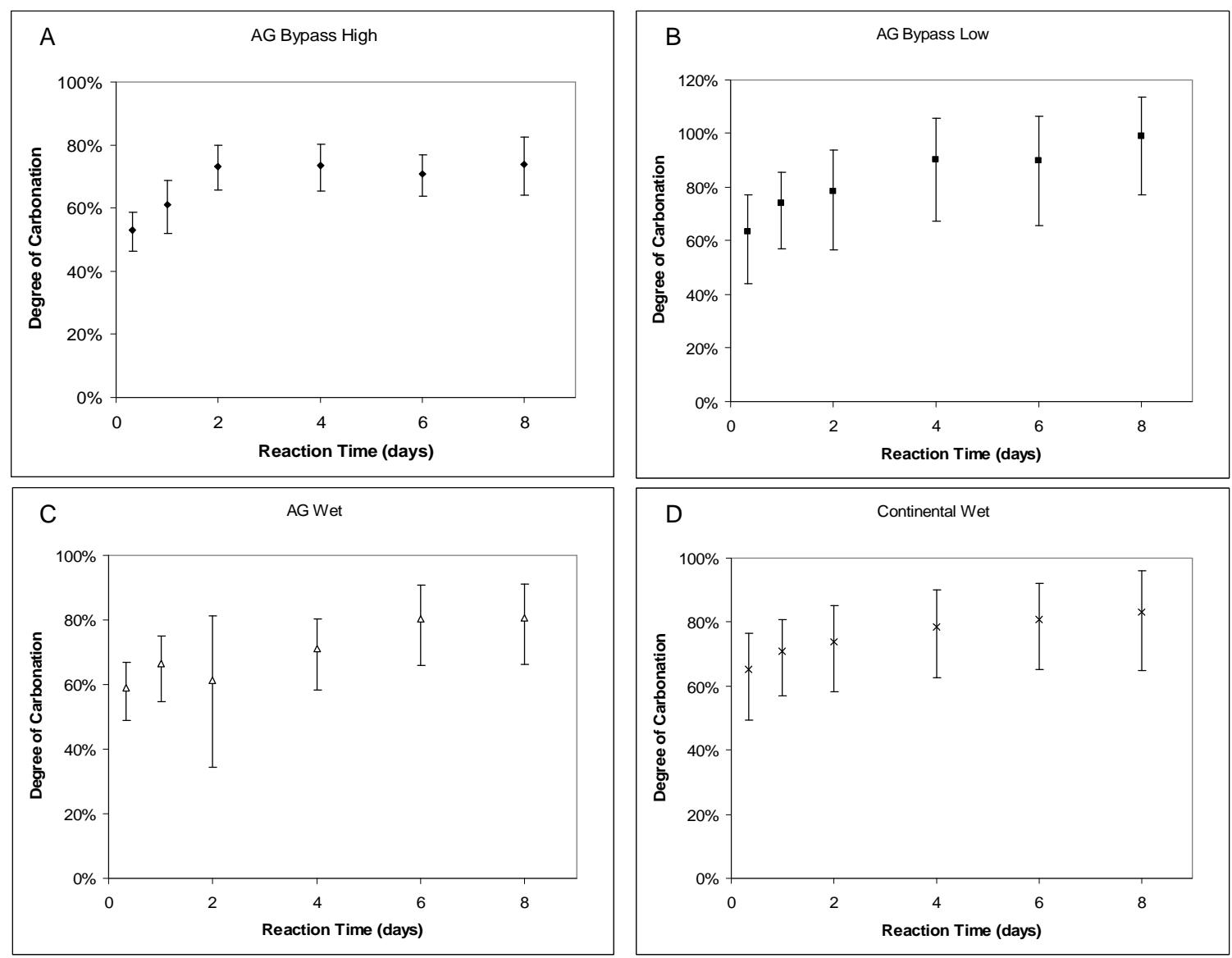

Figure 4. Degree of carbonation in four CKD types as a function of time: (A) AG Bypass High, (B) AG Bypass Low, (C) AG Wet, and (D) Continental Wet. Samples were reacted at $25^{\circ} \mathrm{C}$ and $100 \%$ relative humidity with an initial water-to-solids ratio of 0.85 . Error bars express range in calculated degree as a function of the uncertainty associated with both the mass change measurements and the theoretical calculation. 


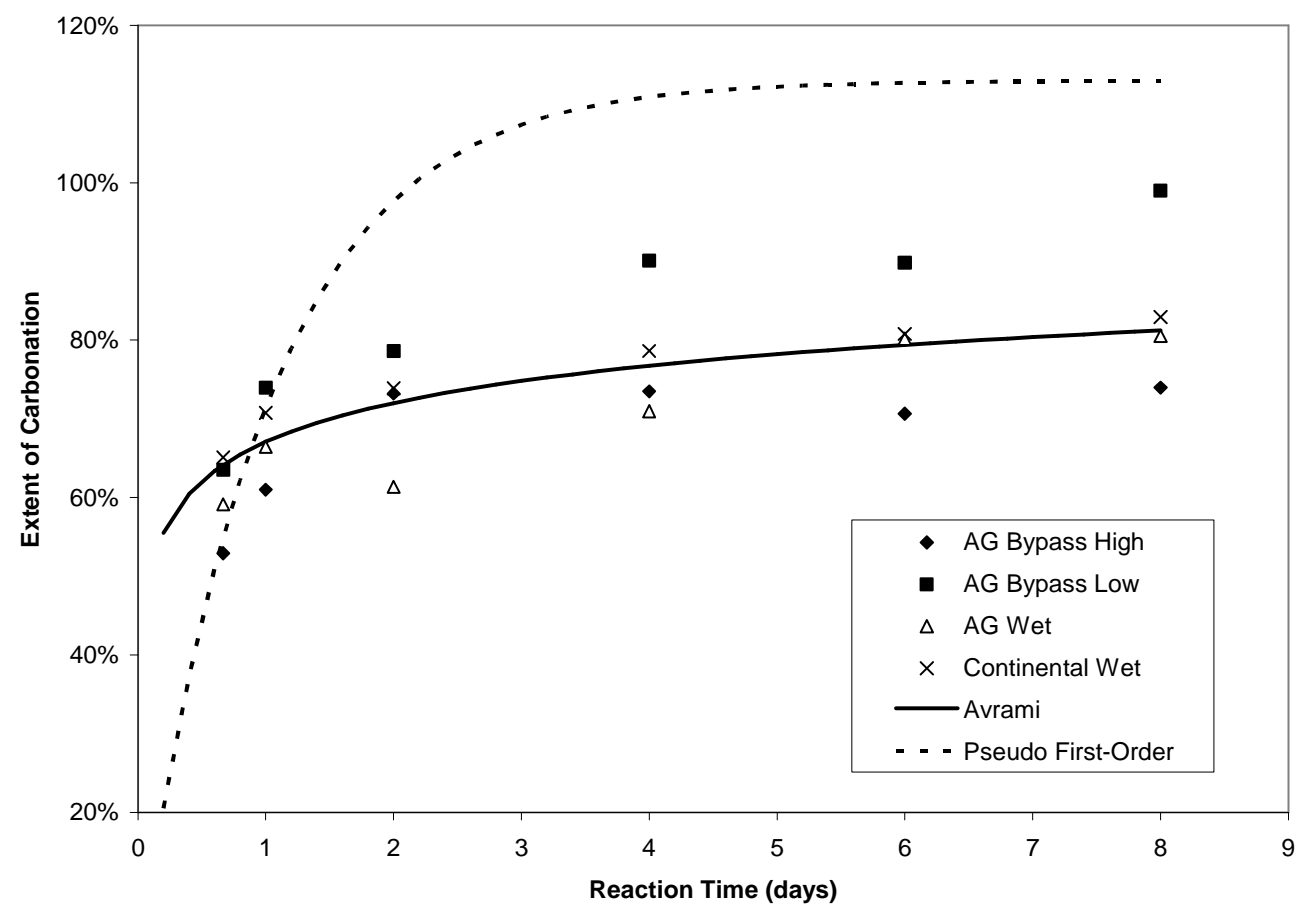

Figure 5. Experimental and predicted degree of $\mathrm{CO}_{2}$ consumption in the CKD types examined in this study based on the Avrami equation (Avrami 1939) and a rate expression following pseudo first-order rate assumptions

Column Paper: Effects of Vapor Transport and Particle-Scale Reaction Mechanisms on the Extent of Carbonation in CKD

The Core and Batch Papers demonstrate both the feasibility and potential of $\mathrm{CO}_{2}$ sequestration in CKD. However, rigorous examination of carbonation has been primarily restricted to batch-scale tests, not only with $\mathrm{CKD}$, but in studies utilizing other industrial wastes. The goal of this third paper/study was to examine the degree of sequestration achievable under non-ideal conditions, where dynamic gas flow and other macro-scale processes (such as preferential gas flow in channels and bulk diffusion in interchannel regions) may impede carbonation extents; conditions more likely to be expected under pilot or plant-scale operation. 
Under ideal conditions, particle-scale reaction and transport mechanisms (e.g., intraparticle diffusion) were shown to be important factors controlling the rate of carbonation (refer to Batch Paper and Anderson 2006). These microscale mechanisms were conceptualized (Figure 6) by combining the work presented in the Batch Paper and results from microscopic analysis conducted by Anderson 2006 with analogous processes that control oxygen diffusion and mineral oxidation in mine tailings (Wunderly et al. 1996). The conceptual model assumes that the reactions take place in the aqueous phase on, within, or near a reacting solid. Upon dissolution and dissociation, $\mathrm{CO}_{2}$ (as carbonate ion) is thought to diffuse from the particle surface to its core in response to concentration gradients. As it comes in contact with free $\mathrm{Ca}^{2+}$ ions, carbonates are precipitated. A reaction front develops that propagates inward towards the center of the particle and thickens with time. Thus, as the reaction ring develops, the mass-transfer rate of dissolved $\mathrm{CO}_{2}$ species to the unreacted core decreases, limiting the rate and possibly the extent of reaction.

Is this microscale conceptual model still important when gas and reactant contact may be imperfect? Or, as the system grows in scale does carbonation performance become governed by macroscale processes (e.g., mass transfer limitations, preferential gas flow, Figure 6)? A series of experiments were conducted under steady gas flow conditions with 7 uniformly packed columns of AG Bypass CKD (6-cm long, 5-cm diameter) and wellcontrolled influent mixtures of nitrogen, water vapor, and $\mathrm{CO}_{2}$. Gas flow rates and influent $\mathrm{CO}_{2}$ concentrations were systematically varied to differentiate the effects of transport and reaction mechanisms on the extent of carbonation, holding other parameters constant, such as initial moisture content, CKD type, and gas conditions (humidified) 
(refer to the Column Paper for more detail on column operating conditions). If

macroscale gas transport and transformation processes become rate- or extent-limiting at the column scale, then variations in applied gas flow rate within the columns (holding other factors constant) should impact the overall degree of carbonation observed in the columns, as well as the shape of the $\mathrm{CO}_{2}$ breakthrough curve. The same logic applies for rate-controlled reaction processes when influent $\mathrm{CO}_{2}$ concentrations are varied.

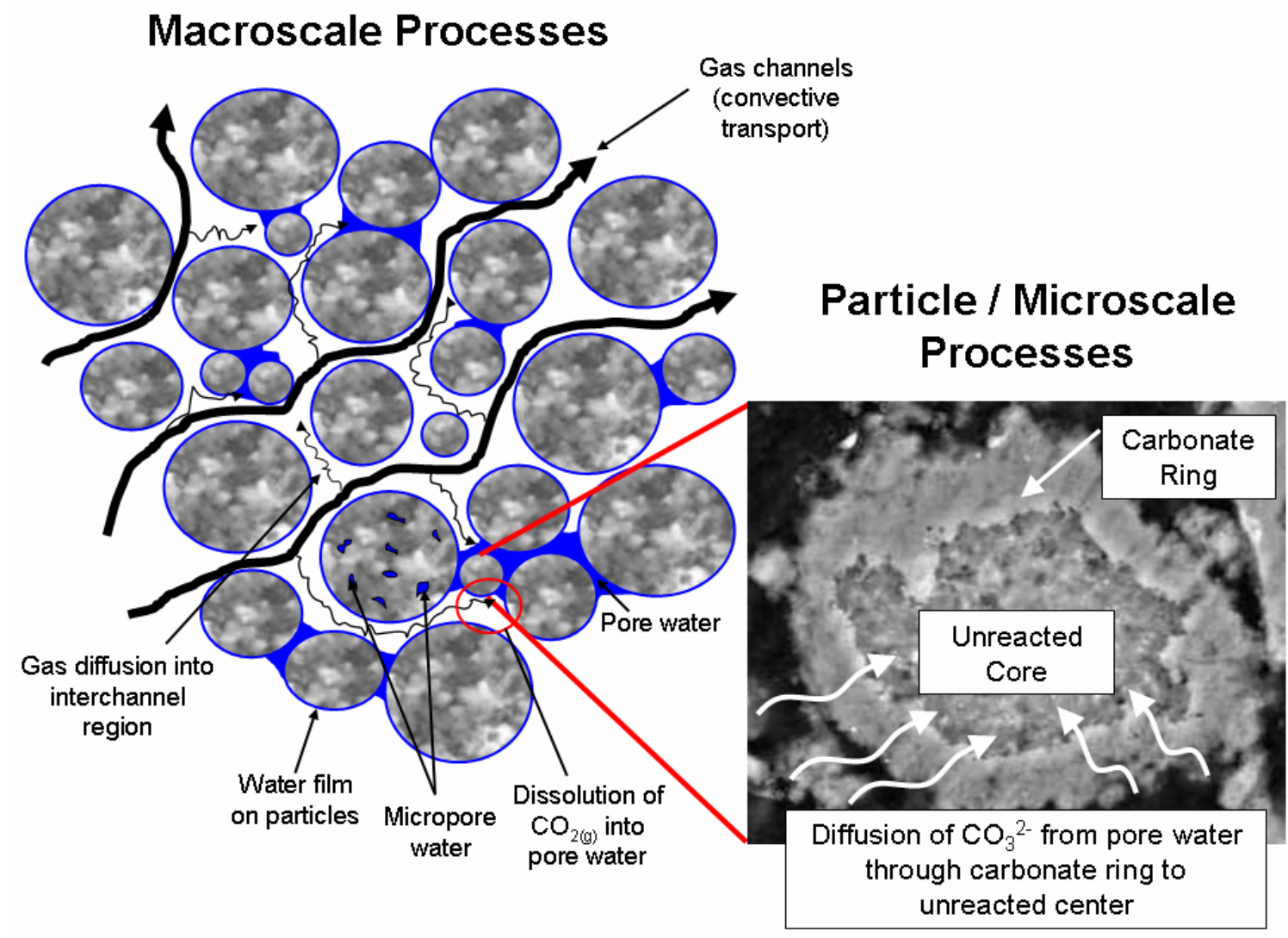

Figure 6. Conceptual model of the macro- and micro-scale processes that may control the extent and rate of carbonation at the column scale.

The total amount of sequestration (i.e., mass of $\mathrm{CO}_{2}$ captured) in each column was determined from both observed mass change and frontal analysis of column effluent. It was expected that some carbonation efficiency would be lost as the reaction system grew in scale; however variations in gas flow rate and influent concentration had little effect on 
observed carbonation efficiency in the columns. In fact, the overall sequestration

performance in the AG Bypass columns (Table 2) was comparable to that observed under controlled batch experiments (refer to Batch Paper). There is no discernable trend in sequestration performance (outside of the calculated margin of error) both between the column and batch studies and among the AG Bypass columns.

Table 2. Comparison of the degree of carbonation achieved in different CKD types between column study and previous batch experiments. Columns operated at 40 $\mathrm{ml} / \mathrm{min}$ with influent $\mathrm{CO}_{2}$ concentrations of $100,000 \mathrm{ppm}_{\mathrm{v}}$.

\begin{tabular}{|c|c|c|c|c|}
\hline \multirow{2}{*}{$\begin{array}{c}\text { CKD } \\
\text { Type }\end{array}$} & $\begin{array}{c}\text { Ideal } \\
\text { Behavior }\end{array}$ & $\begin{array}{c}\text { Maximum } \\
\text { Achieved in } \\
\text { Column }\end{array}$ & $\begin{array}{c}\text { Batch at } \\
\text { Similar } \\
\text { GWC and } \\
\text { Time }^{\mathbf{c}}\end{array}$ & $\begin{array}{c}\text { Maximum } \\
\text { Achieved in } \\
\text { Batch }^{\mathbf{d}}\end{array}$ \\
\hline AG & 71.2 & 75.6 & 77.2 & 77.5 \\
Bypass & $(70.9-71.7)$ & $(70.2-82.1)$ & $(70.5-82.8)$ & $(70.2-83.7)$ \\
\hline AG Wet & 38.1 & 58.7 & 49.2 & 80.6 \\
& $(37.5-38.5)$ & $(48.7-70.7)$ & $(38.0-57.5)$ & $(66.3-91.2)$ \\
\hline CT Wet & 46.6 & 59.6 & 70.5 & 83.0 \\
& $(45.9-47.1)$ & $(49.6-72.5)$ & $(50.2-85.2)$ & $(64.8-96.1)$ \\
\hline
\end{tabular}

${ }^{a}$ Average values are shown, along with a reasonable range in degree of carbonation that embodies both the error associated with mass of $\mathrm{CO}_{2}$ sequestered and calculations of the theoretical extent (Table 1 in Batch Paper).

${ }^{\mathrm{b}}$ Degree of carbonation achieved before deviated from ideal (i.e., before $\mathrm{CO}_{2}$ breakthrough on effluent end of column).

${ }^{\mathrm{c}}$ Degree of carbonation achieved in batch experiments conducted at a water:solids ratio of approximately 0.30 for a duration of 2 days (refer to Batch Paper). Sequestration in columns was complete after 2 to 3 days.

${ }^{\mathrm{d}}$ Maximum degree of carbonation achieved in batch experiments under humidified gas conditions and varied water:solids ratios (refer to Batch Paper).

Carbonation performance by the columns was also compared to ideal behavior, where all of the $\mathrm{CO}_{2}$ introduced to the system is consumed by the waste until the capacity of the column has been achieved (Figure 7). On average, $85 \%$ (standard deviation $=5.6 \%, \mathrm{n}=$ 7) of the sequestration achieved in the columns followed ideal behavior, with the remaining carbonation taking place more slowly. Similar trends were observed in the 
batch experiments (refer to Batch Paper) where approximately $90 \%$ of the observed $\mathrm{CO}_{2}$ sequestration was achieved with 2 days and additional carbonation occurred gradually over the remainder of the experiment (total time $=8$ days). Declines in sequestration rates can be explained using the conceptualized model discussed above and shown in Figure 6, where the rate of sequestration is controlled, at least in part, by the extent of carbonation. Under the operating conditions applied in this study, gas residence time and influent concentration appear to have no measurable effect on overall carbonation efficiency. Even though the complexity of the reaction system has increased, particle-scale mechanisms (Figure 6) are still playing a dominant role in the degree of carbonation achievable in the wastes.

The influence of a waste's reactive oxide fraction on carbonation performance was also assessed by conducting column experiments with two additional CKD types (AG Wet and CT Wet). Each of the CKD's examined has a varying amount of highly reactive oxides (HROs) or free $\mathrm{CaO}$ and $\mathrm{Ca}(\mathrm{OH})_{2}$. This $\mathrm{HRO}$ fraction is different from overall available oxide content (Table 3), which embodies both the HROs and those oxides that are available for reaction, but bound in semi-reactive phases such as calcium silicates. One of the hypotheses examined in this paper is the correlation between ideal behavior and the waste's HRO fraction. It is assumed that when the column is consuming all the $\mathrm{CO}_{2}$ injection (i.e., ideal behavior) carbonation reactions are taking place mostly through the consumption of the HRO fraction. As reaction conditions shift towards the consumption of less reactive $\mathrm{Ca}^{2+}$ species (i.e., those bound in $\mathrm{Ca}$ silicates or other oxide complexes), then carbonation rates begin to slow and $\mathrm{CO}_{2}$ breakthrough occurs. For each of the CKD types, the mass of $\mathrm{CO}_{2}$ sequestered prior to $\mathrm{CO}_{2}$ breakthrough was compared 
to the mass fraction of $\mathrm{CaO}$, the performance of the $\mathrm{AG}$ Wet column is consistent with this hypothesis (Table 3). The performance of the AG Bypass column does not correlate as clearly. However, the HRO content of this waste is much higher and accounts for a greater percentage of the overall oxide content (>90\%) of the waste (refer to Column $\underline{\text { Paper). SEM microanalysis (Anderson 2006) conducted on carbonated samples from }}$ batch tests indicate that $\mathrm{CaCO}_{3}$ skin development and precipitation of $\mathrm{CaCO}_{3}$ in particle micropores may encapsulate reaction sites before the full extent of carbonation was achieved. Because of the greater fraction of HRO in the AG Bypass CKD, this effect may be more pronounced. Therefore, it is possible that both reaction mechanisms (i.e., effect of HRO fraction) and diffusion controls (i.e., ring development) are controlling the rates of carbonation with time.

Table 3. Relation of cement kiln dust composition to the mass of $\mathrm{CO}_{2}$ sequestered before $\mathrm{CO}_{2}$ breakthrough occurred in the column. All columns were operated at 40 $\mathrm{ml} / \mathrm{min}$ with an influent $\mathrm{CO}_{2}$ concentration of $100,000 \mathrm{ppm}_{\mathrm{v}}$.

\begin{tabular}{|c|c|c|c|c|c|}
\hline CKD Type & $\begin{array}{c}\text { Available } \\
\text { CaO } \\
(\mathbf{W t} . \%)^{\mathbf{a}} \\
\end{array}$ & $\begin{array}{c}\text { HRO } \\
\text { Fraction } \\
(\text { Wt. \% })^{\text {b }} \\
\end{array}$ & $\begin{array}{c}\text { Mass of } \mathrm{CO}_{2} \\
\text { Sequestered } \\
\text { under Ideal } \\
\text { Behavior }(\mathrm{g})^{\mathbf{c}} \\
\end{array}$ & $\begin{array}{l}\text { Corresponding } \\
\text { Mass of } \mathrm{CaO} \\
\text { consumed }(\mathrm{g})^{\mathbf{d}}\end{array}$ & $\begin{array}{l}\text { Fraction of } \\
\text { Consumed } \\
\text { CaO to } \\
\text { Initial Mass } \\
(\%)^{\mathrm{e}} \\
\end{array}$ \\
\hline AG Bypass & 40.9 & 39.2 & 20.8 & 26.5 & 27.2 \\
\hline AG Wet & 23.6 & 8.0 & 6.1 & 7.8 & 7.4 \\
\hline CT Wet & 14.4 & -- & 7.6 & 9.7 & 8.0 \\
\hline
\end{tabular}

\footnotetext{
${ }^{a}$ Based on X-ray fluorescence, thermal gravimetric analysis, and estimations of initial $\mathrm{CaCO}_{3}$ and $\mathrm{CaSO}_{4}$ content.

${ }^{\mathrm{b}} \mathrm{HRO}$ refers to highly reactive oxide fraction or unbound $\mathrm{CaO}$ and $\mathrm{Ca}(\mathrm{OH})_{2}($ as $\mathrm{CaO})$. Values were obtained from Ash Grove's Rietveld refinement of X-ray diffraction patterns.

${ }^{\mathrm{c}}$ From frontal analysis of $\mathrm{CO}_{2}$ breakthrough in columns. "Ideal behavior" refers to the mass of $\mathrm{CO}_{2}$ sequestered before $\mathrm{CO}_{2}$ breakthrough was detected in the column effluent.

${ }^{\mathrm{d}}$ The corresponding amount of $\mathrm{CaO}$ consumed prior to $\mathrm{CO}_{2}$ breakthrough, assuming that all $\mathrm{CO}_{2}$ consumed was due to reaction with $\mathrm{CaO}$.

${ }^{\mathrm{e}}$ Reported as mass fraction of calculated $\mathrm{CaO}$ consumed (corresponding mass of $\mathrm{CaO}$ consumed $(\mathrm{g})$ ) to the initial dry mass of CKD in the column.
} 


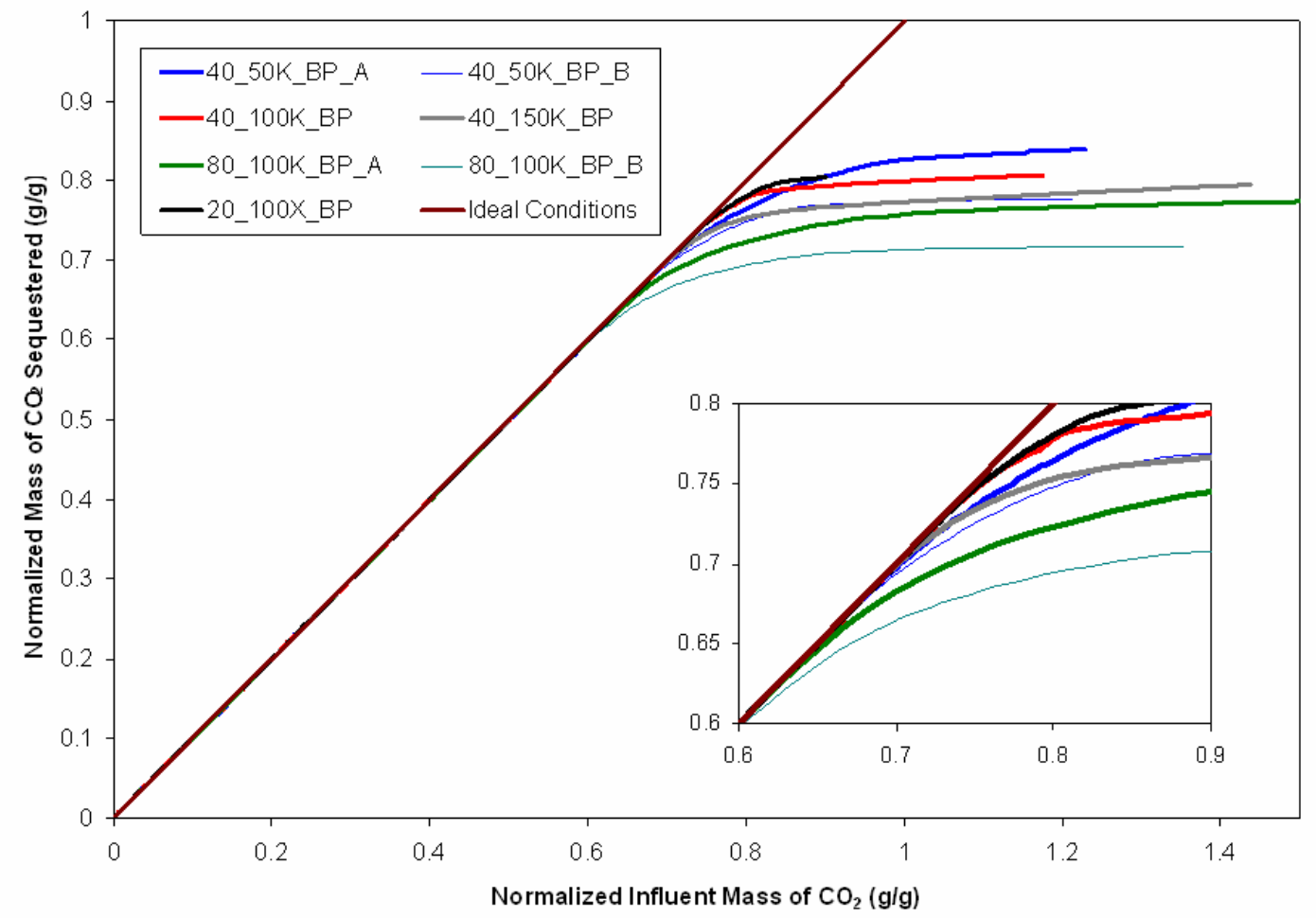

Figure 7. Normalized mass of $\mathrm{CO}_{2}$ sequestered in the eight Ash Grove Bypass CKD columns under various flow rates and influent $\mathrm{CO}_{2}$ conditions. The inset shows the point at which the performance of each column begins to deviate from ideal sequestration conditions $\left(\mathrm{CO}_{2}\right.$ breakthrough at the effluent end begins).

Scanning Electron Microscopy with Energy Dispersive X-ray (SEM-EDX)

The study conducted by Anderson (2006) complemented the work summarized in the $\underline{\text { Batch }}$ and $\underline{\text { Column }}$ Papers by providing particle-scale characterization of pre- and postcarbonated CKD samples and helped to elucidate the predominant mechanisms and pathways of the carbonation reactions. Anderson (2006) used a combination of SEMEDX and environmental scanning electron microscopy (ESEM) to describe chemical and morphological changes in particles due to carbonation. Direct particle comparison was performed using a Philips XL40 ESEM. Etched line grids were used on the sample stubs 
to aid in the identification and imaging of specific particles and allowed for assessment of overall structural changes in the particles due to carbonation. Elemental mapping and EDX microanalysis was also conducted on pre and post-carbonated samples to provide information on chemical changes as a result of carbonation reactions within, on, or near reacting particles. This information, combined with the composition analysis discussed above (refer to the Batch Paper), provided insight into the mechanisms of reaction.

The microscopy study was limited to the three CKD samples provided by Ash Grove Cement Company: AG Bypass High, AG Bypass Low, and AG Wet. All post-carbonated specimens examined through SEM-EDX were taken from samples produced during the batch experiments summarized above and discussed in detail in the Batch Paper. The major results of the microscopy work are discussed below and can be divided into two main areas: reaction pathways and precipitation mechanisms.

\section{Reaction Pathways:}

Carbon sequestration in CKD is believed to occur through two predominant pathways, both of which involve the carbonation of $\mathrm{Ca}^{2+}$. The primary route is likely the release of $\mathrm{Ca}^{2+}$ from free oxides such as $\mathrm{CaO}$ or $\mathrm{Ca}(\mathrm{OH})_{2}$ and the subsequent reaction with dissolved $\mathrm{CO}_{3}{ }^{2-}$ to form calcium carbonate. The second possible pathway is through the weathering of calcium-silicate minerals within the wastes. Material analysis provided by Ash Grove on the AG Bypass CKDs identified fractions of the common cement species $\mathrm{C}_{2} \mathrm{~S}\left(\mathrm{Ca}_{2} \mathrm{SiO}_{4}\right)$. Silicate species react with water to form gels that are integral in the hardening of cement. While release of $\mathrm{Ca}^{2+}$ from calcium silicates is expected, the rate of carbonation is likely slower than with the free or unbound oxides. 
Evidence of both pathways was observed in carbonated samples of the different CKD types; however, as hypothesized, the dominant reaction pathway appears to be through the carbonation of $\mathrm{Ca}(\mathrm{OH})_{2}$. While signs of calcium-silicate weathering and subsequent carbonation were observed in the EDX analysis, this pathway appears to be a minor contributor in the sequestration of $\mathrm{CO}_{2}$ (Anderson 2006). The substitution of potassium $(\mathrm{K})$, sodium $(\mathrm{Na})$ and iron $(\mathrm{Fe})$ in some of the carbonate minerals was also observed to a minor extent in carbonated particles.

Precipitation Mechanisms:

Microanalysis investigations on selected pre- and post-carbonated samples (Anderson 2006) indicate three dominant precipitation mechanisms: (1) the diffusion of dissolved $\mathrm{CO}_{2}$ species into $\mathrm{Ca}(\mathrm{OH})_{2}$ particles resulting in micropore precipitation and the formation of a carbonate ring that grows inward and thickens with reaction time (Figure 8 ); (2) the precipitation of $\mathrm{CaCO}_{3}$ on existing calcite particles; and (3) the precipitation of $\mathrm{CaCO}_{3}$ from aqueous solution. The primary pattern of precipitation varies among the different CKD types examined and appears to be a function of the reactive free lime content of the waste, as well as the effective water:solids ratio of the reacting mixture (Anderson 2006). Carbonation in the AG Bypass Low (which achieved the highest degree of carbonation) was dominated by precipitation from aqueous solution, where the other CKD types primarily exhibited precipitation in micropores within $\mathrm{Ca}(\mathrm{OH})_{2}$ particles or as coatings on pre-existing calcite particles (Table 4). 
Table 4. Cement kiln dust (CKD) types with hypothesized precipitation mechanisms. Modified from Anderson 2006.

\begin{tabular}{|c|l|l|}
\hline CKD Type & Material Characteristics & \multicolumn{1}{c|}{ Precipitation Mechanisms } \\
\hline $\begin{array}{c}\text { AG Bypass } \\
\text { High }\end{array}$ & $\begin{array}{l}\text { Free Lime }(\sim 37 \%) \text {, sylvite } \\
(\sim 10 \%), \text { water:solids ratio } \\
<1\end{array}$ & $\begin{array}{l}\text { Diffusion of dissolved } \mathrm{CO}_{2} \\
\text { species into } \mathrm{Ca}(\mathrm{OH})_{2} \text { particles } \\
\text { causing precipitation in the } \\
\text { particle pores and formation of } \\
\text { a carbonate ring } \\
\text { - Precipitation by nucleation }\end{array}$ \\
\hline $\begin{array}{c}\text { AG Bypass } \\
\text { Low }\end{array}$ & $\begin{array}{l}\text { Free Lime }(\sim 15 \%), \text { sylvite } \\
(>35 \%), \text { water:solids ratio }\end{array}$ & $\begin{array}{l}\text { - Precipitation from a saturated } \\
\text { solution } \\
\text { - Precipitation by nucleation }\end{array}$ \\
\hline AG Wet & $\begin{array}{l}\text { Free lime }(\sim 8 \%), \text { no } \\
\text { sylvite, water:solids ratio }< \\
1\end{array}$ & $\begin{array}{l}\text { - Precipitation by nucleation } \\
\text { Diffusion of dissolved } \mathrm{CO}_{2} \\
\text { species into Ca(OH) })_{2} \text { particles } \\
\text { causing precipitation in the } \\
\text { particle pores and formation of } \\
\text { a carbonate ring }\end{array}$ \\
\hline
\end{tabular}

${ }^{\text {a }}$ Percents are shown as weight fractions and were obtained from material analysis conducted by Ash Grove Cement Company.

Sylvite is very soluble in water and tends to absorb significant quantities of moisture from the atmosphere. As discussed above in the summary of the Batch Paper, the increased sequestration performance of the AG Bypass Low CKD was attributed, in part, to its high sylvite content. Halides have been used to catalyze carbonation reactions by increasing the ionic strength of the system, which promotes the precipitation of carbonates (refer to Batch Paper). The added moisture that sylvite attracts to the system may also enhance the dissolution of $\mathrm{Ca}$ species. 

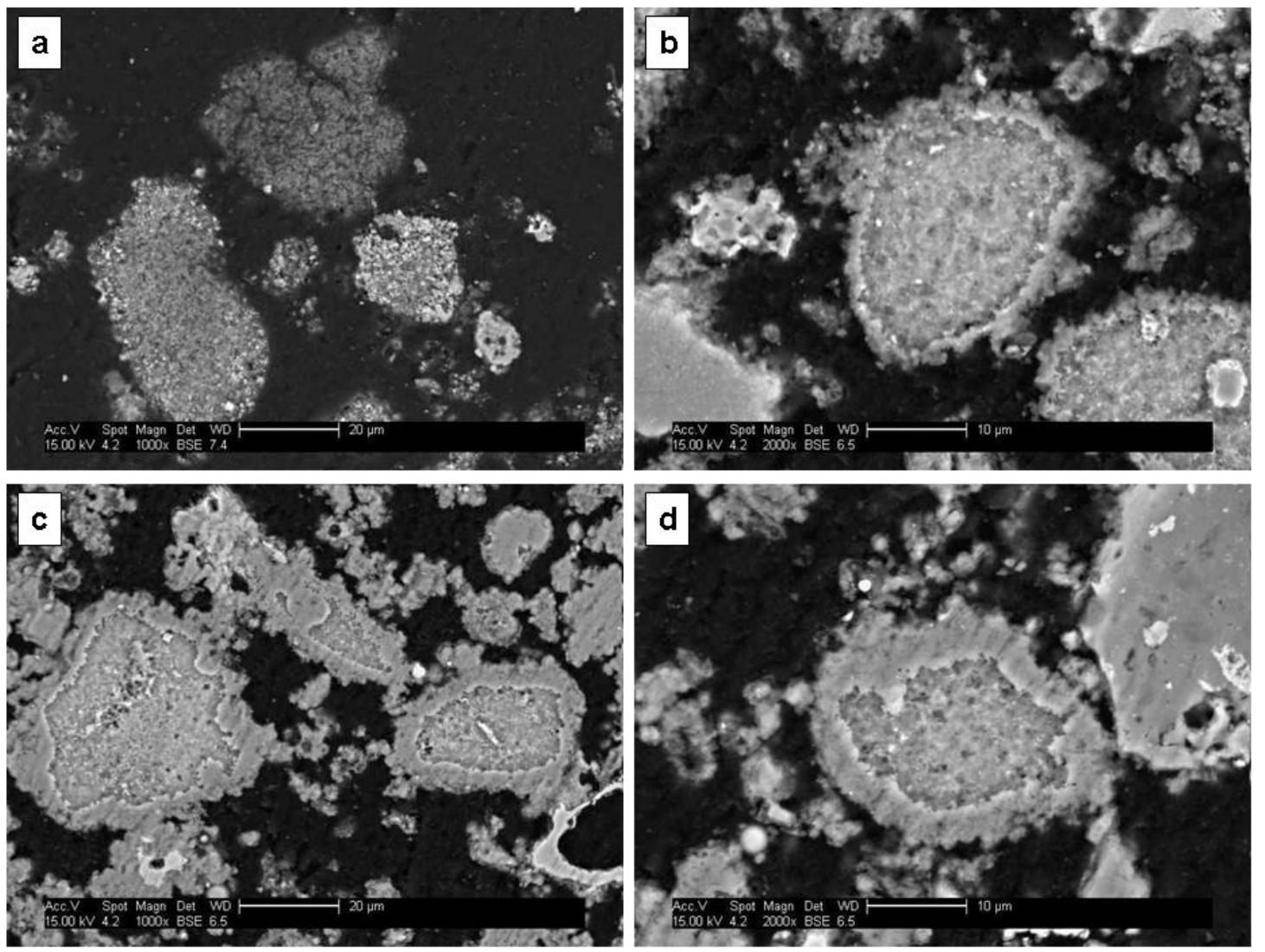

Figure 8. Back scattered electron images of AG Bypass High: (a) pre-carbonated sample, (b) 8-hour reacted sample, and (c-d) 4-day reacted samples. Figure 6a shows likely unreacted $\mathrm{Ca}(\mathrm{OH})_{2}$ particles. $\mathrm{CaCO}_{3}$ precipitated in micropore regions within the $\mathrm{Ca}(\mathrm{OH})_{2}$ particles and as reaction rings that thickened over time as evident in Figures6b-d. From Anderson 2006.

The study performed by Anderson (2006) provided insight into the nature of the precipitation reactions and the mechanisms of carbonation at the particle scale. The results were used to build a conceptual model (as discussed above) to help explain the slowing rates of carbonation observed in the batch and column studies (Figure 6). Such particle scale processes (Figure 8) appear to be important to carbonation performance in CKD, inhibiting complete carbonation in the waste. 


\section{LCA Paper: Life Cycle Assessment of Portland Cement Manufacturing}

A tangential study was conducted in collaboration with Thomas Eatmon, Ph.D. candidate at Southern University, to examine the possible reduction in global warming potential by the use of alternatives to the traditional cement manufacturing processes. The idea for this work was borne out of a course project and our common interest in the cement industry. Mr. Eatmon has participated in several research projects investigating the use of natural pozzolans (a mineral admixture that reacts with $\mathrm{Ca}(\mathrm{OH})_{2}$ and water to produce gels important to the hardening of cement) as partial substitutes for Portland cement in final concrete mixes (Harris et al. 2005 and Mihelcic et al. 2006). His interest in pozzolans and my work in carbon sequestration utilizing CKD lead us to focus our efforts on the potential benefits of these alternative processes when incorporated into the production of Portland cement. Cement is the main binding ingredient in concrete and is composed largely of calcium oxides, silica, aluminum, iron, and some gypsum (refer to LCA Paper). On average, approximately one ton of concrete is produced each year for every human being in the world (Lipiatt and Ahmand 2004), making concrete (i.e., cement) one of the World's most significant manufactured materials. Because of its abundance, understanding the environmental implications of cement manufacturing is becoming increasingly important (van Oss and Padovani 2002, 2003, Lippiatt and Ahmand 2004, Masanet et al. 2005). Life-cycle assessment (LCA) was used as a tool to estimate the environmental impact resulting from different product life stages, and to compare manufacturing processes incorporating alternatives such as pozzolan substitution, sequestration in $\mathrm{CKD}$, and complete $\mathrm{CKD}$ recycling to the traditional production process (refer to LCA Paper). 
The production of cement involves the consumption of large quantities of raw materials, energy, and heat. Cement production also results in the release of a significant amount of solid waste materials (e.g., CKD) and gaseous emissions (e.g., $\mathrm{CO}_{2}$ ). Although simple in theory, the manufacturing process is very complex due to the large number of materials, pyroprocessing techniques, and fuel sources used in the industry. Therefore, creating an appropriate inventory of inputs and outputs for LCA can be quite complicated. In addition, while a number of LCA studies have been conducted to examine the benefits/impacts of various concrete products (refer to LCA Paper), the life span, performance, and strength of these products greatly depend on their applications and end-uses. Because of these differences, comparative LCA among concrete products is difficult and the extrapolation of these results to a variety of application types is limited. Therefore in an attempt to reduce uncertainty, the study in the LCA Paper presents a cradle-to-gate LCA of several different cement products. We felt this reduced scope was reasonable since the cement manufacturing process is the most energy and emission intensive process in the production of concrete.

The comparable global warming impact/potential of cement was examined for 4 different manufacturing processes (Figure 9): the production of (1) traditional Portland cement; (2) blended cement using natural pozzolans; (3) cement where $100 \%$ of waste CKD is recycled back into the kiln; and (4) cement using the generated CKD to sequester a portion of the process relation $\mathrm{CO}_{2}$ emissions. 


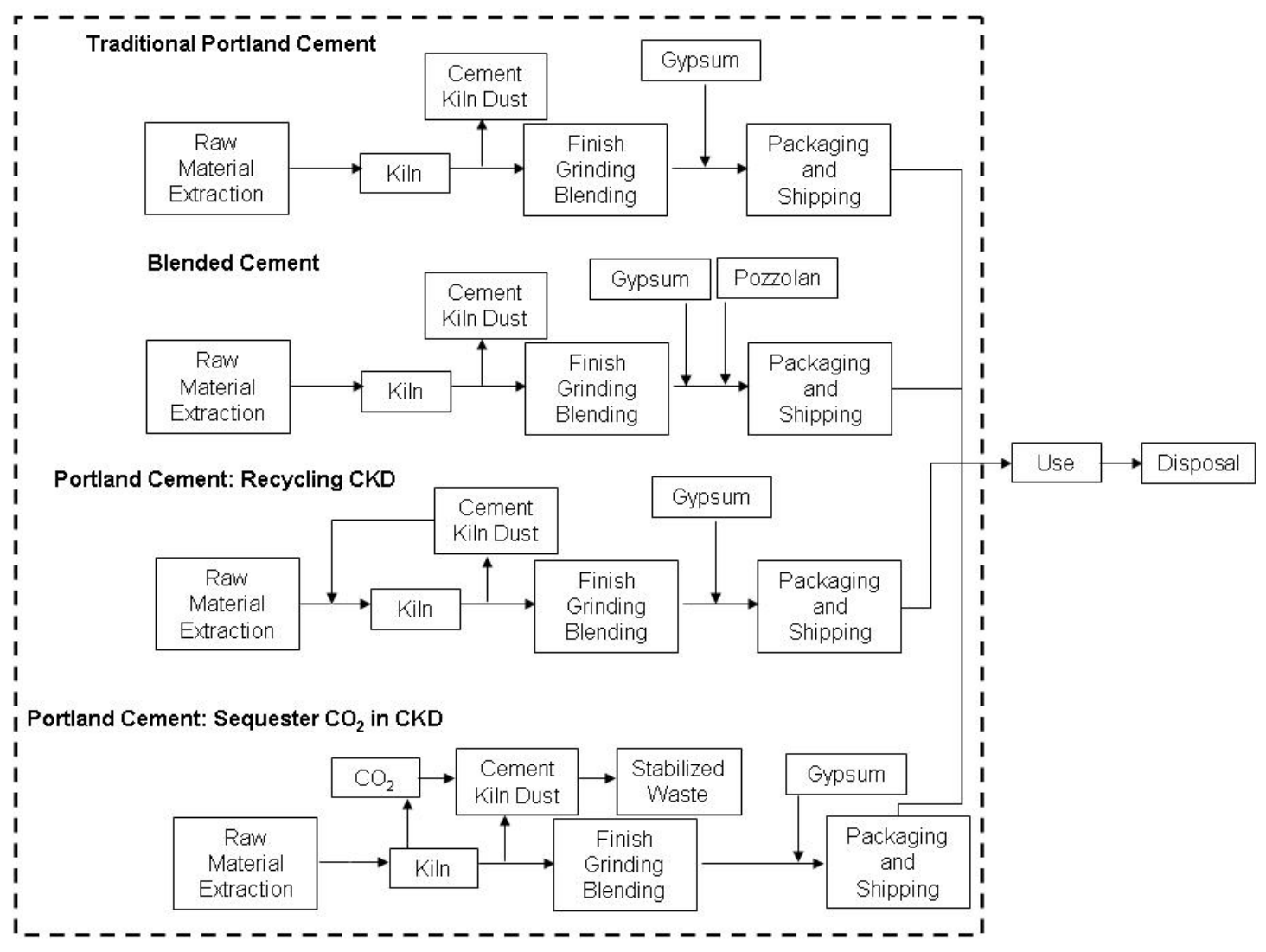

Figure 9. Scope of comparative LCA for four different cement manufacturing processes. The dashed line signifies the boundaries of the system examined.

The functional unit of analysis was the production of the equivalent of 20 bags $(\sim 1$ ton, each bag $100 \mathrm{lbs}$ ) of general use Class I Portland cement. One ton is a convenient quantity because it is often used in the reporting of energy and material consumption, as well as emissions. The U.S. cement industry produces approximately 79,500 thousand metric tons $(\mathrm{kMt})$ of clinker each year. On average, 1.58 tons of raw materials are required to produce 0.95 tons of clinker or 1.0 ton of finished product (refer to LCA Paper). Using the LCA software, SimaPro 6.0, the environmental impact scores, as well as product assemblies and life cycles for the 4 different cement processes were developed. There is a wide range of energy related information available in SimaPro. A 
majority of the cement kiln operations are powered (heated) by a combination of coal, petroleum, coke, and waste derived fuels, such as tires, waste oils, and hazardous materials (see LCA Paper for more details on fuel consumption by the cement industry). However, the specific blend of fuels used depends heavily on the manufacturing facility. Therefore, three major fuel sources (coal, fuel oil, and natural gas) were selected for inclusion in this study, based on the available information, both in SimaPro and on annual consumption rates. See to the LCA Paper for details concerning other assumptions made in the inventory analysis for each of the cement manufacturing processes examined.

The environmental impacts of cement manufacturing can be local, regional, or global in scale. Local effects include noise, air quality, and natural disturbance due to the mining of raw materials such as limestone, iron ore, and clay. Emissions such as sulfur dioxide $\left(\mathrm{SO}_{2}\right)$ and nitrogen oxides $\left(\mathrm{NO}_{\mathrm{x}}\right)$ contribute to acid rain on a regional scale, while carbon emissions originating from the calcining process and combustion of fossil fuels (e.g., coal, natural gas, fuel oil) contribute to global climate change. The focus of this analysis is global environmental impacts, particularly global warming, and how alternative cement mixes and/or processing technologies impact the overall global warming potential of cement production.

Of the cement products examined, the blended cement process has the lowest global warming or greenhouse potential followed by cement produced when a portion of the process related carbon emissions are captured back by sequestration in CKD. The improvement of blended cements on global warming potential over traditional Portland cement is to be expected. The kiln or pyroprocessing step is the most energy and environmentally impact intensive stage of the manufacturing process. This results both 
from the energy requirements to heat the kiln (to above $1400^{\circ} \mathrm{C}$ ) and the carbon released during the calcining step. By reducing the demand for clinker (through substitution), the environmental impacts of the end cement product are reduced proportionately. Although blended or pozzolanic cements reduce the $\mathrm{CO}_{2}$ emissions generated for a given ton of cement produced, what is not considered is the national and global demand for cement products. High demand and low imports of cement have led to increased prices and even shortages within the United States (Hagenbaugh 2004). Imports typically compensate for the shortfall between domestic capacity and consumption (PCA, 2004), however, increased demand for building materials in countries like Iraq and China have lessened the amount of imports available to the U.S. (Geddes 2004, Hagenbaugh 2004, PCA 2004). Other factors such as increased building activity within the U.S. and global transportation issues have also been cited as contributing to the U.S. cement shortage (PCA 2004). Because many kilns are operating at or above their effective capacity (PCA 2004), the use of blended cements is not likely to reduce net emissions of $\mathrm{CO}_{2}$. Instead, blended cements will allow for an increase in concrete production without any real modification to the existing amounts of clinker or portland cement produced within the United States (refer to LCA Paper).

The overall impact score for the cement manufacturing processes utilizing carbon sequestration in the waste product CKD is also lower than the traditional process. However, unlike natural pozzolans, sequestration presents a real capture of carbon emissions, which translates to approximately a $5 \%$ reduction in impact score over traditional Portland cement. Recycling CKD into the process line has little to no effect on the overall impact score. Since the CKD is recycled into the kiln feed there is no real 
reduction in emissions or energy required in the most environmentally damaging step, the kiln.

The results of this LCA show that blended cements provide the greatest environmental savings, followed by utilization of CKD for sequestration. While pozzolanic cements provide the illusion of environmental benefit over traditional cements in terms of energy consumption and associated carbon emissions, if the demand of concrete and cement products remains higher than the supply, the use of blended cements is not likely to provide any real reduction in net $\mathrm{CO}_{2}$ emissions or energy consumption.

\section{Conclusions}

The studies presented in this dissertation systematically investigate the sequestration of $\mathrm{CO}_{2}$ in the waste product cement kiln dust (CKD). The technical investigations progressed logically from proof of feasibility by investigating the sequestration in core samples taken from an aged CKD waste pile, to more detailed analysis of the rates and mechanism of the mineral carbonation reactions in a series of batch and microscopy studies using a variety of fresh CKD types. Finally the scale of the system was increased to assess the importance of particle-scale processes on carbonation extents under flowing gas (i.e., dynamic) conditions. Through this investigation it was shown that CKD readily sequesters $\mathrm{CO}_{2}$ at ambient temperatures and pressures. Such a finding is important because other mineral carbonation studies examining sequestration in mined mineral feedstocks require significant energy inputs during both the pre-processing and carbonation steps. 
The most significant findings of this work are:

- During the carbonation of CKD, the major precipitation product is calcium carbonate $\left(\mathrm{CaCO}_{3}\right)$. While other oxides may participate in reactions through substitution or the formation of additional mineral carbonates, $\mathrm{CaCO}_{3}$ appears to dominate the carbonation processes.

- The rate of carbonation appears to be dependent on the extent of carbonation. From microscopic and EDX analysis of carbonation particles, one of the dominant mechanism of precipitation was the diffusion of dissolved $\mathrm{CO}_{2}$ species into $\mathrm{Ca}(\mathrm{OH})_{2}$ particles resulting in micropore precipitation and the formation of a carbonate ring that grows inward and thickens with reaction time. This shell or ring appears to hinder further diffusion of $\mathrm{CO}_{2}$ and effectively seals of the center of the particle from further carbonation. Extents of carbonation estimated based on cross-sectional area analysis of particles from SEM images ( 75\%) compared well with degrees of carbonation calculated in the batch study $(\sim 80 \%)$.

- The degree of carbonation with time is best represented using a lumped-rate expression that represents both the reaction and mass transfer mechanisms. The results indicate that reaction mechanisms alone are not likely the limiting factor controlling the progress of carbonation. Intraparticle diffusion appears to be controlling the rate of reactions, particularly with increased degrees of conversion. This conclusion corresponds with the results of SEM and microanalysis.

- Similar sequestration performance was achieved in both the batch and column studies. Under the operational conditions applied in the columns $(50,000$ to 150,000 $\mathrm{ppm}_{\mathrm{v}} \mathrm{CO}_{2}$ and 20 to $80 \mathrm{ml} / \mathrm{min}$ gas flow rate), the degree of carbonation achievable in 
the waste under more dynamic conditions appears to be still dominated by particlescale processes.

- The ability and rate of carbonation in CKD appears to depend more on the fraction of highly reactive oxides (free or unbound $\mathrm{CaO}$ and $\mathrm{Ca}(\mathrm{OH})_{2}$ ) then overall oxide content. Therefore, in addition to the extent of carbonation at the particle scale, reaction rates may be influenced by the nature of the oxides participation in the reaction. As the free or unbound oxides are consumed and reaction conditions shift towards the consumption of less reactive $\mathrm{Ca}^{2+}$ species (i.e., those bound in $\mathrm{Ca}$ silicates or other oxide complexes), carbonation rates appear to slow. It is difficult, however, to separate out the effects of diffusion and reaction mechanisms controls on the rates of carbonation.

\section{Reference Cited}

Avrami, M., "Kinetics of Phase Change. I General Theory," Journal of Chemical Physics, Vol. 7, pp. 1103-1112, 1939.

Anderson, C.P., "Effects of Carbonation on the Mineral Composition of Cement Kiln Dust," Master's Thesis, Michigan Technological University, 2006.

Biernacki, J. J., P. J. Williams, and P. E. Stutzman, "Kinetics of Reaction of Calcium Hydroxide and Fly Ash," ACI Materials Journal, Title No. 98-M37, July/August, pp. 340-349, 2001.

Energy Information Administration (EIA), "Analysis of S.1844, the Clear Skies Act of 2003; S.843, the Clean Air Planning Act of 2003; and S.366, the Clean Power Act of 2003," Office of Integrated Analysis and Forecasting, U.S. Department of Energy, SR/OIAF/2004-05, 2004.

Falkowski, P. R.J. Scholes, E. Boyle, J. Canadell, D. Canfield, J Elser, N. Gruber, K. Hibbard, P. Hogberg, S. Linder, F.T. Mackenzie, B. Moore III, T. Pedersen, Y. Rosenthal, S. Seitzinger, V. Smetacek, and W. Steffen, "The Global Carbon Cycle: A Test of Our Knowledge of Earth as a System," Science, 290, pp.291-296, 13 July, 2000. 
Fauth, D.J., P.M. Goldberg, J.P. Knoer, Y. Soong, W.K. O'Connor, D.C. Dahlin, D.N. Nilsen, R.P. Walters, K.S. Lackner, H.J . Ziock, M.J. McKelvy, and Z.Y. Chen, "Carbon Dioxide Storage as Mineral Carbonates," Symposium-American Chemical Society, Division Fuel Chemistry, pp. 708-712, 2000.

Fauth, D.J., J.P. Baltrus, Y. Soong, J.P. Knoer, B.H. Howard, W.J. Graham, M.M. Maroto-Valer, and J.M. Andresen, Chapter: "Carbon Storage and Sequestration as Mineral Carbonates", Book: Environmental Challenges and Greenhouse Gas Control for Fossil Fuel Utilization in the $21^{\text {st }}$ Century, Kluwer Academic / Plenum Publishers, 2002.

Feely R.A, C.L. Sabine, K. Lee, W. Berelson, J. Kleypas, V.J. Fabry, and F. J. Millero, "Impact of Anthropogenic $\mathrm{CO}_{2}$ on the $\mathrm{CaCO}_{3}$ System in the Oceans," Science, 305, pp.362-366, 16 July 2004.

Field, C.B. and M.R. Raupach (eds.), The Global Carbon Cycle: Integrating Humans, Climate, and the Natural World, SCOPE 62, Island Press, Washington DC, 2004.

Hagenbaugh, B., "Cement Weighs on Construction," USA Today, August 8, 2004.

Harris, R.A., T. Eatmon, and C. Seifert "Natural Pozzolans for Sustainable Development: Environmentally Friendly Concrete Technology," Conference Proceedings of the $25^{\text {th }}$ Annual ESRI International User Conference, San Diego, California, July 2005.

Hendriks, C.A., E. Worrell, D. deJager, K. Block, and P. Riemer, "Emission Reduction of Greenhouse Gases from the Cement Industry," IEA Greenhouse gas R\&D Programme, http://www.ieagreen.org.uk/prghgt42.htm, 2000.

Huijgen, W.J.J. and R.N.J. Comans, "Carbon Dioxide Sequestration by Mineral Carbonation Literature Review," Energy Resource Center of the Netherlands, ECNC-03-016, 2003.

Geddes, R., "Strong Global Demand Puts Cement in Short Supply," Jacksonville Business Journal, June 4, 2004.

Intergovernmental Panel on Climate Change (IPCC), "Climate Change 2001: The Scientific Basis. Contribution of Working Group I to the Third Assessment Report of the Intergovernmental Panel on Climate Change," Cambridge University Press, 2001.

Lackner, K.S., D.P. Butt, and C.H. Wendt, "Progress on Binding $\mathrm{CO}_{2}$ in Mineral Substrates," Energy Conversion and Management, 38, sp259-264, 1997.

Lippiatt, B., and S. Ahmad, "Measuring the Life-Cycle Environmental and Economic Performance of Concrete: The BEES Approach," International Workshop on Sustainable Development and Concrete Technology, Beijing, May 20-21, 2004.

Masanet, E., L. Price, S. de la Rue du Can, and R. Brown, "Reducing Greenhouse Gas Emissions from Products Manufactured in California," Second Annual Climate Change Research Conference, Sacramento, CA, September 14, 2005.

Mihelcic, J., T. Eatmon, H. Muga, and R.A. Harris, "Engineering Sustainable Construction Materials for the Developing World: Consideration of Engineering, Societal, and Economic Issues," The International Journal of Engineering Education, to appear in special issue on sustainability, 2006. 
National Energy Information Center (NEIC), "Greenhouse Gases, Climate Change, and Energy," Energy Information Administration, Internet:

<http://www.eia.doe.gov/oiaf/1605/ggccebro/chapter1.html>, April 2004.

National Energy Technology Laboratory (NETL), “Carbon Sequestration Technology Roadmap and Program Plan 2004: Developing the Technology Base and Infrastructure to Enable Sequestration as a Greenhouse Gas Mitigation Option," U.S. Department of Energy, Office of Fossil Energy, April 2004.

National Research Council (NRC), "Novel Approaches to Carbon Management: Separation, Capture, Sequestration, and Conversion to Useful Products," Workshop Report, 2003.

Pedit, J.R., J. Jouzel, D. Raynaud, N.I. Barkov, J.M. Barnola, I. Basile, M. Benders, J. Chappellaz, M. Davis, G. Delaygue, M. Delmotte, V.M. Kotlyakov, M. Legrand, V.Y. Lipenkov, C. Lorius., L. Peplin, C. Ritz, E. Saltzman, and M. Stievenard, "Climate and Atmospheric History of the past 420,000 years from the Vostok Ice Core, Antarctica," Nature, 399, pp. 429-435, 3 June 1999.

Portland Cement Association (PCA), "Cement Shortage Assessment," The Monitor, Flash Report: Breaking Analysis of the Economy, Construction, and Cement Industries, May 13, 2004.

Sabine, C.L., R.A. Feely, N. Gruber, R.M. Key, K. Lee, J.L. Bullister, R. Wanninkhof, C.S. Wong, D.W.R. Wallace, B. Tilbrook, F.J. Millero, T.H. Peng, A. Kozyr, T. Ono, and A.F. Rios, "The Oceanic Sink for Anthropogenic $\mathrm{CO}_{2}$," Science, 305, pp. 367371, 16 July 2004.

SCOPE 62, "The Global Carbon Cycle: Integrating Humans, Climate, and the Natural World,” Edited by C.B. Field and M.R. Raupach, Island Press 2004.

Snoeyink, V.L. and D. Jenkins, Water Chemistry, John Wiley \& Sons, New York, NY, 1980.

Steinour, H.H., "Some Effects of Carbon Dioxide on Motars and Concrete - Discussion," Concrete Briefs, Journal of the American Concrete Institute, pp. 905-907, February 1959.

U.S. Department of Energy, "Carbon Sequestration Technology Roadmap and Program Plan 2005, Developing the Technology Base and Infrastructure to Enable Sequestration as a Greenhouse Gas Mitigation Option," May 2005.

U.S. Environmental Protection Agency, "The Potential Effects of Global Climate Change in the United States, Report to Congress," Washington, D.C., US Government Printing Office, EPA-230-05-89-050, 1989.

U.S. Environmental Protection Agency, "Inventory of U.S. Greenhouse Gas Emissions and Sinks," EPA 430-R-05-003, April 15, 2005.

Van Oss, H.G. and A.C. Padovani, "Cement Manufacture and the Environment, Part 1: Chemistry and Technology," Journal of Industrial Ecology, 6(1), 89-105, 2002. 
Van Oss, H.G. and A.C. Padovani, "Cement Manufacture and the Environment, Part II: Environmental Challenges and Opportunities," Journal of Industrial Ecology, 7(1), 93-127, 2003.

Wunderly, M.D., D.W. Blowes, E.O. Frind, and C.J. Ptacek, "Sulfide Mineral Oxidation and Subsequent Reactive Transport of Oxidation Products in Mine Tailings Impoundments: A numerical Model," Water Resources Research, 32(10), pp. 31733187, October 1996. 


\title{
Mineral Carbonation for Carbon Sequestration in Cement Kiln Dust from Waste Piles
}

\author{
Deborah N. Huntzinger ${ }^{1}$, John S. Gierke ${ }^{1}$, Lawrence L. Sutter ${ }^{2}$, S. Komar Kawatra ${ }^{3}$, and
} Timothy C. Eisle ${ }^{3}$

\begin{abstract}
Alkaline earth metals, such a calcium and magnesium oxides, readily react with carbon dioxide $\left(\mathrm{CO}_{2}\right)$ to produce stable carbonate minerals. Carbon sequestration through the formation of carbonate minerals is a potential means to reduce $\mathrm{CO}_{2}$ emissions. Calcium-rich, industrial solid wastes and residues provide a potential source of highly reactive oxides, without the need for pre-processing. This paper presents the first study examining the feasibility of carbon sequestration in cement kiln dust (CKD), a byproduct generated during the manufacturing of cement. A series of column experiments were conducted on segments of intact core taken from landfilled CKD. Based on stoichiometry and measured consumption of $\mathrm{CO}_{2}$ during the experiments, degrees of carbonation greater than $70 \%$ of the material's potential theoretical extent were achieved under ambient temperature and pressure conditions. The overall extent of carbonation/sequestration was greater in columns with lower water contents. The major sequestration product appears to be calcite; however, more detailed material characterization is need on pre- and post-carbonated samples to better elucidate carbonation pathways and products.
\end{abstract}

\footnotetext{
${ }^{1}$ Department of Geological \& Mining Engineering and Sciences/Sustainable Futures Institute, Michigan Technological University, 1400 Townsend Drive, Houghton, MI 49931

2 Michigan Technological University Transportation Institute, 1400 Townsend Drive, Houghton, MI 49931

3 Department of Chemical Engineering and Sciences, Michigan Technological University, 1400 Townsend Drive, Houghton, MI 49931
} 


\section{Introduction}

Increased public awareness of the threats posed by global warming has led to greater concern over the impact of anthropogenic carbon emissions on the global climate.

Several carbon sequestration technologies have emerged as potential means to mitigate rising concentrations of $\mathrm{CO}_{2}$ in the atmosphere. One of these options is mineral carbonation, the reaction of alkaline earth metals with $\mathrm{CO}_{2}$ to form relatively stable and benign carbonate minerals according to the general reaction:

$$
(\mathrm{Ca}, \mathrm{Mg}) \mathrm{SiO}_{3}+2 \mathrm{CO}_{2}+3 \mathrm{H}_{2} \mathrm{O} \rightarrow(\mathrm{Ca}, \mathrm{Mg}) \mathrm{CO}_{3}+\mathrm{H}_{4} \mathrm{SiO}_{4}+\mathrm{H}_{2} \mathrm{O}+\mathrm{CO}_{2}
$$

Carbonation occurs naturally through geologic processes of silicate weathering; however, the reaction rates are slow (on geologic time scales; Beecy and Ferrell 2001) and economic feasibility of wide-spread application is not fully known. The stability of the end-products (i.e., carbonates), however, has prompted investigations into ways to mimic and catalyze the weathering process in the laboratory. The majority of mineral carbonation research to date has examined sequestration in mined silicate minerals (e.g., serpentine, olivine) (Lackner et al. 1997, Guthrie et al. 2001, Wu et al. 2001, Fauth et al. 2000 and 2002a, Huijgen and Comans 2003). Mining operations and subsequent physical and chemical processing are required to produce a mineral form suitable for sequestration reactions. Both the mineral acquisition and pre-processing steps require energy inputs, reducing the overall efficiency of the process in terms of net carbon reduction. However, more readily available oxide mineral sources may be available through the reuse of industrial solid wastes and residues.

The extent of carbonation in alkaline wastes, such as coal fly ash, municipal solid waste incinerator ash, and steel slag has been investigated in preliminary experiments 
(e.g., Fauth and Soong 2001, Fuji et al. 2001, Fauth et al. 2002b, Bertos et al. 2004a and 2004b, Huijgen et al. 2005) with favorable results. The utilization of alkaline waste materials provides several advantages: (1) waste materials supply a readily available source of calcium or magnesium mineral matter without the need for pre-processing; (2) they are typically fine-grained with high reactive surface areas; and (3) the environmental quality of the waste materials can be improved through $\mathrm{pH}$-neutralization and mineral transformation (Huijen and Comans 2003, Bertos et al. 2004b). In addition, alkaline industrial wastes are typically generated at or near point sources of $\mathrm{CO}_{2}$.

For a waste to be amenable for mineral carbonation it must provide alkalinity in the form of calcium or magnesium oxides. Many fine-grained industrial wastes, such as cement kiln dust, coal fly ash, and steel slag, have high mass percentages of $\mathrm{CaO}$. While a majority of the research conducted on mineral carbonation of feedstocks (mined metal oxides) has focused on $\mathrm{Mg}$ silicates because of their availability, the carbonation of $\mathrm{CaO}$ is more thermodynamically favorable at ambient temperatures and pressures (Huijgen and Comans 2003). One industrial waste that has high mass fractions of $\mathrm{CaO}(20 \%$ to $60 \%$ ) is cement kiln dust (CKD). The cement manufacturing process produces millions of tons of CKD each year, which consists of fine particles of unburned and partially burned raw materials, clinker, and some trace elements (van Oss and Padovani 2003). Although a fraction of CKD is used for beneficial agricultural applications, the U.S. cement industry disposes of several million tons of CKD annually in piles, quarries, and landfills (US EPA 1999 and PCA 2003). In addition to the generation of CKD, the cement industry is one of the largest $\mathrm{CO}_{2}$ emitters in the U.S. (US EPA 2004) and globally (Hendriks et al. 2000). Roughly half of the industry's $\mathrm{CO}_{2}$ comes from the calcining process, while the 
other half is from the combustion of fossil fuels (Hendriks et al. 2000). The calcining process releases $\mathrm{CO}_{2}$ from the conversion of calcite $\left(\mathrm{CaCO}_{3}\right)$ to lime $(\mathrm{CaO})$ at high temperatures $\left(>1300^{\circ} \mathrm{C}\right)$.

In this paper, the feasibility of carbon sequestration in waste CKD under ambient pressure and temperature conditions is investigated. The aims of this study are to (1) determine if landfilled $\mathrm{CKD}$ will readily sequester $\mathrm{CO}_{2}$ and (2) to measure the extent of carbonation (sequestration) under varying operating conditions (water content and $\mathrm{CO}_{2}$ concentrations). Very few studies have been conducted that examine the sequestration of $\mathrm{CO}_{2}$ in industrial wastes (cf. Bertos et al. (2004a, 2004b)), and none have measured the extent of sequestration in cement kiln dust under ambient conditions. This paper presents the first study of the feasibility of $\mathrm{CO}_{2}$ capture in $\mathrm{CKD}$ and identifies conditions that appear to improve the extent of sequestration.

\section{Materials and Methods}

A series of column experiments were conducted using intact core segments of CKD taken from a landfilled waste pile in Alpena, Michigan (depth of sample 25 feet). The columns were operated under varying conditions to determine the impact of humidity and $\mathrm{CO}_{2}$ concentration on the extent of carbonation or sequestration.

\section{Column Set-up and Operation}

Four segments were cut from the core $(7.3-\mathrm{cm}$ diameter) and fitted with PVC end caps (Table 1.1) . High-purity carbon dioxide $\left(\mathrm{CO}_{2}\right)$ and nitrogen $\left(\mathrm{N}_{2}\right)$ (Airgas, Marquette, MI) were mixed and regulated with Dwyer gas flow meters (Models VA1043 and VA1045, Michigan City, IN) to achieve the desired input $\mathrm{CO}_{2}$ concentration. Gas flow rates between 45 to $60 \mathrm{~mL} / \mathrm{min}$ were maintained through the columns, and effluent 
samples were analyzed with a gas chromatograph (MTI Analytical Instruments Quad 4 Model Q30L, Fremont, CA) until full breakthrough of the input $\mathrm{CO}_{2}$ was observed.

Figure 1.1 provides a schematic of the experimental set-up. The extent of carbon sequestration was measured under varied influent gas concentrations, relative humidity conditions, gas flow rates, and initial column moisture contents (Table 1.1). At the end of each experiment, the column was flushed with $\mathrm{N}_{2}$ gas and $\mathrm{CO}_{2}$ effluent concentrations were monitored to determine the amount of unsequestered $\mathrm{CO}_{2}$ within the column tubing, end caps, pore spaces, and dissolved in the aqueous phase. After nitrogen flushing, the columns were dismantled and the gravimetric water content of the carbonated CKD was measured. The dried content of each column was homogenized by grinding in a Bico, B100 pulverizer (Type UA, Burbank, CA) and tumbling the material for 5 minutes. Two 20-ml aliquots were obtained from the bulk mix of each column for compositional analyses.

Table 1.1 Column and operating conditions for the four cement kiln dust columns.

\begin{tabular}{|c|c|c|c|c|c|c|c|}
\hline Column & $\begin{array}{c}\text { Length } \\
(\mathbf{c m})\end{array}$ & $\begin{array}{c}\text { Flow } \\
\text { Rate } \\
(\mathbf{m l} / \mathbf{m i n})\end{array}$ & $\begin{array}{c}\text { Influent CO } \\
\text { Concentration } \\
\left(\mathbf{p p m}_{\mathbf{v}}\right)\end{array}$ & $\begin{array}{c}\text { Influent } \\
\text { Gas } \\
\text { Humidity }\end{array}$ & $\begin{array}{c}\text { Initial } \\
\text { Material } \\
\text { Dry Mass } \\
(\mathbf{g})\end{array}$ & $\begin{array}{c}\text { Initial } \\
\text { Gravimetric } \\
\text { Water } \\
\text { Content }\end{array}$ & $\begin{array}{c}\text { Bulk } \\
\text { Density } \\
(\mathbf{g} / \mathbf{m l})\end{array}$ \\
\hline $\mathrm{A}$ & 5.1 & 45 & 75,800 & $>98 \%$ & 136 & $75 \%$ & 0.60 \\
\hline $\mathrm{B}$ & 5.0 & 45 & 69,900 & $>98 \%$ & 140 & $45 \%$ & 0.61 \\
\hline $\mathrm{C}$ & 4.9 & 61 & 84,900 & $<1 \%$ & 191 & $38 \%$ & 0.81 \\
\hline $\mathrm{D}$ & 13.6 & 53 & 35,600 & $<1 \%$ & 424 & $68 \%$ & 0.74 \\
\hline
\end{tabular}

\section{Material Characterization}

The elemental composition of pre-carbonated CKD was analyzed with a Philips PW 2404 X-ray spectrometer (Cambridge, UK). Sample specimens were homogenized by grinding in a SPEX shatterbox (Edison, NJ). Portions of the bulk sample were ignited to a constant mass of $980{ }^{\circ} \mathrm{C}$ and then fused into glass disks with a LECO FX-503 (St. Johns, 
MI) automated fuser. Mineralogical composition of pre- and post-carbonated samples was assessed using powder X-ray diffraction (Siemens D 500, Cherry Hill, NJ) equipped with a $\mathrm{Cu}$ X-ray tube operated at $50 \mathrm{kV}$ and $27 \mathrm{~mA}$ medium resolution slits. Specimens were scanned from 5 to 70 degrees $2 \theta$, with a step-size of $0.05^{\circ}$ and a dwell time of two seconds per step.

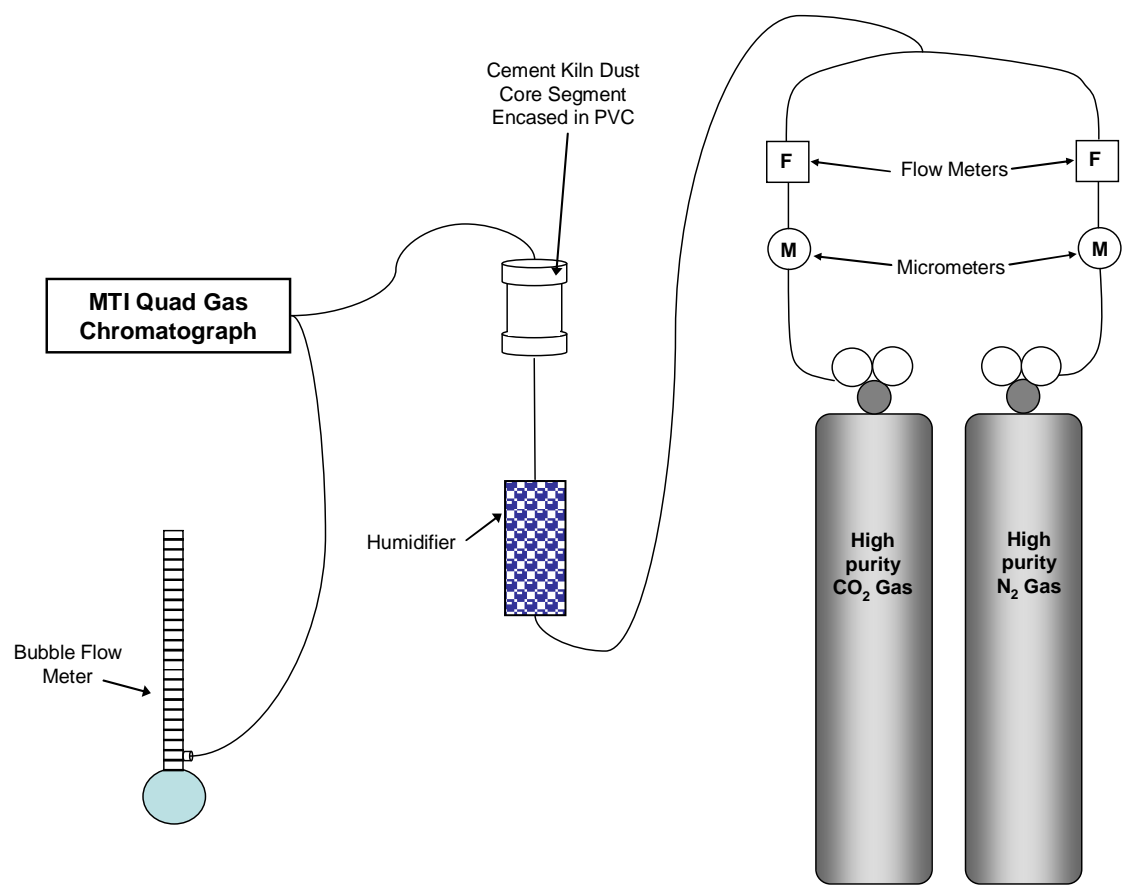

Figure 1.1 Schematic of column set-up

\section{Extent of Carbonation}

The extent of mineral carbonation was determined by complementary analytical and empirical methods: (1) thermal decomposition (TGA-DTA), (2) observed mass change before and after column experiment; and (3) frontal analysis of effluent $\mathrm{CO}_{2}$ 
concentrations (i.e. difference between the cumulative influent and eluted mass of $\mathrm{CO}_{2}$ in the columns; Shackelford 1994).

Thermal analysis was performed with a SDT 2960 TA-Instruments (New Castle, DE) Thermal Gravimetric Analyzer to determine carbonate content of pre- and postcarbonated CKD samples from the column experiments. Representative samples ( 22 $\mathrm{mg}$ ) were heated in corundum crucibles in a nitrogen environment from ambient to 1100 ${ }^{\circ} \mathrm{C}$ at $20{ }^{\circ} \mathrm{C} /$ minute. Weight loss in the samples was monitored by gravimetric analysis (TGA) as a function of time. Phase change was simultaneously evaluated with differential thermal analysis (DTA) by measuring the temperature difference between the sample and inert, heat-treated corundum. Loss of calcium carbonate (i.e., $\mathrm{CO}_{2}$ ) in both pre- and post-carbonated samples was observed in the temperature region of $500-800{ }^{\circ} \mathrm{C}$. Other weight loss regions associated with the loss of moisture, ettringite $\left(110-150^{\circ} \mathrm{C}\right)$, and portlandite $\left(300-500{ }^{\circ} \mathrm{C}\right)$ were also observed.

In addition to thermal analysis, the extent of carbonation was measured by monitoring the mass change of each column before and after $\mathrm{CO}_{2}$ injection and through frontal analysis of measured effluent $\mathrm{CO}_{2}$ concentrations. For those columns where dry gas was used, the recorded mass change was corrected for water vapor loss during the course of the column experiment. The loss of water mass was calculated as a function of flow rate, operation time, and the vapor pressure of water at ambient temperature and pressure conditions $\left(21^{\circ} \mathrm{C}, 1 \mathrm{~atm}\right)$.

Degree of Sequestration

The degree of sequestration refers to the amount of $\mathrm{CO}_{2}$ captured as carbonated mineral mass compared to the mass of $\mathrm{CO}_{2}$ that would be consumed if all available 
oxides were carbonated. For this study, the degree of sequestration was determined by comparing the observed mass of $\mathrm{CO}_{2}$ sequestered in each column via frontal analysis to the amount theoretically possible based on the elemental and phase composition of the pre-carbonated CKD. For pure oxides (e.g., $\mathrm{CaO}$ and $\left.\mathrm{Ca}(\mathrm{OH})_{2}\right)$, the theoretical extent of carbonation is a function of basic stoichiometry:

$$
\mathrm{CaO}_{(\mathrm{s})}+\mathrm{CO}_{2(\mathrm{aq})} \rightarrow \mathrm{CaCO}_{3(\mathrm{~s})}
$$

Thus, every ton of $\mathrm{CaO}$ can potentially sequester up to 0.785 tons of $\mathrm{CO}_{2}$. For waste mixtures such as CKD, the theoretical extent of carbonation can still be calculated as a function of stoichiometry, however, the extent also depends on the availability of those oxides for reaction. $\mathrm{CKD}$ can host a number of reaction pathways to the capture of $\mathrm{CO}_{2}$ in addition to equation 1.2:

$$
\begin{gathered}
\mathrm{MgO}+\mathrm{CO}_{2} \rightarrow \mathrm{MgCO}_{3} \\
\mathrm{Ca}(\mathrm{OH})_{2}+\mathrm{CO}_{2} \rightarrow \mathrm{CaCO}_{3}+\mathrm{H}_{2} \mathrm{O} \\
\mathrm{K}_{2} \mathrm{O}+\mathrm{CO}_{2} \rightarrow \mathrm{K}_{2} \mathrm{CO}_{3} \\
\mathrm{Na}_{2} \mathrm{O}+\mathrm{CO}_{2} \rightarrow \mathrm{Na}_{2} \mathrm{CO}_{3}
\end{gathered}
$$

Potassium and sodium oxides can also react with $\mathrm{CO}_{2}$ to form bicarbonates. The amount of free oxide in CKD available for reaction depends on the type of kiln, source material, fuel type used, and the manner in which CKD was recovered from the system (Klemm 1994, Haynes and Kramer 1982, Strydom et al. 1996). Because of the wide range in CKD composition it can be difficult to specify a theoretical extent of carbonation. Nevertheless, estimates of $\mathrm{CO}_{2}$ consumption can be made by taking into consideration the amount of calcite present in the pre-carbonated waste, along with the $\mathrm{CaO}$ bound in anhydrite. Similar to estimates of $\mathrm{CO}_{2}$ consumption in mortars and 
concrete by Steinour (1959), an estimate of the theoretical extent of carbonation in a given CKD can be calculated as follows:

$$
\begin{gathered}
\% \mathrm{CO}_{2}=0.785\left(\% \mathrm{CaO}-0.56 \% \mathrm{CaCO}_{3}-0.7 \% \mathrm{SO}_{3}\right)+1.091 \% \mathrm{MgO} \\
+0.71 \% \mathrm{Na}_{2} \mathrm{O}+0.468 \% \mathrm{~K}_{2} \mathrm{O}
\end{gathered}
$$

Where the $\% \mathrm{CO}_{2}$ refers to the mass of $\mathrm{CO}_{2}$ consumed in the carbonation reactions compared to the original, unreacted mass of the sample. The stoichiometric mass factors shown in equation 1.7 assume that all of the $\mathrm{CaO}$ (except that bound in $\mathrm{CaSO}_{4}$ and $\mathrm{CaCO}_{3}$ ) will react to form $\mathrm{CaCO}_{3}$, all the $\mathrm{MgO}$ will react to form $\mathrm{MgCO}_{3}$, and all of $\mathrm{Na}_{2} \mathrm{O}$ and $\mathrm{K}_{2} \mathrm{O}$ will convert to $\mathrm{Na}_{2} \mathrm{CO}_{3}$ and $\mathrm{K}_{2} \mathrm{CO}_{3}$. The mass factors for $\mathrm{K}_{2} \mathrm{O}$ and $\mathrm{Na}_{2} \mathrm{O}$ are doubled if bicarbonates form instead of carbonates.

\section{Results and Discussion}

\section{Material Characterization and Theoretical Extent of Carbonation}

The elemental composition of the pre-carbonated CKD used in this study, given as weight percent of oxides, is listed in Table 1.2 along with the typical range in oxide composition reported for CKD (Corish and Coleman 1995). The unreacted CKD is high in $\mathrm{CaO}$, with moderate to low amounts of $\mathrm{K}, \mathrm{Mg}$, and $\mathrm{Na}$ oxides. Based on thermal analysis of pre-carbonated samples, the existing carbonate composition of the waste is relatively high $(42.3 \%)$. It is possible that other carbonate species are present in the sample in addition to calcite, such as dolomite $\left(\mathrm{CaMg}\left(\mathrm{CaCO}_{3}\right)_{2}\right)$ or ankerite $(\mathrm{Ca}(\mathrm{Fe}, \mathrm{Mg}$, $\left.\mathrm{Mn})\left(\mathrm{CO}_{3}\right)_{2}\right)$. However, dolomite (and ankerite) overlap severely with arcanite in XRD diffractograms. Therefore, in this waste, it is difficult to definitively determine their occurrence. Assuming that the predominant carbonate phase in the unreacted CKD is calcite, only $7.8 \% \mathrm{CaO}$ is available for carbonation, with a small fraction of that bound 
in anhydrite $\left(\mathrm{CaSO}_{4}\right)$. Gypsum $\left(\mathrm{CaSO}_{4} \cdot 2 \mathrm{H}_{2} \mathrm{O}\right)$ is thermodynamically stable at temperatures below $52{ }^{\circ} \mathrm{C}$. Therefore, it is assumed that under moist conditions and at ambient temperatures and pressures anhydrite will readily hydrate to form gypsum rather than releasing $\mathrm{Ca}$ for reaction with $\mathrm{CO}_{2}$.

Table 1.2 Elemental composition of pre-carbonated CKD as oxides.

\begin{tabular}{|c|c|c|}
\hline \multirow{2}{*}{ Oxide } & \multicolumn{2}{|c|}{ Mass Fraction (\% dry wt.) } \\
\cline { 2 - 3 } & $\begin{array}{c}\text { CKD } \\
\text { (This Study) }\end{array}$ & $\begin{array}{c}\text { Typical Range } \\
\text { for CKD }\end{array}$ \\
\hline $\mathrm{Na}_{2} \mathrm{O}$ & 0.52 & $0-2$ \\
\hline $\mathrm{MgO}$ & 2.08 & $0-2$ \\
\hline $\mathrm{Al}_{2} \mathrm{O}_{3}$ & 3.41 & $3-6$ \\
\hline $\mathrm{SiO}_{2}$ & 13.17 & $11-16$ \\
\hline $\mathrm{P}_{2} \mathrm{O}_{5}$ & 0.05 & -- \\
\hline $\mathrm{SO}_{3}$ & 4.78 & $4-18$ \\
\hline $\mathrm{K}_{2} \mathrm{O}$ & 5.84 & $3-13$ \\
\hline $\mathrm{CaO}$ & 34.5 & $38-50$ \\
\hline $\mathrm{TiO}_{2}$ & 0.19 & -- \\
\hline $\mathrm{Fe}_{2} \mathrm{O}_{3}$ & 2.89 & $1-4$ \\
\hline $\mathrm{SrO}^{\mathrm{Mn}} \mathrm{O}_{3}$ & 0.02 & -- \\
\hline $\mathrm{LOI}^{\mathrm{b}}$ & 0.04 & -- \\
\hline $\mathrm{Oxide} \mathrm{Total}^{\mathrm{b}}$ & 31.2 & $5-25$ \\
\hline & 98.7 & -- \\
\hline
\end{tabular}

${ }^{a}$ From Corish and Coleman, 1995

${ }^{\mathrm{b}}$ LOI is the loss on ignition.

The major and minor mineral phases identified by powdered X-ray diffraction (XRD) in the unreacted CKD were calcite $\left(\mathrm{CaCO}_{3}\right)$, quartz $\left(\mathrm{SiO}_{2}\right)$, anhydrite $\left(\mathrm{CaSO}_{4}\right)$, ettringite $\left(\mathrm{Ca}_{6} \mathrm{Al}_{2}\left(\mathrm{SO}_{4}\right)_{3}(\mathrm{OH})_{12}-26 \mathrm{H}_{2} \mathrm{O}\right)$, and arcanite $\left(\mathrm{K}_{2} \mathrm{SO}_{4}\right)$. It is likely that the sample contains small amounts of other mineral phases, but reliable detection of minerals present in weight percents below 1 or $2 \%$ is difficult with XRD. The high percentage of calcite and the presence of ettringite indicate that the waste pile from which the CKD core was taken had been exposed to moisture and likely undergone some carbonation after its deposition. 
Ettringite is a common hydration product found in cements (Gabrovsek et al. 2006) and other materials high in $\mathrm{Ca}, \mathrm{Al}$, and $\mathrm{SO}_{3}$, such as $\mathrm{CKD}$ and fly ash (Sreekrishnavilasam et al. 2006).

Based on TGA-DTA analysis, the amount of ettringite in pre-carbonated samples is approximately $11.7 \%\left(2.24 \% \mathrm{SO}_{3}\right)$. Based on the elemental and phase composition of the pre-carbonated CKD, the theoretical extent of carbonation (consumption of $\mathrm{CO}_{2}$ ) can be estimated using equation 1.7. Assuming that half of the remaining $\mathrm{SO}_{3}$ is bound in anhydrite and that all of the $\mathrm{Na}, \mathrm{K}$, and $\mathrm{Mg}$ oxides are available to react to form carbonates, the theoretical extent of carbonation for CKD used in this study is $11.5 \%$ (Table 1.3). This theoretical percentage is the mass of $\mathrm{CO}_{2}$ that can be captured compared to the initial dry mass of material. Table 1.4 summarizes the expected amount of $\mathrm{CO}_{2}$ sequestration for each column if all oxides available for reaction were carbonated.

Table 1.3 Theoretical extent of sequestration possible for CKD type used in this study.

\begin{tabular}{|c|c|c|c|c|}
\hline \multirow[b]{2}{*}{ Parameter } & \multicolumn{4}{|c|}{ Oxide } \\
\hline & $\mathrm{CaO}$ & $\mathrm{MgO}$ & $\mathrm{Na}_{2} \mathrm{O}$ & $\mathrm{K}_{2} \mathrm{O}$ \\
\hline Molecular Weight & 56.0 & 40.3 & 62.0 & 94.2 \\
\hline Weight Percent of Oxide & $34.5 \%$ & $2.1 \%$ & $0.5 \%$ & $5.8 \%$ \\
\hline Weight Percent Available & $7.8 \%$ & $2.1 \%$ & $0.5 \%$ & $5.8 \%$ \\
\hline Stoichiometric Mass Factor ${ }^{a}$ & 0.8 & 1.1 & 0.7 & 0.5 \\
\hline$\%$ of $\mathrm{CO}_{2}$ Capture Possible ${ }^{b}$ & $6.13 \%$ & $2.27 \%$ & $0.37 \%$ & $2.73 \%$ \\
\hline$\%$ of Total Theoretical Sequestration & $53.3 \%$ & $19.8 \%$ & $3.2 \%$ & $23.7 \%$ \\
\hline
\end{tabular}

${ }^{\text {a }}$ Stoichiometric mass factors assume that all of the available oxides react to form carbonates.

${ }^{b}$ Based on stoichiometry and the composition of the unreacted CKD. The total sequestration capacity of the waste is calculated to be $11.5 \%$ (i.e., for every $1 \mathrm{~kg}$ of $\mathrm{CKD}$, has potential to capture $0.115 \mathrm{~kg}$ of $\mathrm{CO}_{2}$ ) 
Table 1.4 The observed mass of $\mathrm{CO}_{2}$ sequestered compared to the theoretical amount of sequestration possible, along with the degree of sequestration achieved for each column.

\begin{tabular}{|c|c|c|c|c|c|}
\hline Column & $\begin{array}{c}\begin{array}{c}\text { Operation } \\
\text { Time } \\
\text { (days) }\end{array} \\
\end{array}$ & $\begin{array}{l}\text { Observed } \\
\text { Mass } \\
\text { Change }^{a} \\
\text { (g) }\end{array}$ & $\begin{array}{c}\mathrm{CO}_{2} \\
\text { Sequestered }^{\mathbf{b}} \\
(\mathrm{g})\end{array}$ & $\begin{array}{c}\text { Theoretical } \\
\text { Sequestration }^{c} \\
(\mathrm{~g})\end{array}$ & $\begin{array}{c}\text { Observed } \\
\text { Sequestration }^{\text {Degree }^{d}} \\
\end{array}$ \\
\hline $\mathrm{A}$ & 3.4 & 10.8 & 11.8 & 15.7 & $75.0 \%$ \\
\hline $\mathrm{B}$ & 4.9 & 14.9 & 15.3 & 16.2 & $94.3 \%$ \\
\hline $\mathrm{C}$ & 3.3 & 22.5 & 22.3 & 22.0 & $101.2 \%$ \\
\hline $\mathrm{D}$ & 12.0 & 29.2 & 34.6 & 49.0 & $70.6 \%$ \\
\hline
\end{tabular}

${ }^{a}$ Observed mass changes in Columns C and D were corrected for water vapor loss due to injection of dry gas.

${ }^{\mathrm{b}} \mathrm{CO}_{2}$ sequestered is based on frontal analysis of effluent $\mathrm{CO}_{2}$ concentrations from each column.

${ }^{\mathrm{c}}$ Theoretical mass of sequestration assuming that $\mathrm{Na}$ and $\mathrm{K}$ carbonates form.

${ }^{\mathrm{d}}$ Degree of carbonation achieved in each column based on theoretical mass of sequestration.

\section{Post-Carbonation Characterization and Extent of Carbonation}

Post-carbonation XRD and TGA/DTA analysis was conducted on a sample taken from column B. Only three major and minor mineral phases were identified: calcite, quartz, and gypsum. The absence of ettringite and anhydrite indicate that the assumptions of calcium availability and anhydrite conversion to gypsum were reasonable. For the CKD used in this study, $\mathrm{CaO}$ and $\mathrm{K}_{2} \mathrm{O}$ appear to have the largest capacity for mineral carbonation (Table 1.3). Although no Na or K carbonate or bicarbonate species were identified with XRD analysis on the post-carbonated waste, the amount of $\mathrm{CO}_{2}$ sequestered in each column suggests that calcite was not the only carbonate species formed during the experiments (Table 1.4). From TGA conducted on post-carbonated samples taken from column B, the derivative weight loss curve shows an increase in the area of the carbonate peak, particularly on the leading edge (Figure 1.2). The greater mass loss in the carbonated sample in the lower temperature region of carbonate decomposition may be either from the formation of finer, less defined calcite crystals or 
the precipitation of other carbonate phases. The decomposition of an addition, unidentified phase(s) was detected in the carbonated sample in the temperature region between 820 and $1000{ }^{\circ} \mathrm{C}$ (Figure 1.2). More detailed quantitative analysis of pre- and post-carbonated CKD materials is needed to better quantify carbonation products. Batch scale experiments, microscopy, and additional material analysis by XRD and TGA-DTA are currently being conducted to elucidate reaction pathways and carbonation products.

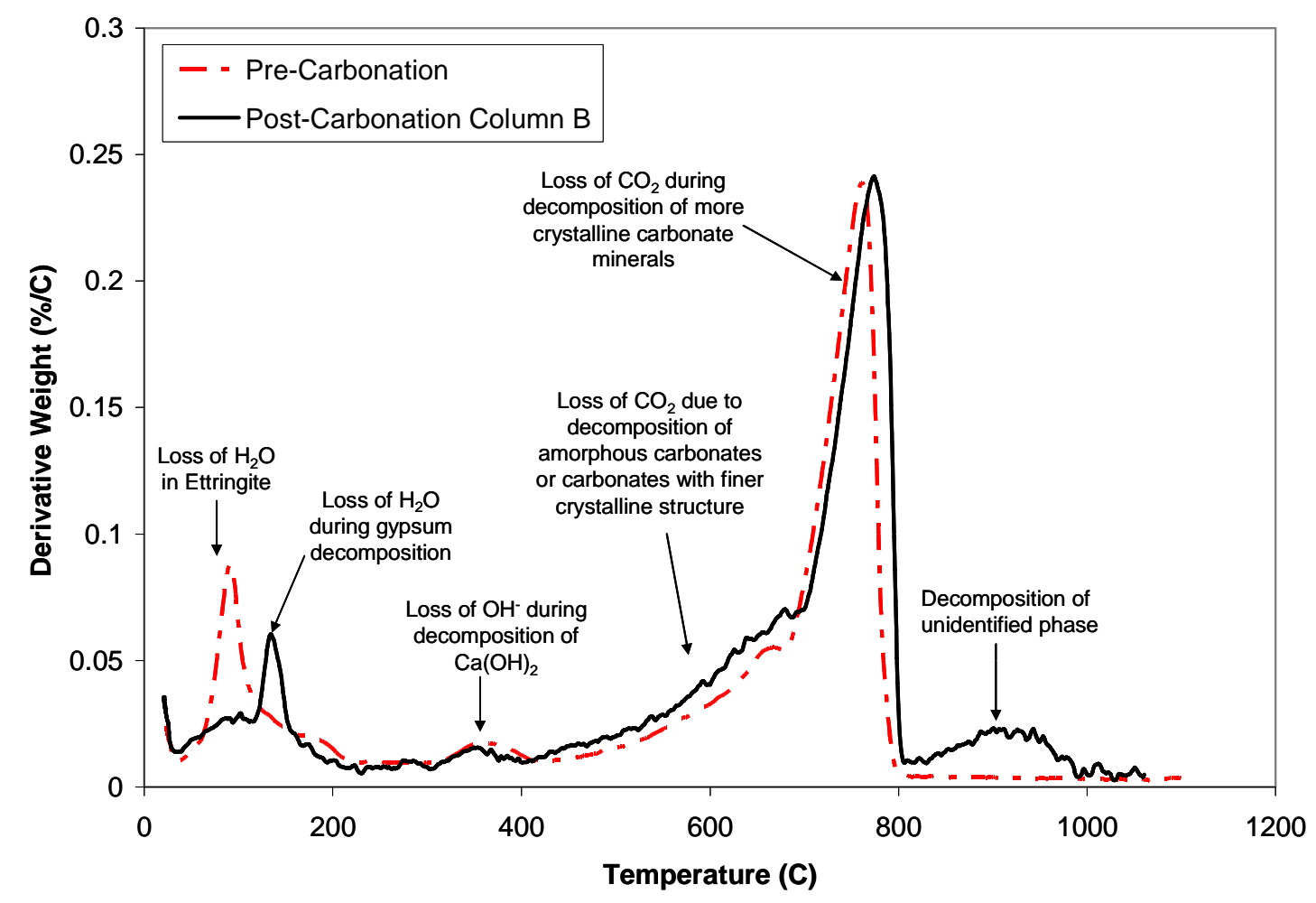

Figure 1.2 Derivative weight loss curve from thermal gravimetric analysis of preand post-carbonated CKD. The carbonated sample was taken from Column B.

The extent of sequestration in terms of total mass of $\mathrm{CO}_{2}$ consumed (via frontal analysis) in each column is presented in Table 1.4, along with the theoretical sequestration capacity of each column calculated using equation 1.7. Thermal analysis conducted on samples taken from Column B show an increase in $\mathrm{CO}_{2}$ content between 
unreacted and reacted CKD of 7.7\% (from weight loss in TGA curve). Based on the dry mass of column material before and after carbonation, this equates to an increase in $\mathrm{CO}_{2}$ content in the column of $15.84 \mathrm{~g}$. The total amount of $\mathrm{CO}_{2}$ sequestered via frontal analysis and observed mass change for column B was $15.3 \mathrm{~g}$ and $14.9 \mathrm{~g}$, respectively. The good agreement among the TGA, mass change, and frontal analysis results suggests that the methods used in this study for determining carbonation extent were appropriate.

\section{Extent of Sequestration as a Function of Operating Conditions}

The extent of $\mathrm{CO}_{2}$ sequestration was measured in four (4) columns, operated under varied moisture and gas concentration conditions. Columns A and B were injected with humidified gas, at relatively the same influent $\mathrm{CO}_{2}$ concentration (Table 1.1). However, the water content of Column A was elevated prior to the experiment by injecting heated, humidified $\mathrm{N}_{2}$ into the column and allowing water to condense in pore spaces. Columns $\mathrm{C}$ and $\mathrm{D}$ were injected with dry gas at moderate and low concentrations of $\mathrm{CO}_{2}$, respectively. The extent of sequestration in each column is presented in Figure 1.3 (based on frontal analysis of column $\mathrm{CO}_{2}$ effluent). The mass of $\mathrm{CO}_{2}$ injected and the corresponding mass sequestered with time are normalized by the theoretical extent of sequestration for each column assuming that $\mathrm{Na}$ and $\mathrm{K}$ carbonates form (Table 1.4). Ideal sequestration conditions (where all $\mathrm{CO}_{2}$ injected is consumed by the material until the carbonation capacity of the waste has been achieved) are also shown in Figure 1.3. 


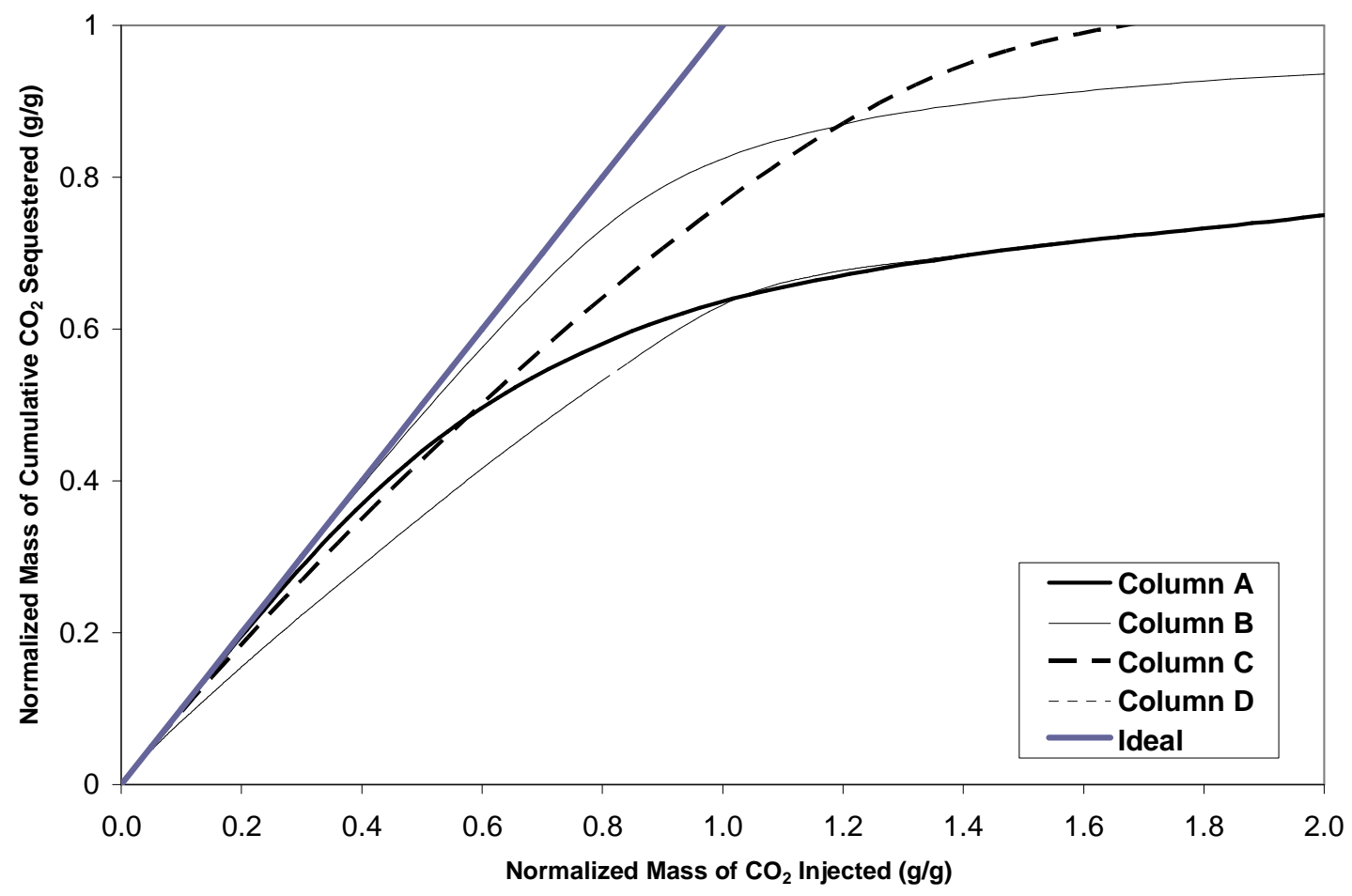

Figure 1.3 Cumulative mass of $\mathrm{CO}_{2}$ sequestered in $\mathrm{CKD}$ columns under varied operating conditions: normalized by theoretical extent of sequestration for each column. Under Ideal conditions, all the $\mathrm{CO}_{2}$ injected into the column would be consumed by the waste until the carbonation capacity of the material has been achieved (blue line).Column $A$ : humidified gas, elevated initial water content; Column B: humidified gas, normal water content; Column $C$ : dry gas, normal water content, moderate concentration; Column D: dry gas, normal water content, low concentration. Refer to Table 1 for more detailed operating conditions.

The columns were operated for a period of 3.5 to 12 days, until full breakthrough of $\mathrm{CO}_{2}$ concentration was observed. At early times, the columns follow ideal conditions, consuming all $\mathrm{CO}_{2}$ that is injected. Columns $\mathrm{A}$ and $\mathrm{B}$ (humidified gas) track the idealized curve longer than Columns C and D (dry gas), however higher water contents appear to decrease the overall sequestration extent by slowing or hindering the transport of $\mathrm{CO}_{2}$ to reaction sites. The shape of the normalized cumulative sequestration curves for those columns where dry gas was used deviate more from ideal conditions at early times, indicating that the absence of humidity may reduce the rate of carbonation. Or, the added 
humidity to the system results in increased aqueous absorption of gaseous $\mathrm{CO}_{2}$ creating the appearance of higher $\mathrm{CO}_{2}$ consumption and the variation in the curve shapes between dry and humidified columns. The overall extent of carbonation, however, appears to be inversely related to the water content of the columns (Figure 1.4). The increase in overall carbonation in columns of lower water content is likely the result of greater gas pore volume and lower diffusion limitations (Table 1.1, Figure 1.4). The significant increase in the extent of carbonation between column $\mathrm{C}$ and $\mathrm{D}$ indicates that the carbonation reaction rates may be dependent upon concentration (i.e., $1^{\text {st }}$ or $2^{\text {nd }}$ order) and higher concentrations may lead to faster rates and greater overall carbonation in a given period of time. However, more comprehensive column experiments are necessarily to determine if column performance is dependant on influent $\mathrm{CO}_{2}$ concentrations.

Without more detailed characterization of pre- and post-carbonated CKD, it is difficult to determine if heterogeneity in the columns influenced their ability to sequester $\mathrm{CO}_{2}$. Because the columns were constructed of intact core segments, extracting a precarbonation sample from each column for compositional analysis was not possible. It is likely that the composition of the CKD waste pile varies with depth and the core segment used in this study may have intersected layers with differing composition. Additional column studies are being conducted with fresh CKD from a number of different manufacturing facilities, kiln types, and CKD collection systems. Detailed composition analysis of pre- and post-carbonated samples is being conducted to separate the impacts of varied material composition from operating conditions $\left(\mathrm{CO}_{2}\right.$ concentration, gas flow rate, and moisture conditions). 


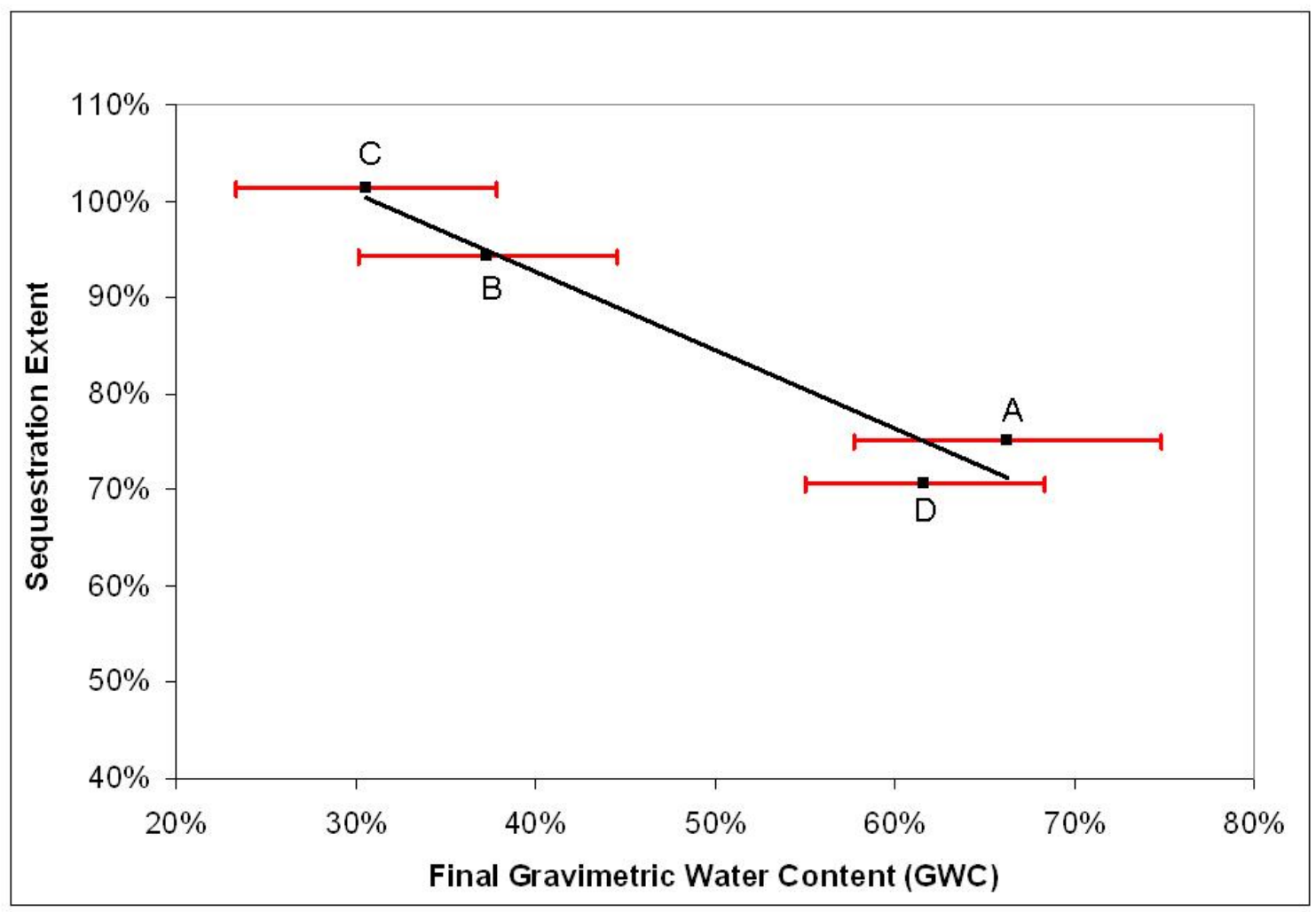

Figure 1.4 Variation in extent of sequestration with gravimetric water content (GWC) in columns of cement kiln dust. Sequestration extent refers to the mass of $\mathrm{CO}_{2}$ consumed compared to the amount of $\mathrm{CO}_{2}$ sequestration theoretically possible. Error bars represent uncertainty in water content measurements due to column heterogeneity.

\section{Conclusions}

This paper demonstrates the feasibility of mineral carbonation in landfilled CKD. A series of column experiments were conducted in core segments of waste CKD under varied operating conditions (input $\mathrm{CO}_{2}$ rate, gas, and water content). The results indicate:

- Cement kiln dust readily sequesters $\mathrm{CO}_{2}$ at ambient temperatures and pressures.

- The major product of carbonation appears to be calcite in both crystalline and amorphous form. However, more detailed material characterization of pre- 
and post-carbonated CKD are needed to better elucidate reaction pathways and products.

- Carbonation extents greater than $70 \%$ of its theoretical capacity, based on stoichiometry, can be achieved without any amendments or modifications to the waste material.

- The extent of carbonation is greater at lower gravimetric water contents due to increased access to reaction sites.

- Heterogeneity in the core segments caused variability in observed carbonation extents. Additional, more detailed experiments are needed to separate the impacts of varied material composition from operating conditions $\left(\mathrm{CO}_{2}\right.$ concentration, gas flow rate, and moisture conditions).

\section{Reference Cited}

Beecy, D.J. and F.M. Ferrell, "Advanced Concepts for $\mathrm{CO}_{2}$ Conversion, Storage, and Reuse," Symposium, American Chemical Society, Division Fuel Chemistry, 2001.

Bertos, M.F., X. Li, S.J.R. Simons, C.D. Hills, and P.J. Carey, "Investigation of Acceleration Carbonation for the Stabilisation of MSW Incinerator Ashes and the Sequestration of $\mathrm{CO}_{2}$," Green Chemistry, Vol. 6, pp. 428-436, 2004a.

Bertos, M.F., S.J.R. Simons, C.D. Hills, and P.J. Carey, “A Review of Accelerated Carbonation Technology in the Treatment of Cement-Based Materials and Sequestration of $\mathrm{CO}_{2}$," Journal of Hazardous Materials, B112, pp. 193-205, 2004b.

Corish, A. and T. Coleman, "Cement Kiln Dust," Concrete, September/October, pp. 4042, 1995.

Fauth, D.J., P.M. Goldberg, J.P. Knoer, Y. Soong, W.K. O’Connor, D.C. Dahlin, D.N. Nilsen, R.P. Walters, K.S. Lackner, H.J. Ziock, M.J. McKelvy, and Z.Y. Chen, "Carbon Dioxide Storage as Mineral Carbonates," Symposium-American Chemical Society, Division Fuel Chemistry, pp. 708-712, 2000.

Fauth, D.J. and Y. Soong, "Mineral Sequestration Utilizing Industrial By-Products, Residues, and Minerals," Presentation, Mineral Sequestration Workshop, National Energy Technology Laboratory, August 8, 2001. 
Fauth, D.J., J.P. Baltrus, Y. Soong, J.P. Knoer, B.H. Howard, W.J. Graham, M.M. Maroto-Valer, and J.M. Andresen, "Carbon Storage and Sequestration as Mineral Carbonates", in Environmental Challenges and Greenhouse Gas Control for Fossil Fuel Utilization in the $21^{\text {st }}$ Century, Kluwer Academic / Plenum Publishers, 2002a.

Fauth, D.J., Y. Soong, and C.M. White, "Carbon Sequestration Utilizing Industrial Solid Residues," Symposium-American Chemical Society, Division Fuel Chemistry, pp. 37$38,2002 b$.

Fuji, M., A. Yamasaki, M. Kakizawa, and Y. Yanagisawa, "Reduction of $\mathrm{CO}_{2}$ Emission by Treatment of Waste Concrete via an Artificial Process," Symposium, American Chemical Society, Division Fuel Chemistry, 75-77, 2001.

Gabrovsek, R., T. Vuk, and V. Kaucic, "Evaluation of the Hydration of Portland Cement Containing Various Carbonates by Means of Thermal Analysis," Acta Chim. Solv., vol. 53, pp. 159-165, 2006.

Guthrie, G.D., J.W. Carey, D. Bergfeld, D. Byler, S. Chipera, H.J. Ziock, and K.S. Lackner, "Geochemical Aspects of the Carbonation of Magnesium Silicates in an Aqueous Medium,” NETL Conference on Carbon Sequestration, 2001.

Haynes, B.W. and G.W. Kramer, "Characterization of U.S. Cement Kiln Dust," United States Department of the Interior, Bureau of Mines, 1982.

Hendriks, C.A., E. Worrell, D. deJager, K. Block, and P. Riemer, "Emission Reduction of Greenhouse Gases from the Cement Industry," IEA Greenhouse Gas R\&D Programme, http://www.ieagreen.org.uk/prghgt42.htm, 2000.

Huijgen, W.J.J. and R.N.J. Comans, "Carbon Dioxide Sequestration by Mineral Carbonation Literature Review," Energy Resource Center of the Netherlands, ECNC-03-016, 2003.

Huijgen, W.J.J., G.J. Witkamp, and R.N.J. Comans, "Mineral $\mathrm{CO}_{2}$ Sequestration by Steel Slag Carbonation," Environmental Science and Technology, 39(24), pp. 9676-9682, 2005.

Klemm, W.A., "What are CKD's Uses and Characteristics?" Rock Products, Cement Edition, pp. 38-44, July 1994.

Lackner, K.S., D.P. Butt, and C.H. Wendt, "Progress on Binding $\mathrm{CO}_{2}$ in Mineral Substrates," Energy Conversion and Management, 38, pp. 259-264, 1997.

Portland Cement Association, "Cement Kiln Dust Production, Management, and Disposal," PCD R\&D Serial No. 2737, 2003.

Shackelford, C., "Critical Concepts for Column Testing," Journal of Geotechnical Engineering, 120 (10), pp. 1804-1828, 1994.

Sreekrishnavilasam, A. S. Kind, and M. Santagata, "Characterization of Fresh and Landfilled Cement Kiln Dust for Reuse in Construction Applications," Engineering Geology, 85, pp. 165-173, 2006. 
Steinour, H.H., "Some Effects of Carbon Dioxide on Motars and Concrete - Discussion," Concrete Briefs, Journal of the American Concrete Institute, pp. 905-907, February 1959.

Strydom, C.A., Q.I. Roode, and J.H. Potgieter, "Thermogravimetric and X-Ray Powder Diffraction Analysis of Precipitator Dust from a Rotating Lime Kiln," Cement and Concrete Research, 26(8), pp. 1269-1276, 1996.

Van Oss, H.G. and A.C. Padovani, "Cement Manufacture and the Environment, Part II: Environmental Challenges and Opportunities," Journal of Industrial Ecology, 7(1), pp. 93-127, 2003.

U.S. Environmental Protection Agency, "Standards for Management for Cement Kiln Dust, Proposed Rule," 64-FR 45632, Friday, August 20, 1999.

U.S. Environmental Protection Agency, "Inventory of U.S. Greenhouse Gas Emissions and Sinks," EPA 430-R-04-003, April 15, 2004.

Wu, J.C.S., J. Sheen, S. Chen, and Y. Fan, "Feasibility of $\mathrm{CO}_{2}$ Fixation via Artificial Rock Weathering," Industrial Engineering Chemical Resources, 40, pp. 3902-3905, 2001. 


\title{
Carbon Dioxide Sequestration in Cement Kiln Dust through Mineral Carbonation
}

\author{
Deborah N. Huntzinger ${ }^{1}$, John S. Gierke ${ }^{1}$, S. Komar Kawatra ${ }^{2}$, Timothy C. Eisele ${ }^{2}$, and \\ Lawrence L. Sutter ${ }^{3}$
}

\begin{abstract}
Alkaline earth metals react with carbon dioxide $\left(\mathrm{CO}_{2}\right)$ to produce stable carbonate minerals, a process known as mineral carbonation. Carbon sequestration through the formation of carbonates is a promising means to reduce $\mathrm{CO}_{2}$ emissions. Alkaline industrial solid wastes are a potential source of highly reactive oxides that require little to no pre-processing. In this paper, the degree of mineral carbonation in cement kiln dust $(\mathrm{CKD})$ is examined through a series of batch experiments. The mechanisms, products, and rate behavior of the carbonation process are assessed through a complementary set of analytical and empirical methods, including mass change, thermal analysis, and X-ray diffraction. The carbonation reactions are carried out primarily through the reaction of $\mathrm{CO}_{2}$ with $\mathrm{Ca}(\mathrm{OH})_{2}$, and $\mathrm{CaCO}_{3}$ was observed as the predominant carbonation product. With the exception of sylvite $(\mathrm{KCl})$, the composition of $\mathrm{CKD}$ does not appear to have a significant impact on the degree of carbonation achievable. Sequestration appears to follow pseudo first-order reaction kinetics at early times, however as carbonation progresses, the kinetics deviate significantly from first-order conditions. A rate expression lumping both reaction and transport controlled processes better represented the carbonation reactions over time.
\end{abstract}

\footnotetext{
1 Geological and Mining Engineering and Sciences, Michigan Technological University, 1400 Townsend Drive, Houghton, MI 49931-1195

2 Department of Chemical Engineering and Sciences, Michigan Technological University, 1400 Townsend Drive, Houghton, MI 49931

3 Michigan Technological University Transportation Institute, 1400 Townsend Drive, Houghton, MI 49931
} 


\section{Introduction}

Mineral carbonation is a naturally occurring weathering process where alkaline earth metals $(\mathrm{Ca}, \mathrm{Mg})$ combine with carbon dioxide to form stable carbonates. Even though the reactions are highly exothermic, they occur slowly in nature during the gradual weathering of silicate minerals:

$$
\begin{array}{r}
\mathrm{CaSiO}_{3}+4 \mathrm{H}_{2} \mathrm{O}+2 \mathrm{CO}_{2} \rightarrow \mathrm{Ca}^{2+}+2 \mathrm{HCO}_{3}^{-}+2 \mathrm{H}^{+}+\mathrm{SiO}_{3}^{2-} \rightarrow \\
\mathrm{CaCO}_{3}+\mathrm{SiO}_{2} \cdot \mathrm{H}_{2} \mathrm{O}+\mathrm{H}_{2} \mathrm{O}+\mathrm{CO}_{2}
\end{array}
$$

Because of the thermodynamic stability of the carbonate products, however, mineral $\mathrm{CO}_{2}$ sequestration is an attractive technology for reducing carbon emissions. To improve the viability of the process for application on an industrial-scale, attempts have been made to accelerate the carbonation process in the laboratory by using chemically and mechanically pre-treated silicate mineral feedstocks, such as olivine and serpentine (e.g., Lackner et al.1995, Fauth et al. 2000 and 2002a, O'Conner et al. 2001, Guthrie et al. 2001, Wu et al. 2001, Huijgen et al. 2003). A majority of this research has focused on the aqueous batch reaction of pre-treated feedstocks and $\mathrm{CO}_{2}$ at elevated temperatures and/or pressures. However, the mining, processing, and reaction conditions required for mineral carbonation of raw feedstocks are energy intensive. An alternative source of metal oxides is solid alkaline waste materials that are rich in calcium and/or magnesium. The oxide content and high surface area of alkaline wastes make them potentially suitable for carbonation reactions without the need for extensive pre-processing. Several studies have investigated the feasibility and/or reaction mechanisms of $\mathrm{CO}_{2}$ sequestration in industrial wastes such as: steel slag (Huijgen et al. 2005), fly ash (Fauth and Soong 2001), spray dryer ash (Fauth et al. 2002b), municipal solid waste incinerator ashes (MSWI) (Bertos et al. 2004a), and cement kiln dust (Huntzinger et al. 2006). The impacts of carbonation on 
the stability of the waste material have also been investigated, particularly for its reduction of pH and heavy metal mobility (e.g., Eighmy et al. 1995, Bertos et al., 2004b, Huijgen and Comans 2005).

One of the difficulties in using alkaline wastes for $\mathrm{CO}_{2}$ sequestration is the large variability in composition within a given waste type, complicating the optimization and standardization of the process. The composition of cement kiln dust (CKD) is highly dependent upon the type of kiln, raw materials and fuels, as well as the types of cements that are being produced (Adams 1984, Klemm 1994, Corish and Coleman 1995). In many cases, there is no typical composition. CKD recovered from traditional baghouse or electrostatic precipitators tends to be partially calcined, containing both burned material and unburned raw fines (Klemm 1994). However, in many regions, reduction of sodium and potassium oxides in the final cement mix is required to lessen the potential for alkalisilica reactions (ASR) in concrete (Adams 1984, Helmuth et al. 1993). When low-alkali cements are required, kilns often incorporate an alkali bypass system that continually recirculates gases to remove the volatile alkalis. Therefore, CKD from alkali bypass systems are generally highly calcined and contain a greater percentage of reactive free lime compared to CKD from baghouses. Since the high alkalis prohibit recycling into the kiln, these CKDs are most likely to be disposed on or off-site, through landfilling and/or sale for agricultural application. It is not known, however, whether the high mass percentages of volatile substances (alkali salts, sulfates, and chlorides) affect the formation of carbonates.

Preliminary experiments of mineral carbonation in core segments of aged CKD (i.e., landfilled) indicate favorable sequestration extents (> 50\%) under ambient pressure and 
temperature conditions (Huntzinger et al. 2006). However, a full analysis of the extent of carbonation in a range of fresh CKD types has not yet been completed. This study aims to better elucidate the extent of carbonation achievable in various CKD types, as well as the mechanism and products of the carbonation reactions. A systematic examination of the degree of mineral carbonation in fresh CKD is presented, along with insight into the possible mechanisms, products, and rate behavior of the mineral carbonation process.

\section{Materials and Methods}

Fresh cement kiln dust from four different cement manufacturing processes were used in this study, including two separate wet kiln systems and the alkali bypass system of a recently renovated dry kiln operated under different kiln conditions (Table 2.1). The CKD samples were received dry and stored at room temperature in air-tight containers. Representative subsets were taken from each homogeneous mix for use in the carbonation experiments.

Table 2.1 Source and properties of cement kiln dusts (CKD) used in batch experiments.

\begin{tabular}{|c|c|c|c|c|}
\hline CKD Type & $\begin{array}{l}\text { Kiln } \\
\text { Type }\end{array}$ & Collection System & $\begin{array}{c}\text { Initial } \\
\text { CaCO }_{3} \\
\text { (Mass \%) }^{4}\end{array}$ & $\begin{array}{l}\text { Free CaO } \\
(\text { Mass \%) }\end{array}$ \\
\hline AG Bypass High $^{1}$ & Dry & Alkali Bypass System & 14.5 & 37 \\
\hline AG Bypass Low ${ }^{1}$ & Dry & Alkali Bypass System & 4.3 & 15 \\
\hline AG $\mathrm{Wet}^{2}$ & Wet & $\begin{array}{c}\text { Baghouse/Electrostatic } \\
\text { Precipitator }\end{array}$ & 46.4 & 8 \\
\hline Continental Wet $^{3}$ & Wet & $\begin{array}{l}\text { Baghouse/Electrostatic } \\
\text { Precipitator }\end{array}$ & 57.6 & -- \\
\hline
\end{tabular}

${ }^{1}$ Ash Grove Cement Company, Chanute Manufacturing Facility, Chanute, Kansas.

${ }^{2}$ Ash Grove Cement Company, Midlothian Manufacturing Facility, Midlothian, Texas.

${ }^{3}$ Continental Cement Company, Hannibal, Missouri.

${ }^{4}$ Calculated (within +/- 5\%) from thermal mass-loss curves obtained by thermal gravimetric analysis of precarbonated samples. Calcite is assumed to be the predominant carbonate species formed during the carbonation reactions.

${ }^{5}$ Obtained from Rietveld refinement of X-ray diffraction patterns: supplied by Ash Grove Cement Manufacturing Co. (Overland Park, KS) for pre-carbonated samples. 
Carbonation experiments were performed in a stainless steel $288 \mathrm{~L}$ ( 60 by 60 by 88 $\mathrm{cm}$ long) "glove" box, with $\sim 100 \%$ relative humidity and $\sim 80 \% \mathrm{CO}_{2}$ atmosphere (Table 2.2). One- to 5-gram samples of CKD were placed in aluminum weighing tins, ovendried at $80^{\circ} \mathrm{C}$ for $24 \mathrm{hrs}$, and combined with nanopure, deionized water at desired waterto-solids ratios (0 to 1.25). Prepared samples were weighed and placed in the chamber for reaction with $\mathrm{CO}_{2}$ under ambient temperature and pressure conditions. Each experiment was carried out in triplicate. Control samples of raw kiln feed from the Ash Grove Chanute, Kansas manufacturing facility (no reactive oxide content) were prepared and reacted in the same manner to verify that observed dry mass change was due to reaction with $\mathrm{CO}_{2}$. In addition, a variety of material characterization methods were employed to confirm that observed mass change in carbonated samples was a result of mineral carbonation reactions. These methods are discussed in detail below. During the experiments, the chamber was constantly supplied with humidified $\mathrm{CO}_{2}$ to replenish any carbon dioxide consumed during the reactions and to create a slight positive pressure in the chamber, preventing the diffusion of lab air into the glove box apparatus. The gas within the chamber was continuously circulated using a small $12 \mathrm{~V}, 0.15$ amp fan (2000 rpm with air flow of $41.9 \mathrm{cfm}$ ) and $\mathrm{CO}_{2}$ concentrations were monitored with a MTI Quad Model Q30L gas chromatograph (Fremont, CA). Humidity and temperature within the chamber were monitored with a traceable Humidity/Temperature Pen (Control Company, Friendswood, TX). After the specified reaction time, samples were removed from the chamber, weighed and oven dried at $80^{\circ} \mathrm{C}$ for 24 hours. The final dry mass of the samples were recorded and the samples were stored at room temperature in sealed 20-ml vials for 
material characterization. If needed, duplicate samples were combined to produce a bulk sample sufficient in size for material analysis.

Table 2.2 Experimental conditions for reaction of different cement kiln dust types with $\mathrm{CO}_{2}$ at different water to solids (w/s) ratios, reaction times, and relative humidity.

\begin{tabular}{|c|c|c|c|}
\hline CKD Type & $\mathbf{w} / \mathbf{s}$ & $\begin{array}{c}\text { Reaction Time } \\
\text { (days) }\end{array}$ & $\begin{array}{c}\text { Relative } \\
\text { Humidity (\%) }\end{array}$ \\
\hline \multirow{4}{*}{ AG Bypass High } & \multirow{2}{*}{0.00} & \multirow{2}{*}{$0.3,1,2,4,6,8$} & 100 \\
\hline & & & 35 \\
\hline & $\begin{array}{c}0.00,0.06 \\
0.25,0.4,0.85 \\
1.15\end{array}$ & 2 & 100 \\
\hline & 0.85 & $0.3,1,2,4,6,8$ & \\
\hline \multirow{3}{*}{ AG Bypass Low } & 0.00 & $0.3,1,2,4,6,8$ & \multirow{3}{*}{100} \\
\hline & $\begin{array}{c}0.00,0.06 \\
0.25,0.40 \\
0.58,0.85 \\
\quad 1.15 \\
\end{array}$ & 2 & \\
\hline & 0.85 & $0.3,1,2,4,6,8$ & \\
\hline \multirow{3}{*}{ AG Wet } & 0.00 & $0.3,1,2,4,6,8$ & \multirow{3}{*}{100} \\
\hline & $\begin{array}{c}0.00,0.06 \\
0.40,0.80 \\
1.15\end{array}$ & 2 & \\
\hline & 1.25 & $0.3,1,2,4,6,8$ & \\
\hline \multirow{4}{*}{ Continental Wet } & $\begin{array}{c}0.00,0.06 \\
0.40,0.80 \\
1.15\end{array}$ & 2 & \multirow{4}{*}{100} \\
\hline & 0.47 & 4 & \\
\hline & 0.85 & $4,6,8$ & \\
\hline & 1.25 & $0.3,1,2$ & \\
\hline \multirow[t]{2}{*}{$\begin{array}{l}\text { AG Raw Feed } \\
\text { Control }\end{array}$} & $\begin{array}{c}0.00,0.06 \\
0.40,0.80 \\
1.15\end{array}$ & 2 & \multirow[t]{2}{*}{100} \\
\hline & 1.25 & $0.3,1,2,4,6,8$ & \\
\hline
\end{tabular}




\section{Material Characterization}

The elemental composition of the pre-carbonated CKD samples was analyzed with a Philips PW 2404 X-ray spectrometer (Cambridge, UK). Sample specimens were homogenized by grinding in a SPEX Shatterbox (Edison, NJ). Portions of the bulk sample were ignited at $980{ }^{\circ} \mathrm{C}$ to a constant mass and then fused into glass disks with a LECO FX-503 (St. Johns, MI) automated fuser. Qualitative analysis of mineralogical composition in pre- and post-carbonated samples was assessed using powder X-ray diffraction (Siemens D 500 Diffractometer, Cherry Hill, NJ) equipped with a Cu X-ray tube operated at $50 \mathrm{kV}$ and using $27 \mathrm{~mA}$, medium resolution slits. Specimens were scanned from $5-70^{\circ} 2 \theta$, with a step-size of $0.05^{\circ}$ and a dwell time of 2 seconds per step.

The carbonate content ( $\mathrm{wt} \% \mathrm{CO}_{2}$ ) of pre- and post-carbonated samples was determined by complementary analytical and empirical methods: (1) observed dry mass change of the samples, (2) thermal decomposition (TGA-DTA), (3) total carbon analysis (TCA), and (4) quantitative X-ray diffraction (QXRD) analysis using the Relative Intensity Ratio (RIR) method.

The gain in dry mass between the initial pre-carbonated samples and dried carbonated product was assumed to equal the mass of $\mathrm{CO}_{2}$ sequestered by the sample:

$$
M_{C_{2}}(t)=M(t)-M(t=0)
$$

Where $M_{\mathrm{CO}_{2}}(t)$ is the mass of $\mathrm{CO}_{2}$ sequestered after some time, $t, M(t)$ is the dry mass of the sample corrected for the mass gain due to hydration reactions, such as gypsum formation and/or the production of calcium-silicate gels, and $M(t=0)$ is the initial dry mass of the sample. The change in carbonate content between pre- and post-carbonated samples is expressed in terms of $\% \mathrm{CO}_{2}$ (dry mass): 


$$
\% \mathrm{CO}_{2}(t)=\frac{M_{\mathrm{CO}_{2}}(t)}{M(t)} \times 100 \%
$$

In order to verify that observed mass increases were due to $\mathrm{CO}_{2}$ sequestration, a subset of the samples were examined by a combination of thermal decomposition (TGA/DTA, TCA) and X-ray diffraction methods.

The overall carbonate (i.e., $\mathrm{CO}_{2}$ ) content of selected pre- and post-carbonated CKD samples was measured with a TA-Instruments Simultaneous DTA-TGA (Model SDT 2960, New Castle, DE). Representative samples ( $22 \mathrm{mg}$ ) were heated in corundum crucibles in a nitrogen environment to $1100{ }^{\circ} \mathrm{C}$ at $20{ }^{\circ} \mathrm{C} /$ minute. Sample mass losses were monitored by thermal gravimetric analysis (TGA). Phase change was simultaneously evaluated with differential thermal analysis (DTA) by measuring the temperature differences between the sample and inert, heat-treated corundum. Carbonate decomposition in both pre- and post-carbonated samples was observed in the temperature region of $500-850{ }^{\circ} \mathrm{C}$. Other mass-loss regions associated with the loss of hydrated water $\left(<200^{\circ} \mathrm{C}\right)$, and the decomposition of gypsum $\left(110-180^{\circ} \mathrm{C}\right)$, portlandite $\left(300-500{ }^{\circ} \mathrm{C}\right)$, and halides $\left(>1000^{\circ} \mathrm{C}\right)$ were also observed.

Additional measurements of the change in carbon content between fresh and reacted samples were conducted by total carbon analysis (TCA). Samples were crushed, weighed into a combustion boat, and analyzed in triplicate with a LECO SC444DR (St. Joseph, MI) Carbon and Sulfur Analyzer (furnace temperature of $1350^{\circ} \mathrm{C}$ ). As with the other material analysis methods, the change in total carbon content was assumed to be solely the result of $\mathrm{CO}_{2}$ sequestration (increases in inorganic carbon).

Finally, to assess the importance of calcite precipitation in the carbonation reactions, the calcite abundance in selected samples was measured by quantitative X-ray diffraction 
(QXRD) using the Relative Intensity Ratio (RIR) method based on work by Chung (1974) and discussed in Chung and Smith (2000). For each of the CKD types, 1.5-g aliquots of pre- and post-carbonated samples were doped with $0.3 \mathrm{~g}$ of rutile $\left(\mathrm{TiO}_{2}\right)$. The area intensity ratio (calcite to rutile) in the doped samples was compared to the intensity ratio in a standard sample (1:1 mass fraction of pure grade $\mathrm{CaCO}_{3}$ to rutile). Their ratio was used to compute crystalline calcite fractions in the doped samples. Only the strongest peaks were compared and computed mass fractions of calcite were corrected for dilution due to the rutile addition. Since the previously discussed methods (TGA, TCA, mass change) measure the change in $\mathrm{CO}_{2}$ content (i.e., carbonates) of the samples, and QXRD determines crystalline $\mathrm{CaCO}_{3}$, comparison between the different methods should indicate the role that amorphous or other carbonates play in the sequestration of $\mathrm{CO}_{2}$ in CKD.

\section{Degree of Carbonation}

The degree of carbonation $(\xi(t))$ was estimated by comparing the observed change in dry mass of each sample $\left(M_{\mathrm{CO}_{2}}(t)\right)$ with the calculated theoretical extent of carbonation based on the composition of the pre-carbonated waste:

$$
\xi(t)=\frac{M_{\mathrm{CO}_{2}}(t)}{M(t=0) \cdot \mathrm{ThCO}_{2}}
$$

Where $\mathrm{ThCO}_{2}$ is the theoretical mass fraction of $\mathrm{CO}_{2}$ sequestration achievable based on stoichiometry and the reactive oxide content of the waste. It is assumed that reactive calcium species in the waste (e.g., free $\mathrm{CaO}, \mathrm{Ca}(\mathrm{OH})_{2}, \mathrm{Ca}_{2} \mathrm{SiO}_{3}$ ) are the major phases participating in the carbonation reactions. The carbonation of $\mathrm{CaO}$ (through $\left.\mathrm{Ca}(\mathrm{OH})_{2}\right)$ can be expressed in simplified form as:

$$
\mathrm{CO}_{2(\mathrm{~g})}+\mathrm{H}_{2} \mathrm{O}_{(\mathrm{l})} \rightarrow 2 \mathrm{H}_{(\mathrm{aq})}^{+}+\mathrm{CO}_{3(\mathrm{aq})}^{2-}
$$




$$
\begin{aligned}
& \mathrm{CaO}_{(\mathrm{s})}+\mathrm{H}_{2} \mathrm{O}_{(\mathrm{l})} \rightarrow \mathrm{Ca}(\mathrm{OH})_{2(\mathrm{~s})} \\
& \mathrm{Ca}(\mathrm{OH})_{2(\mathrm{~s})} \rightarrow \mathrm{Ca}_{(\mathrm{aq})}^{2+}+2 \mathrm{OH}_{(\mathrm{aq})}^{-} \\
& \mathrm{Ca}_{(\mathrm{aq})}^{2+}+\mathrm{CO}_{3(\mathrm{aq})}^{2-} \rightarrow \mathrm{CaCO}_{3(\mathrm{~s})}
\end{aligned}
$$

Because of the wide range in $\mathrm{CKD}$ composition, however, other oxides (e.g., $\mathrm{MgO}, \mathrm{FeO}_{2}$, $\mathrm{K}_{2} \mathrm{O}$, and $\mathrm{Na}_{2} \mathrm{O}$ ) may also contribute, to a lesser extent, to the sequestration of $\mathrm{CO}_{2}$ through a variety of reaction pathways. Therefore, in order to estimate theoretical $\mathrm{CO}_{2}$ sequestration, consideration must be given to the waste composition and the extent to which the oxides are available for reaction. Similar to estimates of $\mathrm{CO}_{2}$ sequestration in mortars and concrete by Steinour (1959), the theoretical extent (as a percentage of dry mass) of carbonation in CKD was calculated as follows:

$$
\begin{gathered}
\% \mathrm{ThCO}_{2}=0.785\left(\% \mathrm{CaO}-0.56 . \% \mathrm{CaCO}_{3}-0.7 \cdot \% \mathrm{SO}_{3}\right)+1.091 . \% \mathrm{MgO}+ \\
0.71 . \% \mathrm{Na}_{2} \mathrm{O}+0.468\left(\% \mathrm{~K}_{2} \mathrm{O}-0.632 . \% \mathrm{KCl}\right)
\end{gathered}
$$

The mineral species in equation 2.9 are represented in percent of dry mass and the stoichiometric mass factors assume that all of the $\mathrm{CaO}$ (except that bound in $\mathrm{CaSO}_{4}$ and $\mathrm{CaCO}_{3}$ ) will form $\mathrm{CaCO}_{3}, \mathrm{MgO}$ will form $\mathrm{MgCO}_{3}$, and $\mathrm{Na}_{2} \mathrm{O}$ and $\mathrm{K}_{2} \mathrm{O}$ (less that bound in sylvite, $\mathrm{KCl}$ ) will form $\mathrm{Na}_{2} \mathrm{CO}_{3}$ and $\mathrm{K}_{2} \mathrm{CO}_{3}$.

\section{Reaction Mechanisms}

The specific carbonation pathways in wastes such as CKD are not fully known. Transport-controlled mechanisms such as $\mathrm{CO}_{2}$ and $\mathrm{Ca}^{2+}$ diffusion to reaction sites, boundary layer effects (diffusion across precipitate coatings on particles), and pore blockage can all affect the extent of carbonation and their effects can change with time. The results of a kinetic study examining the reactivity of fly ash mixtures doped with calcium hydroxide $\left(\mathrm{Ca}(\mathrm{OH})_{2}\right)$ suggest that the reaction rates are a function of not only the 
hydroxide to fly ash ratio but also the extent to which calcium hydroxides have been consumed in the reactions (Biernacki et al. 2001). Similarly, mineral carbonation studies in waste steel slag hypothesize that the rate-limiting mechanism during carbonation is the diffusion of $\mathrm{Ca}^{2+}$ to reaction sites (Huijgen et al. 2005), influencing the extent of reaction with time. Therefore, the kinetics of carbonation appears to be influenced by a combination of reactions mechanism, which individually can be difficult to measure. Because of the similarity of CKD composition to that of cement, analytical rate expressions used to describe the complex chemistry of cement hydration were applied here to provide insight into the carbonation reactions.

Hydration reaction rates in cement are often analyzed using lumped expressions, such as Knudsen (1984) or Avrami (1939), because they encompass both the reaction kinetic and mass transfer (diffusion) mechanisms typically thought to control the hydration process (Biernacki et al. 2001). From the work developed by Avrami (1939) and applied by Biernacki et al. (2001), the extent of the reaction can be expressed as:

$$
\xi(t)=1-e^{-k t^{n}}
$$

Where $k$ is the rate constant and $n$ is an exponential factor, which is proposed to have fundamental process underpinnings but really is an empirical parameter. Equation 2.10 is based on the kinetics of phase change. Because of the complexity of the carbonation reactions, particularly the combination of rate-controlling mechanisms, expressions that use "lumped" rate constants and reaction extents, rather than stoichiometry, may provide a more practical evaluation of the process kinetics. 


\section{Results and Discussion}

\section{Mineralogy and Characterization}

The elemental compositions of the different CKD types used in this study are presented in Table 2.3 along with the typical range in oxide composition reported for $\mathrm{CKD}$. The wastes are all rich in $\mathrm{CaO}$ and contain moderate to high amounts of $\mathrm{K}, \mathrm{Na}, \mathrm{Fe}$, $\mathrm{Si}$, and $\mathrm{S}$ oxides. The alkali bypass dusts also contain high percentages of $\mathrm{Cl}$, which originate from the raw materials and/or the fuels used to fire the kiln (Adams 1984). In addition, the bypass dusts have greater percentages of alkali salts $\left(\mathrm{Na}_{2} \mathrm{O}\right.$ and $\left.\mathrm{K}_{2} \mathrm{O}\right)$, most of which are bound in halides, such as sylvite $(\mathrm{KCl})$.

Table 2.3 Elemental composition of the pre-carbonated cement kiln dust (CKD) samples used in this study along with the typical range in oxide composition for CKD.

\begin{tabular}{|c|cc|c|c|c|}
\hline \multirow{2}{*}{ Oxide } & $\begin{array}{c}|c| \\
\text { Typical } \\
\text { Range for } \\
\text { CKD }^{\mathbf{a}}\end{array}$ & $\begin{array}{c}\text { AG } \\
\text { Bypass } \\
\text { High }\end{array}$ & $\begin{array}{c}\text { AG } \\
\text { Bypass } \\
\text { Low }\end{array}$ & AG Wet & $\begin{array}{c}\text { Continental } \\
\text { Wet }\end{array}$ \\
\hline $\mathrm{Na}_{2} \mathrm{O}$ & $0-2$ & 0.65 & 1.83 & 0.49 & 0.26 \\
\hline $\mathrm{MgO}$ & $0-2$ & 1.39 & 0.52 & 0.55 & 2.22 \\
\hline $\mathrm{Al}_{2} \mathrm{O}_{3}$ & $3-6$ & 3.45 & 1.59 & 4.09 & 4.02 \\
\hline $\mathrm{SiO}_{2}$ & $11-16$ & 13.31 & 5.09 & 12.61 & 15.53 \\
\hline $\mathrm{P}_{2} \mathrm{O}_{5}$ & -- & 0.06 & 0.04 & 0.11 & 0.08 \\
\hline $\mathrm{K}_{2} \mathrm{O}$ & $3-13$ & 7.04 & 24.04 & 4.03 & 2.01 \\
\hline $\mathrm{CaO}$ & $38-50$ & 48.03 & 22.72 & 47.14 & 46.41 \\
\hline $\mathrm{TiO}_{2}$ & -- & 0.23 & 0.12 & 0.22 & 0.25 \\
\hline $\mathrm{MnO}^{\mathrm{Mn}}$ & -- & 0.06 & 0.03 & 0.13 & -- \\
\hline $\mathrm{Mn}_{2} \mathrm{O}_{3}$ & -- & -- & -- & -- & 0.10 \\
\hline $\mathrm{Fe}_{2} \mathrm{O}_{3}$ & $1-4$ & 2.14 & 1.16 & 1.79 & 1.28 \\
\hline $\mathrm{SO}_{3}$ & $4-18$ & 2.73 & 5.78 & 7.66 & 2.04 \\
\hline $\mathrm{Cl}^{-}$ & $0-5$ & 5.22 & 20.41 & 0.18 & -- \\
\hline $\mathrm{Br}^{-}$ & -- & 0.21 & 1.03 & 0.03 & -- \\
\hline $\mathrm{LOI}^{\mathrm{b}}$ & $5-25$ & 14.88 & 15.07 & 20.37 & 25.80 \\
\hline Total $^{-}$ & -- & $\mathbf{9 9 . 3 9}$ & $\mathbf{9 9 . 4 3}$ & $\mathbf{9 9 . 4 0}$ & $\mathbf{1 0 0 . 0 0}$ \\
\hline
\end{tabular}

${ }^{a}$ Values reported by Corish and Coleman (1995)

${ }^{\mathrm{b}}$ LOI: Loss on Ignition 


\section{Theoretical Extent}

Table 2.4 summarizes the theoretical extent of carbonation calculated for each of the waste types based on their reactive-oxide content. Inherent in this theoretical calculation is the assumption that the oxides in certain calcium and potassium phases (i.e., calcite, anhydrite, and sylvite) are unlikely to react with $\mathrm{CO}_{2}$ at ambient temperatures and pressures. The abundance of these "unreactive" phases in the pre-carbonated wastes was deduced normatively, using material analysis and stoichiometry, along with simplifying assumptions regarding material composition. The peak-intensity ratios from the XRD analyses of pre- and post-carbonated AG Bypass Low indicates that the relative abundance of sylvite does not appear to change upon carbonation, supporting the assessment of $\mathrm{K}$ availability in high alkali $\mathrm{CKD}$. The fraction of calcite in the unreacted material, however, has a significant impact on calculated theoretical capacities, and therefore the theoretical extents presented in Table 2.4 reflect the uncertainty associated with the $\mathrm{CaCO}_{3}$ determinations. Based on the theoretical calculations, the high free-lime bypass dust (AG Bypass High) has the greatest potential for sequestration, followed by the CKD collected from the Ash Grove wet kiln (AG Wet). The smaller calculated theoretical extents in the low free-lime bypass dust and the wet kiln CKD from Continental are attributed to their higher mass fractions of unreactive species, such as calcite and/or sylvite. 
Table 2.4 Calculated theoretical extent of carbonation achievable presented as the mass of $\mathrm{CO}_{2}$ that can be sequestered per dry initial mass of waste. Values are based on the mass fraction of oxides assumed to be available for reaction, along with material analysis by XRF and XRD. Range of theoretical extent is shown along with average based on estimated error in $\mathrm{CaCO}_{3}$ determination.

\begin{tabular}{|c|c|}
\hline Cement Kiln Dust & $\begin{array}{c}\text { Theoretical Extent } \\
\left(\mathbf{C O}_{\mathbf{2}} \text { Mass \% }\right)^{\mathbf{1}}\end{array}$ \\
\hline AG Bypass High & $\begin{array}{c}29-61-34.04 \\
(31.84)\end{array}$ \\
\hline AG Bypass Low & $\begin{array}{c}12.45-16.54 \\
(14.65)\end{array}$ \\
\hline AG Wet & $\begin{array}{c}13.04-17.44 \\
(15.24)\end{array}$ \\
\hline Continental Wet & $\begin{array}{c}11.53-15.93 \\
(13.73)\end{array}$ \\
\hline
\end{tabular}

\footnotetext{
${ }^{1}$ The range in theoretical extent reflects the uncertainty in the $\mathrm{CaCO}_{3}$ estimations from TGA $(+/-5 \%)$, where calcite is assumed to be the dominant carbonate formed during the carbonation reactions.
}

\section{Reaction Mechanisms and Products}

Table 2.5 summarizes the major and minor mineralogical phases identified in representative samples of the pre- and post-carbonated CKDs. Calcite and trace amounts of ankerite $\left(\mathrm{Ca}\left(\mathrm{Fe}^{2+}, \mathrm{Mg}\right)\left(\mathrm{CO}_{3}\right)_{2}\right)$ and dolomite $\left(\mathrm{CaMg}\left(\mathrm{CO}_{3}\right)_{2}\right)$ were the only carbonate species detected by XRD. The calcite precipitation was also confirmed with SEM microanalysis and element mapping. Small fractions of $\mathrm{Na}, \mathrm{K}, \mathrm{Mg}$, and Fe were found in precipitate regions between particles and some particle coatings (Anderson 2006). Mineral substitution in carbonates is common (Hurlbut and Klein 1977) and appears to occur during the carbonation reactions.

Two major reactive calcium species were identified in pre-carbonated CKD samples: $\mathrm{CaO}$ and $\mathrm{Ca}(\mathrm{OH})_{2}$ (Table 2.4). In all cases, no free $\mathrm{CaO}$ was found in the reacted samples. In the presence of water, $\mathrm{CaO}$ will quickly react to form portlandite $\left(\mathrm{Ca}(\mathrm{OH})_{2}\right)$, evolving considerable amounts of heat. This was observed in preliminary experiments 
conducted with pure-grade $\mathrm{CaO}$, as well as in those CKD samples containing high amounts of free $\mathrm{CaO}$ (e.g., AG Bypass High). Based on stoichiometry and observed mass change, the extent of carbonation achieved in preliminary experiments conducted with pure-grade $\mathrm{CaO}$ was greater than $90 \%$ (at higher water-to-solids ratios). Similar experiments were conducted with pure grade $\mathrm{Ca}(\mathrm{OH})_{2}$ and even greater extents of reaction were observed. Analysis of the carbonated products from $\mathrm{CaO}$ experiments by TGA show calcite to be the predominant carbonation product $(>87 \%)$ and trace amounts of portlandite $(\sim 4 \%)$. Therefore, the assumption that carbonation reactions in calcium species proceed through the reaction of $\mathrm{Ca}(\mathrm{OH})_{2}$ appears valid. Similar to $\mathrm{CaO}$, in most cases $\mathrm{Ca}(\mathrm{OH})_{2}$ is absent in carbonated samples (Table 2.4). However, small fractions of $\mathrm{Ca}(\mathrm{OH})_{2}$ were found in reacted high free-lime bypass dust samples, suggesting that the carbonation reactions had not yet reached completion.

Table 2.5 Mineral phases identified with X-ray diffraction (XRD) in pre-and postcarbonated CKD samples; $\mathbf{N}=$ Present, $\mathbf{N P}=$ Not Present.

\begin{tabular}{|c|c|c|c|c|c|c|c|c|c|}
\hline \multirow[b]{2}{*}{$\begin{array}{r}\text { Mineral } \\
\text { Phase }\end{array}$} & \multirow[b]{2}{*}{ Chemical Formula } & \multicolumn{2}{|c|}{$\begin{array}{c}\text { AG Bypass } \\
\text { High }\end{array}$} & \multicolumn{2}{|c|}{$\begin{array}{c}\text { AG Bypass } \\
\text { Low }\end{array}$} & \multicolumn{2}{|c|}{ AG Wet } & \multicolumn{2}{|c|}{$\begin{array}{c}\text { Continental } \\
\text { Wet }\end{array}$} \\
\hline & & Pre & Post & Pre & Post & Pre & Post & Pre & Post \\
\hline Calcite & $\mathrm{CaCO}_{3}$ & $\mathrm{P}$ & $\mathrm{P}$ & $\mathrm{P}$ & $\mathrm{P}$ & $\mathrm{P}$ & $\mathrm{P}$ & $\mathrm{P}$ & $\mathrm{P}$ \\
\hline Quartz & $\mathrm{SiO}_{2}$ & $P$ & $P$ & $P$ & $\mathrm{P}$ & $\mathrm{P}$ & $\mathrm{P}$ & $\mathrm{P}$ & $\mathrm{P}$ \\
\hline Free Lime & $\mathrm{CaO}$ & $\mathrm{P}$ & NP & $\mathrm{P}$ & NP & $\mathrm{P}$ & NP & $\mathrm{P}$ & NP \\
\hline Portlandite & $\mathrm{Ca}(\mathrm{OH})_{2}$ & $\mathrm{P}$ & $\mathrm{P}$ & $\mathrm{P}$ & NP & $\mathrm{P}$ & NP & NP & NP \\
\hline Anhydrite & $\mathrm{CaSO}_{4}$ & $\mathrm{P}$ & NP & $\mathrm{P}$ & $\mathrm{P}$ & $\mathrm{P}$ & $\mathrm{P}$ & $\mathrm{P}$ & NP \\
\hline Gypsum & $\mathrm{CaSO}_{4} \cdot 2 \mathrm{H}_{2} \mathrm{O}$ & NP & $\mathrm{P}$ & $\mathrm{NP}$ & NP & NP & $\mathrm{P}$ & NP & $\mathrm{P}$ \\
\hline Sylvite & $\mathrm{KCl}$ & $\mathrm{P}$ & $\mathrm{P}$ & $\mathrm{P}$ & $\mathrm{P}$ & NP & NP & $\mathrm{P}$ & $\mathrm{P}$ \\
\hline Arcanite & $\mathrm{K}_{2} \mathrm{SO}_{4}$ & NP & NP & $\mathrm{NP}$ & NP & NP & NP & $\mathrm{P}$ & $\mathrm{P}$ \\
\hline Halite & $\mathrm{NaCl}$ & NP & NP & $\mathrm{P}$ & $P$ & $\mathrm{NP}$ & $\mathrm{NP}$ & $\mathrm{P}$ & $\mathrm{P}$ \\
\hline Ankerite & $\mathrm{Ca}\left(\mathrm{Fe}^{+2}, \mathrm{Mg}\right)\left(\mathrm{CO}_{3}\right)_{2}$ & NP & NP & $\mathrm{NP}$ & NP & NP & NP & $\mathrm{NP}$ & $\mathrm{P}$ \\
\hline Dolomite & $\mathrm{CaMg}\left(\mathrm{CO}_{3}\right)_{2}$ & NP & NP & $\mathrm{NP}$ & NP & NP & NP & NP & $\mathrm{P}$ \\
\hline
\end{tabular}


The increase in carbonate content between reacted and unreacted CKD samples was confirmed with TGA-DTA, TCA, and QXRD analysis. The broad leading edge of the calcite peak in the derivative TGA curve (Figure 2.1) indicates the possible presence of other carbonate phases (such as magnesium or iron carbonates), and/or the early decomposition of calcite with finer or less-defined crystal structures. In most cases the calcite peak on the derivative mass loss curve shifts to the right between unreacted and reacted samples, suggesting the formation of a larger and/or more-defined crystal structure with carbonation. However, the thermal curves in the post-reacted samples are also considerably skewed on the leading edge. This gradual transition into a more predominant peak indicates the presence of additional carbonate species (other than calcite), and/or the precipitation of less defined carbonate phases (Figure 2.1). Examination of the decomposition curve of carbonated pure grade $\mathrm{CaO}$ suggests the latter (Figure 2.1), where there is close similarity in the leading edges of the carbonated peaks (600 to $850^{\circ} \mathrm{C}$ ). The same is true for the other CKD types (not shown), with the exception of the AG Wet CKD, which exhibits a more gradual decomposition and earlier onsite of mass loss than that of the carbonated pure-grade $\mathrm{CaO}$.

Selected samples were analyzed by thermal decomposition (TGA-DTA and TCA) and quantitative XRD to confirm carbonate formation and to verify that mass change is an appropriate measure of sequestration extent (Table 2.6). The results of the different characterization methods, expressed as $\% \mathrm{CO}_{2}$, are presented in Table 2.6, along with the observed change in dry mass. In general, gravimetric determinations of sequestration extent agree reasonably well with the other characterization techniques and appear an appropriate method for assessing the degree of carbonation achieved in the various batch 
experiments. The difference in the abundance of crystalline calcite in pre-and postcarbonated samples measured via QXRD illustrates the significant role that Ca species play in the mineral carbonation reactions. In most cases, the formation of well-defined calcite phases (via QXRD) accounts for over $75 \%$ of the observed carbonation.

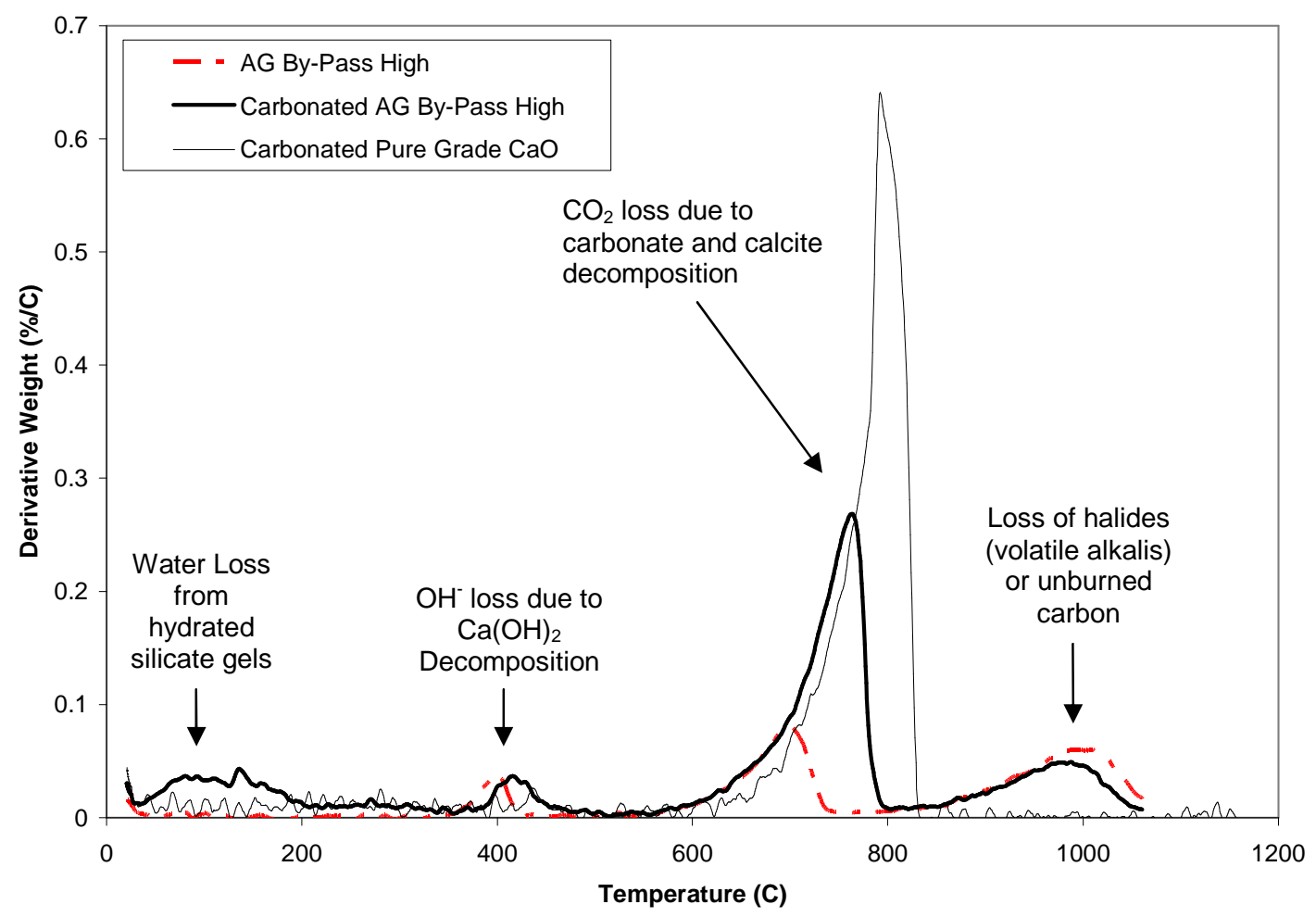

Figure 2.1 Derivative of the thermal mass-loss curve from thermal gravimetric analysis (TGA) of pre- and post-carbonated AG Bypass High CKD and carbonated pure grade $\mathrm{CaO}$. 
Table 2.6 The change in calcium carbonate content on selected samples, expressed in terms of $\mathrm{CO}_{2}$ (mass \%) due to carbonation based on the change in dry mass of the sample, thermal analysis, and quantitative $\mathrm{X}$-ray diffraction. All samples were reacted at $25{ }^{\circ} \mathrm{C}, 100 \%$ relative humidity, and $\sim 80 \% \mathrm{CO}_{2}$ atmosphere.

\begin{tabular}{|r|c|c|c|c|}
\hline CKD & $\begin{array}{c}\text { Mass } \\
\text { Change }^{\mathbf{1}}\end{array}$ & TGA $^{\mathbf{2}}$ & TCA $^{\mathbf{3}}$ & $\mathbf{X R D}^{\mathbf{4}}$ \\
\hline AG Bypass High & $16.7(0.73,9)$ & 16.5 & $13.3(1.2,3)$ & 9.8 \\
\hline AG Bypass Low & $10.5(0.56,6)$ & 9.2 & $10.0(0.5,2)$ & 10.8 \\
\hline AG Wet & $9.8(0.02,3)$ & 8.5 & 6.3 & 7.4 \\
\hline Continental Wet & $9.3(0.21,6)$ & 7.0 & 6.9 & -- \\
\hline
\end{tabular}

\footnotetext{
${ }^{1}$ Average mass change; based on equation 3 (std. dev., number of samples).

${ }^{2}$ Thermal gravimetric analysis; calculated (within $+/-5 \%$ ) from percent mass loss as a result of carbonate decomposition.

${ }^{3}$ Total carbon analysis; average (std. dev., number of samples).

${ }^{4}$ Determined from Quantitative XRD analysis and the Relative Intensity Ration (RIR) method; according to Scott Schlorhortlz (personal communication) the analytical error associated with estimates is $+/-20 \%$.
}

\section{Degree of Carbonation}

The degree of carbonation or the ratio of observed to theoretical extent for the different CKD types was determined both as a function of water-to-solids ratio and time (Figures 2.2 and $\underline{2.3}$, respectively). Overall, the greatest degree of carbonation was achieved in the AG Bypass Low CKD. Among the other CKD types the maximum degrees of carbonation achieved were similar. However, on a mass basis (i.e., mass of $\mathrm{CKD}$ required to sequester a given mass of $\mathrm{CO}_{2}$ ), $\mathrm{AG}$ Bypass High exhibits the greatest overall potential for mineral carbonation, due mostly to its high free $\mathrm{CaO}$ content and the relatively low initial mass fraction of $\mathrm{CaCO}_{3}$ (Tables 2.1 and $\underline{2.6}$ ). It appears that the high alkali content of the two bypass CKDs does not adversely affect the ability of the material to sequester $\mathrm{CO}_{2}$. On the contrary, high sylvite content may enhance the carbonation reactions by promoting the dissolution of $\mathrm{Ca}(\mathrm{OH})_{2}$. The two AG Bypass CKDs have a significant mass fraction of sylvite ( 10\% in the AG Bypass High and > $45 \%$ in the AG Bypass Low) compared to the other CKD types (not detected in AG Wet 
and $<3 \%$ in the Cont. Wet). Direct mineral carbonation of magnesium silicates from mined feedstocks has been enhanced through the use of salt additives, primarily $\mathrm{NaCl}$, in the aqueous reaction system (Huijgen and Comans 2005). The function of the salts is to increase the ionic strength of the solution which consequently, increases the solubility of the calcium through complexation reactions. The higher degree of carbonation observed in the AG Bypass Low CKD suggests that the increased halide content of the waste may enhance the degree of carbonation achieved in the samples by promoting the dissolution of $\mathrm{CaO}$ and $\mathrm{Ca}(\mathrm{OH})_{2}$ and the subsequent precipitation of $\mathrm{CaCO}_{3}$. More experiments, however, are needed to ascertain the importance of sylvite content on the degree of carbonation achievable, as well as its influence on the mechanisms of precipitation.

\section{Effect of Water:Solids Ratio}

In general, the degree of carbonation increases with increased initial water:solids ratio in low-alkali CKD types (AG Wet and Continental Wet; Figure 2.2). This trend is opposite of the results reported for the carbonation of other wastes (Huijgen et al. 2005, Bertos et al. 2004a, 2004b). If the carbonation reactions are carried out primarily through the carbonation of $\mathrm{Ca}(\mathrm{OH})_{2}$, water may serve as a catalyst for the reactions by promoting the conversion of $\mathrm{CaO}$ to $\mathrm{Ca}(\mathrm{OH})_{2}$. In addition, a large portion of $\mathrm{CKD}$ is soluble in water (Dyer et al. 1999) and therefore, higher water:solids ratios might increase the availability of cations such as $\mathrm{Ca}^{2+}$. There appears to be a limit, however, on the ability to which water promotes the carbonation reactions and appears to be related to the material composition of the waste. 

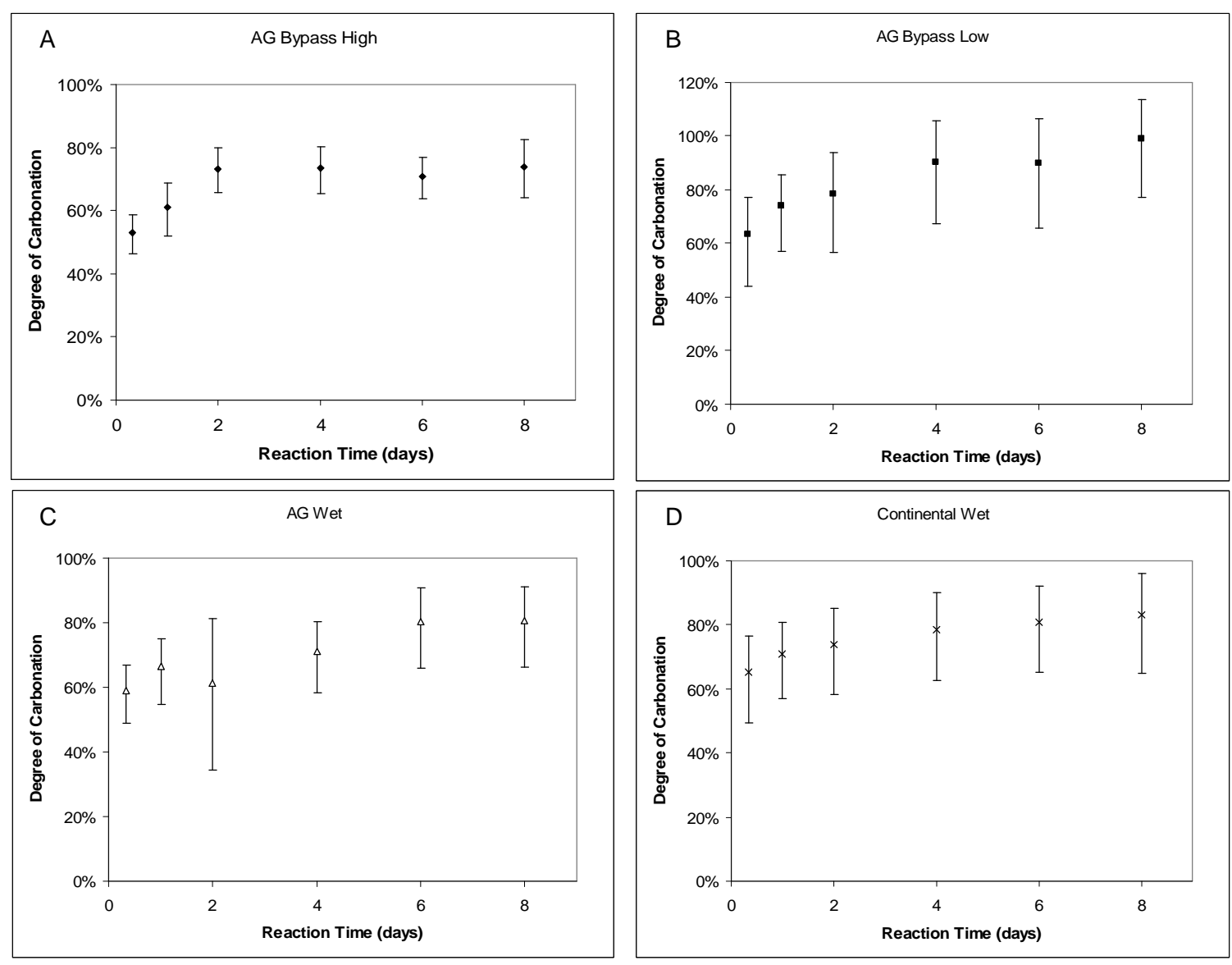

Figure 2.2 Degree of carbonation in four CKD types as a function of initial water-tosolids ratio: (A) AG Bypass High, (B) AG Bypass Low, (C) AG Wet, and (D) Cont. Wet. Samples were reacted for 2 days at $25^{\circ} \mathrm{C}$ and $100 \%$ relative humidity. Error bars express range in calculated degree as a function of the uncertainty associated with both the mass change measurements and the theoretical calculation.

The bypass dusts contain significant amounts of the mineral sylvite, which readily absorbs water from the atmosphere. Both initially dry and water-spiked bypass dust samples absorbed significant amounts of water in the $100 \%$ relative humidity reaction chamber. The combined impacts of higher initial water:solids ratios and adsorption of water from the gas likely caused diffusion limitations in the transport of $\mathrm{CO}_{2}$ and $\mathrm{Ca}^{2+}$ to and from reaction sites, lowering the degree of carbonation with higher initial water-tosolids ratios. Based on regression analysis of degree of carbonation with increasing 
water:solids ratio (Figure 2.2), a significant linear relationship (confidence level $=95 \%$ ) exists between degree of carbonation and water content in all CKD types. However the lowering of carbonation extent with increased water content in the bypass wastes is very small $(<10 \%)$ and not nearly as pronounced as the increase $(>35 \%)$ in carbonation with water content in the AG Wet and Continental Wet CKDs.

\section{Degree of Carbonation with Time}

In all CKD types, the degree of carbonation increases with time, with greater than 75$80 \%$ of the carbonation occurring at early times ( $<2$ days) and more gradual conversion of oxides to carbonates as the reactions progressed (Figure 2.3). The exponential shape of the time-dependent curve indicates that the rate-limiting mechanisms controlling carbonation may change as extent of carbonation proceeds. Researchers investigating the use of $\mathrm{CaO}$ sorbents in the removal of $\mathrm{CO}_{2}$ from flue gas (e.g., Wei et al. 1997, Mess et al. 1999, Agnihotri et al. 1999) have observed $\mathrm{CaCO}_{3}$ coatings and pore blockages in carbonated $\mathrm{CaO}$ samples. The observed result was a decrease in carbonation efficiency of the $\mathrm{CaO}$ sorbents with time and with repeated calcination/decalcination cycles. Similar limits to the decreases in the rate of carbonation extent with time were observed by Huijgen et al. (2005) in their study of the carbonation of steel slag. Analogous precipitation patterns and limits were observed in this study. SEM EDX microanalysis investigations indicate micropore blocking due to the $\mathrm{CaCO}_{3}$ precipitation, along with the propagation of a carbonate shell in $\mathrm{Ca}(\mathrm{OH})_{2}$ particles that grew inward and became denser with time (Anderson 2006). The skin or ring development on reactive particles appears to limit $\mathrm{CO}_{2}$ diffusion to reaction sites, as well as the overall degree of carbonation in the waste, particularly for the AG Bypass High CKD. 

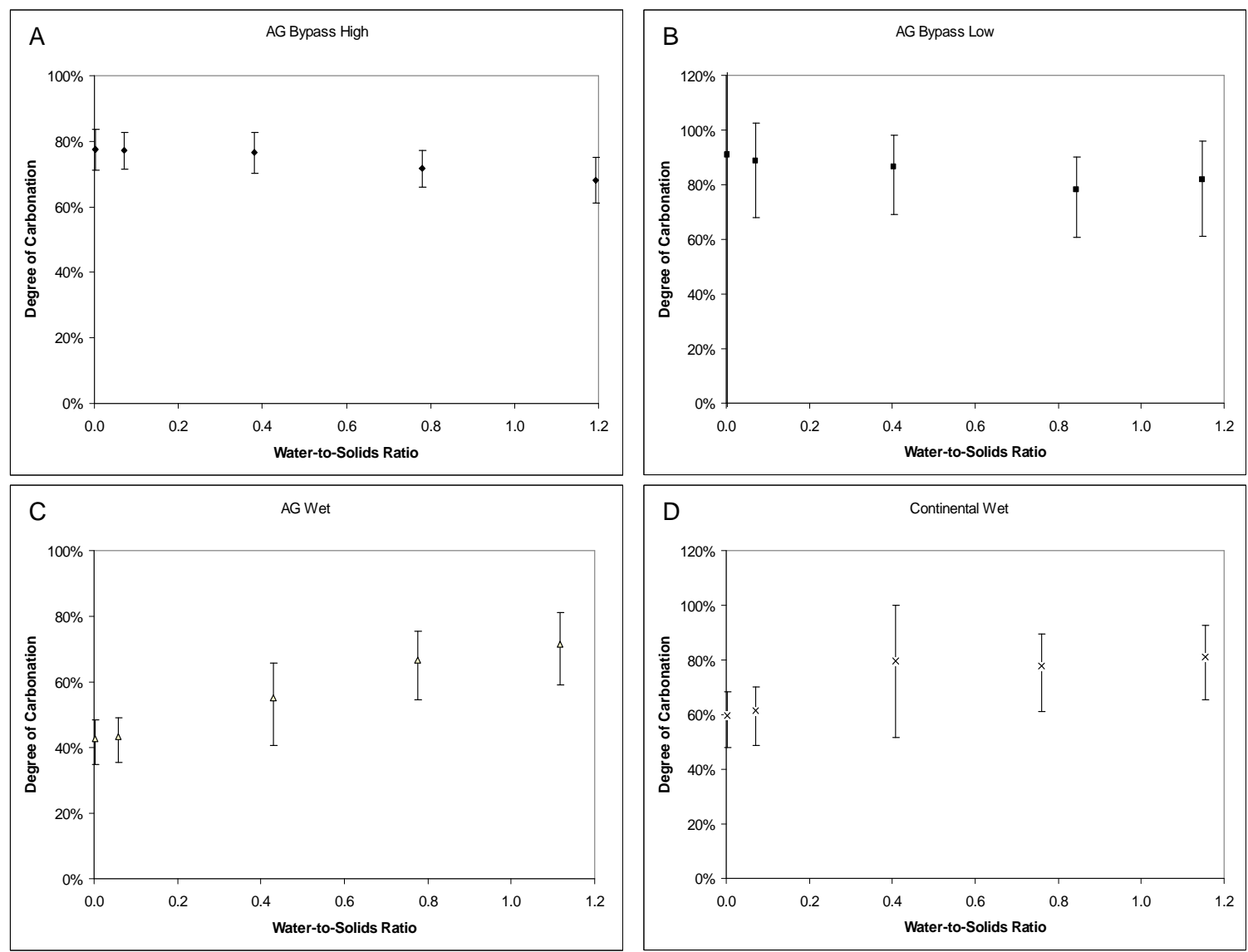

Figure 2.3 Degree of carbonation in four CKD types as a function of time: (A) AG Bypass High, (B) AG Bypass Low, (C) AG Wet, and (D) Continental Wet. Samples were reacted at $25^{\circ} \mathrm{C}$ and $100 \%$ relative humidity with an initial water-to-solids ratio of 0.85 . Error bars express range in calculated degree as a function of the uncertainty associated with both the mass change measurements and the theoretical calculation.

In order to better elucidate the importance of transport limitations in the carbonation of $\mathrm{CKD}$, the degree of carbonation with time achieved in the different waste types was assessed with the empirical kinetic model outline above (equation 2.10). First-order rate equations represent the trend in carbonation at very early times $(<1$ day), but fail to adequately characterize observed trends at later times. Individually, the mechanisms controlling the rate of carbonation can be difficult to measure. Therefore, analogous processes were sought out to help provide insight into the factors controlling mineral carbonation in CKD. Because of the similarity in CKD composition to that of cement, 
conventional, empirical models describing cement hydration (equation 2.10) were applied to the time-dependant results. The observed trend in degree of carbonation with time is the same for all CKD types. Therefore, the empirical rate expression was fit to the batch results from all CKDs as a whole, rather than independently. The values for the rate constant $(k)$ and reaction exponent $(n)$ were optimized by minimizing the root mean square of the sum of the normalized residuals between predicted and experimental degrees of carbonation. The actual fitted values for $k$ and $n$ are not important. As discussed previously, the rate constant, $k$, and the fitting exponent, $n$, are lumped parameters which values are influenced by both reaction and transport mechanisms. Extracting the relative importance of one mechanism (e.g., reaction) over the other (e.g., transport) from these fitted values is difficult and impractical. What is significant from this analysis is that the functional form of the empirical hydration equation describes the degree of carbonation with time better than conventional first- or second-order kinetic equations (refer to Figure 2.4).

From the material analysis and experimental results discussed above, the following conclusions related to the carbonation of cement kiln dust can be made: (1) carbonation reactions are carried out primarily through the carbonation of $\mathrm{Ca}(\mathrm{OH})_{2}$ and $\mathrm{CaCO}_{3}$ is the predominant carbonation product; (2) variations in composition (with the exception of sylvite content) appears to have little effect on the degree of carbonation achievable; and (3) both reaction mechanisms and transport processes appear to control the overall kinetics of the carbonation process. The shape of the time-dependent curve indicates that the degree of sequestration follows pseudo first-order reaction kinetics at early times; however as carbonation proceeds, reaction kinetics deviate significantly from first-order 
conditions. Lumped-rate expressions that include both reaction and diffusion controlled mechanisms better characterize the overall extent of carbonation with time.

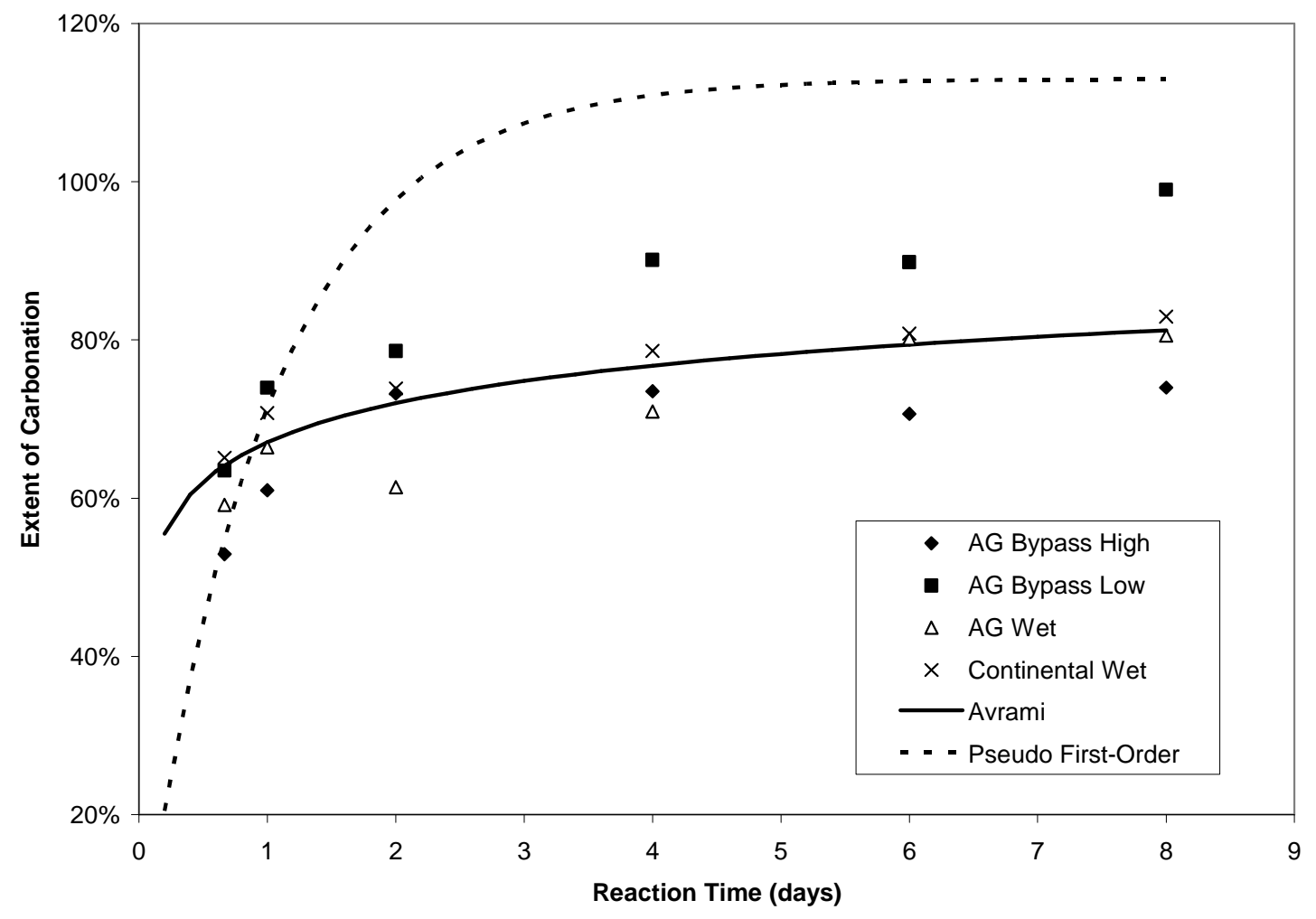

Figure 2.4 Experimental and predicted degree of $\mathrm{CO}_{2}$ consumption in the CKD types examined in this study based on the Avrami equation (equation 10 in text) and a rate expression following pseudo first-order rate assumptions.

\section{Reference Cited}

Adams, L.D., "Build-ups in Suspension Preheaters," Central Process Laboratory, Southwestern Portland Cement Co., October, 1984.

Agnihotri, R., S.K. Mahuli, S.S. Chauk, and L.S. Fan, "Influence of Surface Modifiers on the Structure of Precipitated Calcium Carbonate," Industrial Engineering Chemical Resources, Vol. 38, pp. 2283-2291, 1999.

Anderson, C.P., "Effects of Carbonation on the Mineral Composition of Cement Kiln Dust," Master's Thesis, Michigan Technological University, 2006.

Avrami, M., "Kinetics of Phase Change. I General Theory," Journal of Chemical Physics, vol. 7, pp. 1103-1112, 1939. 
Biernacki, J. J., P.J. Williams, and P.E. Stutzman, "Kinetics of Reaction of Calcium Hydroxide and Fly Ash," ACI Materials Journal, Title No. 98-M37, July/August, pp. 340-349, 2001.

Bertos, M.F., X. Li, S.J.R. Simons, C.D. Hills, and P.J. Carey, "Investigation of Acceleration Carbonation for the Stabilisation of MSW Incinerator Ashes and the Sequestration of $\mathrm{CO}_{2}$," Green Chemistry, Vol. 6, pp. 428-436, 2004a.

Bertos, M.F., S.J.R. Simons, C.D. Hills, and P.J. Carey, “A Review of Accelerated Carbonation Technology in the Treatment of Cement-Based Materials and Sequestration of $\mathrm{CO}_{2}$," Journal of Hazardous Materials, B112, pp. 193-205, 2004b.

Chung, F.H., "Quantitative Interpretation of X-Ray Diffraction Patterns, I. MatrixFlushing Method of Quantitative Multicomponent Analysis," Acta Crystallographica, vol. 7, pp. 519-525, 1974.

Chung, F.H. and D.K. Smith, "The Practice of Diffraction Analysis," in Industrial Applications of X-ray Diffraction, Chung, F.H. and D.K. Smith Eds., Marcel Dekker, New York, NY, 2000.

Corish, A., and T. Coleman, "Cement Kiln Dust," Concrete, September/October, pp. 4042, 1995.

Dyer, T.D, J. E. Halliday, and R.K. Dhir, "An Investigation of the Hydration Chemistry of Ternary Blends Containing Cement Kiln Dust," Journal of Materials Science, vol. 34, pp. 4975-4983, 1999.

Eighmy, T.T., J.D. Eusden, Jr., J.E. Krzanowski, D.S. Domingo, D. Stampfli, J.R. Martin, and P.M. Erickson, "Comprehensive approach toward understanding element speciation and leaching behavior in municipal solid waste incineration electrostatic precipitator ash," Environmental Science \& Technology, vol. 29, pp. 629-646, 1995.

Fauth, D.J., P.M. Goldberg, J.P. Knoer, Y. Soong, W.K. O’Connor, D.C. Dahlin, D.N. Nilsen, R.P. Walters, K.S. Lackner, H.J. Ziock, M.J. McKelvy, and Z.Y. Chen, "Carbon Dioxide Storage as Mineral Carbonates," Symposium-American Chemical Society, Division Fuel Chemistry, pp. 708-712, 2000.

Fauth D.J. and Y. Soung, "Mineral Sequestration Utilizing Industrial By-Products, Residues, and Minerals," Mineral Sequestration Workshop, National Energy Technology Laboratory, August 8, 2001.

Fauth, D.J., J.P. Baltrus, Y. Soong, J.P. Knoer, B.H. Howard, W.J. Graham, M.M. Maroto-Valer, and J.M. Andresen, "Carbon Storage and Sequestration as Mineral Carbonates", in Environmental Challenges and Greenhouse Gas Control for Fossil Fuel Utilization in the $21^{\text {st }}$ Century, Kluwer Academic / Plenum Publishers, 2002a.

Fauth, D.J., Y. Soong, and C.M. White, "Carbon Sequestration Utilizing Industrial Solid Residues," Symposium-American Chemical Society, Division Fuel Chemistry, pp. 37$38,2002 b$.

Guthrie, G.D., J.W. Carey, D. Bergfeld, D. Byler, S. Chipera, H.J. Ziock, and K.S. Lackner, "Geochemical Aspects of the Carbonation of Magnesium Silicates in an Aqueous Medium," NETL Conference on Carbon Sequestration, 2001. 
Helmuth, R., D. Stark, S. Diamond, and M. Moranville-Regourd, "Alkali-Silica Reactivity: An Overview of Research," Strategic Highway Research Program, National Research Council, SHRP-C-342, 1993.

Huijgen, W.J.J. and R.N.J. Comans, "Carbon Dioxide Sequestration by Mineral Carbonation Literature Review," Energy Resource Center of the Netherlands, ECNC-03-016, 2003.

Huijgen, W.J.J., G.J. Witkamp, and R.N.J. Comans, "Mineral $\mathrm{CO}_{2}$ Sequestration by Steel Slag Carbonation," Environmental Science and Technology, vol. 39 (42), pp. 96769682, 2005.

Huijgen, W.J.J. and R.N.J. Comans, “Carbon Dioxide Sequestration by Mineral Carbonation Literature Review Update 2003-2004," Energy Resource Center of the Netherlands, ECN-C-05-022, 2005.

Huntzinger, D.N., J.S. Gierke, L.L. Sutter, S.K. Kawatra, and T.C. Eisle, "Mineral Carbonation for Carbon Sequestration in Cement Kiln Dust Waste Piles," prepared for submission to Journal of Hazardous Materials, 2006.

Hurlburt, C. and C. Klein, Manual of Mineralogy $-21^{\text {st }}$ Edition, John Wiley \& Sons, Inc., New York, 681 pp., 1977.

Klemm, W.A., "What are CKD's Uses and Characteristics?" Rock Products, Cement Edition, pp. 38-44, July 1994.

Knudsen, T., "The Dispersion Model for Hydration of Portland Cement 1. General Concepts," Cement and Concrete Research, Vol. 14, pp. 622-630, 1984.

Lackner, K.S., C. H. Wendt, D.P. Butt, E.L. Joyce and D.H. Sharp, “Carbon dioxide disposal in carbonate minerals," Energy, vol. 20, pp. 1153-1170, 1995.

Mess, D., A.F. Sarofim, and J.P. Longwell, "Product Layer Diffusion during the Reaction of Calcium Oxide with Carbon Dioxide," Energy \& Fuels, vol. 13, 999-1005, 1999.

O’Connor, W.K., D.C. Dahlin, D.N. Nilsen, R.P. Walters, and P.C. Turner, "Carbon Dioxide Sequestration by Direct Mineral Carbonation: Results from Recent Studies and Current Status," Proceedings from National Energy Technology Laboratory (NETL) Workshop on Mineral $\mathrm{CO}_{2}$ Sequestration, 2001.

Steinour, H.H., "Some Effects of Carbon Dioxide on Mortars and Concrete Discussion," Concrete Briefs, Journal of the American Concrete Institute, pp. 905907, February 1959.

Wei, S.H., S.K. Mahuli, R. Agnihotri, and L.S. Fan, "High Surface Area Calcium Carbonate: Pore Structural Properties and Sulfation Characteristics," Industrial Engineering Chemical Resources, vol. 36, 2141-2148, 1997.

Wu, J.C.S., J. Sheen, S. Chen, and Y. Fan, "Feasibility of $\mathrm{CO}_{2}$ Fixation via Artificial Rock Weathering," Industrial Engineering Chemical Resources, vol. 40, 3902-3905, 2001. 


\title{
Effects of Vapor Transport and Particle-Scale Reaction Mechanisms on the Extent of Carbonation in Cement Kiln Dust
}

\author{
Deborah N. Huntzinger ${ }^{1}$ and John S. Gierke ${ }^{1}$
}

\begin{abstract}
The sequestration of carbon dioxide $\left(\mathrm{CO}_{2}\right)$ in cement kiln dust is a potential technology for reducing carbon emissions. A majority of the research related to the mineral carbonation of wastes, including CKD, has been conducted at the batch scale, therefore the viability of the process at the pilot- or plant-scale is still uncertain. Further examination of the degree of sequestration achievable under nonideal (dynamic flow, limited-supply) conditions is required. A set of experiments was conducted to elucidate the importance of gas transport effects, flow rate, and $\mathrm{CO}_{2}$ concentration on the extent of carbonation. It was expected that as the reaction system grew in scale some carbonation efficiency would be lost due gas transport limitations and reduced access to reaction sites. Instead, variations in reactive oxide content of the waste had a greater influence on sequestration performance. Equivalent sequestration performance was achieved in the column experiments as obtained in batch experiments conducted with the same CKD types. Variations in the operating conditions (flow rate, influent concentration) applied in this study had little influence on carbonation efficiency in the columns, suggesting that reaction and precipitation mechanisms are still playing a dominant role in the degree of carbonation achievable in the wastes under non-ideal transport conditions.
\end{abstract}

\footnotetext{
${ }^{1}$ Geological and Mining Engineering and Sciences, Michigan Technological University, 1400 Townsend Drive, Houghton, MI 49931-1195
} 


\section{Introduction}

Mineral carbonation in alkaline waste materials has been shown to be a potentially viable technology for reducing carbon emissions (e.g., Fauth et al. 2002, Bertos et al. 2004a, 2004b, Huijgen et al. 2005, Huntzinger et al. 2006a, 2006b). A majority of the experimental work to date examining the sequestration of carbon in waste materials has been conducted in aqueous batch reaction systems (e.g., Fauth and Soong 2001, and Fauth et al. 2002, Huijgen et al. 2005), and many of these studies were performed at elevated temperatures and pressures. Recent work, however, suggests that the reactive oxides within cement kiln dust (CKD), a byproduct of the cement manufacturing industry, are readily carbonated at ambient temperatures and pressures without amendments or modification (Huntzinger et al. 2006a, 2006b). Under ideal conditions (bench-scale, static/no-flow batch reactor, "infinite” supply), degrees of carbonation greater than $80 \%$ were observed based on calculated theoretical extents and comprehensive analyses of pre- and post-carbonated samples (Huntzinger et al. 2006b). The predominant products of carbonation were calcium carbonates, with well-defined calcite phases accounting for over $75 \%$ of the observed carbonation (Huntzinger et al. 2006b).

Huntzinger et al. (2006b) demonstrated in preliminary estimates of carbonation reaction kinetics in $\mathrm{CKD}$ that $\mathrm{CO}_{2}$ sequestration (carbonate precipitation) follows pseudo first-order reaction kinetics at early times; however, as carbonation proceeds, reaction kinetics deviate significantly from first-order conditions. Lumped-rate expressions that include both reaction and diffusion controlled mechanisms appear to better characterize the overall extent of carbonation as a function of time (Huntzinger et al. 2006b). Similar 
lumped-rate expressions are often used to describe cement hydration (Biernacki et al. 2001) and appear appropriate for describing the combination of factors that play a significant role in the sequestration of alkaline wastes.

Precipitation (carbonation) reactions are generally quite complex, with several mechanisms involved in the reaction between the solid and the solution. For example, initial reaction kinetics may follow equilibrium conditions during the carbonation of more-reactive, accessible oxides (e.g., free $\mathrm{CaO}$ and $\mathrm{Ca}(\mathrm{OH})_{2}$ ). However, as carbonation progresses to the consumption of less-reactive calcium species, rates may slow in response to the gradual release of $\mathrm{Ca}^{2+}$ from those particles. In studies examining the carbonation of steel slag, the diffusion of calcium from the interior of particles to its surface was reported to be the rate-limiting reaction step (Huijgen et al. 2005).

Declining precipitation rates may also indicate a shift to diffusion-controlled reaction conditions, limited by the transport of ions to and from reaction sites (Morse, 1983). In studies examining the use of lime sorbents to separate $\mathrm{CO}_{2}$ from flue gas, the rate of mineral carbonation decreased with time, never achieving the total mineralization capacity of the material. It has been suggested that micropore blockage and mineral "skin" formation on particle surfaces decreases the overall mass transfer rate and/or the kinetics of carbonation (Bhatia and Perlmutter 1983; Wei et al. 1997; Mess et al. 1999; Wu et al. 2001; Gupta and Fan 2002; and Himanshu and Fan 2002). Similar patterns of precipitation were observed in microscopic and X-ray microanalysis conducted on carbonated samples of CKD (Anderson 2006). The reaction and transport mechanisms controlling carbonation at the particle scale can be conceptualized (Figure 3.1) by combining the observations from the microscopic analysis conducted by (Anderson 2006) 
with analogous processes that control oxygen diffusion and mineral oxidation in mine tailings (Wunderly et al. 1996). Assuming that all particles are surrounded by a thin film of immobile water, the reactions can be thought of as taking place in the aqueous phase on, within, or near a reacting solid. $\mathrm{CO}_{2}$ partitions from the gas to the immobile water film via Henry's law forming carbonic acid, bicarbonate and carbonate ions, according to carbonate chemical equilibrium and these species (predominately carbonate ions) diffuse from the particle surface, through the mineral carbonate coating to the center or uncarbonated core in response to concentration gradients. As carbonation proceeds, the radius of the unreacted core decreases, thickening the mineral carbonate shell on the particle. Thus, as the mineral-carbonate reaction ring develops, the mass-transfer rate of dissolved $\mathrm{CO}_{2}$ species to the unreacted core decreases, limiting the rate and possibly the extent of reaction.

While such particle-scale limitations appear to be significant in controlling carbonation under ideal (static-flow, infinite supply) conditions (Huntzinger et al. 2006 and Anderson 2006), their importance under nonideal (dynamic flow, limited-supply) and larger scales is unknown. Therefore, for mineral carbonation of industrial wastes to become a viable technology for reducing $\mathrm{CO}_{2}$ emissions, studies that examine the extent of reaction under dynamic conditions are required. This paper summarizes the results of a series of column experiments performed with CKD. The purpose of the study is to elucidate the importance of gas transport effects, flow rate, and $\mathrm{CO}_{2}$ concentration on the extent of carbonation. These experiments were designed to determine if reaction mechanisms and particle-scale processes (i.e., mass-transfer limitations, pattern of precipitation) still play a major role in the extent of carbonation or if under flowing 
conditions with limited supplies of $\mathrm{CO}_{2}$ that macroscale processes related to mass transport affects become rate or extent limiting.

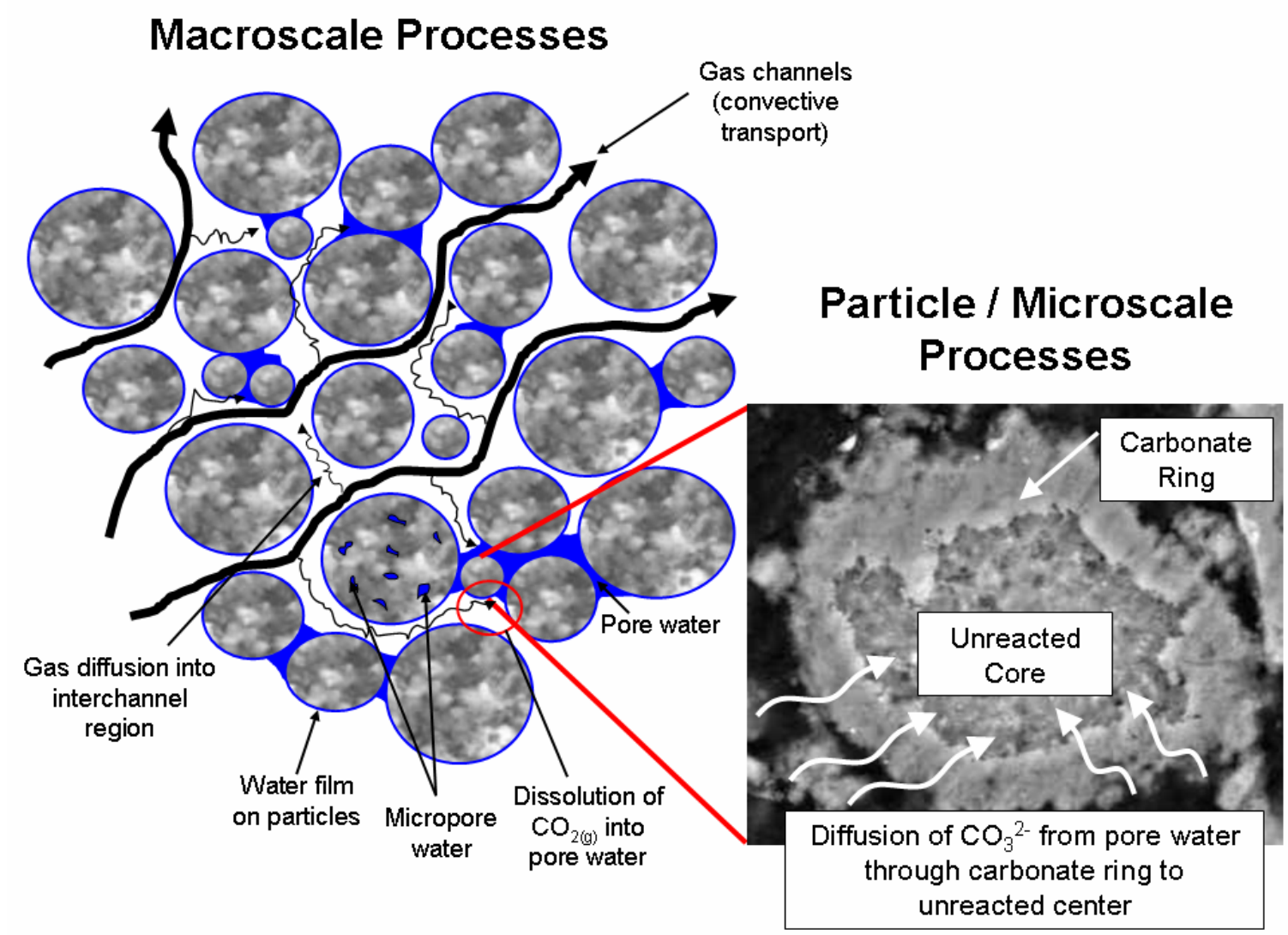

Figure 3.1 Conceptual model of the macro- and micro-scale processes that may control the extent and rate of carbonation at the column scale. Scanning electron microscope image from Anderson (2006).

\section{Materials and Methods}

The experiments (Figure 3.2) were conducted in columns under steady gas flow conditions with uniformly packed CKD and well-controlled influent mixtures of nitrogen, water vapor, and $\mathrm{CO}_{2}$. Operating conditions were systematically varied to differentiate the effects of transport and reaction mechanisms on the extent of carbonation. Holding other variables constant (i.e., CKD type, initial water content, humidity conditions of influent gas), flow rate and influent $\mathrm{CO}_{2}$ concentration were varied in a series of 9 
column experiments. The importance of macroscopic gas transport effects on carbonation were assessed by varying the applied gas flow rate. Rates were selected such that the residence time of the influent gas ranged between 0.5 and 2 minutes, which would be comparable to residence times in a plant-scale system based on average CKD and flue gas generation rates. To assess the importance of reaction rate and mechanisms at the column-scale, influent $\mathrm{CO}_{2}$ concentrations were varied while holding the gas flow rate constant. Concentrations comparable with $\mathrm{CO}_{2}$ composition in cement manufacturing offgas were used (14 to 33\%; Hendriks et al. 2000). The upper bound on influent concentrations, however, was restricted by the detection limit $\left(15 \% \mathrm{CO}_{2}\right)$ of the gas chromatograph used in this study. In addition, the influence of material composition on carbonation was assessed by conducting a series of column experiments with different CKD types having varying reactive fractions (highly reactive free oxides versus less reactive calcium silicate species). The water-to-solids ratio was not varied during this study. Based on results from a comprehensive set of batch experiments (Huntzinger et al. 2006b), water content did not appear to have a significant impact on the extent of carbonation in the bypass CKDs having moderate to low amounts of halides. Therefore, an initial gravimetric water content of $20 \%$ was used to maximize gas pore volume and to assure that the availability of water was not a limiting factor in the reaction. 


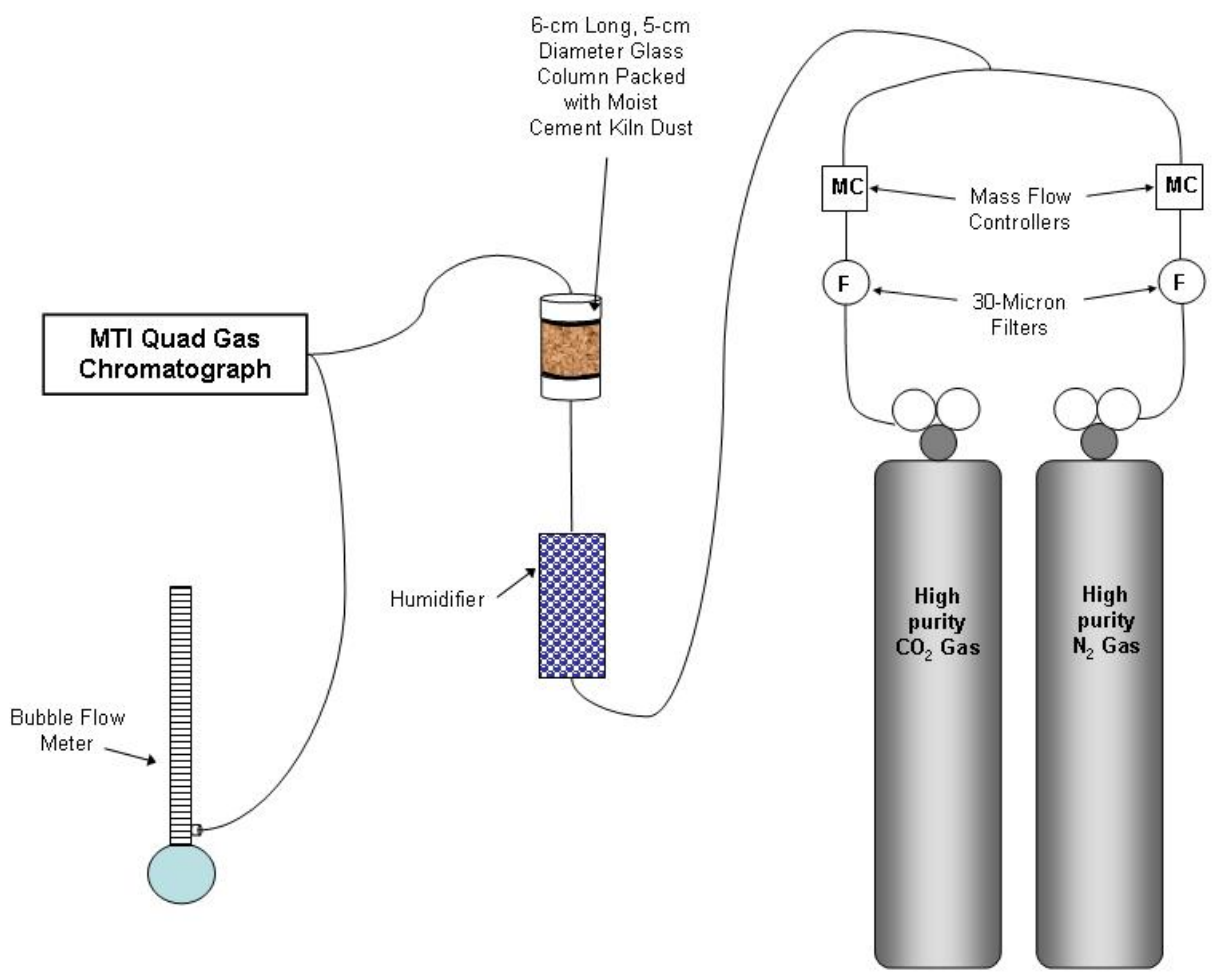

\section{Figure 3.2 Schematic of column set-up.}

\section{Column Set-up and Operation}

Three CKD types were used in this study (Table 3.1): (1) AG Bypass: an alkali bypass dust with a high fraction of free $\mathrm{CaO}(37 \%)$ taken from the alkali recirculation system of a modern, dry kiln (Ash Grove, Chanute, KS); (2) AG Wet: an electrostatic precipitator dust from a long, wet kiln (Ash Grove, Midlothian, TX) with a moderate amount of available oxides and less than $10 \%$ highly reactive free $\mathrm{CaO}$ and $\mathrm{Ca}(\mathrm{OH})_{2}$; and (3) CT Wet: an electrostatic precipitator dust from a long, wet kiln (Continental Cement, Hannibal, MO) with a moderate to low fraction of available (14\%) and an unknown amount of free or unbound oxides. 
Table 3.1 Elemental and reactive free oxide composition as weight percent of the different cement kiln dust types. Elemental analysis was conducted using X-ray flourescences.

\begin{tabular}{|c|c|c|c|}
\hline \multirow[b]{2}{*}{ Oxide } & \multicolumn{3}{|c|}{ Weight Percent } \\
\hline & $\begin{array}{c}\text { AG } \\
\text { Bypass }^{\mathrm{a}}\end{array}$ & AG Wet ${ }^{b}$ & CT Wet ${ }^{\mathrm{c}}$ \\
\hline $\mathrm{Na}_{2} \mathrm{O}$ & 0.65 & 0.49 & 0.26 \\
\hline $\mathrm{MgO}$ & 1.39 & 0.55 & 2.22 \\
\hline $\mathrm{Al}_{2} \mathrm{O}_{3}$ & 3.45 & 4.09 & 4.02 \\
\hline $\mathrm{SiO}_{2}$ & 13.31 & 12.61 & 15.53 \\
\hline $\mathrm{P}_{2} \mathrm{O}_{5}$ & 0.06 & 0.11 & 0.08 \\
\hline $\mathrm{K}_{2} \mathrm{O}$ & 7.04 & 4.03 & 2.01 \\
\hline $\mathrm{CaO}$ & 48.03 & 47.14 & 46.41 \\
\hline $\mathrm{TiO}_{2}$ & 0.23 & 0.22 & 0.25 \\
\hline $\mathrm{MnO}$ & 0.06 & 0.13 & -- \\
\hline $\mathrm{Mn}_{2} \mathrm{O}_{3}$ & -- & -- & 0.10 \\
\hline $\mathrm{Fe}_{2} \mathrm{O}_{3}$ & 2.14 & 1.79 & 1.28 \\
\hline $\mathrm{SO}_{3}$ & 2.73 & 7.66 & 2.04 \\
\hline $\mathrm{Cl}^{-}$ & 5.22 & 0.18 & -- \\
\hline $\mathrm{Br}^{-}$ & 0.21 & 0.03 & -- \\
\hline $\mathrm{LOI}^{\mathrm{d}}$ & 14.88 & 20.37 & 25.80 \\
\hline Total & 99.39 & 99.40 & 100.00 \\
\hline Available $\mathrm{CaO}^{\mathrm{e}}$ & 40.9 & 23.6 & 14.4 \\
\hline Free $\mathrm{CaO}^{\mathrm{f}}$ & 37 & 8 & -- \\
\hline
\end{tabular}

${ }^{a}$ Ash Grove alkali bypass system dust from Chanute, KS manufacturing facility.

${ }^{\mathrm{b}}$ Ash Grove precipitator dust from wet kiln at Midlothian, TX manufacturing facility.

${ }^{\mathrm{c}}$ Continental Cement precipitator dust from wet kiln at Hannibal, MS manufacturing facility.

${ }^{\mathrm{d}} \mathrm{LOI}=$ loss on ignition

${ }^{\mathrm{e}}$ Calculated weight percentage of $\mathrm{CaO}$ available based on initial $\mathrm{CaCO}_{3}$ and $\mathrm{CaSO}_{4}$ content (Huntzinger et al. 2006).

${ }^{\mathrm{f}}$ Estimated amounts of free (unbound) $\mathrm{CaO}$, based on Rietveld refinement (provided by Ash Grove, Inc.) of $\mathrm{X}$-ray diffraction patterns. This Information is not available for CT Wet sample.

The column experiments were conducted in a 6-cm long, 5-cm diameter glass column (Ace Glass, Inc., Vineland, NJ), fitted with Teflon ${ }^{\mathrm{TM}}$ end caps (No. 50 thread) and Viton o-ring face seals. The inlet cap was equipped with $10.9 \mathrm{ml}(1.2-\mathrm{cm}$ deep by $3.4-\mathrm{cm}$ diameter) of $2.5 \mathrm{~mm}$ glass beads packed between two, 150-mesh stainless steel screens to create a disperse gas injection front. For each experiment, $120 \mathrm{~g}$ of dry CKD was mixed 
with $40 \mathrm{~g}$ of nanopure water. The moist CKD was packed into the column in 1-cm lifts with a 4.5-cm diameter tamping device. The remaining CKD was divided into three samples for measurement of initial gravimetric water content. Prior to the study, porosity and bulk density of the CKD types were gravimetrically determined.

High-purity carbon dioxide $\left(\mathrm{CO}_{2}\right)$ and nitrogen $\left(\mathrm{N}_{2}\right)$ (Airgas, Marquette, $\mathrm{MI}$ ) were mixed and regulated with Mass Precision Gas Flow controllers (MC Series, Alicat Scientific, Tucson, AZ) to achieve the desired flow rate and input $\mathrm{CO}_{2}$ concentrations (Table 3.2). Flow rates were also measured with a bubble meter downstream of the column to check for leaks and confirm that gas flow rates were maintained. Influent gas was humidified prior to injection to prevent drying of the column material. Effluent gas samples were analyzed with a gas chromatograph (MTI Analytical Instruments Quad 4 Model Q30L, Fremont, CA) until full breakthrough of the input $\mathrm{CO}_{2}$ concentration was observed. Prior to the column study, $\mathrm{CO}_{2}$ gas standards were prepared and analyzed to check against the influent mixes. At the end of each experiment, the column was flushed with $\mathrm{N}_{2}$ gas and $\mathrm{CO}_{2}$ effluent concentrations were monitored to determine the amount of unsequestered $\mathrm{CO}_{2}$ within the column tubing, end caps, pore spaces, and dissolved in the aqueous phase. After nitrogen flushing, the columns were weighed, dismantled and the gravimetric water content of the carbonated CKD was determined. 
Table 3.2 Column properties and operating conditions.

\begin{tabular}{|c|c|c|c|c|c|c|}
\hline Column & $\begin{array}{l}\text { CKD } \\
\text { Type } \\
\end{array}$ & $\begin{array}{c}\text { Vol. Gas } \\
\text { Flow } \\
\text { Rate } \\
\text { (ml/min) } \\
\end{array}$ & $\begin{array}{c}\begin{array}{c}\text { Influent } \mathrm{CO}_{2} \\
\text { Concentration } \\
\left(\mathbf{p p m}_{\mathrm{v}}\right)\end{array} \\
\end{array}$ & $\begin{array}{c}\text { Initial } \\
\text { Gravimetric } \\
\text { Water } \\
\text { Content }(\%) \\
\end{array}$ & $\begin{array}{c}\text { Gas } \\
\text { Pore } \\
\text { Volume } \\
(\mathbf{m l}) \\
\end{array}$ & $\begin{array}{c}\text { Initial } \\
\text { Dry } \\
\text { Mass } \\
(\mathrm{g}) \\
\end{array}$ \\
\hline 40_50K_BP_A & \multirow{7}{*}{$\begin{array}{c}\text { AG } \\
\text { Bypass }\end{array}$} & \multirow{4}{*}{40} & \multirow{2}{*}{50,000} & 19.5 & 51.1 & 95.4 \\
\hline 40_50K_BP_B & & & & 22.1 & 47.6 & 92.9 \\
\hline 40_100K_BP & & & 100,000 & 24.2 & 44.9 & 97.1 \\
\hline 40_150K_BP & & & 150,000 & 18.1 & 52.8 & 95.3 \\
\hline 20_100K_BP & & 20 & \multirow{5}{*}{100,000} & 21.5 & 48.4 & 93.0 \\
\hline 80_100K_BP_A & & \multirow{2}{*}{80} & & 21.4 & 48.5 & 93.1 \\
\hline 80_100K_BP_B & & & & 22.4 & 47.3 & 90.1 \\
\hline 40_100K_AGW & AG Wet & \multirow{2}{*}{40} & & 25.7 & 45.9 & 105.1 \\
\hline 40_100K_CTW & CT Wet & & & 16.7 & 75.8 & 120.9 \\
\hline
\end{tabular}

\section{Material Characterization}

In-depth material characterization of pre-carbonated samples of the three CKD types used in this study was completed and discussed in detail in a companion paper containing experimental results from batch-scale experiments (Huntzinger et. al. 2006b). The elemental and phase composition of pre-carbonated samples were analyzed with a combination of X-ray fluorescence, X-ray Diffraction, thermal gravimetric analysis (TGA), and total carbon analysis (TCA). Pre- and post-carbonated samples from the batch experiments were also examined using a Philips XL40 (Hillsboro, Oregon) environmental scanning electron microscope (ESEM). The morphology of reaction products and the patterns of precipitation are discussed in detail in Anderson (2006), along with phase chemistry analysis obtained from elemental mapping and energydispersive X-ray (EDX) spot analysis of fresh and carbonated particles. 


\section{Degree of Carbonation}

The amount of carbonation achieved in each column was determined through: (1) the observed mass change before and after carbonation, and (2) frontal analysis of effluent $\mathrm{CO}_{2}$ concentrations. Based on preliminary column experiments (Huntzinger et al. 2006a) and in-depth carbonation studies at the batch-scale (Huntzinger et al. 2006b), both mass change and effluent analysis are appropriate methods for assessing the extent of sequestration.

The degree of carbonation refers to the amount of $\mathrm{CO}_{2}$ captured as carbonated mineral mass compared to the mass of $\mathrm{CO}_{2}$ that would be consumed if all available oxides were carbonated. For this study, the degree of carbonation was determined by comparing the observed mass of $\mathrm{CO}_{2}$ sequestered from frontal analysis to the amount theoretically possible based on the elemental and phase composition of the precarbonated CKD. This is the same method of analysis used in a preliminary column study carried out on intact core segments of CKD taken from a landfilled waste pile (Huntzinger et al. 2006a). In summary, the theoretical estimate of $\mathrm{CO}_{2}$ consumption takes into consideration the amount of calcite present in the pre-carbonated waste, along with other mineral phases that are not likely to carbonate under ambient temperature and pressure conditions (i.e., anhydrite and sylvite) (Huntzinger et al. 2006b). Thus, the theoretical extent of carbonation in the different CKD types was calculated as follows:

$$
\begin{aligned}
\% \mathrm{ThCO}_{2}= & 0.785\left(\% \mathrm{CaO}-0.56 \% \mathrm{CaCO}_{3}-0.7 \% \mathrm{SO}_{3}\right)+1.091 \% \mathrm{MgO} \\
& +0.71 \% \mathrm{Na}_{2} \mathrm{O}+0.468\left(\% \mathrm{~K}_{2} \mathrm{O}-0.632 \% \mathrm{KCl}\right)
\end{aligned}
$$

Where the $\% \mathrm{ThCO}_{2}$ refers to the mass of $\mathrm{CO}_{2}$ consumed in the carbonation reactions compared to the original, unreacted mass of the sample. The stoichiometric mass factors shown in equation 3.1 assume that all of the $\mathrm{CaO}$ (except that bound in $\mathrm{CaSO}_{4}$ and 
$\mathrm{CaCO}_{3}$ ) will react to form $\mathrm{CaCO}_{3}$, all the $\mathrm{MgO}$ will react to form $\mathrm{MgCO}_{3}$, and all of $\mathrm{Na}_{2} \mathrm{O}$ and $\mathrm{K}_{2} \mathrm{O}$ (except that bound in $\mathrm{KCl}$ ) will convert to $\mathrm{Na}_{2} \mathrm{CO}_{3}$ and $\mathrm{K}_{2} \mathrm{CO}_{3}$. The mass factors for $\mathrm{K}_{2} \mathrm{O}$ and $\mathrm{Na}_{2} \mathrm{O}$ are doubled if bicarbonates form instead of carbonates.

\section{Results and Discussion}

The goal of this work was to establish whether micro- or macro-scale processes control the degree of carbonation attainable under column conditions. It is expected that some carbonation efficiency will be lost as the reaction system grows in scale and conditions move from ideal (completely mixed, infinite supply) to more dynamic, where the gas and reacting media are no longer in perfect contact. In order to assess the importance of reaction and transport processes, the influence of changes in gas flow rate and concentration on sequestration performance was evaluated during a series of 7 column experiments using the AG Bypass CKD. Other operational parameters such as initial moisture content, CKD type, and gas conditions (humidified) were held constant. As discussed below, variations in gas flow rate and influent concentration had little effect on observed carbonation efficiency in the columns. Instead, variations in material composition (i.e., reactive oxide content) had a greater influence on sequestration performance, as seen in batch tests conducted with the same CKD types.

\section{Effects of Flow and Concentration on Carbonation}

The total amount of sequestration (i.e., mass of $\mathrm{CO}_{2}$ captured) in each column (Table 3.3) was determined from both observed mass change and frontal analysis of column effluent (see Appendix for graphs of column effluent). Also provided in Table 3.3 is the theoretical sequestration capacity (equation 3.1) for each column based on the material composition of the waste and the initial dry mass of column material prior to carbonation. 
The fraction of calcite in the unreacted material has a significant impact on the calculated theoretical carbonation for each column. Therefore the theoretical capacities presented in Table 3.3 reflect the uncertainty associated with the $\mathrm{CaCO}_{3}$ determinations.

Table 3.3 Measured extent of carbonation compared the amount of sequestration theoretically possible in each column.

\begin{tabular}{|c|c|c|c|c|}
\hline Column & $\begin{array}{l}\text { Observed } \\
\text { Change in } \\
\text { Mass }^{\mathrm{a}} \\
\text { (g) }\end{array}$ & $\begin{array}{c}\text { Mass } \mathrm{CO}_{2} \\
\text { Sequestered }^{b} \\
(\mathrm{~g})\end{array}$ & $\begin{array}{c}\text { Theoretical } \\
\text { Mass of } \mathrm{CO}_{2} \\
\text { Sequestration } \\
\text { Possible }^{\mathrm{c}} \\
\text { (g) }\end{array}$ & $\begin{array}{c}\text { Degree of } \\
\text { Carbonation }^{\mathrm{d}} \\
(\xi) \\
(\%)\end{array}$ \\
\hline 40_50K_BP_A & 24.37 & $\begin{array}{c}25.25 \\
(25.19-25.45)\end{array}$ & $\begin{array}{c}30.4 \\
(28.3-32.5)\end{array}$ & $\begin{array}{c}83.2 \\
(77.6-90.1)\end{array}$ \\
\hline 40_50K_BP_B & 22.46 & $\begin{array}{c}22.75 \\
(22.69-22.79)\end{array}$ & $\begin{array}{c}29.6 \\
(27.5-31.6)\end{array}$ & $\begin{array}{c}77.0 \\
(71.8-82.8)\end{array}$ \\
\hline 40_100K_BP & 21.93 & $\begin{array}{c}23.37 \\
(23.19-23.61)\end{array}$ & $\begin{array}{c}30.9 \\
(28.8-33.0)\end{array}$ & $\begin{array}{c}75.6 \\
(70.2-82.1)\end{array}$ \\
\hline 40_150K_BP & 21.98 & $\begin{array}{c}23.31 \\
(23.03-23.52)\end{array}$ & $\begin{array}{c}30.3 \\
(28.2-32.4)\end{array}$ & $\begin{array}{c}76.9 \\
(71.0-83.3)\end{array}$ \\
\hline 20_100K_BP & 22.68 & $\begin{array}{c}23.67 \\
(23.43-23.79)\end{array}$ & $\begin{array}{c}29.6 \\
(27.6-31.7)\end{array}$ & $\begin{array}{c}80.0 \\
(74.0-86.3)\end{array}$ \\
\hline 80_100K_BP_A & 22.76 & $\begin{array}{c}22.74 \\
(21.90-22.92)\end{array}$ & $\begin{array}{c}28.7 \\
(26.7-30.7)\end{array}$ & $\begin{array}{c}76.4 \\
(69.1-83.1)\end{array}$ \\
\hline 80_100K_BP_B & 19.95 & $\begin{array}{c}20.11 \\
(18.12-21.12) \\
\end{array}$ & $\begin{array}{c}29.6 \\
(27.6-31.7) \\
\end{array}$ & $\begin{array}{c}70.1 \\
(59.1-79.1)\end{array}$ \\
\hline 40_100K_AGW & 9.31 & $\begin{array}{c}9.40 \\
(8.92-9.69)\end{array}$ & $\begin{array}{c}16.0 \\
(13.7-18.3)\end{array}$ & $\begin{array}{c}58.7 \\
(48.7-70.7)\end{array}$ \\
\hline 40_100K_CTW & 9.74 & $\begin{array}{c}9.90 \\
(9.56-10.11)\end{array}$ & $\begin{array}{c}16.6 \\
(13.9-19.3)\end{array}$ & $\begin{array}{c}59.6 \\
(49.6-72.5)\end{array}$ \\
\hline
\end{tabular}

\footnotetext{
${ }^{a}$ Observed mass of $\mathrm{CO}_{2}$ sequestered via frontal analysis compared to theoretical extent of sequestration possible.

${ }^{\mathrm{b}}$ Based on frontal analysis of effluent $\mathrm{CO}_{2}$ concentrations corrected for $\mathrm{CO}_{2}$ removed during $\mathrm{N}_{2}$ flush prior to dismantling the column. The average value is shown along with the range in values due to uncertainty associated with the influent mix concentration (i.e., gas flow regulation).

${ }^{\mathrm{c}}$ The average value is shown, along with the range in theoretical extent that takes into consideration the uncertainty in determination of initial $\mathrm{CaCO}_{3}(+/-5 \%) . \mathrm{CaCO}_{3}$ in the theoretical calculations (equation 1) was determined via thermal gravimetric analysis.

${ }^{\mathrm{d}}$ Degree of carbonation is the observed mass of $\mathrm{CO}_{2}$ sequestered compared to the mass of sequestration theoretically possible.
} 
The overall sequestration performance in the AG Bypass columns (Table 3.4) was comparable to that observed under controlled batch experiments conducted under humidified, ambient temperature and pressure conditions $\left(\sim 80 \% \mathrm{CO}_{2}\right.$ gas, water:solids ratio $\cong 0.30$; Huntzinger et al. $2006 \mathrm{~b}$ ). The average degree of carbonation achieved in the columns was $76.9 \%$ (standard deviation $=2.7 \%, \mathrm{n}=7$ ) and under comparable conditions (water:solids ratio, reaction time), the carbonation obtained in batch studies was $77.2 \%$. This equivalent sequestration performance, both between the column and batch studies and among the AG Bypass columns, indicates a lack of macroscale controls (i.e., preferential gas flow paths) on overall carbonation at the column scale. Even though the complexity of the reaction system has increased, reaction and precipitation mechanisms are still playing a dominant role in the degree of carbonation achievable in the wastes.

Table 3.4 Comparison of the degree of carbonation achieved in different CKD types between column study and previous batch experiments. Columns operated at 40 $\mathrm{ml} / \mathrm{min}$ with influent $\mathrm{CO}_{2}$ concentrations of $100,000 \mathrm{ppm}_{\mathrm{v}}$.

\begin{tabular}{|c|c|c|c|c|}
\hline \multirow{2}{*}{$\begin{array}{c}\text { CKD } \\
\text { Type }\end{array}$} & $\begin{array}{c}\text { Ideal } \\
\text { Behavior }\end{array}$ & $\begin{array}{c}\text { Degree of Carbonation, } \boldsymbol{\xi}^{\mathbf{a}}(\%) \\
\text { Achieved in } \\
\text { Column }\end{array}$ & $\begin{array}{c}\text { Batch at } \\
\text { Similar } \\
\text { GWC and } \\
\text { Time }^{\mathbf{c}}\end{array}$ & $\begin{array}{c}\text { Maximum } \\
\text { Achieved in } \\
\text { Batch }^{\mathbf{d}}\end{array}$ \\
\hline AG & 71.2 & 75.6 & 77.2 & 77.5 \\
Bypass & $(70.9-71.7)$ & $(70.2-82.1)$ & $(70.5-82.8)$ & $(70.2-83.7)$ \\
\hline AG Wet & 38.1 & 58.7 & 49.2 & 80.6 \\
& $(37.5-38.5)$ & $(48.7-70.7)$ & $(38.0-57.5)$ & $(66.3-91.2)$ \\
\hline CT Wet & 46.6 & 59.6 & 70.5 & 83.0 \\
& $(45.9-47.1)$ & $(49.6-72.5)$ & $(50.2-85.2)$ & $(64.8-96.1)$ \\
\hline
\end{tabular}

\footnotetext{
${ }^{a}$ Average values are shown, along with the range in degree of carbonation (in parentheses) due to the error associated with the measured mass of $\mathrm{CO}_{2}$ sequestered and uncertainty in calculations of the theoretical extent (Table 1 and Huntzinger et al. 2006b).

${ }^{b}$ Degree of carbonation achieved before deviated from ideal (i.e., before $\mathrm{CO}_{2}$ breakthrough on effluent end of column).

${ }^{\mathrm{c}}$ Degree of carbonation achieved in batch experiments conducted at a water:solids ratio of approximately 0.30 for a duration of 2 days (Huntzinger et al. 2006b). Sequestration in columns was complete after 2 to 3 days.

${ }^{\mathrm{d}}$ Maximum degree of carbonation achieved in batch experiments under humidified gas conditions and varied water:solids ratios (Huntzinger et al. 2006b).
} 
Carbonation performance by the columns was also compared to ideal behavior, in which all of the $\mathrm{CO}_{2}$ introduced to the system is consumed by the waste in the given gas residence time. For each column, the mass of $\mathrm{CO}_{2}$ injected and the corresponding mass sequestered with time were normalized by the theoretical extent of sequestration and plotted together in conjunction with the trend for ideal sequestration (Figure 3.3 $)$. On average, $85 \%$ (standard deviation $=5.6 \%, \mathrm{n}=7$ ) of the sequestration is achieved while following ideal behavior, with the remaining carbonation taking place more slowly. This deviation from the ideal is likely controlled by a combination of gas diffusion or reaction limitations. Similar trends were observed in batch experiments (Huntzinger et al. 2006b) where approximately $90 \%$ of the observed $\mathrm{CO}_{2}$ sequestration was achieved at early times ( $<2$ days) and additional carbonation occurred gradually over the remainder of the experiment (total time $=8$ days). Declines in sequestration rates can be explained using the conceptualized model discussed above and shown in Figure 3.1, where the rate of sequestration is controlled, at least in part, by the extent of carbonation. SEM microanalysis of reacted samples (Anderson 1996) shows that carbonation reactions on and within $\mathrm{Ca}(\mathrm{OH})_{2}$ particles leads to pore plugging, precipitate coatings, and the development of $\mathrm{CaCO}_{3}$ skin, all of which limit the diffusion of $\mathrm{CO}_{2}$ to reaction sites. The reactive nature of the oxides in the waste may also contribute to the carbonation efficiency of the material over time. 


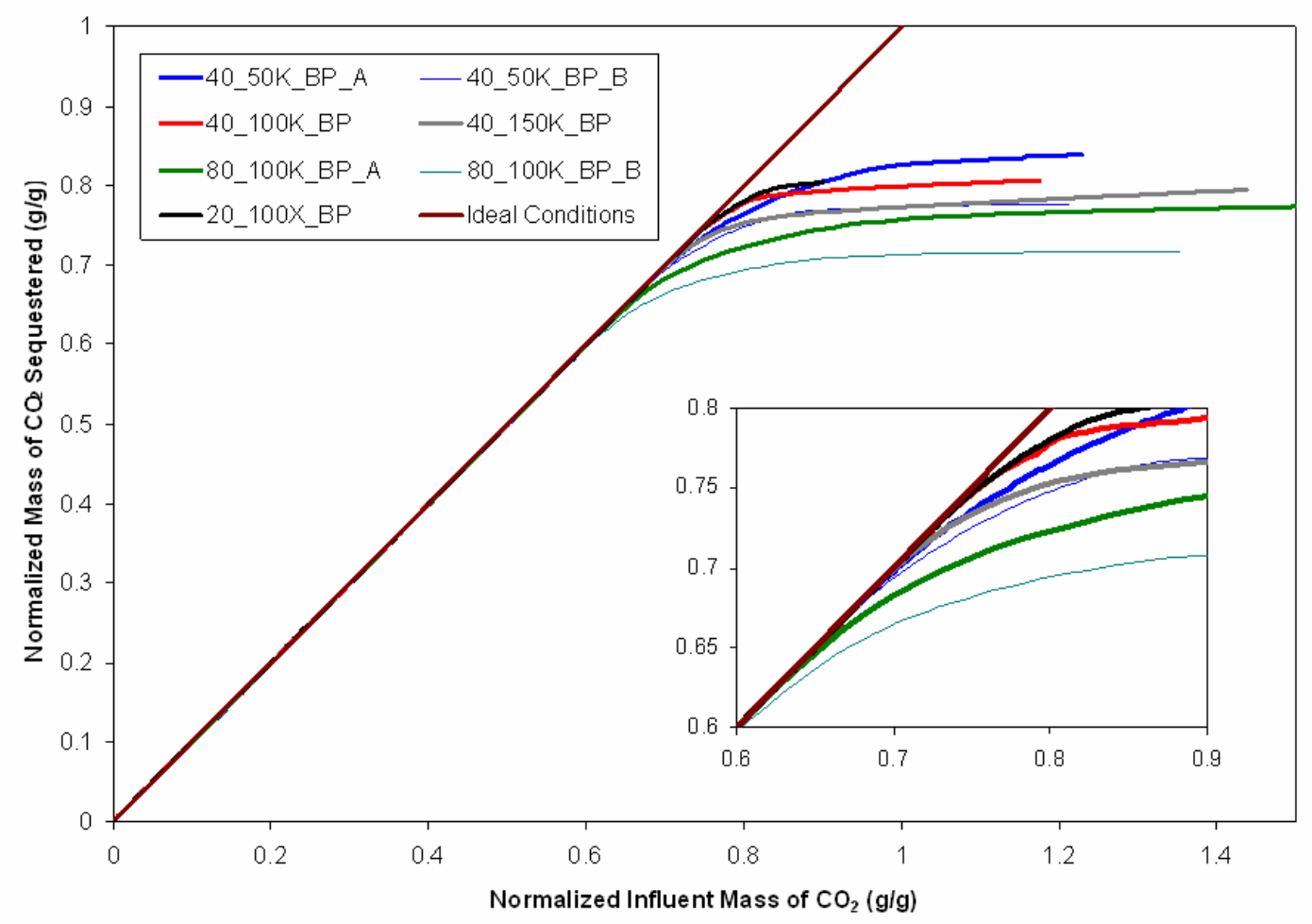

Figure 3.3 Normalized mass of $\mathrm{CO}_{2}$ sequestered in the seven Ash Grove Bypass CKD columns under various flow rates and influent $\mathrm{CO}_{2}$ conditions. The inset shows the point at which the performance of each column begins to deviate from ideal sequestration conditions ( $\mathrm{CO}_{2}$ breakthrough at the effluent end begins).

\section{Effect of Reactive Oxide Composition}

A series of column experiments were conducted with different CKD types to assess the impact of reactive oxide content (free $\mathrm{CaO}$ and $\mathrm{Ca}(\mathrm{OH})_{2}$ ) on carbonation performance at the column scale. As with the AG Bypass CKD, the two CKD samples from the wet process kilns (AG Wet and CT Wet) achieved degrees of carbonation comparable to that obtained under controlled batch experiments (Table 3.4, Figure 3.4). The degree of carbonation achieved following ideal behavior (all $\mathrm{CO}_{2}$ injected was consumed) appears correlated to the free oxide content of the wastes. For discussion purposes, the free or 
unbound oxide content (i.e., free $\mathrm{CaO}$ and $\mathrm{Ca}(\mathrm{OH})_{2}(\mathrm{as} \mathrm{CaO})$ ) is referred to as the highly reactive oxide (HRO) fraction, whereas the overall available oxide content (Table 3.5) refers to both this highly reactive fraction as well as those oxides that are available for reaction but bound in semi-reactive phases (e.g., calcium silicates). Although direct measurement of the HRO fraction was not conducted for the 3 CKDs, Rietveld analysis of XRD patterns was performed by Ash Grove Cement Manufacturing Co. and this provides an estimate of free $\mathrm{CaO}$ and $\mathrm{Ca}(\mathrm{OH})_{2}$ content for the AG Bypass and $\mathrm{AG}$ Wet CKD samples (Table 3.5).

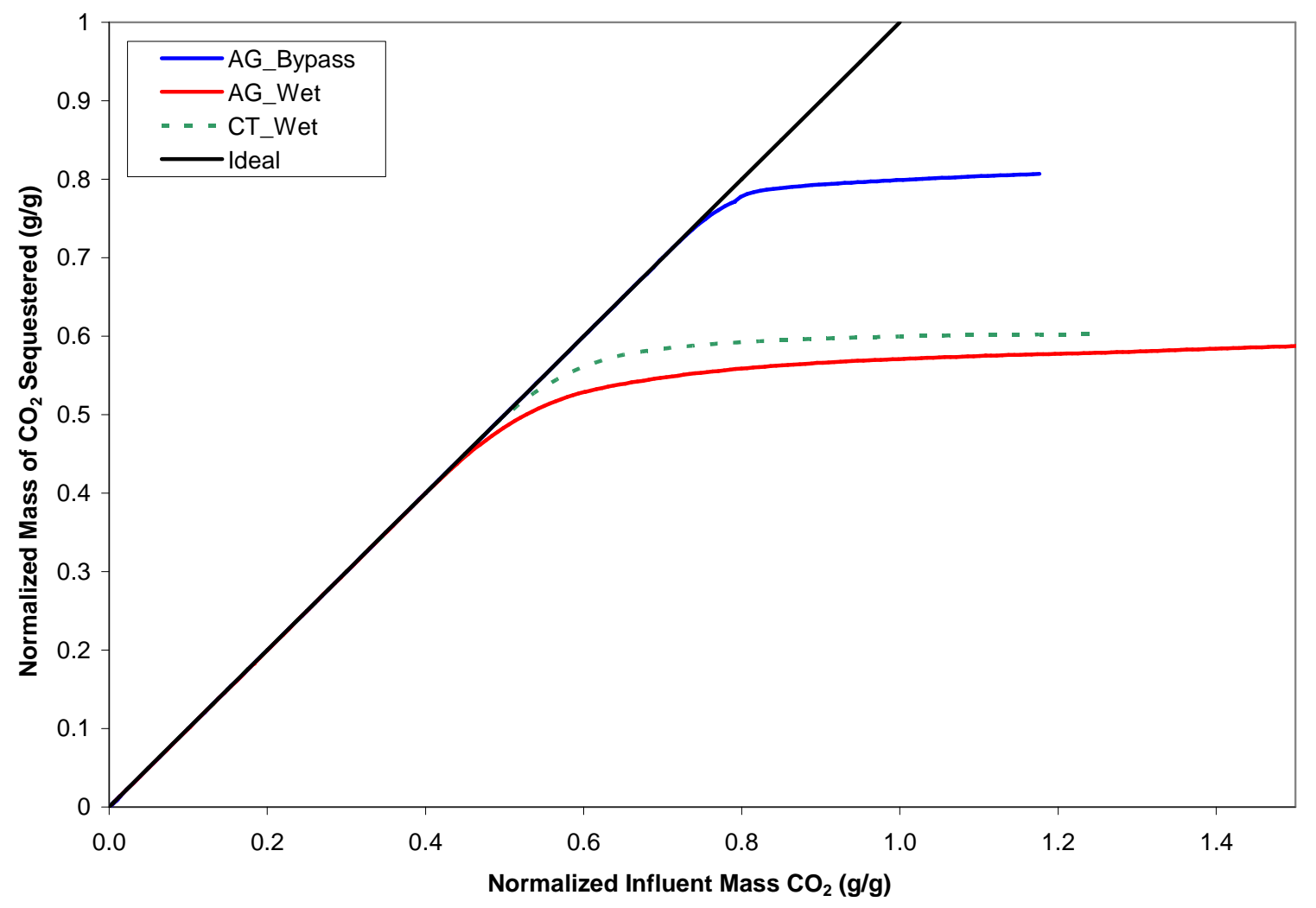

Figure 3.4 Normalized mass of $\mathrm{CO}_{2}$ sequestered in the Ash Grove Bypass, AG Wet and CT Wet CKD columns. Columns were operated at $40 \mathrm{ml} / \mathrm{min}$ with an influent $\mathrm{CO}_{2}$ concentration of $100,000 \mathrm{ppm}_{\mathrm{v}}$. 
It was hypothesized that the sequestration behavior in the columns would follow ideal conditions, consuming all $\mathrm{CO}_{2}$ introduced to the system until the $\mathrm{HRO}$ fraction was exhausted. As reaction conditions moved towards the consumption of less reactive $\mathrm{Ca}^{2+}$ species (i.e., those bound in $\mathrm{Ca}$ silicates or other oxide complexes), carbonation rates would slow and $\mathrm{CO}_{2}$ breakthrough would begin to occur. Assuming that the mass of $\mathrm{CO}_{2}$ sequestered prior to $\mathrm{CO}_{2}$ breakthrough can be correlated to a mass fraction of $\mathrm{CaO}$, the performance of the AG Wet column is consistent with this hypothesis (Table 3.5). The performance of the AG Bypass column does not correlate as clearly. However, the HRO content of this waste is much higher and accounts for a greater percentage of the overall oxide content (>90\%) of the waste (Table 3.5). SEM microanalysis (Anderson 2006) conducted on carbonated samples from batch tests (Huntzinger et al. 2006b) indicate that $\mathrm{CaCO}_{3}$ skin development and precipitation of $\mathrm{CaCO}_{3}$ in particle micropores may encapsulate reaction sites before the full extent of carbonation was achieved. Because of the greater fraction of $\mathrm{HRO}$ in the AG Bypass CKD, this effect may be more pronounced.

In addition, there is some level of uncertainty related to the Rietveld refinement provided by Ash Grove. Inconsistencies were found between the weight fractions of calcium species determined by Ash Grove and independent measurements of element abundance via X-ray fluorescence (XRF). Phase identifications through SEM microanalysis (Anderson 2006) correspond with those phases identified by Ash Grove (e.g., the presence of $\mathrm{Ca}$ silicate species). However in the AG Bypass CKD, the total $\mathrm{CaO}$ equivalent from Rietveld exceeds that determined by XRF by almost $30 \%$. Such a discrepancy is not found in the $\mathrm{AG}$ Wet $\mathrm{CKD}$, where calculated equivalent $\mathrm{CaO}$ fractions are within $0.06 \%$. It is likely that the free $\mathrm{CaO}$ fraction in the AG Bypass CKD is 
overestimated in the Ash Grove determinations. Because Rietveld refinement depends on whole-pattern analysis, the accuracy of the quantitative determinations depends on the completeness of the crystalline data set in which the sample is compared to. Amorphous phases, preferred orientations, and minerals with crystallographic variability can lead to errors of mass fraction determinations (Elton and Smith 2000). In addition, if the full range of diffraction angles is not collected, the calculated mass fractions can be overestimated. If the $\mathrm{HRO}$ fraction reported in Table 3.5 for the AG Bypass CKD is reduced by $30 \%$ (to 27.44 ), the correlation between the HRO fraction and ideal sequestration behavior of the column becomes more apparent.

Table 3.5 Relation of cement kiln dust composition to the mass of $\mathrm{CO}_{2}$ sequestered before $\mathrm{CO}_{2}$ breakthrough occurred in the column. All columns were operated at 40 $\mathrm{ml} / \mathrm{min}$ with an influent $\mathrm{CO}_{2}$ concentration of $100,000 \mathrm{ppm}_{\mathrm{v}}$.

\begin{tabular}{|c|c|c|c|c|c|}
\hline CKD Type & $\begin{array}{c}\text { Available } \\
\text { CaO } \\
(\mathbf{W t .} \%)^{\mathrm{a}} \\
\end{array}$ & $\begin{array}{c}\text { HRO } \\
\text { Fraction } \\
(\text { Wt. \% })^{\text {b }} \\
\end{array}$ & $\begin{array}{c}\text { Mass of } \mathrm{CO}_{2} \\
\text { Sequestered } \\
\text { under Ideal } \\
\text { Behavior }(\mathrm{g})^{\mathrm{c}} \\
\end{array}$ & $\begin{array}{l}\text { Corresponding } \\
\text { Mass of } \mathrm{CaO} \\
\text { consumed }(\mathrm{g})^{\mathrm{d}}\end{array}$ & \begin{tabular}{|c|} 
Fraction of \\
Consumed \\
CaO to Initial \\
Mass $(\%)^{\mathrm{e}}$ \\
\end{tabular} \\
\hline AG Bypass & 40.9 & 39.2 & 20.8 & 26.5 & 27.2 \\
\hline AG Wet & 23.6 & 8.0 & 6.1 & 7.8 & 7.4 \\
\hline CT Wet & 14.4 & -- & 7.6 & 9.7 & 8.0 \\
\hline
\end{tabular}

\footnotetext{
${ }^{a}$ Based on X-ray fluorescence, thermal gravimetric analysis, and estimations of initial $\mathrm{CaCO}_{3}$ and $\mathrm{CaSO}_{4}$ content.

${ }^{\mathrm{b}} \mathrm{HRO}$ refers to highly reactive oxide fraction or unbound $\mathrm{CaO}$ and $\mathrm{Ca}(\mathrm{OH})_{2}(\mathrm{as} \mathrm{CaO})$. Values were obtained from Ash Grove's Rietveld refinement of X-ray diffraction patterns.

${ }^{c}$ From frontal analysis of $\mathrm{CO}_{2}$ breakthrough in columns. "Ideal behavior" refers to the mass of $\mathrm{CO}_{2}$ sequestered before $\mathrm{CO}_{2}$ breakthrough was detected in the column effluent.

${ }^{d}$ The corresponding amount of $\mathrm{CaO}$ consumed prior to $\mathrm{CO}_{2}$ breakthrough, assuming that all $\mathrm{CO}_{2}$ consumed was due to reaction with $\mathrm{CaO}$.

${ }^{\mathrm{e}}$ Reported as mass fraction of calculated $\mathrm{CaO}$ consumed (corresponding mass of $\mathrm{CaO}$ consumed $(\mathrm{g})$ ) to the initial dry mass of CKD in the column.
}

Although this correlation between HRO content and ideal behavior cannot be definitively stated at this time, the results of this study indicate that a relationship exits. 
The results also show that microscale processes and reaction mechanisms still play a dominant or controlling role at the column scale and that further studies examining ratelimiting behaviors at even greater scales is warranted 


\section{SUPPLEMENTAL INFORMATION}

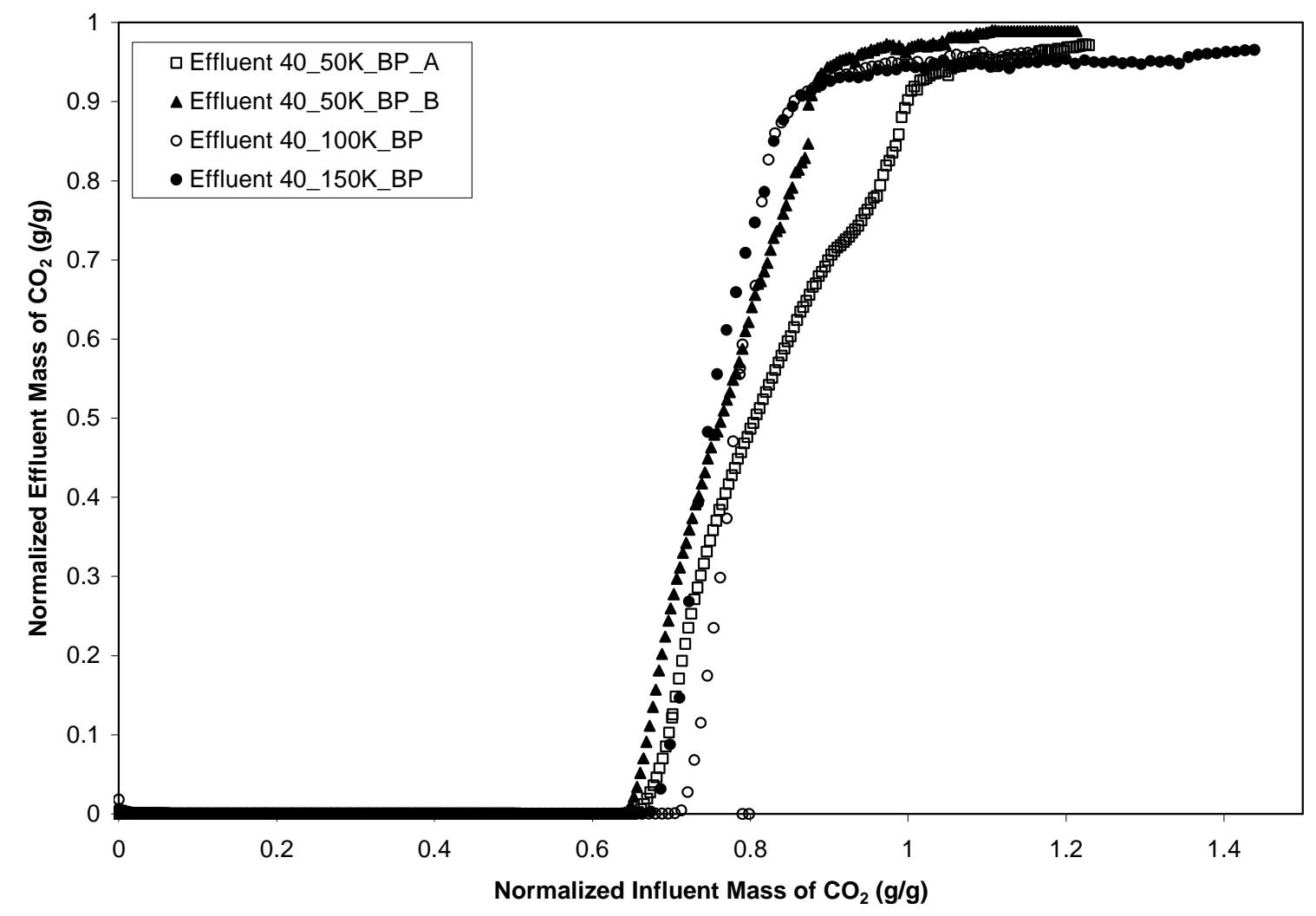

Supplemental Figure 1. Normalized effluent in AG Bypass columns as a function of influent $\mathrm{CO}_{2}$ concentration. All columns were operated with an applied gas flow rate of $40 \mathrm{ml} / \mathrm{min}$. 


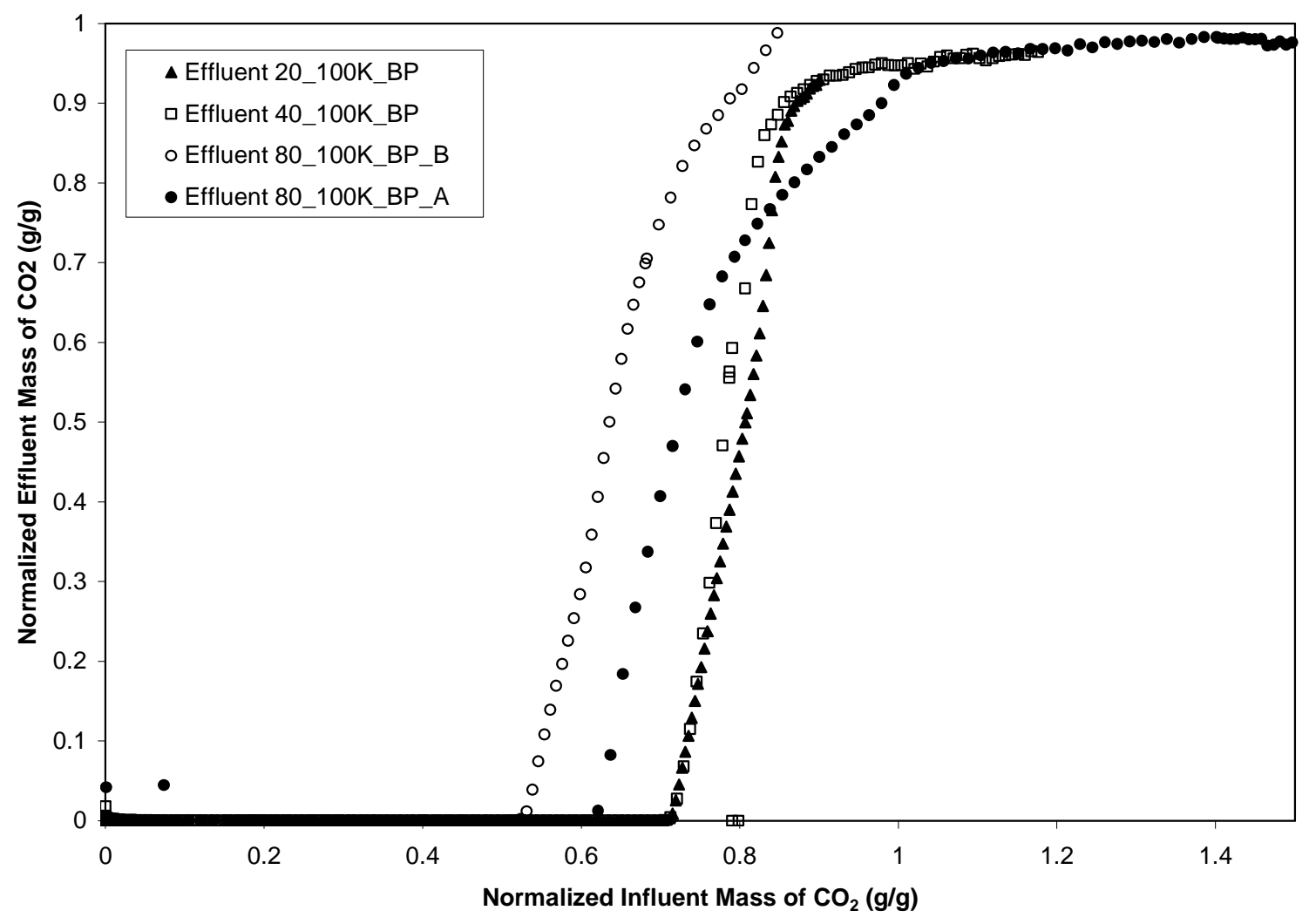

Supplemental Figure 2. Normalized effluent in AG Bypass columns as a function of applied gas flow rate. All columns were operated with an influent $\mathrm{CO}_{2}$ concentration of $100,000 \mathrm{ppm}_{\mathrm{v}}$. 


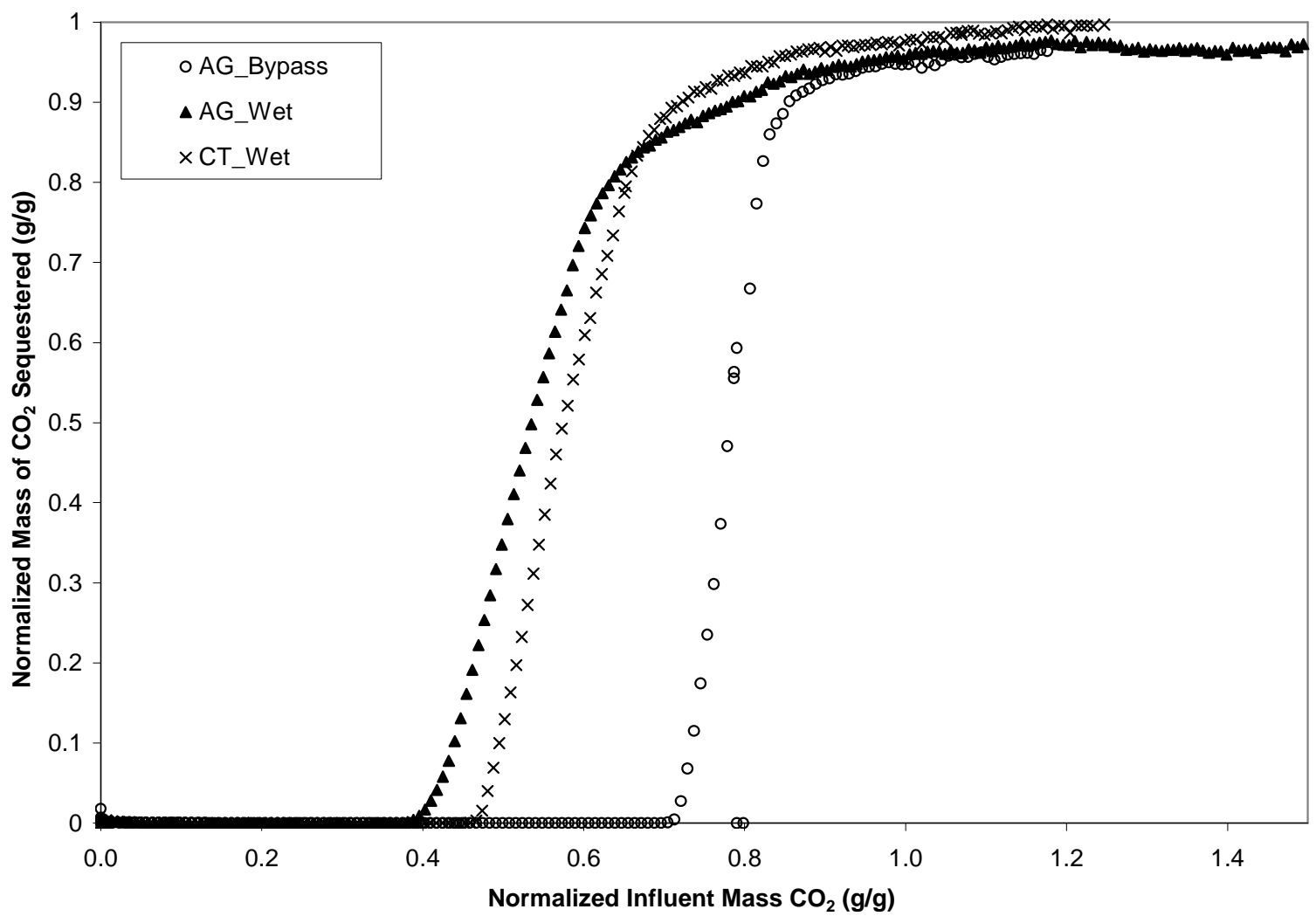

Supplemental Figure 3. Normalized effluent as a function of cement kiln dust (CKD) type. Columns were operated at $40 \mathrm{ml} / \mathrm{min}$ with an influent $\mathrm{CO}_{2}$ concentration of $100,000 \mathrm{ppm}_{\mathrm{v}}$. 


\section{Reference Cited}

Anderson, C.P., "Effects of Carbonation on the Mineral Composition of Cement Kiln Dust," Master's Thesis, Michigan Technological University, 2006.

Biernacki, J.J., P.J. Williams, and P.E. Stutzman, "Kinetics of Reaction of Calcium Hydroxide and Fly Ash," ACI Materials Journal, Title No. 98-M37, July/August, pp. 340-349, 2001.

Bertos, M.F., X. Li, S.J.R. Simons, C.D. Hills, and P.J. Carey, "Investigation of Acceleration Carbonation for the Stabilisation of MSW Incinerator Ashes and the Sequestration of $\mathrm{CO}_{2}$," Green Chemistry, vol. 6, pp. 428-436, $2004 \mathrm{a}$.

Bertos, M.F., S.J.R. Simons, C.D. Hills, and P.J. Carey, "A Review of Accelerated Carbonation Technology in the Treatment of Cement-Based Materials and Sequestration of $\mathrm{CO}_{2}$," Journal of Hazardous Materials, B112, pp. 193-205, 2004b.

Bhatia, S.K. and D.D. Perlmutter, "Effect of the Product Layer on the Kinetics of the $\mathrm{CO}_{\mathrm{s}}$-Lime Reaction," AIChE Journal, 29(1), pp. 79-86, 1983.

Elton, N.J. and D.K. Smith, "Silica," in Industrial Applications of X-Ray Diffraction, F.H. Chung and D. K. Smith eds., Marcel Dekker Inc., 2000.

Fauth, D.J. and Y. Soong, "Mineral Sequestration Utilizing Industrial By-Products, Residues, and Minerals," Proceedings, Mineral Sequestration Workshop, National Energy Technology Laboratory, August 8, 2001.

Fauth, D.J., Y. Soong, and C.M. White, "Carbon Sequestration Utilizing Industrial Solid Residues," Symposium-American Chemical Society, Division Fuel Chemistry, pp. 3738, 2002.

Gupta, H., and L. Fan, "Carbonation-Calcination Cycle Using High Reactivity Calcium Oxide for Carbon Dioxide Separation from Flue Gas," Industrial Engineering Chemical Resources, vol. 41, pp. 4035-4042, 2002.

Hendriks, C.A., E. Worrell, D. deJager, K. Block, and P. Riemer, "Emission Reduction of Greenhouse Gases from the Cement Industry," IEA Greenhouse gas R\&D Programme, Greenhouse Gas Control Technologies (GHGT) Conference Paper: http://www.wbcsd.ch/web/projects/cement/tf1/prghgt42.pdf, 2000.

Himanshu, G. and L.S. Fan, "Carbonation-Calcination Cycle Using High Reactivity Calcium Oxide for Carbon Dioxide Separation from Flue Gas," Industrial Engineering Chemical Resources, pp. 4035-4042, 2002.

Huijgen, W.J.J., G.J. Witkamp, and R.N.J. Comans, "Mineral $\mathrm{CO}_{2}$ Sequestration by Steel Slag Carbonation," Environmental Science and Technology, 39 (42), pp. 9676-9682, 2005.

Huntzinger, D.N., J.S. Gierke, L.L. Sutter, S.K. Kawatra, T.C. Eisele, "Mineral Carbonation for Carbon Sequestration in Cement Kiln Dust Waste Piles," Journal of Hazardous Materials, in preparation, 2006a. 
Huntzinger, D. N., J.S. Gierke, S.K. Kawatra, T.C. Eisele, and L.L. Sutter, “Carbon Dioxide Sequestration in Cement Kiln Dust through Mineral Carbonation." Environmental Science and Technology, in preparation, 2006b.

Mess, D., A.F. Sarofim, and J.P. Longwell, "Product Layer Diffusion during the Reaction of Calcium Oxide with Carbon Dioxide," Energy \& Fuels, vol. 13, pp. 999-1005, 1999.

Morse, J.W., "The Kinetics of Calcium Carbonate Dissolution and Precipitation," Carbonates: Mineralogy and Chemistry, Review in Mineralogy, Volume 11, Editor R.J. Reeder, Mineralogical Society of America, pp. 227-264, 1983.

Wei, S.H., S.K. Mahuli, R. Agnihotri, and L.S. Fan, "High Surface Area Calcium Carbonate: Pore Structural Properties and Sulfation Characteristics," Industrial Engineering Chemical Resources, vol. 36, pp. 2141-2148, 1997.

Wu, J.C.S., J. Sheen, S. Chen, and Y. Fan, "Feasibility of $\mathrm{CO}_{2}$ Fixation via Artificial Rock Weathering," Industrial Engineering Chemical Resources, vol. 40, pp. 39023905, 2001.

Wunderly, M.D., D.W. Blowes, E.O. Frind, and C.J. Ptacek, "Sulfide Mineral Oxidation and Subsequent Reactive Transport of Oxidation Products in Mine Tailings Impoundments: A numerical Model," Water Resources Research, 32(10), pp. 31733187, October 1996. 


\title{
A Life Cycle Assessment of Portland Cement Manufacturing: Comparing the Traditional Process with Alternative Technologies
}

\author{
Deborah N. Huntzinger ${ }^{1}$ and Thomas Eatmon ${ }^{2}$
}

\begin{abstract}
Concern over the impact of anthropogenic carbon emissions on the global climate has increased in recent years due to growth in global warming awareness. Approximately $5 \%$ of global $\mathrm{CO}_{2}$ emissions originate from the manufacturing of cement, which is also the third largest source of carbon emission in the United States. In addition to the generation of $\mathrm{CO}_{2}$ the cement manufacturing process produces millions of tons of the waste product cement kiln dust (CKD) each year contributing to respiratory and pollution health risks. In this paper LCA is used to evaluate the environmental impact of four cement manufacturing processes: (1) the production of traditional portland cement, (2) blended cement (natural pozzolans), (3) cement where $100 \%$ of waste cement kiln dust is recycled into the kiln process, and (4) portland cement produced when cement kiln dust $(\mathrm{CKD})$ is used to sequester a portion of the process related $\mathrm{CO}_{2}$ emissions. To reduce uncertainty this manuscript presents a cradle-to-gate life cycle assessment of several cement products. Analysis using SimaPro 6.0 software shows that blended cements provide the greatest environmental savings followed by utilization of CKD for sequestration. The recycling of CKD was found to have little environmental savings over the traditional process.

\footnotetext{
${ }^{1}$ Department of Geological and Mining Engineering and Sciences, Michigan Technological University, Houghton, MI , 49931

2 Nelson Mandela School of Public Policy, Southern University, Baton Rouge, LA, 70813
} 


\section{Introduction}

Increased public awareness of the threats posed by global warming has led to greater concern over the impact of anthropogenic carbon emissions on the global climate. The current level of carbon dioxide $\left(\mathrm{CO}_{2}\right)$ in the atmosphere is approaching $380 \mathrm{ppm}$ (Feely et al. 2004; Sabine et. al 2004). Without drastic market, technological, and societal changes $\mathrm{CO}_{2}$ concentrations are projected to increase to over $800 \mathrm{ppm}$ by the end of the century (Feely et al. 2004). The cement industry is the third largest source of $\mathrm{CO}_{2}$ emissions in the U.S. (United States Environmental Protection Agency [USEPA] 2004). Approximately 5\% of global carbon emissions originate from the manufacturing of cement, with roughly half of the $\mathrm{CO}_{2}$ originating from the calcining process while the remaining results from energy usage during the production process (Hendriks et al. 2000). The calcining process releases $\mathrm{CO}_{2}$ from the conversion of calcium carbonates to clinker at high temperatures. According to the International Energy Agency's (IEA) Greenhouse Gas R\&D Programme (Hendriks et al. 2000), cement production generates an average world carbon emission of $0.81 \mathrm{~kg} \mathrm{CO}_{2}$ per $\mathrm{kg}$ cement produced. While North America is not the largest cement producer it is one of the most carbon intensive, second only to India with $0.89 \mathrm{~kg} \mathrm{CO}_{2}$ generated per $\mathrm{kg}$ cement produced (Hendriks et al. 2000).

In addition to the generation of $\mathrm{CO}_{2}$, the cement manufacturing process produces millions of tons of the waste product cement kiln dust (CKD) each year. CKD consists of fine particles of unburned and partially burned raw material and clinker, as well as trace elements such as heavy metals and other contaminants (van Oss and Padovani 2002, 2003). These outputs ( $\mathrm{CO}_{2}$ and $\left.\mathrm{CKD}\right)$ stress the environment by contributing to global 
warming $\left(\mathrm{CO}_{2}\right)$ and present a respiratory and pollution health risk $(\mathrm{CKD})$ when improperly managed and disposed (USEPA 1994a, 1999a, 1999b).

Portland cement is the main binding ingredient of concrete and is composed largely of calcium, quartz, aluminum, iron, and gypsum (Portland Cement Association [PCA website1] and Van Oss and Padovani, 2002). Lime and silica comprise up to $85 \%$ of the final mass of cement. On average approximately one ton of concrete is produced each year for every human being in the world (Lippiatt and Ahmad 2004). Therefore concrete (i.e. cement) is one of the World's most significant manufactured materials. Because of it's abundance in the world market, understanding the environmental implications of concrete and cement manufacturing is becoming increasingly important (Lippiatt and Ahmad 2004, van Oss and Padovani 2002, 2003, Masanet et al. 2005). For globally important products such as cement, environmental life-cycle assessment (LCA) is a valuable tool for improving the understanding of the environmental hazards posed by a product's life stages, as well as helping companies to optimize the manufacturing process and reduce adverse environmental impacts.

\section{Background}

Life Cycle Assessment (LCA) is a method of evaluation to assess the environmental impacts of technologies from "cradle to grave" and may be performed on both products and processes. There are several benefits of LCA including ability to evaluate material and energy efficiency of a system, identifying pollution shifts between operations, and providing benchmarks for improvement (Ross et al. 2002, Owens 1997). The production of cement involves the consumption of large quantities of raw materials, energy, and heat. Cement production also results in the release of a significant amount of 
solid waste materials and gaseous emissions. The manufacturing process is very complex, involving a large number of materials (with varying material properties), pyroprocessing techniques (e.g. wet and dry kiln, preheating, recirculation; van Oss and Padovani 2002), and fuel sources (e.g., coal, fuel oil, natural gas, tires, hazardous wastes, petroleum coke; van Oss and Padovani, 2002). Therefore inventory analyses and complete LCAs can be quite complicated. The Portland Cement Association (PCA) has conducted life cycle assessments of products such as insulated foam concrete forms and blocks compared to traditional wood frame built construction (PCA website2). Although these types of analysis can be useful when comparing different construction materials (e.g., concrete forms versus wood frame), they do not provide information for reducing the environmental impact of cement manufacturing itself. Lippiatt and Ahmad (2004) conducted a combined environmental and economic life-cycle assessment of concrete using a Building for Environmental and Economic Sustainability (BEES) approach. In their analysis they examined the environmental life cycle and economic performance data of five (5) different concrete products (100\% portland cement, $20 \%$ limestone cement, Lafarge silica fume, Lafarge NewChem (50\%), and 35\% fly ash cement). The functional unit for their analysis was a concrete slab with a thickness required to create a 25 -ft span with a compressive strength of $21 \mathrm{MPa}$ (life $=50$ years). Their results indicate that while the limestone blend concrete examined might be more environmentally friendly on a mass by mass basis, more of the blended limestone cement was required to make an equivalent strength slab. The increased mass requirements of the limestone blend resulted in an overall performance score equal to the traditional or generic portland cement concrete. The other blended concretes examined had equivalent strength characteristics as 
generic concrete and therefore earned better environmental and economic performance scores than the traditional concrete product. In another study, Masanet et al. (2005) examined the life-cycle emissions of cement and concrete manufacturing by comparing the total estimated greenhouse gas (GHG) emissions from the manufacturing, use, and end-of-life stages to the annual operation of an equivalent number of automobiles. Their results indicate that the most significant environmental burden and GHG emissions result from the manufacturing of cement (comparing complete life cycle of concrete). Their study also suggest that the combined use of waste fuels, blended cements and the implementation of improved energy efficient technology can reduce GHG emissions from cement manufacturing by up to $11 \%$ (in California). Unlike the study by Lippiatt and Ahmad (2004), Masanet et al. (2005) estimate that the addition of limestone to portland cement (during the production of concrete) can reduce GHG emissions by up to 4\%. Improvements to the transportation and end-of-life processes had relatively little impact on the overall GHG emissions of the cement and concrete manufacturing processes (less than $2 \%$ combined).

While several life-cycle assessment studies have been conducted to examine the performance of different concrete products (e.g., Lippiatt and Ahmad 2004, Masanet et al. 2005), the life span, performance, and strength of these products greatly depend on their applications and end-uses. Because of the wide range of strength requirements (early and late), setting and curing times, and types of concrete applications (e.g., volume requirements, steel reinforcement requirements), comparative LCA between different concrete products is difficult and the extrapolation of these results to a variety of application types is limited. Therefore in an attempt to reduce uncertainty this manuscript 
presents a cradle-to-gate life cycle assessment of several cement products. Since cement manufacturing is the most energy and emission intensive process in the production of concrete, such a reduced scope analysis is reasonable.

\section{Manufacturing Process}

Traditional portland cement is composed primarily of calcium silicate minerals (refer to Table 4.1). The raw materials are quarried or mined and transferred to the manufacturing facility to be crushed and milled into a fine powder before entering the kiln. The materials are then mixed, preheated and placed in a large, rotary kiln where material temperatures reach greater than $1400{ }^{\circ} \mathrm{C}$ or until the materials fuse and form pellets called clinker (Environmental Roadmapping Initiative (ERI) 2004). The clinker is cooled and the excess heat is typically routed back to the pre-heater units. Prior to packaging, prescribed amounts of gypsum are added to the clinker to regulate setting time and the materials are sent to a finishing mill for grinding. The end product is a very finegrained mixture $(90 \% \cong 10$ micron) known as portland cement (ERI 2004).

\section{Table 4.1 Raw Material Composition of Clinker, the Primary Component of} Portland Cement (ERI 2004).

\begin{tabular}{|c|c|c|}
\hline Raw Materials & Sources & Mass Percent \\
\hline Lime & Limestone, shells, chalk & $60-67 \%$ \\
\hline Silica & Sand, fly ash & $17-25 \%$ \\
\hline Alumina & Clay, shale, fly ash & $2-8 \%$ \\
\hline Iron Oxide & Iron ore & $0-6 \%$ \\
\hline
\end{tabular}

\section{Blended Cements}

The amount of clinker needed to produce a given amount of cement can be reduced by the use of supplementary cementitious materials such as coal fly ash, slag, and natural pozzolans (e.g., rice husk ash and volcanic ashes; Neuwald 2004). The word "pozzolan" 
originates from a large deposit of volcanic ash produced by Mt. Vesuvius near Pozzuoli, Italy. The use of natural pozzolans dates back to ancient Greece where volcanic ash was incorporated with lime to produce mortars (Neuwald 2004). More recently industrial particulates captured with air-pollution control devices (e.g., fly ash, silica fume and blast furnace slag) have been used as supplementary cementitious materials. The addition of these materials into concrete not only reduces the amount of material landfilled (in case of industrials byproducts), but also reduces the amount of clinker required per ton of cement produced. Therefore, cement substitutes offer reduction in environmental impacts such as global warming and material costs of construction. The use of natural pozzolans could save contractors up to $25 \%$ per bag of cement (if the cement is blended and concrete mixed onsite), which can provide an economic benefit to the building of new infrastructure (Mihelcic et al. 2006). In developing countries such as the Philippines, where previous research has mapped natural pozzolans with socioeconomic and industrial indicators (Harris et al. 2005), pozzolanic (blended) cement could be an important technology for sustainable development.

Pozzolans chemically react with calcium hydroxide and water to form calcium silicate hydrates; strong binders that harden the concrete during the hydration of portland cement (Mihelcic et al. 2006). Compressive strength tests indicated that volcanic ash and rice husk ash could be safely substituted for portland cement up to $25 \%$ to create a concrete with similar strength (Mihelcic et al. 2006). Based on work done by Dodson (1988), Lippiatt and Ahmad (2004), and summarized in Helmuth (1987) the strength, durability, and life of certain blended cements such as those utilizing coal fly ash or natural pozzolans is equivalent to traditional general use portland cements within a 
substitution range of 25 to $60 \%$. As the extent of substitution (pozzolan for portland cement) increases (above approximately 35 to $50 \%$ depending on the use of the product), differences emerge in the strength and durability characteristics of the blended versus traditional cements. This analysis examines a substitution degree of $25 \%$ by weight, a ratio well within the range of comparable or equivalent life and durability.

\section{Recycling Cement Kiln Dust into Process Line}

Cement manufacturing produces a waste byproduct when $\mathrm{CO}_{2}$ is driven off carbonate minerals to form clinker. Cement kiln dust (CKD) contains 20 to $60 \%$ calcium oxide and is produced in vast quantities. A large portion of CKD is disposed of in landfills or stored in stockpiles on site. Van Oss and Padovani (2003) estimate that CKD generation rates equal approximately 15 to $20 \%$ (by mass) of clinker production. Most plants in the United States produce between 0.2 and 2 Mt of clinker each year (PCA 2003, van Oss and Padovani 2003). Some manufacturing facilities recycle their CKD (up to $67 \%$ ) into the raw material line entering the kiln. However the degree to which CKD can be recycled depends on its composition (trace metal and contaminants) and regional alkali standards (i.e., potential for alkali silica reactions (ASR) with aggregates), which varies widely within and between plants (van Oss and Padovani 2003, PCA 2003, Adams 1984, Helmuth et al. 1993). In this study the environmental benefit of recycling cement kiln dust back into the process line (prior to the kiln) is examined.

\section{Carbon Sequestration}

Cement kiln dust is a potential hazardous waste according to the EPA (1994a, 1999a, 1999b), in part because of the caustic nature and its potential to be a skin, eye, and respiratory irritant. In addition any contaminants from the raw materials and fuels tend to 
concentrate in CKD (van Oss and Padovani 2003). In the presence of water CKD has the potential to produce leachate with measurable amounts of heavy metals and other harmful substances. Both the environmental and health risks associated with CKD can potentially be reduced by reaction with $\mathrm{CO}_{2}$. Carbon dioxide reacts naturally with mineral and metal oxides to form stable mineral/metal carbonates; a process called mineral carbonation. Carbonation reactions however are typically very slow unless the reaction system is heated and/or placed under intense pressure, both of which require energy. The rate of carbonation can also be increased by a number of pre-processing techniques, the goal of which are to increase the reactive surface area of the oxide. However pre-processing also requires energy unless the oxide is already available in a powdered or fine-grained form. The large surface area (small particle size) and high calcium oxide content of CKD are for all intents and purposes "pre-processed" for sequestration without additional energy required. Based on stoichiometry and material composition, CKD generated within the U.S. has the potential to capture up to approximately 0.4 tons of $\mathrm{CO}_{2}$ per ton of $\mathrm{CKD}$ (Huntzinger et al. 2006b). In recent batch and column studies, CKD readily sequesters $\mathrm{CO}_{2}$ at ambient temperatures and pressures, with greater than $80 \%$ of the theoretical capacity for carbonation being achieved without amendments or modification to the waste (Huntzinger et al. 2006a, 2006b and Huntzinger and Gierke, 2006). As observed in the carbonation of other industrial wastes, sequestering of carbon in CKD may yield additional benefits by stabilizing the waste (reducing the $\mathrm{pH}$ ) which reduces health risks and the generation of harmful leachate (e.g., Huijgen and Comans 2005, Bertos et al., 2004, Eighmy et al. 1995). Because of its close composition to the finished saleable product (cement), disposal of CKD in landfills represents a loss in potential revenue. This 
study examines the potential benefits of utilizing the waste to capture back some of the process related carbon dioxide emissions.

In this life cycle assessment study the comparable global warming impact/potential of concrete is examined for four different cement manufacturing processes: (1) the production of traditional portland cement, (2) blended cement (natural pozzolans), (3) cement where $100 \%$ of waste cement kiln dust is recycled into the kiln process, and (4) portland cement produced when cement kiln dust (CKD) is used to sequester a portion of the process related $\mathrm{CO}_{2}$ emissions.

\section{Methods}

The LCA methodology used in this study follows the steps outlined by International Organization for Standards (ISO) 14040 (ISO, 1997), as well as those described by Allen and Shonnard 2002, Owens 1997, Curran 1996, and Hunt et al. 1992. The four major steps of the LCA applied in this study include:

1) Determination of the assessment scope and boundaries;

2) Selection of inventory of outputs and inputs;

3) Assessment of environmental impact data compiled in the inventory; and

4) Interpretation of results and suggestions for improvement.

\section{Goal and Scope of the Study}

Portland cement is the most common manufactured material in the world (PCA website1). It is generally produced in industrialized countries and exported to less developed countries. The goal of the study is to determine the impacts, specifically global 
warming potential, from the production of approximately 1 ton of cement by examining four products/processes:

(1) Traditional portland cement;

(2) Blended cement (natural pozzolans, fly ash);

(3) Portland cement when a portion of the process related emissions are captured back using sequestration in waste materials (CKD); and

(4) Portland cement when CKD is recycled back into the process.

The system boundaries for this LCA are shown in Figure 4.1. The scope of the project focuses on the raw material acquisition, processing, and product manufacturing stages. Each of the above products (1 through 4) has a life cycle, beginning with raw material extraction to the packaging and shipment of the finished product. Complete life cycle assessments also include the use and disposal stages of products. However, since the four products outlined above have relatively equal use and disposal impacts, these stages of the LCA are not examined in this study (Figure 4.2).

The overall scope of this study includes the stages outlined in Figures 4.1 through $\underline{4.3}$. Several of the processing stages have been combined to simplify the analysis and the calculation of inventory elements (refer to Figure 4.2 and Life-Cycle Inventory section). The functional unit of analysis in this study is the production of the equivalent of 20 bags (each bag $100 \mathrm{lbs}$ ) of general use Class I portland cement. Two hundred bags is approximately a ton of concrete, which is a convenient quantity often used in reporting of energy and material consumption as well as emissions. 


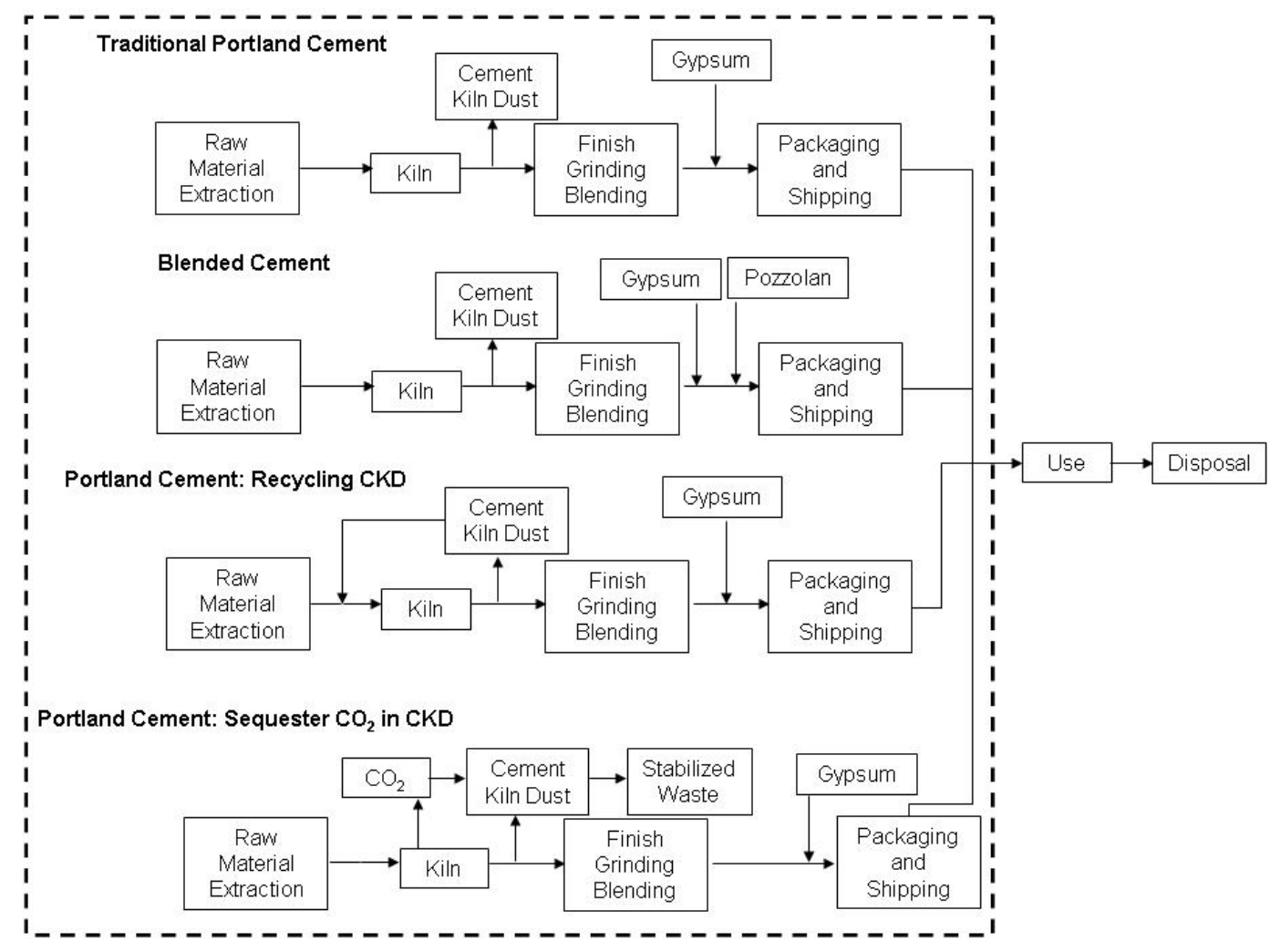

Figure 4.1 Scope of Comparative LCA for Cement Manufacturing Process. The Dashed Line Signifies the Boundaries of the System Examined.

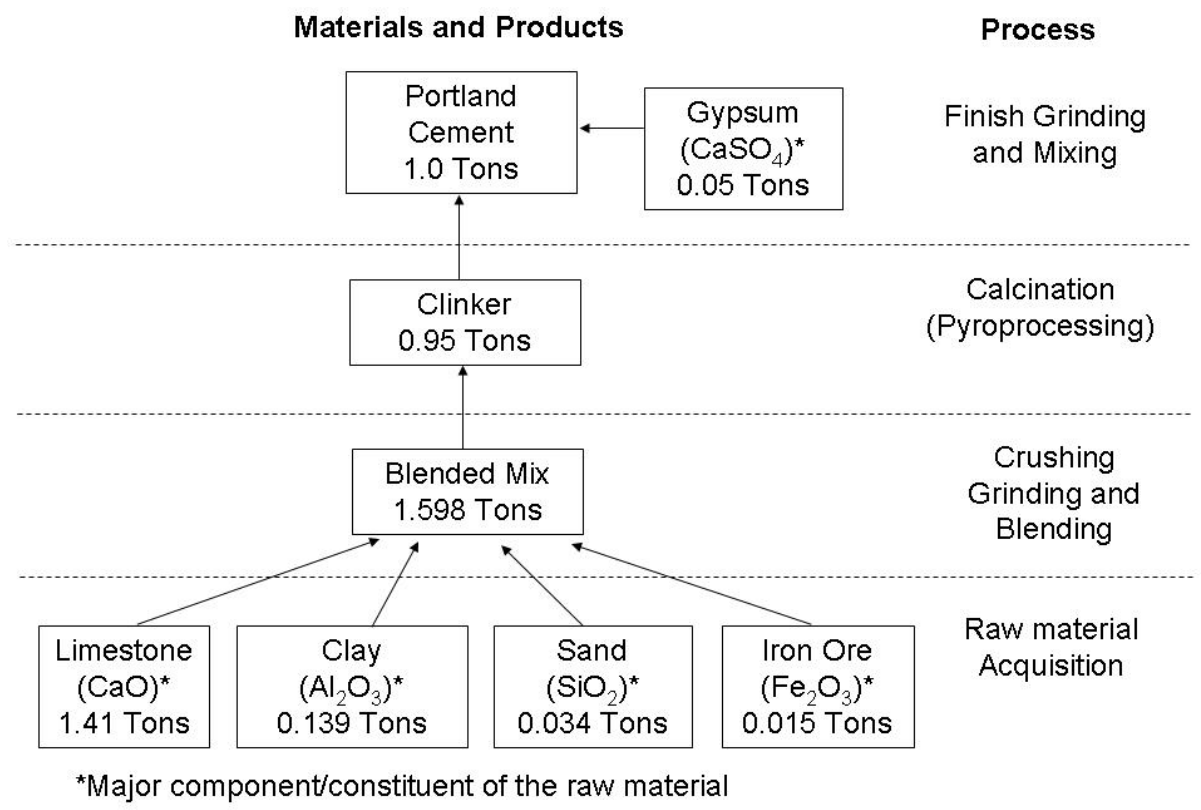

Figure 4.2 Material Flow Diagram for the Production of 1 Ton of Traditional Portland Cement (Adapted from Rundman (2003)). 


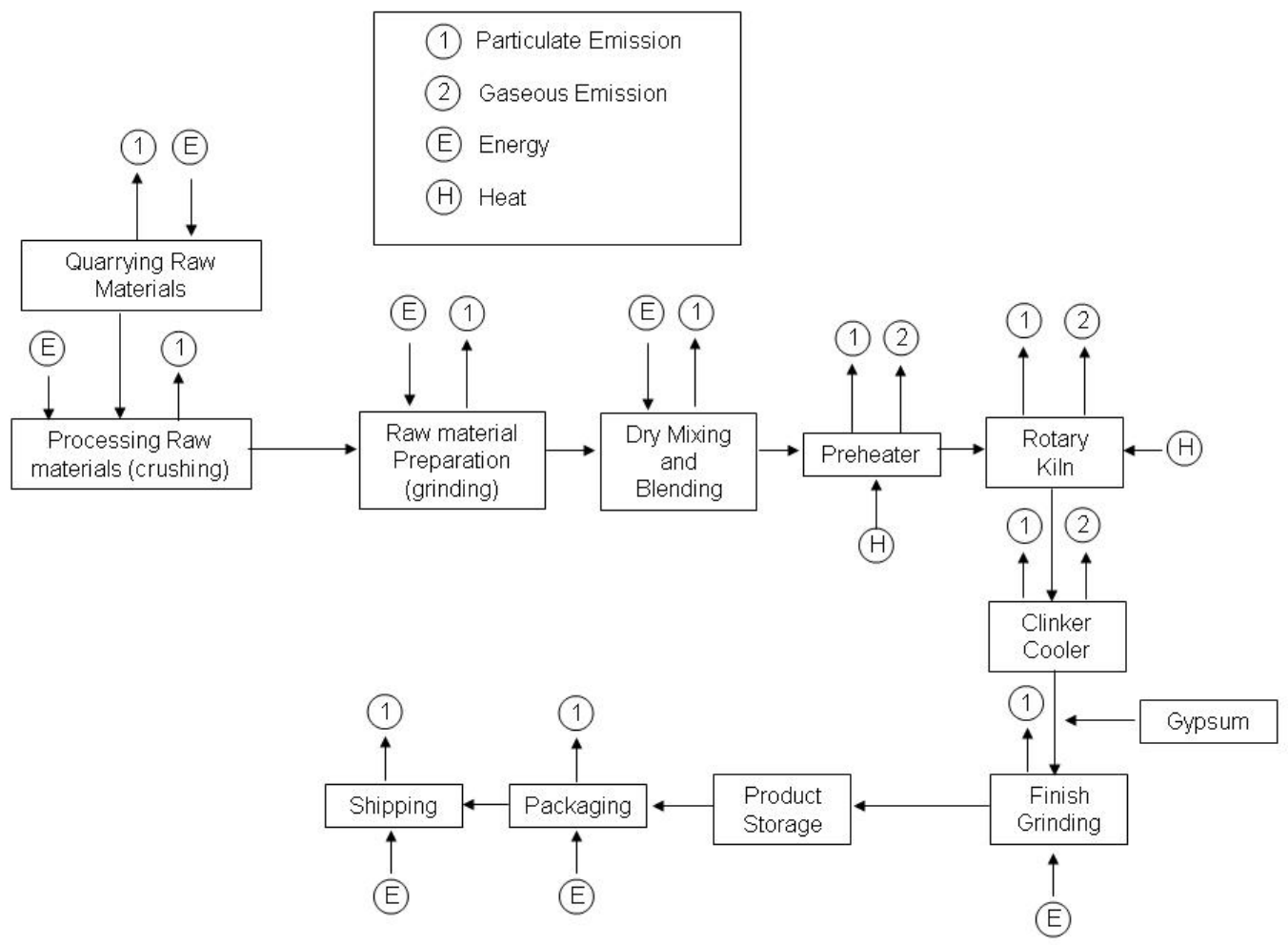

Figure 4.3 Process flow diagram for the cement manufacturing process, showing energy and heat consumption or inputs, as well as gaseous and particulate emissions (Adapted from EPA 1994b). Note that emissions at the preheating and kiln stages include both fugitive emissions and cement kiln dust or those particulates captured in controlled devices.

\section{Life Cycle Inventory}

The United States cement manufacturing industry produces approximately 79,500 $\mathrm{kMt}$ of clinker each year. On average 1.58 tons of raw materials are required to produce 0.95 tons of clinker or 1.0 tons of finished cement (refer to Figure 4.3 for a material flow diagram of the manufacturing process). Non-fuel raw material consumption can be broken down into 5 major components that provide: (1) calcium oxides, (2) aluminum oxides, (3) Silica, (4) Ferrous oxides, and (5) calcium sulfate (van Oss and Padovani 2002). In this assessment the raw materials and corresponding quantities outlined in Figure 4.3 are assumed to provide the necessary chemical balance for the kiln feed. 
$\underline{\text { Figures } 4.1}$ through $\underline{4.4}$ show the material acquisition, processing, and manufacturing steps considered along with the associated life cycle inventory (LCI) data for the four cement manufacturing processes/products of interest. The life-cycle assessment software SimaPro 6.0 was used to evaluate the environmental impacts of inventory elements and to create product assemblies and life cycles for the four different cement products. Inventory data for raw material acquisition (mining of limestone, sand, iron ore, and clay), along with electricity production and heat generation by fuel type for the various processing steps were obtained from the SimaPro libraries and databases. Although SimaPro has several eco-profiles for portland cement which account for all "cradle to gate" impacts cement manufacturing, a separate profile was created in order to compare the alternate manufacturing processes with a higher level of precision.

\section{Energy and Heat Input Data}

There is a wide range of energy related information available in SimaPro. A majority of cement kiln operations in the United States are powered (heated) by coal, coal and petroleum coke, and waste fuels/materials (Van Oss and Padovani 2002, 2003, Worrell et al. 2001, Jacott et al. 2003). However the specific blend of fuel sources depends heavily on the manufacturing facility and can include a unique ratio of fuel types including natural gas, fuel oil, tires, hazardous materials (van Oss and Padovani, 2002, 2003), and the more commonly used fuels listed above (refer to Table 4.2). Based on relative consumption (by fuel type) and information availability (in SimaPro), three major fuel sources were selected for inclusion in this study, along with assumed consumption by mass percent: coal (70\%), fuel oil (15\%), and natural gas (15\%). In addition, published values for energy usage by process step (Worrell et al. 2003) were applied to the selected 
fuel mixture to calculate the energy and electricity allocations for each manufacturing steps (Figure 4.4).

\section{$\underline{\text { Blended Cement Data }}$}

As discussed above, pozzolans refer to either natural or industrial materials rich in silica that react with lime (or portlandite) and water to form calcium silicate hydrates, a gel integral in the hardening process of cements. Within specific mass percentages pozzolans can be substituted for a portion of the clinker in final cement blends. In this study pozzolans are generically addressed and can refer to natural pozzolans such as volcanic ash or rice husk ash or to industrial wastes such as coal fly ash. Since these materials are either naturally occurring or an existing byproduct (i.e. waste) of another manufacturing process, they are not given an environmental benefit or penalty in this study. In other words they are considered benign inputs that have no associated environmental impact. This is a reasonable assumption since these products (e.g., fly ash, volcanic ash, rice husk ash) would be produced (naturally or otherwise) regardless of their inclusion in cement products. A more detailed study might include the environmental impact of acquiring the material (collection procedures, transportation, etc.), however such steps are most likely insignificant compared to the cement manufacturing steps considered in this study. In order to ensure an equivalent performing cement product (i.e. strength, durability, life) a substitution percentage of $25 \%$ (by mass) is assumed. This degree of substitution is commonly used for blended cements and is considered by Mihelcic et al. 2006 as an acceptable substitution percentage for retaining desired functionality. 


\begin{tabular}{|c|c|c|c|c|c|c|c|c|c|c|}
\hline \multicolumn{3}{|c|}{ Traditional Portland Cement } & \multicolumn{3}{|c|}{ Blended Pozzolanic Cement } & \multicolumn{2}{|c|}{ Portland Cement w/ Sequestration } & \multicolumn{3}{|c|}{ Portland Cement w/ Recycled CKD } \\
\hline Process: Crushing, grinding ar & d blending & & \multirow{15}{*}{\multicolumn{3}{|c|}{ Same as Portland Cement }} & \multirow{15}{*}{\multicolumn{2}{|c|}{ Same as Portland Cement }} & Process: Crushing, grinding ar & d blendin & \\
\hline Inputs & Mass & units & & & & & & Inputs & Mass & units \\
\hline Limestone & 1.41 & ton & & & & & & Limestone & 1.41 & ton \\
\hline clay & 0.139 & ton & & & & & & clay & 0.139 & ton \\
\hline & 0.034 & ton & & & & & & sand & 0.034 & ton \\
\hline iron ore & 0.015 & & & & & & & iron ore & 0.015 & ton \\
\hline energy (electricity) & & & & & & & & & 0.1 & ton \\
\hline coal & 0.224 & GJ & & & & & & \multicolumn{2}{|l|}{ energy (electricity) } & ton \\
\hline fuel oil & 0.048 & GJ & & & & & & coal & 0.224 & GJ \\
\hline natural gas & 0.048 & GJ & & & & & & fuel oil & 0.048 & GJ \\
\hline Outputs & & & & & & & & natural gas & 0.048 & GiJ \\
\hline emissions & & & & & & & & Outputs & & \\
\hline particulate matter & 0.01127 & Ibs & & & & & & $\begin{array}{c}\text { emissions } \\
\text { particulate matter }\end{array}$ & 0.01127 & lbs \\
\hline $\begin{array}{l}\text { Product } \\
\text { kiln feed }\end{array}$ & 1.598 & ton & & & & & & Product & & \\
\hline & & & & & & & & kiln feed & 1.598 & ton \\
\hline Process: Preheating and kiln & & & Process: Preheating an & & & Process: Preheating a & & Process: Preheating and kiln & & \\
\hline Inputs & Mass & units & \multirow{10}{*}{\multicolumn{3}{|c|}{ Same as Portland Cement }} & \multirow{10}{*}{\multicolumn{2}{|c|}{ Same as Portland Cement }} & Inputs & Mass & units \\
\hline KIIn reed energy (heat) & 1.598 & & & & & & & KIIn reed energy (heat) & 1.598 & \\
\hline & 3.23 & GJ & & & & & & & 3.23 & GJ \\
\hline fuel oil & 0.693 & GJ & & & & & & fuel oil & 0.693 & GJ \\
\hline natural gas & 0.693 & GJ & & & & & & natural gas & 0.693 & GJ \\
\hline Outputs & & & & & & & & Outputs & & \\
\hline $\begin{array}{l}\text { emissions } \\
\text { particulate matter }\end{array}$ & 0.02 & $\mathrm{~kg}$ & & & & & & $\begin{array}{c}\text { emissions } \\
\text { Darticulate matter }\end{array}$ & 0,02 & $\mathrm{~kg}$ \\
\hline carbon dioxide (process related) & 0.51 & ton & & & & & & carbon dioxide (process related) & 0.51 & ton \\
\hline & 0.1 & ton & & & & & & & & \\
\hline $\begin{array}{l}\text { Product } \\
\text { clinker }\end{array}$ & 0.95 & ton & & & & & & $\begin{array}{l}\text { Product } \\
\text { clinker }\end{array}$ & 0.95 & ton \\
\hline \multicolumn{3}{|c|}{ Process: Finish grinding and blending } & \multicolumn{3}{|c|}{ Process: Finish grinding and blending } & Process: Finish grind & d blending & \multicolumn{3}{|c|}{ Process: Finish grinding and blending } \\
\hline \begin{tabular}{|l} 
Inputs \\
\end{tabular} & Mass & units & Inputs & Mass & units & Inputs & Mass & \multirow{11}{*}{\multicolumn{3}{|c|}{ Same as Portland Cement }} \\
\hline clinker & 0.95 & ton & clinker & 0.7125 & ton & clinker & 0.7125 ton & & & \\
\hline gypsum & 0.05 & ton & gypsum & 0.0375 & ton & gypsum & 0.0375 ton & & & \\
\hline energy (electricity) & & & pozzolan & 0.848 & ton & $\mathrm{CO}_{2}$ sequestered & 0.06 ton & & & \\
\hline coal & 0.322 & GJ & energy (electricity) & & & energy (electricit) & & & & \\
\hline fuel oil & 0.069 & GJ & coal & 0.322 & GJ & coal & 0.322 GJ & & & \\
\hline natural gas & 0.069 & GJ & fuel oil & 0.069 & GJ & fuel oil & 0.069 GJ & & & \\
\hline & & & natural gas & 0.069 & GJ & natural gas & 0.069 GJ & & & \\
\hline Outputs emissions & & & Outputs & & & Outnuts & & & & \\
\hline particulate matter & 0.01195 & lbs & $\begin{array}{l}\text { emissions } \\
\text { particulate matter }\end{array}$ & 0.01195 & Ibs & $\begin{array}{l}\text { emissions } \\
\text { particulate matter }\end{array}$ & $0.01195 \mathrm{lbs}$ & & & \\
\hline $\begin{array}{l}\text { Product } \\
\text { portland cement }\end{array}$ & 1 & ton & $\begin{array}{l}\text { Product } \\
\text { portland/pozzolan mix }\end{array}$ & 1 & ton & $\begin{array}{l}\text { Product } \\
\text { sequestation/portland }\end{array}$ & 1 ton & & & \\
\hline
\end{tabular}

Figure 4.4 Inventory elements for the four major cement manufacturing processing steps. 
Table 4.2 Energy Consumption by Fuel Type in 2000 by the United States Cement Industry (from Jacott et al. 2003).

\begin{tabular}{|l|c|c|}
\hline Fuel Consumption & Amount / Year & Percentage of Total \\
\hline Coal (kMt) & 10,095 & 67 \\
\hline Coke (from coal) $(\mathrm{kMt})$ & 442 & 3 \\
\hline Petroleum Coke $(\mathrm{kMt})$ & 1,351 & 11 \\
\hline Fuel Oil (ML) & 124 & 1 \\
\hline Natural Gas $\left(\mathrm{Mm}^{3}\right)$ & 338 & 3 \\
\hline Tires (kMt) & 374 & 4 \\
\hline Other Solid Wastes (kMt) & 1,016 & 8 \\
\hline Liquid Waste (ML) & 929 & \\
\hline
\end{tabular}

\section{Carbon Sequestration in Cement Kiln Dust Data}

As stated previously the carbon intensity of cement manufacturing is approximately 1 ton of $\mathrm{CO}_{2}$ per ton of clinker produced (Hendriks et al. 2000, van Oss and Padovani 2002, 2003, PCA 2003). In addition to $\mathrm{CO}_{2}$, cement manufacturing produces approximately 0.10 to 0.20 tons of CKD per ton of clinker produced (van Oss and Padovani, 2002). For this analysis it is assumed that CKD can capture 0.4 tons of $\mathrm{CO}_{2}$ per ton of CKD (Huntzinger et al. 2006b). If the average rate of CKD production is 0.15 tons CKD per ton of clinker, and it is assumed that $100 \%$ of the waste is utilized for sequestration, then $\mathrm{CKD}$ has the potential to capture approximately 0.06 tons of $\mathrm{CO}_{2}$ for each functional unit (1 ton of finished product) in this study.

\section{$\underline{\text { Recycling Cement Kiln Dust Data }}$}

A majority of cement manufacturing facilities recycle a portion of their cement kiln dust (PCA 2003, van Oss and Padovani 2002, 2003). However as mentioned above the degree to which CKD is recycled is limited by the chemical composition of the waste. For comparison purposes this limitation is overlooked in this study and $100 \%$ recycling 
of CKD is assumed. Therefore all CKD generated (approximately 0.15 tons per ton of clinker) is recycled into the kiln feed, reducing the amount of raw materials required. The CKD has a comparable composition to clinker. Therefore all input amounts of raw material were decreased proportionally (each by $3.75 \%$ ) to account for the addition of 0.15 tons of CKD in the raw material feed.

\section{$\underline{\text { Packaging and Transportation Data }}$}

Information on the environmental impact from cement packaging and transportation steps (on a mass basis) was available in SimaPro and therefore utilized in this assessment.

\section{Results}

\section{Life Cycle Impact Assessment}

The environmental impacts of cement manufacturing can be local, regional, or global in scale. Local effects include noise, air quality, and natural disturbance (e.g., change in landscape, impacts to local ecosystem) of mining raw materials such as limestone, iron ore, and clay. Emissions such as sulfur dioxide $\left(\mathrm{SO}_{2}\right)$ and nitrogen oxides $\left(\mathrm{NO}_{\mathrm{x}}\right)$ contribute to acid rain on a regional scale. Carbon emissions originating from the calcining process and combustion of fossil fuels (e.g., coal, natural gas, fuel oil) contribute to global climate change. The focus of this analysis is global environmental impacts, particularly global warming, and how alternative cement mixes and or processing technologies impact the overall global warming potential of cement production.

The Eco-indicator95 in SimaPro was used to assess the environmental impact of the four cement products/processes. The production of clinker (pyroprocessing step) is the most energy intensive and emission intensive process in the manufacturing of cement 
(Figure 4.5), accounting for more than 80 to $85 \%$ of the overall environmental impact score. In addition, coal and fuel oil account for a majority of the fuel related environmental impacts.

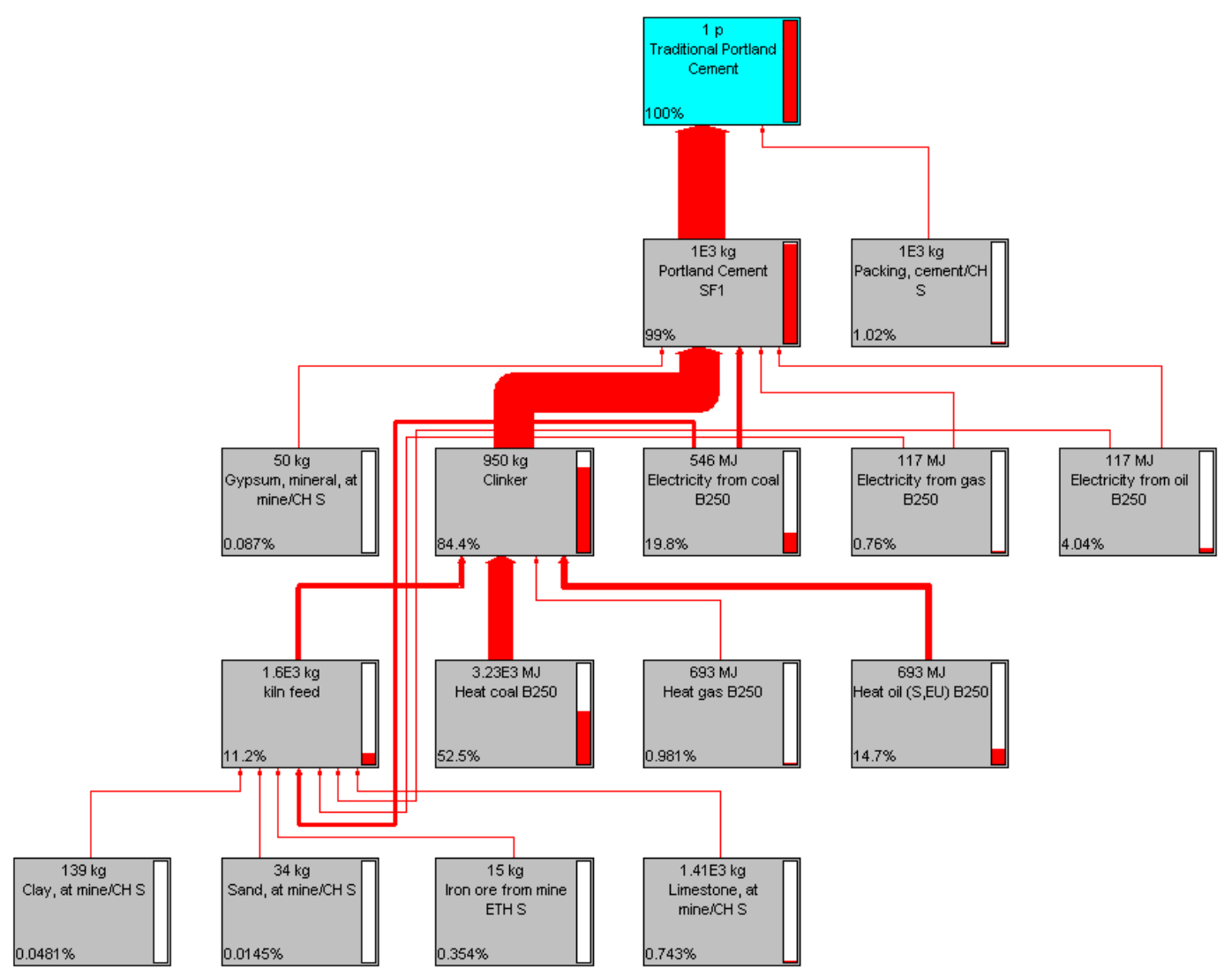

Figure 4.5 Life cycle network (cradle to gate) for traditional Portland Cement.

\section{Classification and Characterization}

The environmental impact score by impact categories for the four different cement products is shown below in Table 4.3. Of primary interest is the greenhouse or global warming potential of the traditional cement product versus the three (3) process/product alternatives. The primary greenhouse gas generated from the manufacturing cement is carbon dioxide $\left(\mathrm{CO}_{2}\right)$. As mentioned above approximately half of the carbon released 
during the manufacturing of cement originates from the calcining process (driving off $\mathrm{CO}_{2}$ from limestone to form clinker) and the remaining carbon results from the burning of fuels to fire the kiln and power the other manufacturing processes. Of the cement products examined, the blended cement has the lowest global warming or greenhouse potential followed by cement produced when a portion of the process related carbon emissions are captured back by sequestration in CKD. The recycling of CKD back into the kiln feed has little to no effect on reducing carbon emissions compared to traditional cement.

In the context of this LCA, the improvement of blended cements on global warming potential over traditional portland cement is to be expected. As discussed above the kiln or pyroprocessing step is the most energy and environmentally impact intensive stage of the manufacturing process. This results both from the energy requirements to heat the kiln (to above $1400^{\circ} \mathrm{C}$ ) and the carbon released during the calcining step. By reducing the demand for clinker (through substitution), the environmental impacts of the end cement product are reduced proportionately. What is not considered, however, is the current national and global supply and demand relationship for cement products. High demand and low imports of cement have led to shortages within the United States (Hagenbaugh 2004). Because many kilns are operating at or above their effective capacity (PCA 2004), the use of blended cements is not likely to reduce net emissions of $\mathrm{CO}_{2}$. Instead, blended cements will allow for an increase in concrete production without any real modification to the existing amounts of clinker or portland cement produced within the United States. 
Table 4.3 Classification of Process Inputs and Outputs for Portland Cement Manufacturing into Environmental Impact Categories.

\begin{tabular}{|c|c|c|c|c|}
\hline $\begin{array}{c}\text { Environmental } \\
\text { Impact Category }\end{array}$ & Traditional & Blended & $\begin{array}{c}\text { Recycled } \\
\text { CKD }\end{array}$ & $\begin{array}{c}\mathbf{C O}_{2} \\
\text { Sequestration }\end{array}$ \\
\hline Greenhouse & 0.088 & 0.069 & 0.088 & 0.084 \\
\hline Acidification & 0.043 & 0.034 & 0.043 & 0.043 \\
\hline Eutrophication & 0.006 & 0.005 & 0.006 & 0.006 \\
\hline Heavy Metals & 0.204 & 0.161 & 0.204 & 0.204 \\
\hline Carcinogens & 0.003 & 0.003 & 0.002 & 0.003 \\
\hline Winter Smog & 0.039 & 0.031 & 0.039 & 0.039 \\
\hline Summer Smog & 0.009 & 0.007 & 0.009 & 0.009 \\
\hline Energy Resources & 0.050 & 0.040 & 0.050 & 0.050 \\
\hline
\end{tabular}

The high impact scores for heavy metals and acidification are believed to be an artifact of the types of fuels selected and the incomplete representation of chemical interactions occurring in the kiln. For instance the actual sulfur dioxide emissions (major contributor to acid rain) are much lower than those predicted in SimaPro. The clinker and CKD serve as partial scrubbers for $\mathrm{SO}_{2}$, removing a significant portion of the sulfur oxides (greater than 70\%) in the combustion gases before they are released to the atmosphere (van Oss and Padovani, 2003). Actual fugitive emissions of $\mathrm{SO}_{2}$ equal approximately 0.27 and $0.54 \mathrm{~kg}$ per ton of clinker produced (van Oss and Padovani 2003, Jacott et al. 2003), compared to the $4.86 \mathrm{~kg}$ estimated by SimaPro. As for heavy metals, the lead $(\mathrm{Pb})$ content of the fuels selected (i.e. fuel oil) is assumed to be the source of the high heavy metal impact score. While heavy metals are released during the burning of many of the fuels typically used during the manufacturing of cement, as with sulfur dioxide $\left(\mathrm{SO}_{2}\right)$, metals tend to concentrate in both the cement kiln dust (primarily) and clinker (van Oss and Padovani 2003). Since the focus of this assessment was global warming potential or greenhouse impact, corrections for heavy metals and sulfur dioxide 
were not made. In the future for a more detailed analysis, such corrections should be included.

\section{Valuation and Recommendation}

The impact scores from the categories outlined in Table 4.3 can be weighted and combined in a single environmental impact score. The blended cement process has approximately three quarters of the environmental impact as the other three processes, including traditional portland cement (Impact Score $=2.0 \mathrm{pts}$ ). Based on the comparison conduction in this LCA, such a reduction is expected since the addition of natural pozzolans to the final mix replaces one quarter of the portland cement with an environmentally benign substitute (in terms of the system boundaries selected for the study). Substitution of pozzolans for clinker effectively reduces the heaviest environment impact process (the kiln or pyroprocessing step) by $21.6 \%$. But, as stated previously, this reduction assumes that clinker production would decrease due to the use of pozzolanic cements. Based on the current demand for concrete and cement productions, such a reduction in cement production is not likely and therefore, no real net reduction in $\mathrm{CO}_{2}$ emissions will be achieved (given the current capacity of U.S. cement manufacturing facilities).

The overall impact score for the cement manufacturing processes utilizing carbon sequestration in the waste product $\mathrm{CKD}$ is also lower than the traditional process. Even

through, sequestration only captures approximately $7 \%$ of carbon emissions (translating to approximately a $5 \%$ reduction in impact score over traditional portland cement) unlike the situation with pozzolanic cements, sequestration offers a real reduction in net $\mathrm{CO}_{2}$ emissions. Recycling CKD into the process line has little to no effect on the overall 
impact score. Since the CKD is recycled into the kiln feed there is no real reduction in emissions or energy required in the most environmentally damaging step, the kiln.

\section{Conclusion}

Mitigating sources of anthropogenic carbon emission will help to lower greenhouse gas levels globally. This study has addressed the relative savings associated with three alternative technologies for the cement manufacturing process. Environmental life-cycle assessment (LCA) is a valuable tool for understanding the environmental hazards of products and for optimizing the manufacturing process to reduce adverse environmental impacts. However there are limitations to the study and it should be noted that data aggregation problems associated with secondary information sources may cause variation in impact values for replication studies. Much of the absolute environmental impact will depend on energy and heat input amounts that vary between processes. Although the results of this LCA show that blended cements provide the greatest environmental savings, the reduction in GHG potential in blended over traditional cements might be an illusion given the current demand for cement and concrete products. The utilization of CKD for sequestration, however, appears to offers a real capture of carbon emissions, translating to a reduction in the environmental impact score of approximately $5 \%$ over the traditional portland cement. The CKD recycle process was found to have little environmental savings over the traditional process. 


\section{Reference Cited}

Adams, L.D., "Build-ups in Suspension Preheaters," Central Process Laboratory, Southwester Portland Cement Co., October, 1984.

Allen, D.T. and D.R. Shonnard, "Green Engineering: Environmentally Conscious Design of Chemical Processes, ” Upper Saddle River: Prentice Hall, 2002.

Bertos, M.F., S.J.R. Simons, C.D. Hills, and P.J. Carey, "A Review of Accelerated Carbonation Technology in the Treatment of Cement-Based Materials and Sequestration of $\mathrm{CO}_{2}$," Journal of Hazardous Materials, B112, pp. 193-205, 2004.

Curran, M.A, Environmental Life-Cycle Assessment, McGraw-Hill, 1996.

Dodson, V.H., "Low Cement/High Fly Ash Concretes: Their Properties and Response to Chemical Admixtures," Material Resource Society Symposium Proceedings, Vol $113,1998$.

Eighmy, T.T., J. D. Eusden, Jr., J. E. Krzanowski, D. S. Domingo, D. Stampfli, J. R. Martin, and P. M. Erickson, "Comprehensive approach toward understanding element speciation and leaching behavior in municipal solid waste incineration electrostatic precipitator ash," Environ. Sci. Technol., 29, pp. 629-646, 1995.

Environmental Roadmapping Initiative (ERI), "Cement Impacts, Risks, and Regulations," website: http://ecm.ncms.org/ERI/new/IRRcement.htm\#profile, last updated: August 10, 2004.

Feely R.A, C.L. Sabine, K. Lee, W. Berelson, J. Kleypas, V.J. Fabry, and F. J. Millero, "Impact of Anthropogenic $\mathrm{CO}_{2}$ on the $\mathrm{CaCO}_{3}$ System in the Oceans," Science, 305, pp.362-366, 16 July 2004.

Hagenbaugh, B., "Cement Weighs on Construction," USA Today, August 8, 2004.

Harris, R. A., T. Eatmon, C. Seifert, "Natural Pozzolans for Sustainable Development: Environmentally Friendly Concrete Technology," Southern University, $25^{\text {th }}$ Annual ESRI International User Conference, San Diego, California, July 2005

Helmuth, R., Fly Ash in Cement and Concrete, Portland Cement Association, 1987.

Helmuth, R., D. Stark, S. Diamond, and M. Moranville-Regourd, "Alkali-Silica Reactivity: An Overview of Research," Strategic Highway Research Program, National Research Council, SHRP-C-342, 1993.

Hendriks, C.A., E. Worrell, D. deJager, K. Block, and P. Riemer, "Emission Reduction of Greenhouse Gases from the Cement Industry," IEA Greenhouse gas R\&D Programme, http://www.ieagreen.org.uk/prghgt42.htm, 2000.

Huijgen, W.J.J. and R.N.J. Comans, "Carbon Dioxide Sequestration by Mineral Carbonation Literature Review Update 2003-2004," Energy Resource Center of the Netherlands, ECN-C-05-022, 2005.

Hunt, R.G., J.D. Sellers, and W.E. Franklin, "Resource and Environmental Profile Analysis: A Life Cycle Environmental Assessment for Products and Procedures," Environmental Impact Assessment Reviews, 12, 245-269, 1992. 
Huntzinger, D. N., J.S. Gierke, L.L. Sutter, S.K. Kawatra, T. C. Eisele, "Mineral Carbonation for Carbon Sequestration in Cement Kiln Dust Waste Piles," Journal of Hazardous Materials, in preparation, 2006a.

Huntzinger, D. N., J.S. Gierke, S.K. Kawatra, T. C. Eisele, and L.L. Sutter, "Carbon Dioxide Sequestration in Cement Kiln Dust through Mineral Carbonation." Environmental Science and Technology, in preparation, 2006b.

Huntzinger, D. N. and J.S. Gierke, "Effects of Vapor Transport and Particle-Scale Reaction Mechanisms on the Extent of Carbonation in Cement Kiln Dust," Environmental Science and Technology, in preparation, 2006.

International Organization for Standardization (ISO), "ISO 14040: Environmental management - life cycle assessment - principles and framework," 1997.

Jacott, M., F. Comunes, C .Reed, A. Taylor, and M. Winfield, "Energy Use in the Cement Industry in North America: Emissions, Waste Generation and Pollution Control, 1990-2001," Prepared for the Commission for Environmental Cooperation, $2^{\text {nd }}$ North American Symposium on Assessing the Environmental Effects of Trade, May 30, 2003.

Lippiatt, B., and S. Ahmad, "Measuring the Life-Cycle Environmental and Economic Performance of Concrete: The BEES Approach," International Workshop on Sustainable Development and Concrete Technology, Beijing, May 20-21, 2004.

Masanet, E., L. Price, S. de la Rue du Can, and R. Brown, "Reducing Greenhouse Gas Emissions from Products Manufactured in California," Second Annual Climate Change Research Conference, Sacramento, CA, September 14, 2005.

Mihelcic, J., T. Eatmon, H. Muga, R. A. Harris, "Engineering Sustainable Construction Materials for the Developing World: Consideration of Engineering, Societal, and Economic Issues," The International Journal of Engineering Education, to appear in special issue on sustainability, 2006.

Neuwald, A., "Supplementary Cementitious Materials, Part I: Pozzolanic SCMs, What are SCMs and How Can You Use Them to Your Advantage?" Manufactured Concrete, 8-16, September/October, 2004.

Owens, J.W., "Life Cycle Assessment: Constraints on Moving from Inventory to Impact Assessment," Journal of Industrial Ecology, 1(1), 37-49, 1997.

Portland Cement Association (PCA) website1: http://www.cement.org/basics/howmade.asp

Portland Cement Association (PCA) website2: http://www.cement.org/homes/brief12.asp

Portland Cement Association (PCA), "Cement Shortage Assessment," The Monitor, Flash Report: Breaking Analysis of the Economy, Construction, and Cement Industries, May 13, 2004.

Ross, S., D. Evans, M. Webber, "How LCA Studies Deal with Uncertainty," The International Journal of Life Cycle Assessment," 1, 47-52, 2002. 
Rundman, K., "Chapter 5: Material Flow in Industry,” Draft Chapter for Materials Book, Prentice Hall, never published: http://www.me.mtu.edu/ jwsuther/erdm/materials.pdf

Sabine, C.L., R.A. Feely, N. Gruber, R.M. Key, K. Lee, J.L. Bullister, R. Wanninkhof, C.S. Wong, D.W.R. Wallace, B. Tilbrook, F.J. Millero, T.H. Peng, A. Kozyr, T. Ono, and A.F. Rios, "The Oceanic Sink for Anthropogenic $\mathrm{CO}_{2}$," Science, 305, 367-371, 16 July 2004.

U.S. Environmental Protection Agency, "Report to Congress on Cement Kiln Dust," 59FR 709, January 6, 1994a.

U.S. Environmental Protection Agency, "Emission Factor Documentation for AP-42, Section 11.6: Portland Cement Manufacturing, Final Report," EPA Contract 68-D20159, MRI Project No. 4601-01, May 18, 1994b.

U.S. Environmental Protection Agency, "Management Standards Proposed for Cement Kiln Dust Waste," Environmental Fact Sheet, EPA 530-F-99-023, 1999a.

U.S. Environmental Protection Agency, "Standards for Management for Cement Kiln Dust, Proposed Rule," 64-FR 45632, Friday, August 20, 1999 b.

U.S. Environmental Protection Agency, "Inventory of U.S. Greenhouse Gas Emissions and Sinks," EPA 430-R-04-003, April 15, 2004.

Van Oss, H.G. and A.C. Padovani, "Cement Manufacture and the Environment, Part 1: Chemistry and Technology," Journal of Industrial Ecology, 6(1), 89-105, 2002a.

Van Oss, H.G. and A.C. Padovani, "Cement Manufacture and the Environment, Part II: Environmental Challenges and Opportunities," Journal of Industrial Ecology, 7(1), 93-127, 2002b.

Worrell, E., L. Price, N. Martin, C. Hendriks, and L.O. Meida, "Carbon Dioxide Emissions from the Global Cement Industry," Annu. Rev. Energy Environ., 26, 3033029, 2001. 


\section{APPENDIX I}




\section{The Feasibility of Carbon Emission Control Policies within the}

\section{United States}

By:

Deborah N. Huntzinger 


\section{Introduction}

Increased public awareness of the threats posed by global warming has led to greater concern over the impact of anthropogenic carbon emissions on the global climate. The current level of carbon dioxide $\left(\mathrm{CO}_{2}\right)$ in the atmosphere is approaching $380 \mathrm{ppm}_{\mathrm{v}}$ (Feely

et al. 2004; Sabine et. al 2004). Without societal, technological, and policy changes, $\mathrm{CO}_{2}$ concentrations are projected to increase to over $800 \mathrm{ppm}_{\mathrm{v}}$ by the end of the century (Feely et al. 2004). The primary source of anthropogenic carbon emissions is from burning fossil fuels. However, process related emissions from the manufacturing of products, such as cement, iron, steel, and aluminum contribute significant quantities of carbon to the atmosphere (USEPA 2005). Although the amount of carbon emissions vary by activity, industry, and region, the impacts of rising atmospheric $\mathrm{CO}_{2}$ (global warming) are world-wide.

Due to heightened concern over global warming, the regulation of $\mathrm{CO}_{2}$ emissions has become the focus of much debate (Dudek and LeBlanc 1990; Boyd et al. 1995; Stavins 1997; Keith and Parson 2000; Richards (pending)). Little, however, has been done in terms of policy enactment due to conflicting views on the need for regulation and the uncertainty surrounding the long-term impacts of climate change. Nevertheless, international consensus is building in support of carbon emission abatement and the stabilization of atmospheric $\mathrm{CO}_{2}$ to pre-1990 levels (i.e. Kyoto protocol). Therefore, more attention is being placed on determining the most effective and efficient domestic and international policy instruments for meeting future carbon emissions targets.

The purpose of this paper is to examine the positive and normative aspects of potential carbon emissions policies within the United States, as well as the social and 
economic implications of potential policy strategies. Examples are drawn from proposed multi-emission control legislation currently under review in Congress, as well as current emission control regulations, such as for $\mathrm{SO}_{2}$ and the phase-out of leaded gasoline during the 1980s. In addition, this paper examines the potential motivation and barriers of different climate change policy alternatives, specifically market-based approaches to reducing $\mathrm{CO}_{2}$ emissions. Social or Public Choice arguments, along with Collective Action problems are used to help explain the hesitancy of Congress and other political stakeholders in supporting market-based controls for $\mathrm{CO}_{2}$ emissions.

The scope of the paper is limited to greenhouse gas control and management measures at the Federal level within the United States. The application of emission regulations at the state and local level is not considered. In addition, although international polices are not directly considered, the impact of global regulatory and pollution actions on the potential success of domestic policies are discussed.

\section{Background}

The fundamental argument for environmental regulation within the United States has been to correct a market failure brought about by pollution. Pollution is a classical example of an externality, in which the impacts (either negative or positive) on a nonconsenting third party are the by-products of the production and/or consumption of goods (Weimer and Vining 2005). In an unconstrained market, pollution generators tend to externalize some of the cost of their production, releasing more pollution. The aggregate effect of these unconstrained emissions is an increase in pollution to socially inefficient ${ }^{12}$ levels (Stavins 1997; Revesz and Stavins 2004). In this context, both environmental

\footnotetext{
${ }^{12}$ The term efficient in this context refers to the maximizing the difference between social benefits and social costs.
} 
quality and public health are not taken into account in market decisions, warranting protection by the government. In an attempt to force industry to internalize more of the social costs of pollution (i.e. more of the full costs of their actions), the United States government has historically imposed technological or performance based standards on polluters in the form of "command-and-control" environmental regulations. However, economists have argued that this form of direct government control is not cost-effective (Coase 1960; Boyd et al. 1995; Stavins 1997; Revesz and Stavins 2004). They argue that market-based approaches (i.e. government subsidies, emissions taxes, or tradable permits) for controlling pollution are more efficient because they reduce overall transaction costs and may potentially increase overall social welfare.

The efficiency of a policy instrument (market or otherwise) may be irrelevant, however, if the policies are not feasible in the current political environment. In addition, the uncertainty surrounding the impacts of regulation, as well as the social and ecological benefits associated with reducing greenhouse gases complicates the debate over policy alternatives. Therefore, it is important to better evaluate both the motivations and barriers to future domestic carbon policies within the United States and to examine the feasibility of policy alternatives in the current political climate.

\section{Motivation for Government Involvement}

Pollution is frequently cited as a classic example of an externality. The solution to this externality problem is often to force companies or firms to internalize the full cost of their actions (Revesz and Stavins 2004). However, Coase (1960) argues that in the absence of transaction costs and third party impacts, private negotiations will lead to the maximization of social welfare, regardless of liability (Coase 1960; Revesz and Stavins 
2004). Therefore, according to Coase (1960) the real issue is maximizing the allocation of resources (socially), not who is liable. However, in cases of environmental pollution, most of the conditions for Coase's theorem (no transaction costs, private goods, no third party impacts, etc.) are invalid. In addition, Coase (1960) suggests that, from an efficiency point of view, it does not matter how a resource is allocated, as long as it is enforceable. From an equity or distributional stand point though, this does matter and organizations or groups may exert pressure politically to gain larger allocations (Weimer and Vining 2005). Therefore, some sort of government involvement is often necessary.

Although government action may be warranted to correct for externalities caused by pollution, there is no assurance that these regulations will improve social welfare and environmental quality (Revesz and Stavins 2004). The government may either under- or over-regulate and these regulations may trigger unexpected impacts. It becomes a sliding scale of sorts, in which one must determine the most effective and efficient degree of regulation. In the case of potential $\mathrm{CO}_{2}$ emissions regulations, the impacts of emissions caps are projected to be widespread across the economy (EIA 2000; 2003; 2004). Due to the lack of carbon specific emission control technology, it is unlikely that command-andcontrol type regulations are going to play a leading role in the reduction of $\mathrm{CO}_{2}$ emissions. It is more likely that the government will opt for a mandatory cap and trade system, allowing companies to determine how they will meet emissions targets. The economic and social impacts of a market-based approach to greenhouse emissions control (specifically $\mathrm{CO}_{2}$ ) can vary depending on the strategy that is used to implement the policy (discussed in more detail later). 


\section{Shift to Market-Based Approach}

With recent concern over the risks posed by global climate change, legislative officials are investigating the domestic policy alternatives for reducing $\mathrm{CO}_{2}$ and other greenhouse gas emissions. Market-based approaches, such as emission taxes, permits, and trading programs have received a majority of the attention. Historically, the United States government has used command-and-control measures in the form of technologyor performance-based regulations (Revesz and Stavins 2004, Schneider and Volkert 1999). Gradually, however, federal policy making is becoming more accepting of marketbased instruments, beginning in the 1970's when the EPA offered states the option of using tradable permits for controlling localized pollution (Stavins 2003). More notably, tradable permits were used in the 1980's to phase-out leaded gasoline and to facilitate the phase-out of ozone depleting aerosols such as chlorofluorocarbons (CFCs). The most significant switch to market-based strategies was in the 1990s, when the Clean Air Act was amended to control $\mathrm{SO}_{2}$ emissions through a permit and trading program (Joshua 1997; Burtraw et al. 2002; and Stavins 2003). Several factors may explain the increased support of market-based solutions over design and performance standards (Stavins 2003): (1) policy makers are questioning the increased abatement and administrative costs associated with the command-and-control regulation of emissions; (2) permitting and trading strategies result in an overall reduction in emissions, rather than a reallocation or redistribution among and across industries; and (3) with Republican control of the Congress and the Presidency, attention has shifted to the use of market-based policies to solve problems rather than increased governmental control. In addition, market-based solutions allow politicians to "separate the ends from the means." In other words, once an 
emissions target or goal is agreed upon, economists and politicians can focus on finding an acceptable, cost-effective means of achieving that goal (Stavins 2003). In the case of $\mathrm{CO}_{2}$ emissions control, the above factors weigh heavily on the decision-making process because politicians are dealing with a clean-slate so to speak. Because $\mathrm{CO}_{2}$ is currently unregulated, there are no constituencies fighting for an existing regulatory approach (Stavins 2003). This may be less of a factor in the case of multi-emission control bills that include pollutants already targeted under the Clean Air Act (like $\mathrm{SO}_{2}$ and $\mathrm{NO}_{\mathrm{x}}$ ).

\section{Nature of the Problem}

To understand the need for policy strategies to address greenhouse gas emissions, one must understand the nature of the problem. The surface temperature of the Earth is regulated by natural greenhouse gases (GHG), such as water vapor, carbon dioxide $\left(\mathrm{CO}_{2}\right)$, nitrogen oxide $\left(\mathrm{NO}_{2}\right)$, and methane $\left(\mathrm{NH}_{4}\right)$. Sunlight is reflected off the Earth's surface in the form of infrared radiation (heat). Greenhouse gases absorb this terrestrial radiation, "trapping" heat in the atmosphere (NEIC 2004). Over time, the amount of energy sent from the sun to the Earth's surface should be about equal the amount of energy radiated back into space (EIA 2004, EPA 2005). However, changes in the concentration of greenhouse gases can alter this energy balance among land, oceans, atmosphere, and space. Holding other components constant, increases in the atmospheric concentration of greenhouses gases can increase the amount of radiation absorbed and "held" in the Earth's atmosphere, raising global temperatures (i.e. global warming) (USEPA 2005). Natural processes, such as plant growth and decay, volcanic activity, and rock weathering regulate greenhouse gases to the atmosphere. Additional quantities of GHG, however, are being added due to anthropogenic activities, resulting in positive and 
negative feedback effects on the Earth's natural systems (Falkowski et al. 2000; Feely et al. 2004; Sabine et al. 2004; Field and Raupach 2004; EPA 2005). The result has been an increase in atmospheric $\mathrm{CO}_{2}$ concentrations of approximately $100 \mathrm{ppm}_{\mathrm{v}}\left(280 \mathrm{ppm}_{\mathrm{v}}\right.$ to 380 $\mathrm{ppm}_{\mathrm{v}}$ ) since the start of the industrial revolution (Feely et al. 2004; EPA 2005). The Earth has not seen $\mathrm{CO}_{2}$ concentrations of this magnitude in at least the last 430,000 years (Pedit et al. 1999) and likely not in the last 20 million years (IPCC 2001). Moreover if current emission patterns remain the same, $\mathrm{CO}_{2}$ concentrations are projected to double by the end of the century (Feely 2004). Although other greenhouse gases, such as methane, trap more heat per molecule than carbon (i.e. higher Global Warming Potential (GWP) $)^{13}$, aside from water vapor, $\mathrm{CO}_{2}$ is the most abundant of the greenhouse gases and is the biggest contribution to the enhanced greenhouse effect ( 70\%) (IPCC 2001).

\section{Carbon Emissions}

Carbon dioxide $\left(\mathrm{CO}_{2}\right)$ is naturally cycled among the Earth's atmospheric, oceanic, and terrestrial systems in a process called the "carbon cycle". Therefore, the fate of $\mathrm{CO}_{2}$ in the atmosphere is function of complex geochemical and biological processes (EPA 2005). While industrial activity and changes in land-use patterns have had a notable influence on atmospheric $\mathrm{CO}_{2}$ concentrations, the largest source of anthropogenic carbon emissions is from fossil fuel combustion. The burning of carbon-based fuels accounts for approximately $80 \%$ of GWP weighted emissions (EPA 2005, IPCC 2001). Table A-1

\footnotetext{
${ }^{13}$ Global Warming Potentials (GWPs) allow for the comparison of the total cumulative warming effects of different greenhouse gases over a specified time. GWP is an index that approximates the time-integrated warming effect of a unit mass of a given greenhouse gas in today's atmosphere relative to that of carbon dioxide. The warming effect of carbon dioxide is assigned a value of 1 and the warming effects of other gases are calculated as multiples of this value. The carbon dioxide equivalent of a non-carbon dioxide gas is calculated by multiplying the mass of the emission of the non-carbon dioxide gas by its GWP (EPA 2005; IPCC 2001).
} 
summarizes U.S. anthropogenic $\mathrm{CO}_{2}$ emissions by source in units of teragrams of $\mathrm{CO}_{2}$ equivalents ( $\mathrm{Tg} \mathrm{CO}_{2}$ Eq.). In 2003, total $\mathrm{CO}_{2}$ emissions grew to 5,841.5 $\mathrm{Tg} \mathrm{CO}_{2}$ Eq., an increase of approximately 15 percent (18\% in the energy sector) over 1990 values. According to the EPA (2005), rising emissions are a result of our growing economy's demand for fuel, as reflected by significant increases in electricity generation and transportation activities. In addition, increasing natural gas prices over the last decade have caused some electric providers to switch to burning coal, a more carbon intensive fuel source (EPA 2005). Tables A-2 and $\underline{\mathrm{A}-3}$ break $\mathrm{CO}_{2}$ emissions from fossil fuel combustion down by fuel type and by the four major end-use sectors (transportation, industrial, commercial, and residential) contributing to $\mathrm{CO}_{2}$ emissions. The level of $\mathrm{CO}_{2}$ emissions from fuel combustion are affected by numerous long- and short-term factors, including economic growth (mentioned above), population growth, energy price fluctuations, technological modifications (including efficiency), consumer behavior, and seasonal temperature variations (State Department 2002). Energy-related $\mathrm{CO}_{2}$ emissions are also a function of the type of fuel consumed (i.e. coal, natural gas, petroleum; Table A-3) and that fuel's carbon intensity.

Non-energy related industrial activities also produce a significant quantity of processrelated $\mathrm{CO}_{2}$ emissions through the transformation of raw materials (EPA 2005). Of these industrial activities, cement manufacturing and iron and steel production are the most carbon intensive (Table 1). Emissions also result from fossil fuel consumption in end-use sectors such as the manufacturing of solvents, lubricants, and plastics, where carbon emissions are released during the manufacturing process, as well as during a product's lifetime (i.e. solvent use; EPA 2005). 
Table A-3. United States Carbon Dioxide Emissions $\left(\mathrm{CO}_{2}\right)$ from Fossil Fuel Combustion by End-Use Sector (Tg $\mathrm{CO}_{2}$ Eq.); Data Source: EPA (2005).

\begin{tabular}{|c|c|c|c|}
\hline $\mathrm{CO}_{2}$ Source & 1990 & 2000 & 2003 \\
\hline Transportation $^{l}$ & 1449.80 & 1741.00 & 1770.40 \\
\hline Combustion & 1446.80 & 1737.70 & 1767.20 \\
\hline Electricity & 3.00 & 3.40 & 3.20 \\
\hline Industrial $^{2}$ & 1553.90 & 1684.40 & 1572.90 \\
\hline Combustion & 882.80 & 905.00 & 858.60 \\
\hline Electricity & 671.10 & 779.40 & 714.30 \\
\hline Residential $^{3}$ & 924.80 & 1124.20 & 1168.90 \\
\hline Combustion & 339.60 & 379.10 & 385.10 \\
\hline Electricity & 585.30 & 745.00 & 783.80 \\
\hline Commercial $^{3}$ & 755.10 & 959.50 & 983.10 \\
\hline Combustion & 224.20 & 235.20 & 234.00 \\
\hline Electricity & 530.90 & 724.30 & 749.20 \\
\hline U.S. Territories ${ }^{4}$ & 28.00 & 35.90 & 56.20 \\
\hline Total $\mathrm{CO}_{2}$ & 4711.60 & 5545.00 & 5551.50 \\
\hline \multicolumn{4}{|c|}{$\begin{array}{l}1 \text { Almost all energy consumption is petroleum based: } 2 / 3 \text { is attributed to gasoline consumption in } \\
\text { automobiles, and the remaining } 1 / 3 \text { is related to consumption of diesel fuel (trucking) and jet } \\
\text { fuel for aircraft. } \\
{ }^{2} \text { Steam and process heat generation account for approximately one half of fuel consumption, } \\
\text { while the remaining half is associated with electricity consumption for motors, heating systems, } \\
\text { ovens and lighting. Industrial sector includes manufacturing, construction, mining and } \\
\text { agriculture. }\end{array}$} \\
\hline \multicolumn{4}{|c|}{$\begin{array}{l}{ }^{3} \text { Residential and commercial sectors are heavily reliant on electricity for lighting, heating, air } \\
\text { conditioning, and operating appliances. About } 30 \% \text { of consumption can be attributed to direct } \\
\text { use of gas and petroleum products for heating and cooking. } \\
{ }^{4} \text { There is a lack of specific end-use consumption data for the U.S. Territories }\end{array}$} \\
\hline
\end{tabular}

\section{Existing Emissions Regulations and Policy}

In 1992, the United States signed the United Nations Framework Convention on Climate Change (UNFCCC) that calls for the "stabilization of greenhouse gas concentrations in the atmosphere at a level that would prevent dangerous anthropogenic interference with the climate system. Such a level should be achieved within a time-frame sufficient to allow ecosystems to adapt naturally to climate change, to ensure that food 
production is not threatened and to enable economic development to proceed in a sustainable manner" (IPCC 1994). Countries party to the convention are required to develop, and periodically publish, national inventories of anthropogenic greenhouse gas emissions and sinks not covered under the Montreal Protocol (ozone depleting pollutants) (IPCC 1994). The U.S. Environmental Protection Agency (EPA), in conjunction with other federal and state agencies, is charged with preparing the Nation's greenhouse gas inventory for the UNFCC. For the most part, the EPA relies on published activity and emission factor data, which relate quantities of emissions to an activity (EPA 2005). The EPA's 2005 inventory report is the source of the $\mathrm{CO}_{2}$ emissions data presented above.

Since 2000, there have been several attempts to pass energy- and climate-related legislation at the national level (Figure A-1). However, these multi-pollutant control bills have had a difficult time in Congress and the United States has yet to adopt regulations mandating control of greenhouse gas emissions. These recent legislative efforts have been ignited by President Bush's rejection of the Kyoto Protocol. In justification of their actions, the Bush administration argued that the established emissions targets (in Kyoto) would be too costly to the U.S. economy. In addition, Bush said that the Kyoto Protocol was "not sound policy" and "the emissions targets are not scientifically based or environmentally effective, given the global nature of greenhouse gas emissions and the Protocol's exclusion of developing countries from its emissions limitation requirements" (State Department 2001). As an alternative, the President announced his National Energy Policy (in May 2001), as well as two initiatives to advance science and technological development related to climate change (Figure A-1). President Bush's Energy Policy calls for the promotion of energy efficiency and conservation and "the reduction of 
greenhouse gas emissions through the use of alternative, renewable, and advanced forms of energy." The policy recommends the use of tax incentives to promote the development and use of renewable and alternative energy sources, as well as the development of a market-based pollution strategy to significantly reduce sulfur dioxide $\left(\mathrm{SO}_{2}\right)$, nitrogen oxides $\left(\mathrm{NO}_{\mathrm{x}}\right)$, and mercury $(\mathrm{Hg})$ emissions from electric power generators (State Department 2001).

1992

US signed the UN Framework Convention on Climate Change (UNFCCC) which requires signatony countries to periodically publish inventories of sources and sinks. anthropogenic $G H G$ emission

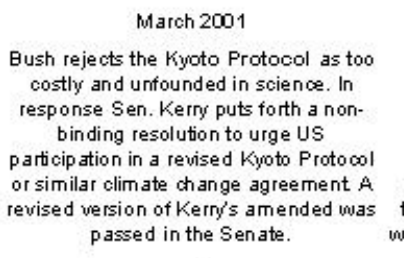

March 2001

Bush rejects the Kyoto Protocol as too costly and unfounded in science. In response Sen. Kerny puts forth a nonbinding resolution to urge US particip ation in a revised Kyoto Protocol or similar climate change agreement A revised version of Kern's amended was passed in the Senate.
parion of Kern's amended was thic 1997

Bard-Hazel Resolution: a nonbinding measure which discouraged U.S. participation in any dimate treaty which either: (1) imposed new commitments upon the developed world without requiring the same of the developing world; or (2) might seriously harm the U.S. economy.

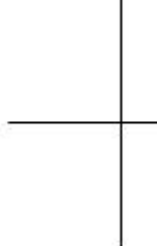

1992

Section 1605(b) of the Energy Policy Act Reporting of Greenhouse Gases Program established the Voluntany

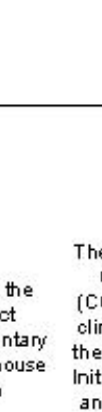

2001

The Bush administration announces its U.S. Climate Change Research Initiative (CCRI) to support study in are as related to climate change science. They also created the National Cli mate Change Technology Initiative (CCTI) to compliment to the CCRI and promote dimate change-related $R \& D$. The CCTI also indudes tax incentives to encourage the development and use of more energy-efficient and renewable technologies
2003

Bush administration proposes amendments to the Clean Air Act through the Clear Skes Initiative. which seeks to reduce $G \mathrm{HG}$ intensity by capping $\mathrm{SO}_{2}, \mathrm{NO}_{2} \& \mathrm{Hg}$ emissions from electric power generation and allowing for emissions trading among emissions 2002

Senate passes amendments to the Energy Policy Act which indudes provisions for mandatony reporting of GHG emissions companies.
March 2003

The Clean Ajr Plaping Acti Carper mhich nould impose a emissions cap and trading program on $\mathrm{SO}_{2}, \mathrm{NO}_{2}$ $\mathrm{Hg} . \& \mathrm{CO}_{2}$

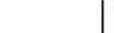

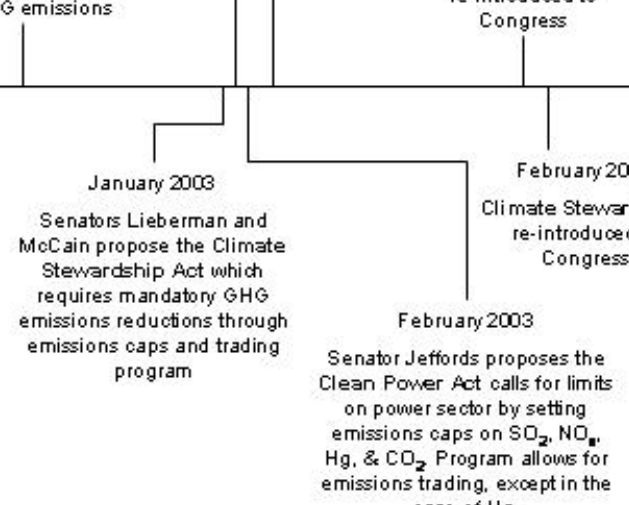

case of $\mathrm{Hg}$.

Figure A-1. Timeline of Major Greenhouse Gas Initiatives and Legislation in the United States over Last Decade.

The Bush administration's lack of consideration of $\mathrm{CO}_{2}$ emissions in their energy proposal sparked the creation of several legislative measures calling for regulation of $\mathrm{CO}_{2}$ emissions, in addition to several other key greenhouse gases, beginning with the Climate 
Stewardship Act proposed by Senators Lieberman and McCain in January of 2003. The Climate Stewardship Act offered a market-based approach including emission caps and tradable allowances to reduce emissions of six greenhouse key greenhouse gases $\left(\mathrm{NO}_{\mathrm{x}}\right.$, $\mathrm{CO}_{2}, \mathrm{NH}_{4}$, hydrofluorocarbons (HFC), perfluorocarbons (PFC), and sulfur hexafluoride (SHF)). The bill covered approximately 75 percent of direct greenhouse emissions $(90 \%$ of $\mathrm{CO}_{2}$ emissions) within the United States ${ }^{14}$. The goal of the Climate Stewardship Act was to bring U.S. emissions down to near 1990 levels by the year 2016 (EIA 2003). Three other market-based emission regulations were brought to Congress on the heels of the Climate Stewardship Act: The Clear Skies Act (Bush administration, No $\mathrm{CO}_{2}$ controls); the Clean Power Act (Senator Jeffords); and the Clean Air Planning Act (Senator Carper) (Figure A-1). All three bills proposed a mandatory cap and trading system similar to the Climate Stewardship Act. However, they differed in stringency, compliance strategy, and the types of pollution controlled (Table A-4). While the Climate Stewardship Act targeted emissions from the industrial, commercial, and energy sectors, the other three legislations were designed to only reduce emissions from energy sector sources. The argument behind this selective targeting was that electric-generating facilities contribute a significant portion of the overall greenhouse gas emissions within the United States (Goodwin Proctor 2003). Figure A-2 presents the projected emissions reductions in the energy sector under the Clear Skies Act, Clean Power Act, and Clean Air and Planning Act, based on their long-term emissions targets.

\footnotetext{
${ }^{14}$ Covered sources include the commercial, industrial, and energy sector that produce greenhouse gas emissions exceeding 10,000 $\mathrm{Tg} \mathrm{CO}_{2}$ Eq., The bill also covers the transportation sector and the producers and importers of high GWP gases (EIA 2003).
} 
Table A-4. Different Compliance Strategies of the Climate Stewardship Act, Clean Power Act, Clear Skies Act, and Clean Air Planning Act all submitted to Congress in 2003.

\begin{tabular}{|c|c|c|c|c|c|c|c|c|}
\hline Act \& Pollutants Covered & 仓̊ํํ & 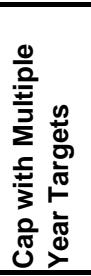 & 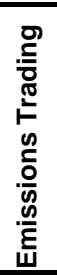 & 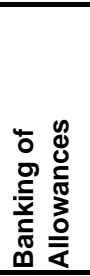 & 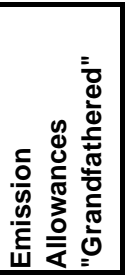 & 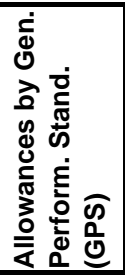 & 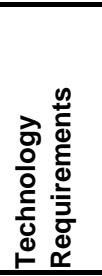 & 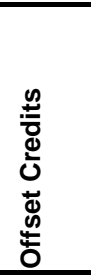 \\
\hline \multicolumn{9}{|l|}{ Climate Stewardship Act ${ }^{\mathrm{a}}$} \\
\hline \multirow{6}{*}{$\begin{array}{r}\text { Nitrogen Oxides }\left(\mathrm{NO}_{\mathrm{x}}\right) \\
\text { Methane }\left(\mathrm{CH}_{4}\right) \\
\text { Carbon Dioxide }\left(\mathrm{CO}_{2}\right) \\
\text { Hydrofluorocarbons }(\mathrm{HFC}) \\
\text { Perfluorocarbons }(\mathrm{PFC}) \\
\text { Sulfur Hexafluoride }\left(\mathrm{SF}_{6}\right) \\
\end{array}$} & & $\checkmark$ & $\checkmark$ & $\checkmark$ & & $\checkmark$ & & $\checkmark$ \\
\hline & & $\checkmark$ & $\checkmark$ & $\checkmark$ & & $\checkmark$ & & $\checkmark$ \\
\hline & & $\checkmark$ & $\checkmark$ & $\checkmark$ & & $\checkmark$ & & $\checkmark$ \\
\hline & & $\checkmark$ & $\checkmark$ & $\checkmark$ & & $\checkmark$ & & $\checkmark$ \\
\hline & & $\checkmark$ & $\checkmark$ & $\checkmark$ & & $\checkmark$ & & $\checkmark$ \\
\hline & & $\sqrt{\checkmark}$ & $\checkmark$ & $\checkmark$ & & $\checkmark$ & & $\checkmark$ \\
\hline \multicolumn{9}{|l|}{ Clean Power Act $^{\mathrm{b}}$} \\
\hline \multirow{4}{*}{$\begin{array}{r}\text { Nitrogen Oxides }\left(\mathrm{NO}_{x}\right) \\
\text { Sulfur Dioxide }\left(\mathrm{SO}_{2}\right) \\
\text { Mercury }(\mathrm{Hg}) \\
\text { Carbon Dioxide }\left(\mathrm{CO}_{2}\right)\end{array}$} & $\checkmark$ & & $\checkmark$ & $\checkmark$ & & $\checkmark$ & $\checkmark$ & \\
\hline & $\checkmark$ & & $\checkmark$ & $\checkmark$ & & $\checkmark$ & $\checkmark$ & \\
\hline & $\checkmark$ & & & $\checkmark$ & & $\checkmark$ & $\checkmark$ & \\
\hline & & $\checkmark$ & $\checkmark$ & $\checkmark$ & & $\checkmark$ & $\checkmark$ & \\
\hline \multicolumn{9}{|l|}{ Clear Skies Act ${ }^{\mathrm{c}}$} \\
\hline \multirow{3}{*}{$\begin{array}{r}\text { Nitrogen Oxides }\left(\mathrm{NO}_{x}\right) \\
\text { Sulfur Dioxide }\left(\mathrm{SO}_{2}\right) \\
\text { Mercury }(\mathrm{Hg})\end{array}$} & & $\checkmark$ & $\checkmark$ & $\checkmark$ & $\checkmark$ & & $\checkmark$ & \\
\hline & & $\checkmark$ & $\checkmark$ & $\checkmark$ & $\checkmark$ & & $\checkmark$ & \\
\hline & & $\checkmark$ & $\checkmark$ & $\checkmark$ & $\checkmark$ & & $\checkmark$ & \\
\hline \multicolumn{9}{|l|}{ Clean Air Planning Act ${ }^{d}$} \\
\hline \multirow{2}{*}{$\begin{array}{r}\text { Nitrogen Oxides }\left(\mathrm{NO}_{\mathrm{x}}\right) \\
\text { Sulfur Dioxide }\left(\mathrm{SO}_{2}\right)\end{array}$} & & $\checkmark$ & $\checkmark$ & & & $\checkmark$ & & $\checkmark$ \\
\hline & & $\checkmark$ & $\checkmark$ & & $\checkmark$ & & & $\checkmark$ \\
\hline \multirow{2}{*}{$\begin{array}{r}\text { Mercury }(\mathrm{Hg}) \\
\text { Carbon Dioxide }\left(\mathrm{CO}_{2}\right)\end{array}$} & & $\checkmark$ & $\checkmark$ & & & $\checkmark$ & & $\checkmark$ \\
\hline & & $\checkmark$ & $\checkmark$ & & & $\checkmark$ & & $\checkmark$ \\
\hline \multicolumn{9}{|c|}{$\begin{array}{l}\text { aBill covers energy, transportation, and industrial sectors. The proposed act would allow companies to offset up to } 15 \% \text { of } \\
\text { their emissions, with qualified reductions in sectors not covered under the bill (such as agriculture) or by purchasing } \\
\text { allowances from another country with a similar cap and trade system. A portion of allowances would be povided free to } \\
\text { producers based on GPS. The remaining allowances are sold through a Credit Corporation. }\end{array}$} \\
\hline \multirow{2}{*}{\multicolumn{9}{|c|}{$\begin{array}{l}\text { bBill covers energy sector only. The proposed act includes a "birthday" provision that requires all plants to have the best } \\
\text { available technology (BACT) (MACT for mercury) beginning in } 2014 \text { or when they reach } 40 \text { years of age (whichever comes } \\
\text { first). Initially, ten percent of emission allowances will be distributed using GPS. The remainder will be allocated } \\
\text { "downstream" and can be purchased by "upstream" sources. In addition, the bill allows for only partial banking of existing } \\
\text { allowances. } \\
\text { 'Bill covers energy sector only. The proposed act absolves power plants who are affected by the multi-pollutant emissions } \\
\text { caps under the Clean Air Act's New Source Review \& Best Available Retrofit Technology requirements. Allowances are } \\
\text { "grandfathered". Also includes a "safety valve" that caps the price power companies would have to pay for additional Hg, } \\
\mathrm{SO}_{2} \text {, and } \mathrm{NO}_{x} \text { allowances. }\end{array}$}} \\
\hline & & & & & & & & \\
\hline \multicolumn{9}{|c|}{$\begin{array}{l}\text { dBill covers energy sector only. The proposed act specifies a minimum removal target for mercury emissions, in addition to } \\
\text { the cap. It also allows companies to offset emissions by purchasing allowances from an international trading program or } \\
\text { another domestic project outside the energy sector. }\end{array}$} \\
\hline
\end{tabular}




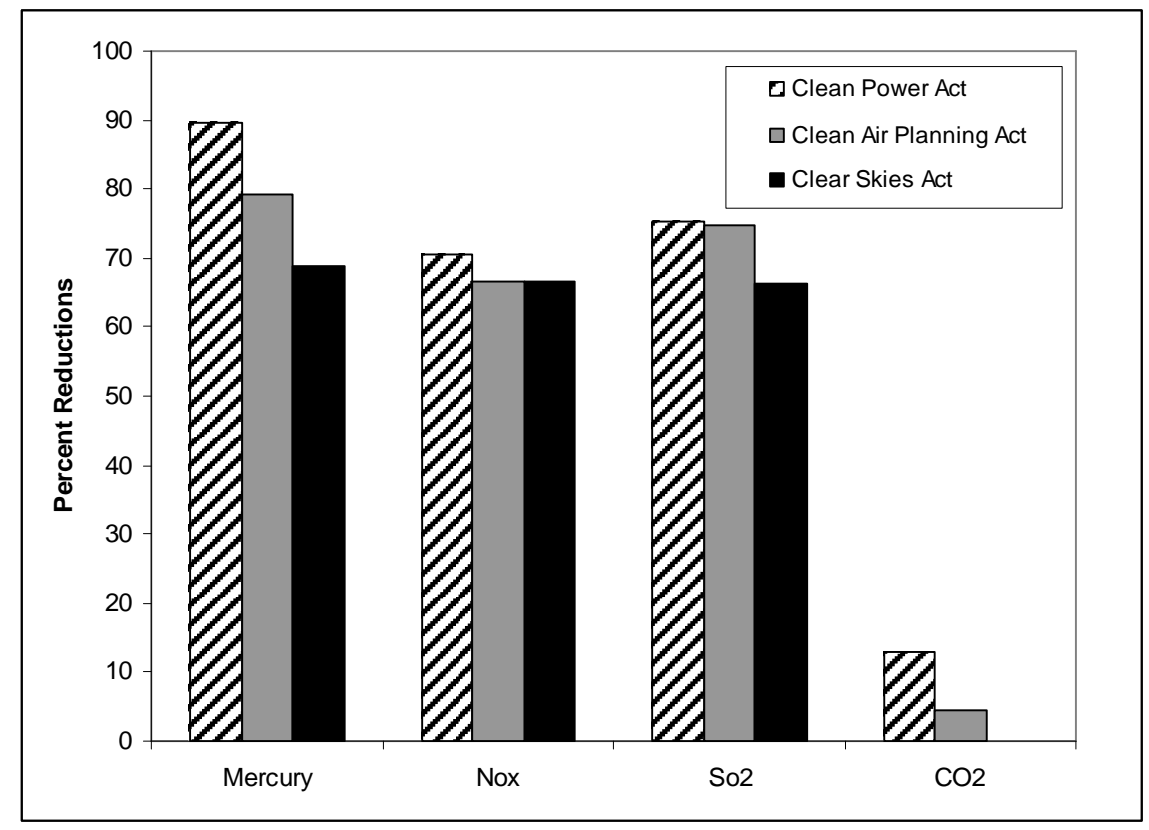

Figure A-2. Projected Percent Reduction in Mercury, Nitrogen Oxides, Sulfur Dioxide, and Carbon Dioxide under Three separate Market-Based Emissions Control Regulations.

Each of the four proposed greenhouse emissions legislations submitted to Congress in 2003 was set to subcommittee for review. As of today, no regulation controlling greenhouse gas emissions within the United States has been passed. The Clear Skies Act and Climate Stewardship Act were resubmitted in January and February of this year and again both have been sent to subcommittee for review. The lack of success in terms of greenhouse gas emissions control policies raises an important question: why did these bills fail? To answer this question, one must evaluate the potential social and industrial costs of greenhouse gas emissions policies, including how the design of carbon policies can impact short and long-term efficiency and overall social welfare. 


\section{Impacts of Proposed Legislation}

Based on recent legislative proposals to Congress (Figure A-1), those in the energy sector may face significant requirements to reduce greenhouse gas emissions (i.e. $\mathrm{CO}_{2}$ ) over the next decade. The timetable and stringency of these requirements is not known. However, if recent patterns in legislation are used as a guide, a market-based approach (rather than command and control requirements) to reduce emissions appears likely. The legislative proposals cited above include a variety of mechanisms to achieve emissions reductions (refer to Table A-4). The resulting impacts on providers and consumers will depend on the type of policy strategy and implementation mechanism exercised by the program. At the request of the Subcommittee on National Economic Growth, Natural Resources, and Regulatory Affairs in the House of Representatives, the Energy Information Administration (EIA) conducted several studies to predict the potential costs and impacts of the multi-emission reduction strategies outlined in Table A-4 (EIA 2003; 2004). In their analysis, the EIA projected the impacts of the proposed legislation using their National Energy Modeling System (NEMS), along with a reference case based on the 2004 Annual Energy Outlook (EIA 2003; 2004). The reference case projections are based on forecasts of business-as-usual trends, taking into account current technology, laws and regulations, as well as projected trends in technology and demographics (EIA 2004). A summary of EIA's projections is provided in Table A-5.

The EIA's findings indicate that in all cases where $\mathrm{CO}_{2}$ emissions are capped there will be significant impacts on coal-fired power plants. Because of coal's high carbon intensity, its use is expected to decline rapidly. Electric generators are likely to substitute natural gas, nuclear and renewable fuels for the capacity once maintained by 
will experience much higher costs if they have to purchase some or all of their allowances (auctioned), rather than having them provided for free ("grandfathering"). As a result, they will likely pass along a large portion of these costs to the consumer through higher electricity prices. The degree to which these costs are transferred depends on the allocation scheme of the allowances (discussed later), as well as the nature of the competitive market.

Based on the impact analyses conducted by EIA (2000; 2003; 2004) and summarized above in Table A-5, several key impacts may result from multi-emission reduction legislation using a permit and trading scheme:

1. Increased demand for natural gas could stress the current gas production system, resulting in substantially higher gas prices (scarcity rent).

2. In addition, increased dependence on natural gas for electricity production can lead to greater volatility in electric prices (move with changing gas prices).

3. The increase use of natural gas by the energy sector is projected to cause natural gas prices to increase in all sectors of the economy (i.e. residential, commercial, and industrial).

4. Consumers may respond to higher electricity prices by decreasing their consumption of electricity, through the purchase of more energy efficient appliances, installation of renewable energy sources (i.e. solar panels), and/or a general decrease in use (more energy saving habits). 
5. Higher electricity, natural gas, and gasoline prices will impact the production of goods and services, as well as consumer spending (higher prices result in lower disposable incomes). The magnitude of these impacts will depend on how revenue generated from emission allocations (when auctioned) is transferred among consumers, fuel producers, and electricity providers (discussed in more detail later).

6. The shift to natural gas, renewable energy, and other non-carbon intensive energy sources will increase production and jobs in these sectors. In contrast, a shift away from coal resources will reduce coal production, as well as jobs associated with coal mining and coal-fired electric utilities.

The impacts of any greenhouse emissions regulation will depend on the timetable, stringency, and implementation strategy of the policy. In addition, electricity prices and the degree to which electric generation shifts away from coal-powered plants depends, to a large degree, on the extent $\mathrm{CO}_{2}$ emissions are controlled. Unlike $\mathrm{NO}_{\mathrm{x}}$ and $\mathrm{SO}_{2}$, there are currently no commercially available technologies for removing and storing (sequestering) $\mathrm{CO}_{2}$. This stems in part from the lack of a market (no existing regulation on $\mathrm{CO}_{2}$ ) and uncertainty surrounding the long-term, stable storage of the $\mathrm{CO}_{2}$ after sequestration. Therefore, under the current system, the only way to achieve large scale reduction in $\mathrm{CO}_{2}$ emissions is to reduce the combustion of carbon rich fuels and improve the efficiency of energy production and use (EIA 2000). The combination of $\mathrm{CO}_{2}$ allowance costs, increased operating costs, changes in production methods, and increased natural gas prices translates into significantly higher electricity prices for producers and consumers. 
This means that any policy including $\mathrm{CO}_{2}$ emission caps may have a significantly harder time being passed in congress (discussed more later).

\section{Feasibility of Future Carbon Emission Regulations}

Although market-based strategies are being endorsed by economists and some politicians and appear to be a more cost-effective alternative to the status quo, they are receiving relatively little political and industry support (Goulder 2000; Stavins 2003). The political resistance to market-based solutions may stem from the inequitable distribution of cost across the economy. Carbon-based emission controls would place a larger share of the regulatory burden on companies within the energy sector (such as electric utilities, petroleum refining, etc.), as well as the producers of fossil fuels. This unequal distribution of costs hinders the political feasibility of market-based instruments because the industries most affected (i.e. electric utilities) are well-organized and can exert considerable political pressure (Goulder 2000). Under a carbon tax or tradable permit scheme (where allowances are not "grandfathered"), the aggregate net benefits (i.e. benefits to future generations, decreased dependence on other countries for fossil fuels, boost of production in alternative energy sectors, etc.) may exceed the net loss to the conventional energy sector. However, the potential concentration of costs among the losing group (cost to each member of group is large) and dilution of benefits among the winning group (benefits to each member are small) can effectively block a policy's enactment (Goulder 2000). Those in the energy sector have more of a motivation and ability to mobilize politically.

This ability of the interest of smaller groups (such as power utilities) to prevail over the interests of a much larger group (social good) can be explained using Mancur Olson's 
arguments of collective action and group behavior. Olson (1965) argues that individuals in a group will typically not act to defend or advance their groups interests, unless they have a personal or individual incentive to do so. He goes on to argue that the ability of a group to organize to achieve their common objective is generally easier for smaller or intermediate sized groups of individuals or organizations than for larger groups. Olson (1965) asserts that in "smaller groups, it is more likely that one member or organization will have a large enough stake in the outcome to justify shouldering a majority of the cost in gaining that collective benefit. Whereas, individuals in a larger group have no incentive to organize a lobby to obtain a collective good." In other words, the marginal benefits (i.e. lower levels of air pollution) do not exceed the marginal costs (time, effort, etc.) of organizing and promoting some social benefit (cleaner air). In terms of environmental regulations, Congress may under-regulate in the form of environmental lax standards (or no standards at all) "because the industry groups that favor less stringent regulations are small and cohesive, whereas individuals who support more stringent regulation are a large more diffuse group" (Revesz 2001). This power exerted by industry can be explained, in large part, by their inherent organization. Because they are already organized (for business) they are able to mobilize easily, forming a powerful economic lobby to fight for some collective benefit or good. This may explain the resistance policies such as the Climate Stewardship Act, Clean Power Act, and Clean Air Planning Act are receiving in Congress. Industries within the energy sector (specifically electric utilities and fossil fuel providers) have a political advantage because their narrow, organized special interests allow them to triumph over the unorganized, inactive interests of "the people" (Olson 1965). 
The type of strategy used in a cap and trade policy can impact the level of resistance that policy receives from "vested" interest groups, such as those in the energy sector. Political feasibility might increase for policies that avoid placing exceptionally large cost burdens on key energy industries (Goulder 2000). Therefore, using some sort of "revenue-recycling" or transfer of payments may alleviate some of the distributional concerns or objections to the policy (Goulder 2000).

\section{Impacts on Feasibility}

\section{Emission Allocation Method}

The idea behind market-based approaches to carbon emissions regulation is that they provide companies with an incentive to "reduce pollution by placing opportunity costs on emissions" (Burtraw et al. 2002). One of the biggest issues in the design of market-based carbon policy is how to allocate emissions allowances. The choice of allocation method has a significant effect on the efficiency and overall social cost of the program (Burtaw et al. 2002). There are several ways that emissions allowances can be allocated. Historically, the United States has "grandfathered" allowances based on historical emissions or generation. This is the allocation method used for the $\mathrm{SO}_{2}$ trading program adopted under amendments the Clean Air Act in 1990 and the method proposed by the Bush Administration in the Clear Skies Act. "Grandfathering", however provides no real incentive to change behavior, since the allocations are predetermined based on historical energy production patterns (Burtraw et al. 2002). Another approach is to allocate allowances on generation performance standards (GPS). Under GPS, allowances are initially based on a company's share of overall emissions. This is the approach used in most of the recent emissions control regulations discussed above. The problem with GPS 
is that by allocating emissions by percent of generation, it gives companies an incentive to increase its emissions because doing so earns them additional allowances which they can sell as profit later (Burtraw et al. 2002). Emissions allocations can also be auctioned, where those regulated purchase emission allowances from either the government, independent entity (such the "Credit Corporation" in the Climate Stewardship Act) or “downstream" users ${ }^{15}$ (Clean Power Act). The revenues from auctioned allowances can then be used to offset the costs of the policy in those sectors hardest hit (i.e. tax breaks to electric providers, consumers, commercial sector, etc.).

Burtraw et al. (2002) and Goulder (2000) conducted studies that show that the free allocation of all emission allowances would enrich covered entities at the expense of downstream consumers. Most analyses of global warming legislation show that, in competitive markets, companies will pass much of their compliance costs to consumers in the form of higher prices, with only a small fraction of the regulation's cost being borne by the company. According to the Natural Resources Defense Council (NRDC 2005) and researchers at Resources for the Future (Burtraw et al. 2002; Goulder 2000), this pass-on to consumers is true under both extremes: where (1) companies are required to purchase all emission allowances; and (2) companies are given those allowances for free. Even when allowances are provided free of charge, companies will raise product prices to reflect the market value of the emission allowances. In other words, each allowance has a market value because companies will always have the opportunity to sell them for profit. Therefore, this "opportunity cost" will be reflected in product prices (Burtraw et al. 2002; Goulder 2000). Policies that depend solely on grandfathering

\footnotetext{
${ }^{15}$ Downstream users are final consumers of fossil fuels and electricity in the residential, commercial, and industrial sectors.
} 
substantially over-compensate firms, causing their equity values to rise considerably; whereas policies that rely solely on the auction of permits can have the opposite effect (Goulder 2000). Therefore, in order to address distributional concerns and ensure that equity values in the energy sector do not decline (or rise too significantly), Goulder (2000) suggests a balance between free ("grandfathered") allowance allocation and auctioning.

\section{Where we Stand}

The proposed legislation discussed above used a variety allocation schemes: Clear Skies Act (grandfathering of all permits); Climate Stewardship Act (partial free allocation through GPS, partial auctioning through Credit Corporation); Clean Power Act (partial free allocation through GPS; partial auctioning by downstream consumers); and Clean Air Planning Act (grandfathering of $\mathrm{SO}_{2}$ and remaining allowances by GPS). In addition, several of these legislations allowed producers to offset some of their emissions through reductions in other markets both domestically and internationally. So then, why with all these options, has no policy been successfully accepted by Congress? The answer may lie in the how society (and the government) perceives the benefits from climate change regulation.

The greenhouse effect is a long-term problem, from which the public does not see many immediate identifiable effects. Therefore, politicians could be hesitant to ask for stringent emissions caps that may negatively impact consumers and producers now, when the present benefits are unapparent and the future benefits are uncertain (Smith 2000). Thus, more pressing social and economic needs may take precedent over the climate change policies. In addition, due to the long-term, uncertain nature of climate change, the 
costs of global warming and the benefits of greenhouse gas policy are almost impossible to determine. Therefore, if a government is depending on a cost-benefit analysis to rationalize global warming policies, they may find no justification for doing so (Smith 2000).

\section{$\underline{\text { Impact of International Policies }}$}

Global warming is an international problem, impacting a common-pool resource (the atmosphere/climate). No single country acting alone will be able to solve the problem. In addition, the impacts of global warming will vary on a region-by-region basis and scientists are uncertain as to what exactly these impacts will be. Although there has been international cooperation to study the potential impacts of greenhouse gases (i.e. IPCC) many governments are taking a "wait and see" approach to global warming policies (Smith 2000). The hesitancy of any one government to take significant steps towards reducing greenhouse gas emissions could be described as a collective action problem: the marginal benefits (which are uncertain) of a country moving forward with climate change polices may not outweigh the marginal cost of those policies on a countries economic performance and competitive advantage. Therefore, it is unlikely that any country (including the U.S.) will take unilateral measures to control greenhouse gas emissions. Countries will, however, have an incentive to free-ride off the decreased emissions of other countries. Free-riding arises when nations that benefit from the abatement of global $\mathrm{CO}_{2}$ emissions do not contribute to its attainment (Stavins 1997). The location (source) of emissions does not impact the potential damages of rising global temperatures (decreased agriculture production, severe weather events, etc.). Although countries like the United States might significantly contribute to overall global $\mathrm{CO}_{2}$ emissions, the impact of these 
emissions may be more significant in other less developed countries. In addition, decreasing greenhouse gas emissions in one country can shift their comparative advantage (in certain markets) to other countries. Those countries may then take up activities that increase their emissions (Stavins 1997). This transfer of emissions is called leakage. The end consequence might be no net impact in greenhouse gas emissions. Furthermore, policies within one country or even a group of cooperating countries will not likely be effective at significantly abating global greenhouse gas emissions. As mentioned above, it becomes a problem of collective action, where no one country has an incentive to pay a share of the "costs" to obtain the overall public good of slowing global warming. Using Olson's (1965) argument of large group theory, without some form of

global coercion forcing countries to enact stringent greenhouse gas emission policies, it is unlikely that countries will voluntarily enact significant $\mathrm{CO}_{2}$ emission reduction policies that could harm their economic and social well-being (in the short-term).

The above arguments could be used to explain the Bush administration's failure to sign the Kyoto Protocol and to some extent, the reluctance of Congress to pass emission caps on $\mathrm{CO}_{2}$. Along with lack of immediate benefits, the uncertainty of future benefits, and the potential domestic impacts of stringent greenhouse gas emission policies, the United States may have no real incentive to take responsibility or action in reducing its emissions.

\section{Conclusions}

In a report to Congress in 1989 concerning global warming, the EPA (1989) stated that "the landscape of North America will change in ways it cannot be fully predicted. The ultimate effects will last for centuries and will be irreversible....Strategies to reverse 
such impacts on natural ecosystem are not currently available.” However, even with such bold and pressing statements by the EPA and others in the research community (i.e. IPCC), relatively little has been done to reduce greenhouse gas emissions, nationally or globally. The common pool characteristics of air pollution problems (particularly the greenhouse effect) make solutions for controlling pollution more difficult. Domestically, the inequitable distribution of regulatory costs and the lack of commercially available technologies for reducing $\mathrm{CO}_{2}$ emissions may diminish the feasibility of many $\mathrm{CO}_{2}$ policy options. As a result of their carbon intensity, electric utilities and coal producers will shoulder a majority of the regulatory burden. Their ability to organize in opposition of $\mathrm{CO}_{2}$ and other emissions caps, as well as the considerable pressure they can exert politically, can impede the implementation of a cap and trade approach to reducing carbon emissions. Revenue recycling and other methods of transferring wealth to those hardest hit (i.e. electric utilities, consumers, etc.) may increase a policy's feasibility. However, the long-term nature of the problem and more urgent direct social and economic needs might cause politicians to shy away from stringent climate change policies. The Bush administration's Clear Skies proposal for reducing greenhouse emission is an example of such hesitancy. Although their plan embraced a market-based strategy to reduce emissions, it left out the most significant of the greenhouse gases, $\mathrm{CO}_{2}$. Perhaps this omission was based on the realization that a policy capping $\mathrm{CO}_{2}$ had little hope of passing in Congress; or maybe it is reflective of the general "wait and see" attitude among governments. Thus, the question remains whether the global warming is such a catastrophic problem that nations (including the U.S.) will be willing to impose policies that may not be in their best short-term interest. 


\section{Reference Cited}

Boyd, R., K. Krutilla, and W.K. Viscusi, "Energy Taxation as a Policy Instrument to Reduce $\mathrm{CO}_{2}$ Emissions: A Net Benefit Analysis," Journal of Environmental Economics and Management, 29, pp. 1-24, 1995.

Burtraw, D., K. Palmer, and R. Bharvirkar, "The Effect on Asset Values of the Allocation of Carbon Dioxide Emission Allowances," Resources for the Future, Discussion Paper 02-15, March 2002.

Coase, R., "The Problem of Social Cost," Journal of Law and Economics, October 1960.

Dudek, D.J. and A. LeBlanc, "Offsetting New $\mathrm{CO}_{2}$ Emissions: A Rational First Greenhouse Policy Step,” Contemporary Policy Issues, 8, pp. 29-41, July 1990.

Energy Information Administration (EIA), "Analysis of Strategies for Reducing Multiple Emissions from Power Plants: Sulfur Dioxide, Nitrogen Dioxides, and Carbon Dioxide," Office of Integrated Analysis and Forecasting, U.S. Department of Energy, SR/OIAF/2000-05, December 2000.

Energy Information Administration (EIA), "Analysis of S.139, the Climate Stewardship Act of 2003," Office of Integrated Analysis and Forecasting, U.S. Department of Energy, SR/OIAF/2003-02/S, 2003.

Energy Information Administration (EIA), "Analysis of S.1844, the Clear Skies Act of 2003; S.843, the Clean Air Planning Act of 2003; and S.366, the Clean Power Act of 2003," Office of Integrated Analysis and Forecasting, U.S. Department of Energy, SR/OIAF/2004-05, 2004.

Falkowski, P. R.J. Scholes, E. Boyle, J. Canadell, D. Canfield, J Elser, N. Gruber, K. Hibbard, P. Hogberg, S. Linder, F.T. Mackenzie, B. Moore III, T. Pedersen, Y. Rosenthal, S. Seitzinger, V. Smetacek, and W. Steffen, "The Global Carbon Cycle: A Test of Our Knowledge of Earth as a System," Science, 290, pp.291-296, 13 July, 2000.

Feely R.A, C.L. Sabine, K. Lee, W. Berelson, J. Kleypas, V.J. Fabry, and F. J. Millero, "Impact of Anthropogenic $\mathrm{CO}_{2}$ on the $\mathrm{CaCO}_{3}$ System in the Oceans," Science, 305, pp.362-366, 16 July 2004.

Field, C.B. and M.R. Raupach (eds.), The Global Carbon Cycle: Integrating Humans, Climate, and the Natural World, SCOPE 62, Island Press, Washington DC, 2004.

Goodwin Proctor, "Recent Initiatives Targeting Greenhouse Gas Emissions," Environmental Law Advisory, March 2003.

Goulder, L.H., "Confronting the Adverse Industry Impacts of $\mathrm{CO}_{2}$ Abatement Policies: What Does it Cost?" Resources for the Future, Climate Issues Brief No. 23, September 2000.

Intergovernmental Panel on Climate Change (IPCC), IPCC Special Workshop - Article 2 of the United Nations Framework Convention on Climate Change, Fortaleza, Brazil, October 17-21 1994. 
Intergovernmental Panel on Climate Change (IPCC), "Climate Change 2001: The

Scientific Basis. Contribution of Working Group I to the Third Assessment Report of the Intergovernmental Panel on Climate Change," Cambridge University Press, 2001.

Joshua, F.T., "Greenhouse Gas Emissions Trading after Kyoto: Insights from UNCATD's Research and Development Project," United Nations Conference on Trade and Development (UNCATD), Internet: <http://www.ecouncil.ac.cr/rio/focus/report/english/unctad.htm> 1997.

Keith, D.W. and E.A. Parson, “A Breakthrough in Climate Change Policy?" Scientific America, pp. 78-79, February 2000.

National Energy Information Center (NEIC), "Greenhouse Gases, Climate Change, and Energy," Energy Information Administration, Internet: <http://www.eia.doe.gov/oiaf/1605/ggccebro/chapter1.html>, April 2004.

National Resources Defense Council (NRDC), "Questions and Answers about the Climate Stewardship Act," Internet: < http://www.nrdc.org/globalWarming/csa/qcsa.asp\#4>, 2005.

Olson, M., The Logic of Collective Action: Public Goods and The Theory of Groups, Harvard University Press, 1965.

Pedit, J.R., J. Jouzel, D. Raynaud, N.I. Barkov, J.M. Barnola, I. Basile, M. Benders, J. Chappellaz, M. Davis, G. Delaygue, M. Delmotte, V.M. Kotlyakov, M. Legrand, V.Y. Lipenkov, C. Lorius., L. Peplin, C. Ritz, E. Saltzman, and M. Stievenard, "Climate and Atmospheric History of the past 420,000 years from the Vostok Ice Core, Antarctica," Nature, 399, pp. 429-435, 3 June 1999.

Revesz, R.L., "Federalism and Environmental Regulation: A Public Choice Analysis," Harvard Law Review, 115(2), December 2001.

Revesz, R.L. and R.N. Stavins, "Environmental Law and Public Policy,” Discussion Paper 04-30, Resources for the Future, September 2004.

Richards, K.R., "A Brief Overview of Carbon Sequestration Economics and Policy," Environmental Management, forthcoming. Internet:

$<$ http://www.spea.indiana.edu/kenricha/Research/A\%20Brief\%20Overview\%20of\%2 0Carbon\%20Sequestration\%20Economics\%20and\%20Pol\%E2\%80\%A6.pdf>

Sabine, C.L., R.A. Feely, N. Gruber, R.M. Key, K. Lee, J.L. Bullister, R. Wanninkhof, C.S. Wong, D.W.R. Wallace, B. Tilbrook, F.J. Millero, T.H. Peng, A. Kozyr, T. Ono, and A.F. Rios, "The Oceanic Sink for Anthropogenic $\mathrm{CO}_{2}$," Science, 305, pp. 367371, 16 July 2004.

Schneider, F. and J. Volkert, "No Change for Incentive-Oriented Environmental Policies in Representative Democracies? A Public Choice Analysis," Ecological Economics, 31, pp. 123-138, 1999.

Smith, Z.A., The Environmental Policy Paradox: Third Edition, Prentice Hall, New Jersey, pp. 284, 2000. 
Stavins, R.N., "Policy Instruments for Climate Change: How Can National Governments Address a Global Problem?" Resources for the Future, Discussion Paper 97-11, January, 1997.

Stavins, R.N., "Environmental Protection and Economic Well-Being: How Does (and How Should) Government Balance These Two Important Values?" Resources for the Future, Discussion Paper 03-48, August 2003.

U.S. Environmental Protection Agency, "The Potential Effects of Global Climate Change in the United States, Report to Congress," Washington, D.C., US Government Printing Office, EPA-230-05-89-050, 1989.

U.S. Environmental Protection Agency, "Inventory of U.S. Greenhouse Gas Emissions and Sinks," EPA 430-R-05-003, April 15, 2005.

U.S. Department of State, “U.S. Position on Climate Change,” Internet: <http://www.state.gov/g/oes/rls/rm/6633.htm>, statements made by Dr. H.L. Watson in Madrid Spain, November 2001.

U.S. Department of State, “The United States of America's Third National Communication Under the United Nations Framework Convention on Climate Change," May 2002.

Weimer, D.L. and A.R. Vining, Policy Analysis: Concepts and Practice $4^{\text {th }}$ Edition, Prentice Hall, 2005. 